ALESSANDRO DIAS

ANÁLISE DO DESEMPENHO HIDRÁULICO DE UMA SOLEIRA LATERAL ATRAVÉS DE CFD 


\title{
ANÁLISE DO DESEMPENHO HIDRÁULICO DE UMA SOLEIRA LATERAL ATRAVÉS DE CFD
}

\author{
Dissertação apresentada à Escola Politécnica \\ da Universidade de São Paulo como requisito \\ parcial para obtenção do título de Mestre em \\ Engenharia Civil
}

Área de Concentração: Engenharia Hidráulica

Orientador: Prof. Dr. José Rodolfo S. Martins

São Paulo 
Este exemplar foi revisado e alterado em relação à versão original, sob responsabilidade única do autor e com a anuência de seu orientador.

São Paulo, de maio de 2011.

Assinatura do autor

Assinatura do orientador

FICHA CATALOGRÁFICA

Dias, Alessandro

Análise do desempenho hidráulico de uma soleira lateral através de CFD / A. Dias. -- ed.rev. -- São Paulo, 2011.

$160 \mathrm{p}$.

Dissertação (Mestrado) - Escola Politécnica da Universidade de São Paulo. Departamento de Engenharia Hidráulica e Sanitária.

1.Vertedores 2.Dinâmica dos fluídos computacional 3.Escoamento superficial I.Universidade de São Paulo. Escola Politécnica. Departamento de Engenharia Hidráulica e Sanitária II.t. 


\section{DEDICATÓRIA}

A Deus, que sempre guiou os meus caminhos;

Aos meus queridos pais Eduardo e Vilma, que me ajudaram nessa caminhada;

A minha amada esposa Sílvia, que caminha junto comigo. 


\section{AGRADECIMENTOS}

A Escola Politécnica da Universidade de São Paulo, que contribuiu com o meu desenvolvimento pessoal e profissional.

Ao meu orientador, Prof. Dr. José Rodolfo Scarati Martins, pela oportunidade, pelo apoio incondicional na realização desse trabalho e os ensinamentos transmitidos ao longo desses anos.

Ao amigo, Eng. Dr. Harley Souza Alencar (ALSTOM), pelos ensinamentos em CFD, pela prontidão e grande apoio na realização desse trabalho.

Aos professores, Dr. Jayme Ortiz e Dr. Podalyro Amaral, pelas sugestões dadas para a realização desse trabalho.

A todos os professores que passaram por minha vida, desde o ensino fundamental, médio, graduação e pós-graduação.

A Planservi Engenharia pelo apoio durante a realização desse trabalho.

A Liliane e Isabela, pela ajuda com o modelo físico e na realização dos ensaios experimentais.

Ao meu irmão Eduardo, que sempre me apoiou e incentivou na minha caminhada.

A todos os meus familiares e amigos, que sempre proporcionam momentos felizes.

Agradeço a todas as pessoas que me ajudaram a vencer essa etapa da minha vida. 
"Se fui capaz de ver mais longe, é porque me apoiei em ombros de gigantes." Isaac Newton (1643-1727) 


\section{RESUMO}

\section{DIAS, A. Análise do desempenho hidráulico de uma soleira lateral através de}

CFD. 2011. 160 f. Dissertação (Mestrado em Engenharia Civil na Área de Engenharia Hidráulica) - Escola Politécnica, Universidade de São Paulo, São Paulo, 2011.

A soleira lateral desempenha um papel importante nos reservatórios de detenção/ retenção (off-line), atuando na captação das vazões afluentes e evitando possíveis enchentes, problema em destaque nos períodos chuvosos das principais capitais brasileiras. Um melhor entendimento do seu comportamento hidráulico possibilitará o desenvolvimento de estruturas laterais mais eficientes. O presente trabalho tem como objetivo criar um modelo da soleira lateral através da tecnologia CFD (Dinâmica dos Fluidos Computacional) e validá-lo através de experimentos em modelo reduzido do Laboratório de Hidráulica da Escola Politécnica da USP. A partir disso, explorar as características hidráulicas do modelo de CFD, como o comportamento dos níveis d'água e a distribuição de velocidades. No estudo da validação estudaram-se três tipos de refinamento de malhas e três modelos de turbulência (k- $\varepsilon, k-\varepsilon$ (RNG) e SST k- $\omega$ ). O modelo computacional validado é composto pela malha 3, com um refinamento cerca de 342000 elementos

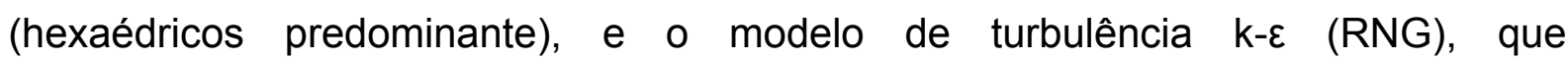
apresentaram a maior precisão dos resultados. A análise da distribuição de velocidades possibilitou visualizar uma região de mínima velocidade abaixo da soleira lateral, e também quantificar uma região de baixas velocidades no início da soleira, onde é pequena a eficiência das vazões escoadas. Através do comportamento da superfície d'água foi possível visualizar a região de influência do dispositivo lateral no canal principal. A comparação do coeficiente de descarga do modelo de CFD com trabalhos de outros pesquisadores, um nacional e outro internacional, mostrou a representatividade do modelo criado para condições diferentes. A ferramenta CFD é promissora para o estudo de estruturas hidráulicas, contribuindo para o seu desenvolvimento e aperfeiçoamento.

Palavras-chave: vertedores, soleira lateral, CFD, escoamento em superfície livre. 


\begin{abstract}
DIAS, A. Analysis of hydraulic performance of a side weir by CFD. 2011. $160 \mathrm{f}$. Dissertation (Master in Civil Engineering in Hydraulic Engineering Area) - Escola Politécnica, Universidade de São Paulo, São Paulo, 2011.
\end{abstract}

The side weir plays an important role in the detention / retention tanks (off-line), operating in the uptake of water inflow and preventing possible flooding, which is a highlighted problem on rainy periods of the main Brazilian capitals. A better understanding of the hydraulic behavior allows the development of more efficient lateral structures. This work aims at creating a model of the side weir through CFD technology (Computational Fluid Dynamics) and validating it through experiments on a reduced model of the Laboratório de Hidráulica da Escola Politécnica da USP. Thereafter, explore the hydraulic characteristics of the CFD model, like the behavior of water levels and the velocity distribution. In the validation study, three types of mesh refinement and three turbulence models were studied (k- $\varepsilon, k-\varepsilon$ (RNG) and SST $k-\omega)$. The computational model is validated by the composite mesh 3 with a refinement about 342,000 elements (hexahedral predominant), and the turbulence model k- $\varepsilon$ (RNG), which had the highest precision of results. Analysis of the velocities distribution allowed us to visualize a region of minimum velocity below the side weir, and also to quantify a region of low velocities at the beginning of the weir, where the efficiency of overflows is small. Through water surface behavior it was possible to visualize the influence region of the side device in the main channel. A comparison of discharge coefficient of the CFD model between other works (one national and the other one international) showed the representativeness of the model created for different conditions. The CFD is a promising tool for the study of hydraulic structures, contributing to its development and improvement.

Keywords: weirs, side weir, CFD, free surface flow. 


\section{LISTA DE FIGURAS}

Figura 3.1 - Distribuição de velocidade em uma seção transversal (fonte: PORTO, 2004).

Figura 3.2 - Distribuição de pressão em fundo curvo, adaptado de Porto (2004)....10

Figura 3.3 - Princípio da Energia em Canais.

Figura 3.4 - Energia específica para o escoamento, adaptado de Streeter e Wylie (1982). 12

Figura 3.5 - Vertedor de parede delgada, adaptado de Porto (2004) ....................14

Figura 3.6 - Vertedor triangular, adaptado de Porto (2004) ..................................17

Figura 3.7 - Vertedor Cipoletti, adaptado de Porto (2004) .................................. 17

Figura 3.8 - Vertedor de soleira espessa horizontal, adaptado de Porto (2004)......18

Figura 3.9 - Vertedor de soleira normal, adaptado de Porto (2004) . ......................19

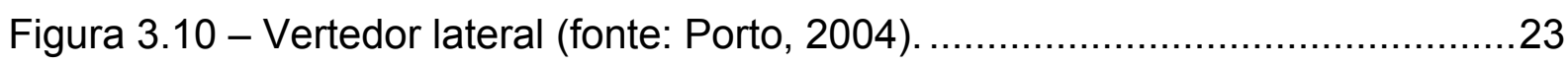

Figura 3.11 - Tipos de perfis longitudinais em vertedores laterais (fonte: MAY et al.,

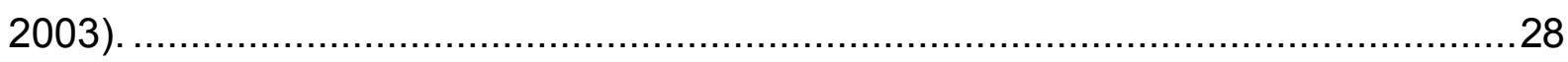

Figura 3.12 - Representação dos dados experimentais em função $C_{d}$ e $\mathrm{Fr}_{m}$ (fonte:

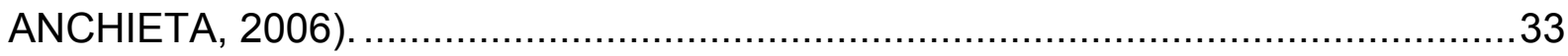

Figura 3.13 - Vertedor lateral em canal circular (fonte: OLIVETO; BIGGIERO; FIORENTINO, 2001).

Figura 3.14 - Modelo do canal San Sevaine com vertedor lateral e coletor (fonte: TAN; EINHELLIG; PUGH, 2001).

Figura 3.15 - Vista em planta da estrutura de transbordamento pelo vertedor lateral (fonte: GERT; GUIDO; JEAN, 2002).

Figura 3.16 - Modelo do canal de adução com vertedores laterais (fonte: SOUZA, 2005).

Figura 3.17 - Vertedor lateral em um canal em forma de U (fonte: UYUMAZ, 1997).

Figura 3.18 - Simulação em CFD da distribuição da velocidade do vertedor lateral combinado com transbordamento de esgoto (fonte: BURT et al., 2002).

Figura 3.19 - Parâmetros do vertedor lateral em canal retangular (fonte: MUSLU, 2002). 40

Figura 4.1 - Tipos de Malha (fonte: BATISTA, 2005). 49 
Figura 5.1 - Vista à montante do modelo do vertedor lateral. 62

Figura 5.2 - Vista à jusante do modelo do vertedor lateral. 63

Figura 5.3 - Detalhe da soleira do vertedor lateral. 63

Figura 5.4 - Vista à jusante do vertedor lateral estudado. 64

Figura 5.5 - Vista frontal do vertedor lateral estudado 64

Figura 5.6 - Sistema de funcionamento do modelo. 65

Figura 5.7 - Vista frontal do vertedor triangular. 66

Figura 5.8 - Vista frontal do vertedor retangular. .66

Figura 5.9 - Vista em planta do modelo físico simulado. 67

Figura 5.10 - Detalhes do modelo físico. 67

Figura 5.11 - Medição do nível d'água com régua metálica. 68

Figura 5.12 - Vista em planta do domínio do modelo. 75

Figura 5.13 - Detalhes do domínio do modelo. 75

Figura 5.14 - Esquema básico para a modelagem do problema. 76

Figura 5.15 - Pontos e curvas da geometria do vertedor lateral. .78

Figura 5.16 - Visão geral do vertedor lateral, visualizado no modo "Solid/ Wireflame".

Figura 5.17 - Detalhe da soleira do vertedor lateral, visualizado no modo "Solid/ Wireflame". .79

Figura 5.18 - Definições da superfície do vertedor lateral. .80

Figura 5.19 - Malha típica do vertedor lateral, formada por elementos hexaédricos.81

Figura 5.20 - Definições do domínio. 82

Figura 5.21 - CFX-Solver após a execução dos cálculos. 86

Figura 5.22 - Obtenção dos níveis d'água sobre a soleira no CFX-Post. .87

Figura 6.1 - Vista isométrica da malha 1. .89

Figura 6.2 - Comparação da simulação para a malha 1. .90

Figura 6.3 - Vista isométrica da malha 2. .91

Figura 6.4 - Comparação da simulação para a malha 2. .92

Figura 6.5 - Vista isométrica da malha 3. .93

Figura 6.6 - Detalhe do vertedor lateral da malha 3. .93

Figura 6.7 - Comparação da simulação para a malha 3. .94

Figura 6.8 - Comparação do erro da simulação entre as malhas. .95

Figura 6.9 - Comparação da simulação para o modelo k- $\varepsilon$. .96

Figura 6.10 - Comparação da simulação para o modelo k-£ (RNG). 
Figura 6.11 - Comparação da simulação para o modelo SST k- $\omega$. .98

Figura 6.12 - Comparação do erro da simulação entre os modelos de turbulência..99 Figura 6.13 - Comparação do nível d'água sobre a soleira para a condição Q1-C8.

Figura 6.14 - Comparação do nível d'água sobre a soleira para a condição Q2-C8. 101

Figura 6.15 - Comparação do nível d'água sobre a soleira para a condição Q3-C8. 101

Figura 6.16 - Comparação da simulação para todas as condições. 103

Figura 6.17 - Comparação do erro da simulação para todas as condições. 104

Figura 6.18 - Vista isométrica da superfície d'água para condição Q1-C6............105

Figura 6.19 - Vista isométrica da superfície d'água para a condição Q1-C8.........105

Figura 6.20 - Vista isométrica da superfície d'água para a condição Q1-C10 .......106

Figura 6.21 - Vista frontal da superfície d'água do vertedor lateral para a condição Q1-C6. 107

Figura 6.22 - Vista frontal da superfície d'água do vertedor lateral para a condição Q1-C8

Figura 6.23 - Vista frontal da superfície d’água do vertedor lateral para a condição Q1-C10 107

Figura 6.24 - Comparação do nível d'água sobre a soleira para a condição Q1-C6. 108

Figura 6.25 - Vista em detalhe do vertedor lateral. 109

Figura 6.26 - Comparação do nível d'água sobre a soleira para a condição Q1-C8.

Figura 6.27 - Comparação do nível d'água sobre a soleira para a condição Q1-C10. 110

Figura 6.28 - Distribuição longitudinal da pressão estática relativa para a condição Q1-C6

Figura 6.29 - Distribuição longitudinal da velocidade para a condição Q1-C6.

Figura 6.30 - Distribuição longitudinal da velocidade para a condição Q1-C8. ......111

Figura 6.31 - Distribuição longitudinal da velocidade para a condição Q1-C10 ...112

Figura 6.32 - Distribuição transversal da velocidade ao longo do vertedor lateral para a condição Q1-C6. 
Figura 6.33 - Distribuição transversal da velocidade ao longo do vertedor lateral para a condição Q1-C8.

Figura 6.34 - Distribuição transversal da velocidade ao longo do vertedor lateral para a condição Q1-C10.

Figura 6.35 - Distribuição transversal da velocidade no vertedor lateral para a condição Q1-C6.

Figura 6.36 - Distribuição transversal da velocidade no vertedor lateral para a condição Q1-C8.

Figura 6.37 - Distribuição transversal da velocidade no vertedor lateral para a condição Q1-C10.

Figura 6.38 - Distribuição longitudinal do vetor velocidade para a condição Q1-C6.

Figura 6.39 - Distribuição longitudinal do vetor velocidade para a condição Q1-C8.

Figura 6.40 - Distribuição longitudinal do vetor velocidade para a condição Q1-C10.

Figura 6.41 - Vista isométrica da superfície d'água para a condição Q2-C6.

Figura 6.42 - Vista isométrica da superfície d'água para a condição Q2-C8.

Figura 6.43 - Vista isométrica da superfície d'água para a condição Q2-C10. 121

Figura 6.44 - Vista frontal da superfície d'água do vertedor lateral para a condição Q2-C6.

Figura 6.45 - Vista frontal da superfície d'água do vertedor lateral para a condição Q2-C8.

Figura 6.46 - Vista frontal da superfície d'água do vertedor lateral para a condição Q2-C10.

Figura 6.47 - Comparação do nível d'água sobre a soleira para a condição Q2-C6.

Figura 6.48 - Comparação do nível d'água sobre a soleira para a condição Q2-C8.

Figura 6.49 - Comparação do nível d'água sobre a soleira para a condição Q2-C10.

Figura 6.50 - Distribuição longitudinal da velocidade para a condição Q2-C6. ......125

Figura 6.51 - Distribuição longitudinal da velocidade para a condição Q2-C8. ......125

Figura 6.52 - Distribuição longitudinal da velocidade para a condição Q2-C10. ....126 
Figura 6.53 - Distribuição transversal da velocidade ao longo do vertedor lateral para a condição Q2-C6.

Figura 6.54 - Distribuição transversal da velocidade ao longo do vertedor lateral para a condição Q2-C8.

Figura 6.55 - Distribuição transversal da velocidade ao longo do vertedor lateral para a condição Q2-C10.

Figura 6.56 - Distribuição transversal da velocidade no vertedor lateral para a condição Q2-C6.

Figura 6.57 - Distribuição transversal da velocidade no vertedor lateral para a condição Q2-C8.

Figura 6.58 - Distribuição transversal da velocidade no vertedor lateral para a condição Q2-C10.

Figura 6.59 - Distribuição longitudinal do vetor velocidade para a condição Q2-C6.

Figura 6.60 - Distribuição longitudinal do vetor velocidade para a condição Q2-C8.

Figura 6.61 - Distribuição longitudinal do vetor velocidade para a condição Q2-C10.

Figura 6.62 - Vista isométrica da superfície d'água para a condição Q3-C6. 134

Figura 6.63 - Vista isométrica da superfície d'água para a condição Q3-C8. 134

Figura 6.64 - Vista isométrica da superfície d'água para a condição Q3-C10. 135

Figura 6.65 - Vista frontal da superfície d'água do vertedor lateral para a condição Q3-C6.

Figura 6.66 - Vista frontal da superfície d'água do vertedor lateral para a condição Q3-C8.

Figura 6.67 - Vista frontal da superfície d'água do vertedor lateral para a condição Q3-C10.

Figura 6.68 - Comparação do nível d'água sobre a soleira para a condição Q3-C6.

Figura 6.69 - Comparação do nível d'água sobre a soleira para a condição Q3-C8.

Figura 6.70 - Comparação do nível d'água sobre a soleira para a condição Q3-C10.

Figura 6.71 - Distribuição longitudinal da velocidade para a condição Q3-C6. 
Figura 6.72 - Distribuição longitudinal da velocidade para a condição Q3-C8. ......139

Figura 6.73 - Distribuição longitudinal da velocidade para a condição Q3-C10. ....140 Figura 6.74 - Distribuição transversal da velocidade ao longo do vertedor lateral para a condição Q3-C6.

Figura 6.75 - Distribuição transversal da velocidade ao longo do vertedor lateral para a condição Q3-C8.

Figura 6.76 - Distribuição transversal da velocidade ao longo do vertedor lateral para a condição Q3-C10.

Figura 6.77 - Distribuição transversal da velocidade no vertedor lateral para a condição Q3-C6.

Figura 6.78 - Distribuição transversal da velocidade no vertedor lateral para a condição Q3-C8.

Figura 6.79 - Distribuição transversal da velocidade no vertedor lateral para a condição Q3-C10. 145

Figura 6.80 - Distribuição longitudinal do vetor velocidade para a condição Q3-C6.

Figura 6.81 - Distribuição longitudinal do vetor velocidade para a condição Q3-C8. 146

Figura 6.82 - Distribuição longitudinal do vetor velocidade para a condição Q3-C10. 147

Figura 6.83 - Comparação dos erros entre coeficientes de descarga obtidos da literatura e do modelo matemático. 150

Figura 7.1 - Acúmulo de sedimentos no vertedor lateral do Córrego Aricanduva, RAR-05 (Fonte: RAIMUNDO, 2007). 


\section{LISTA DE TABELAS}

Tabela 5.1 - Níveis d'água do ensaio e vazões calculadas. ...............................69

Tabela 5.2 - Níveis d'água sobre a soleira do vertedor lateral...........................71

Tabela 5.3 - Cálculos iniciais do ensaio experimental. ..................................73

Tabela 5.4 - Pontos em coordenadas da geometria do vertedor lateral. ................77

Tabela 5.5 - Valores utilizados nas condições de contorno................................84

Tabela 6.1 - Comparação das vazões do vertedor lateral entre as malhas.............94

Tabela 6.2 - Comparação das vazões do vertedor lateral entre os modelos de

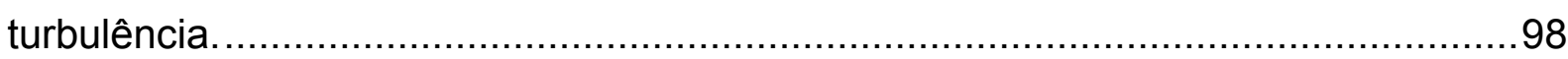

Tabela 6.3 - Comparação das vazões do vertedor lateral. ................................. 102

Tabela 6.4 - Variação do NA sobre a soleira lateral. .....................................106

Tabela 6.5 - Variação do NA sobre a soleira lateral. ....................................121

Tabela 6.6 - Variação do NA sobre a soleira lateral. ...................................... 135

Tabela 6.7 - Comparação dos coeficientes de descarga do vertedor lateral..........149 


\title{
LISTA DE SÍMBOLOS
}

\author{
m Metros \\ m/s Metros por segundo \\ $\mathrm{m}^{2} / \mathrm{s} \quad$ Metros quadrado por segundo \\ Re Número de Reynolds \\ Fr Número de Froude \\ E Energia específica do escoamento \\ Q Vazão volumétrica \\ $\mathbf{C}_{\mathrm{d}} \quad$ Coeficiente de descarga \\ g Aceleração da gravidade \\ $\mathrm{m}^{3} / \mathrm{s} \quad$ Metros cúbicos por segundo \\ $\mathrm{m} / \mathrm{m} \quad$ Metros por metros \\ ${ }^{\circ} \mathrm{C} \quad$ Graus Celsius \\ cm Centímetros \\ L/s Litros por segundo \\ NA Nível d'água \\ Kg/s Quilos por segundo \\ $\mathrm{Kg} / \mathrm{m}^{3} \quad$ Quilos por metros cúbicos \\ $\mathbf{m}^{2} \quad$ Metros quadrado \\ mm Milímetros \\ atm Atmosfera \\ $\mathbf{Q}_{\mathbf{M}} \quad$ Vazão mássica \\ $\mathrm{m} / \mathbf{s}^{2} \quad$ Metros por segundo ao quadrado \\ Pa Pascal
}




\section{SUMÁRIO}

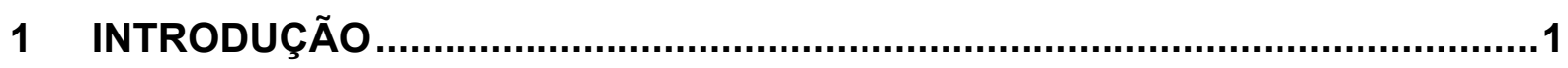

2 OBJETIVOS

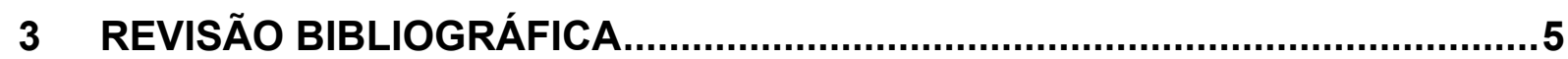

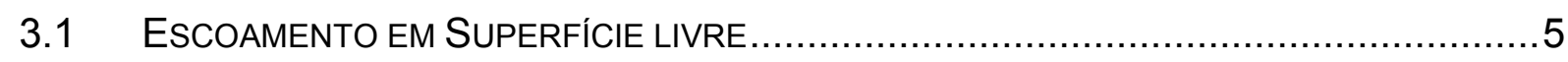

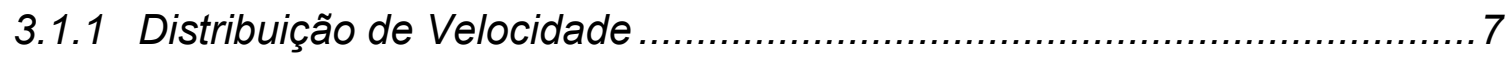

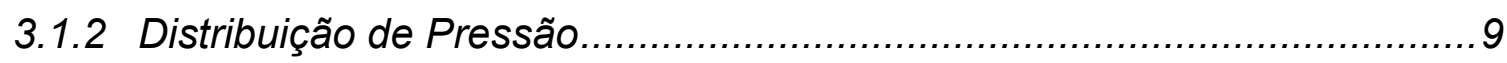

3.1.3 Princípio da Energia em Canais .......................................................11

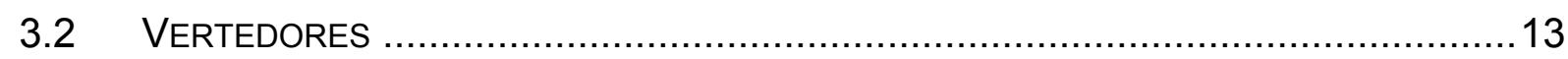

3.2.1 Características dos vertedores...................................................... 14

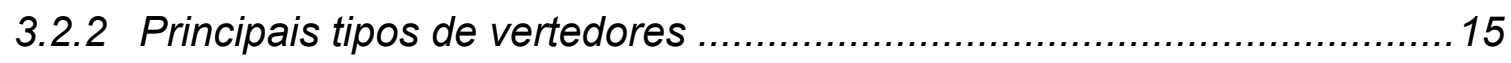

3.2.3 Considerações Gerais sobre o Vertedor Lateral ....................................20

3.2.3.1 Característica do escoamento ..................................................21

3.2.3.2 Equação da Energia ................................................................21

3.2.3.3 Equação da Quantidade de Movimento .........................................25

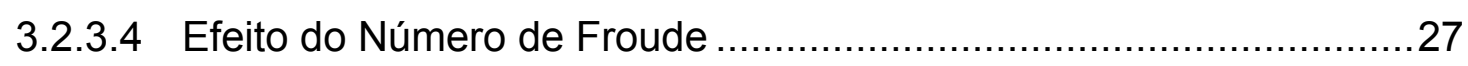

3.3 ESTUdOS EXPERIMENTAIS EM VERTEDORES LATERAIS ....................................29

3.4 Estudos NumÉRICOS do Escoamento EM VERTEDoRES LATERAIS.....................38

4 DINÂMICA DOS FLUIDOS COMPUTACIONAL ............................................42

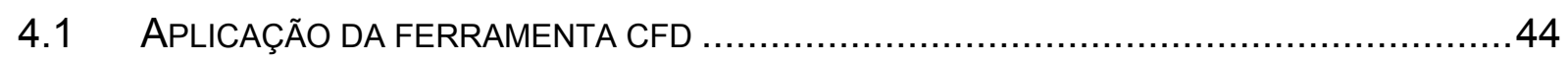

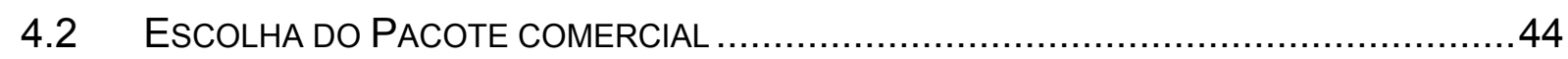

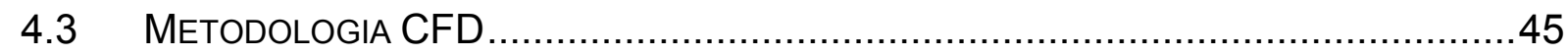

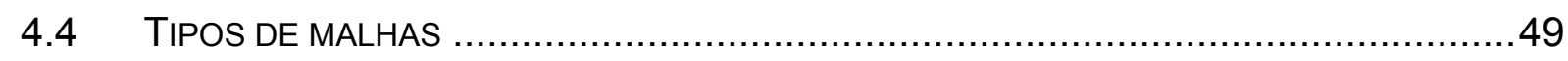

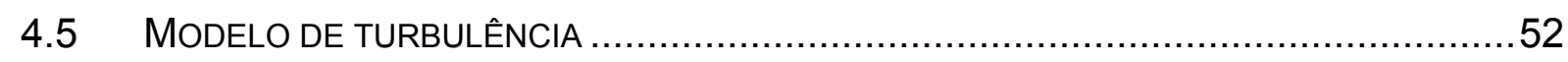

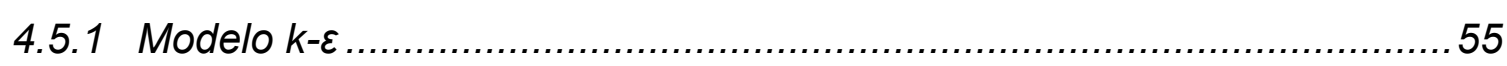

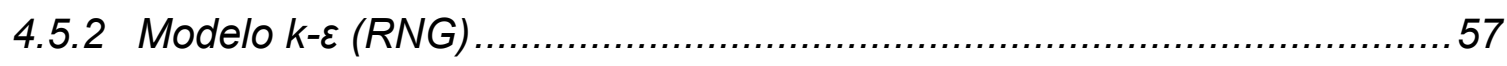

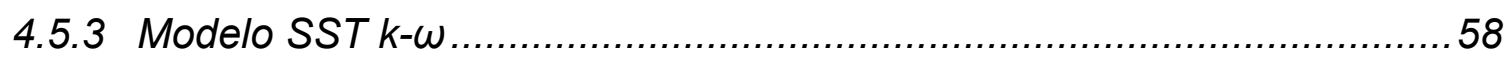




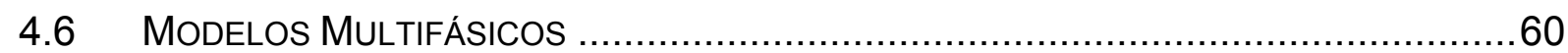

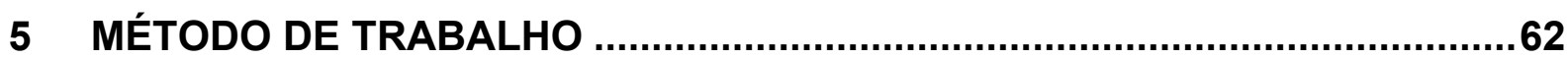

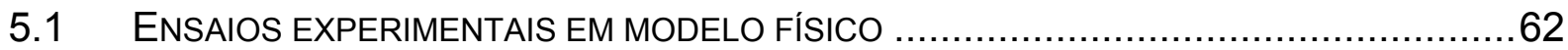

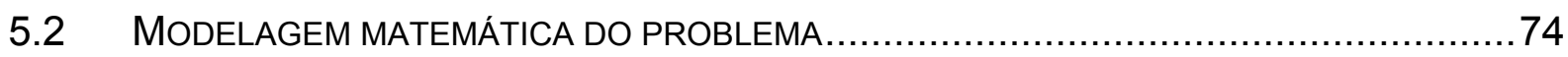

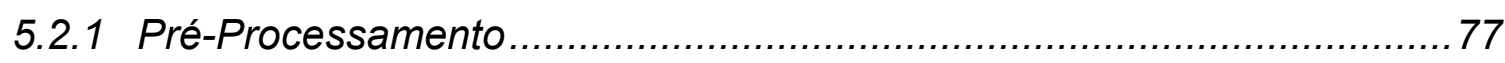

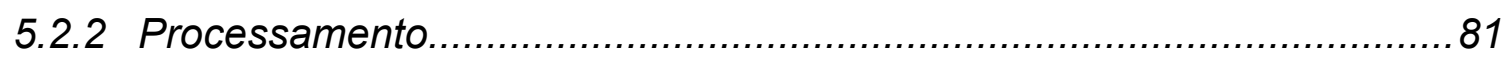

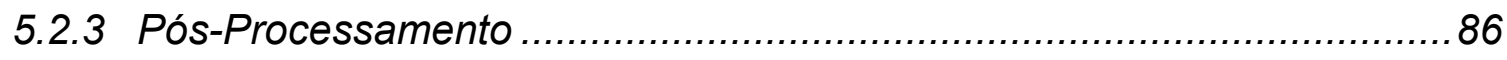

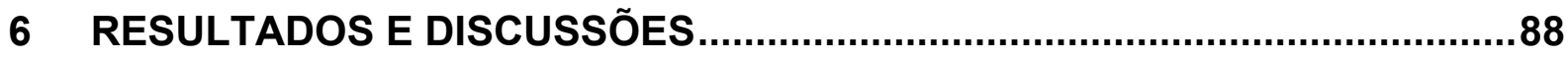

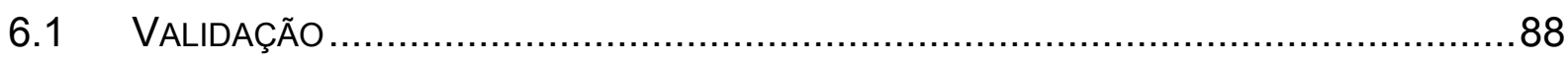

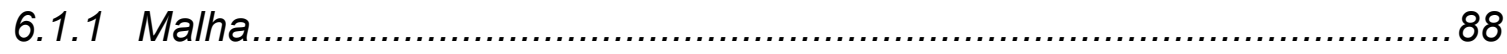

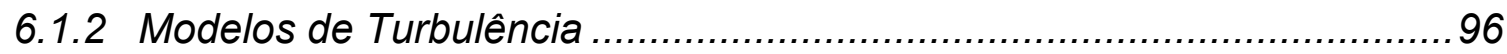

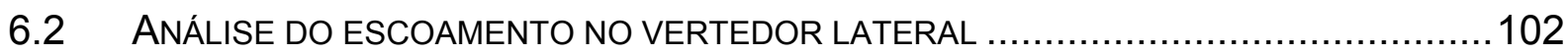

6.2.1 Condição Q1 ...................................................................... 104

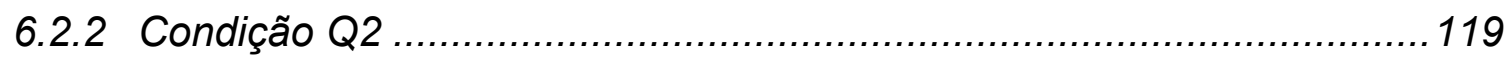

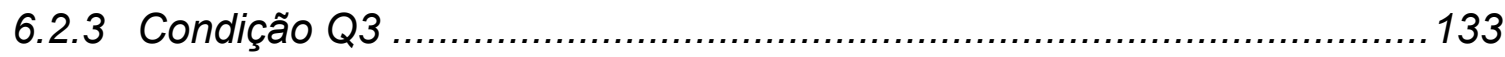

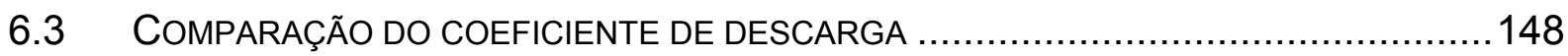

7 CONCLUSÕES E RECOMENDAÇÕES ................................................. 151

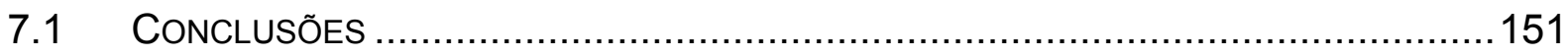

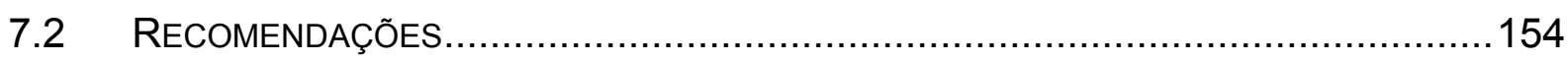

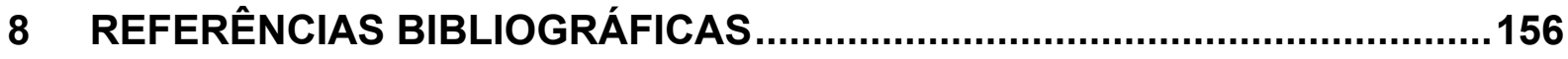




\section{INTRODUÇÃO}

Diversos centros urbanos sofrem com problemas de drenagem, devido ao crescimento acelerado e desordenado desses centros, que resulta na grande impermeabilização do solo e conseqüentemente no aumento do escoamento superficial. $\mathrm{O}$ conceito de drenagem urbana utilizado por projetistas durante muito tempo era projetar obras que levassem a vazão de cheia para jusante, entretanto, com a impermeabilização crescente do solo e as limitações da calhas dos rios, as bacias hidrográficas, principalmente de jusante, começaram a sofrer com os problemas das inundações.

As limitações físicas das calhas dos rios, de escoar a vazão de cheia, provocaram a mudança do conceito de drenagem da bacia, que passaram a armazenar a sua própria água e não sobrecarregar as bacias de jusante. A partir dessa concepção surgiram os reservatórios de detenção/ retenção, conhecidos popularmente como piscinões.

Os reservatórios de controle de cheias urbanas empregam usualmente estruturas de captação ou tomada do tipo 'vertedores laterais', compostos de soleiras alinhadas longitudinalmente ao fluxo. Estes reservatórios, geralmente instalados paralelamente ao escoamento (off-line), têm por função reter volumes de água afluentes a partir de uma determinada vazão, de forma a amortecer o pico da cheia (RAIMUNDO, 2007).

O conceito hidrológico envolvido no dimensionamento dos reservatórios off-line consiste na definição de um volume capaz de amortecer a vazão afluente associada a um determinado período de retorno, de forma a tornar a vazão efluente compatível com a capacidade de condução da canalização de jusante (RAIMUNDO, 2007).

May et al. (2003) afirmam que, os vertedores laterais são amplamente utilizados para desviar o escoamento de rios, canais, esgotos e reservatórios. Porém, a análise hidráulica do escoamento desse tipo de vertedor é complexa e difícil de predizer com precisão através de métodos simples. Chow (1994) afirma que os vertedores laterais são estudados desde o início do século XX.

Os vertedores laterais possuem um comportamento complexo, pois o fluxo varia ao longo do vertedor, o que não ocorre nos vertedores transversais tradicionais, cuja modelagem teórica é um campo bem conhecido da engenharia 
hidráulica e onde as condições de fluxo podem ser determinadas por equações relativamente simples (SOUZA, 2005). Segundo Porto (2004), o escoamento sobre a soleira do vertedor lateral não mantém uma vazão unitária constante e é do tipo espacialmente variado.

Devido às dificuldades apresentadas para o vertedor lateral, torna-se necessário a utilização de resultados experimentais ou numéricos para o projeto desses dispositivos. Por isso, será estudado o comportamento hidráulico do vertedor lateral através da ferramenta ANSYS CFX, e com isso, contribuir para um melhor entendimento de seu funcionamento. Essa ferramenta agrega valores aos projetos de produtos e processos que envolvam o escoamento de fluidos, transferência de calor e/ou reações químicas.

A tecnologia de CFD (Dinâmica dos Fluidos Computacional), utilizada pelo programa ANSYS CFX, se tornou uma parte fundamental no projeto e análise de produtos e processos de muitas empresas, devido a sua habilidade de predizer o desempenho destes equipamentos e processos antes mesmo de serem produzidos ou implementados, e ao baixo custo envolvido na simulação. A simulação numérica realizada através do programa ANSYS CFX emprega um esquema numérico baseado em discretização por Volumes Finitos. Nos escoamentos de fluidos, 0 modelo matemático é estabelecido com base nas equações de conservação da quantidade de movimento, da massa e da energia. Algumas das principais aplicações são: aeroespacial, automotiva, meio ambiente, petróleo e naval (ENGINEERING SIMULATION AND SCIENTIFIC SOFTWARE, 2009).

Existem várias ferramentas computacionais que utilizam a Dinâmica dos Fluidos Computacional, como ANSYS CFX, FLUENT, FLOW-3D, entre outras. Devido o programa ANSYS CFX apresentar um pacote robusto e completo de solução, desde a definição do problema, resolução, análise e apresentação dos resultados, esse foi um dos fatores na escolha dessa ferramenta para 0 desenvolvimento desse trabalho.

O CFD aplica-se a domínios confinados, ou seja, é necessário definir condições de contorno, onde alguns parâmetros como a distribuição de pressão, velocidades, vazões, etc., devem ser obtidos através de resultados experimentais para alimentar o modelo matemático. Os ensaios experimentais também permitem realizar a validação dos modelos computacionais, podendo criar um laboratório virtual, com grande confiabilidade dos resultados obtidos através da simulação. 
Diversos estudos podem ser realizados nas estruturas simuladas, como a análise da distribuição da velocidade e pressão, variação da energia, além da possibilidade de visualização do comportamento hidráulico do fluido em detalhes.

A ausência de estudos do escoamento da soleira lateral utilizando a tecnologia CFD, que possibilita representar o escoamento tridimensional dessa estrutura hidráulica e otimizar o seu tempo (custo) de projeto, é uma motivação para a realização desse trabalho.

O desafio desse trabalho é contribuir com o entendimento do comportamento hidráulico do vertedor lateral, que, no futuro, pode representar uma direção no desenvolvimento de projetos mais eficientes, a partir do conhecimento do seu escoamento. 


\section{OBJETIVOS}

Esse trabalho tem como objetivo criar um modelo matemático computacional de um modelo reduzido do vertedor lateral, utilizando a ferramenta ANSYS CFX, e validá-lo através de ensaio experimental.

Desta forma, busca-se conhecer com mais detalhes o comportamento hidráulico do vertedor lateral e contribuir para uma melhor compreensão de seu funcionamento.

Os objetivos específicos são:

1. Criar um modelo computacional do vertedor lateral em CFD e validá-lo através da comparação de sua vazão volumétrica, escoada através da soleira lateral, com os dados obtidos no ensaio experimental;

2. Analisar e comparar o comportamento dos níveis d'água sobre a soleira do modelo, que varia ao seu longo, com dados observados no ensaio experimental;

3. Obter e visualizar os principais parâmetros físicos no modelo, como a distribuição de velocidade e a variação dos níveis d'água, que permitam caracterizar o comportamento hidráulico do vertedor lateral;

4. Determinar o coeficiente de descarga do modelo computacional e compará-lo com resultados de equações desenvolvidas por pesquisadores referenciados na bibliografia. 


\section{REVISÃO BIBLIOGRÁFICA}

Esta revisão apresenta aspectos gerais sobre o comportamento do escoamento em superfícies livres, principalmente, na sua caracterização sobre os vertedores laterais. Também são apresentados alguns trabalhos que mostram a importância da hidráulica experimental no estudo do escoamento do vertedor lateral e na validação de modelos matemáticos, como na aplicação da ferramenta de Dinâmica dos Fluidos Computacional (CFD).

\subsection{ESCOAMENTO EM SUPERFÍCIE LIVRE}

Os condutos livres estão sujeitos à pressão atmosférica, pelo menos em um ponto da sua seção de escoamento. Eles também são denominados "canais", que são todos os condutos que conduzem águas com uma superfície livre, com seção aberta ou fechada (NETTO; ALVAREZ, 1982). Os cursos d'água naturais constituem o melhor exemplo de condutos livres. Além dos rios e canais, funcionam como condutos livres, por exemplo, os coletores de esgotos, galerias de águas pluviais, calhas, canaletas, etc.

Os escoamentos em canais podem sofrer variações de suas características hidráulicas no espaço e no tempo. As ocorrências das variações no tempo definem se os escoamentos podem ser permanentes e não permanentes. O escoamento permanente ocorre quando a velocidade local em um ponto qualquer da corrente permanecer invariável no tempo, em módulo e direção. Ao contrário, o escoamento não permanente apresenta uma variação da velocidade em certo ponto com o decorrer do tempo (PORTO, 2004).

Já as ocorrências das variações no espaço definem que os escoamentos podem ser uniformes e não uniformes ou variados. O escoamento uniforme acontece quando as velocidades locais são paralelas entre si e constantes ao longo de uma mesma trajetória, sendo as trajetórias retilíneas e paralelas, portanto a linha d'água é paralela ao fundo e a altura d'água é constante. Quando as trajetórias não são paralelas entre si, o escoamento é conhecido como não uniforme, a declividade 
da linha d'água não é igual à declividade de fundo nos canais prismáticos e os elementos característicos do escoamento variam de uma seção para outra (PORTO, 2004).

O escoamento variado pode ser permanente ou variável, acelerado ou desacelerado. Esse tipo de escoamento é subdividido em gradualmente variado, quando os elementos característicos da corrente variam de forma lenta e gradual, de seção para seção, e rapidamente variado, quando ocorre a variação brusca na altura d'água e demais parâmetros, sobre uma distância relativamente pequena. Um exemplo de escoamento rapidamente variado é o fenômeno do ressalto hidráulico, que é a elevação brusca da superfície livre que ocorre quando uma corrente de forte velocidade encontra uma corrente de fraca velocidade (PORTO, 2004).

O escoamento em canais abertos pode ser distinto por dois tipos de regime, laminar e turbulento. Existem dois adimensionais muito utilizados para classificar os escoamentos livres, o número de Reynolds e número de Froude, sendo Reynolds a relação entre a força de inércia e a força viscosa (NETTO; ALVAREZ, 1982), expresso por:

$$
\operatorname{Re}=\frac{V \cdot D_{h}}{v}
$$

Sendo:

Re o numero de Reynolds;

$\mathrm{V}$ a velocidade média da seção considerada, em [m/s];

$D_{\mathrm{h}}$ o diâmetro hidráulico da seção, em [m];

$v$ a viscosidade cinemática, para água a $20^{\circ} \mathrm{C}$ igual a $1,007 \times 10^{-6} \mathrm{em}\left[\mathrm{m}^{2} / \mathrm{s}\right]$.

Para o cálculo do número de Reynolds para os canais, adota-se geralmente, como dimensão linear característica, o valor $D_{h}=4 R_{h}$, sendo $R_{h}$ o raio hidráulico da seção transversal ao escoamento (NETTO; ALVAREZ, 1982).

O número de Reynolds permite classificar os escoamentos livres em dois tipos (MORAES, 2010):

a) Escoamento laminar: $\operatorname{Re}<3000$;

b) Escoamento turbulento: $\operatorname{Re}>3000$. 
O outro adimensional é o número de Froude, definido com a raiz quadrada da relação entre a força de inércia e a força de gravidade, sendo expresso por:

$$
F r=\frac{V}{\sqrt{g \cdot H_{m}}}
$$

Sendo:

Fr o número de Froude;

V a velocidade média da seção considerada, em [m/s];

g a aceleração da gravidade, adotado $9,81\left[\mathrm{~m} / \mathrm{s}^{2}\right]$;

$H_{m}$ a profundidade média hidráulica da seção, em [m].

Com esse adimensional pode-se classificar o escoamento livre em três tipos:

a) Escoamento subcrítico ou fluvial: $\mathrm{Fr}<1$;

b) Escoamento supercrítico ou torrencial: $\mathrm{Fr}>1$;

c) Escoamento crítico: $\mathrm{Fr}=1$.

\subsubsection{Distribuição de Velocidade}

As velocidades das várias partículas em um canal não estão uniformemente distribuídas na seção transversal do mesmo. Em canais naturais as velocidades variam acentuadamente de um ponto a outro. A não uniformidade nos perfis de velocidades nos canais depende da forma geométrica da seção e é devida às tensões de cisalhamento no fundo e paredes, e à presença da superfície livre (PORTO, 2004).

Chow (1994) afirma que, a distribuição de velocidades em uma seção de canal depende também da presença de curvas. Nas curvas a velocidade aumenta de maneira substancial no lado convexo, devido à ação centrífuga do escoamento. $E$ também afirma que, ao contrário do pensamento usual, o vento na superfície tem muito pouco efeito na distribuição de velocidades. 
Para os canais prismáticos a distribuição vertical da velocidade segue uma lei aproximadamente parabólica, com valores decrescentes com a profundidade e a máxima velocidade ocorre um pouco abaixo da superfície livre (PORTO, 2004).

A Figura 3.1 mostra para a seção transversal de um canal prismático, a forma das isotáquias ou linhas de igual velocidade e, para uma seção longitudinal, um perfil de velocidades.
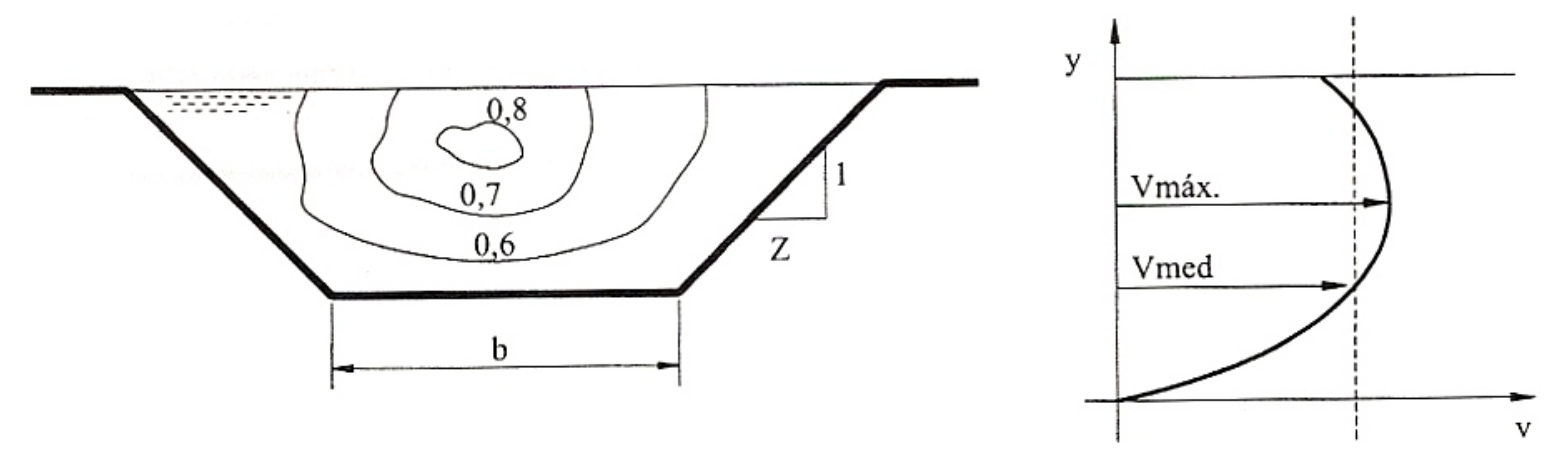

Figura 3.1 - Distribuição de velocidade em uma seção transversal (fonte: PORTO, 2004).

Um escoamento permanente que dependa de três coordenadas $x, y$, e z para a definição de suas propriedades e características é conhecido como tridimensional. Esta situação ocorre em canais cuja relação entre a largura da superfície livre e a altura d'água é menor que três. Com o aumento desta proporção, pode-se utilizar um modelo mais conveniente para descrever o campo de velocidades, chamado bidimensional, no qual a velocidade depende apenas das coordenadas $\mathrm{x} e \mathrm{y}$ (PORTO, 2004). A velocidade média na seção longitudinal de altura d'água y é dada pela expressão 3.3:

$$
V=\frac{1}{y} \cdot \int v(x, y) d y
$$

Com a utilização de modelos unidimensionais, no qual $\mathrm{v}(\mathrm{x})$, a velocidade pontual só depende de uma coordenada geométrica ao longo do canal, e a velocidade média na seção transversal é a velocidade única e representativa, os cálculos são consideravelmente simplificados.

Em algumas aplicações, devido à não uniformidade da distribuição da velocidade, é necessário fazer uso dos coeficientes de correção da energia cinética 
e da quantidade de movimento, sendo o coeficiente de Coriolis e Boussinesq, representados respectivamente pelas expressões (3.4) e (3.5):

$$
\begin{gathered}
\alpha=\frac{\int_{A} V^{3} d A}{V^{3} A} \\
\beta=\frac{\int_{A} V^{2} d A}{V^{2} A}
\end{gathered}
$$

Sendo:

A a área da seção transversal;

$\checkmark$ a velocidade pontual;

$\checkmark$ a velocidade média da seção.

Diversos estudos experimentais indicaram que o valor de a varia entre 1,03 e 1,36 para o escoamento turbulento em canais prismáticos razoavelmente retilíneos, apresentando geralmente o valor maior de a para canais pequenos. Já os valores de $\beta$ variam de 1,01 a 1,12 . Para canais retilíneos de seção regular, o efeito da não uniformidade das velocidades é pequeno, por isso na maioria dos estudos práticos, os coeficientes $\alpha$ e $\beta$ são assumidos iguais à unidade (PORTO, 2004).

\subsubsection{Distribuição de Pressão}

A pressão em qualquer ponto da seção transversal de um canal é diretamente proporcional a profundidade do fluxo abaixo da superfície livre, e igual à pressão hidrostática correspondente a esta profundidade, isto é, a distribuição de pressão a longo da seção transversal do canal é igual à distribuição hidrostática de pressões, e esta distribuição é linear, sendo conhecida com a lei Hidrostática de Distribuição de Pressões (CHOW, 1994).

Sobre o perfil de pressão em uma determinada seção, os escoamentos em canais podem ser classificados como paralelo, no qual as linhas de corrente são retas paralelas, não apresentando curvaturas e o efeito de componentes de 
acelerações normais à direção do fluxo, devido à força centrífuga, é desprezível. Quando o efeito centrífugo devido à curvatura das linhas de corrente não é desprezível, os escoamentos são conhecidos como curvilíneo (PORTO, 2004).

A distribuição de pressão entre a superfície livre e o fundo do canal é dada por:

$$
P=\gamma \cdot y+\rho \cdot \frac{V^{2}}{r} \cdot h
$$

Sendo $\mathrm{P}$ a pressão, $\gamma \cdot y$ a contribuição hidrostática, $\rho$ a massa específica, $\mathrm{V}$ a velocidade média, $\mathrm{r}$ o raio de curvatura da seção longitudinal e $\mathrm{h}$ é a profundidade da água. Pode-se encontrar um modelo de distribuição de pressão mais realístico em Souza, Martins e Fadiga (1991).

Essa equação apresenta que a distribuição de pressão é a soma do efeito hidrostático $\gamma \cdot y$, com o efeito centrífugo devido à aceleração normal do escoamento, que aumenta a pressão no fundo se a curva for côncava e diminui se for convexa, conforme a Figura 3.2.
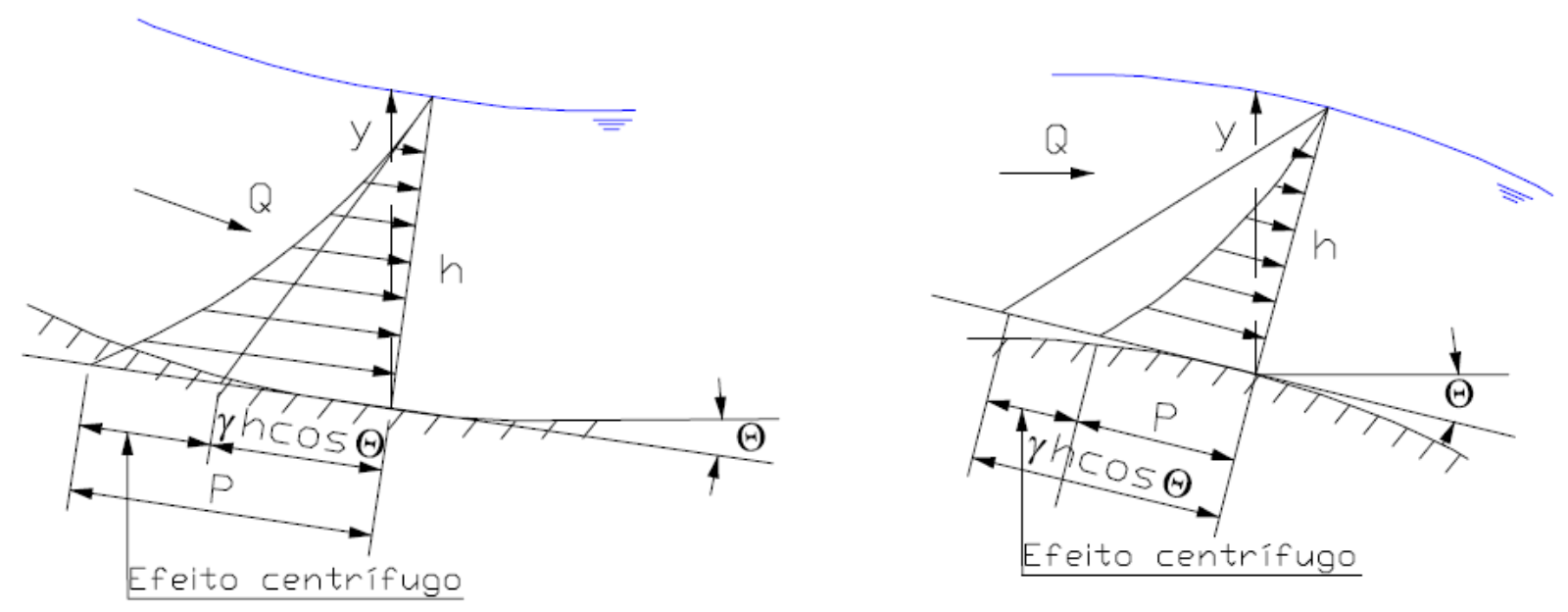

Figura 3.2 - Distribuição de pressão em fundo curvo, adaptado de Porto (2004).

O escoamento em canais com superfície livre coincide com a linha piezométrica, desde que a distribuição de pressão seja hidrostática, quando a curvatura vertical das linhas de corrente e acelerações forem desprezíveis e o canal for de baixa declividade (PORTO, 2004). 
Em escoamento permanente gradualmente variado, levando em conta que a alteração da altura d'água de uma seção para outra é suave e a curvatura das linhas de corrente pequena para efeito prático, o escoamento será admitido paralelo e a distribuição de pressão, hidrostática.

\subsubsection{Princípio da Energia em Canais}

O princípio da energia é utilizado para analisar muitos fenômenos que ocorrem em canais. Para um canal de baixa declividade, e considerando escoamento unidimensional, a aplicação do princípio da conservação de energia entre duas seções consecutivas pode ser visto na figura 3.3 e representado pela equação 3.7.

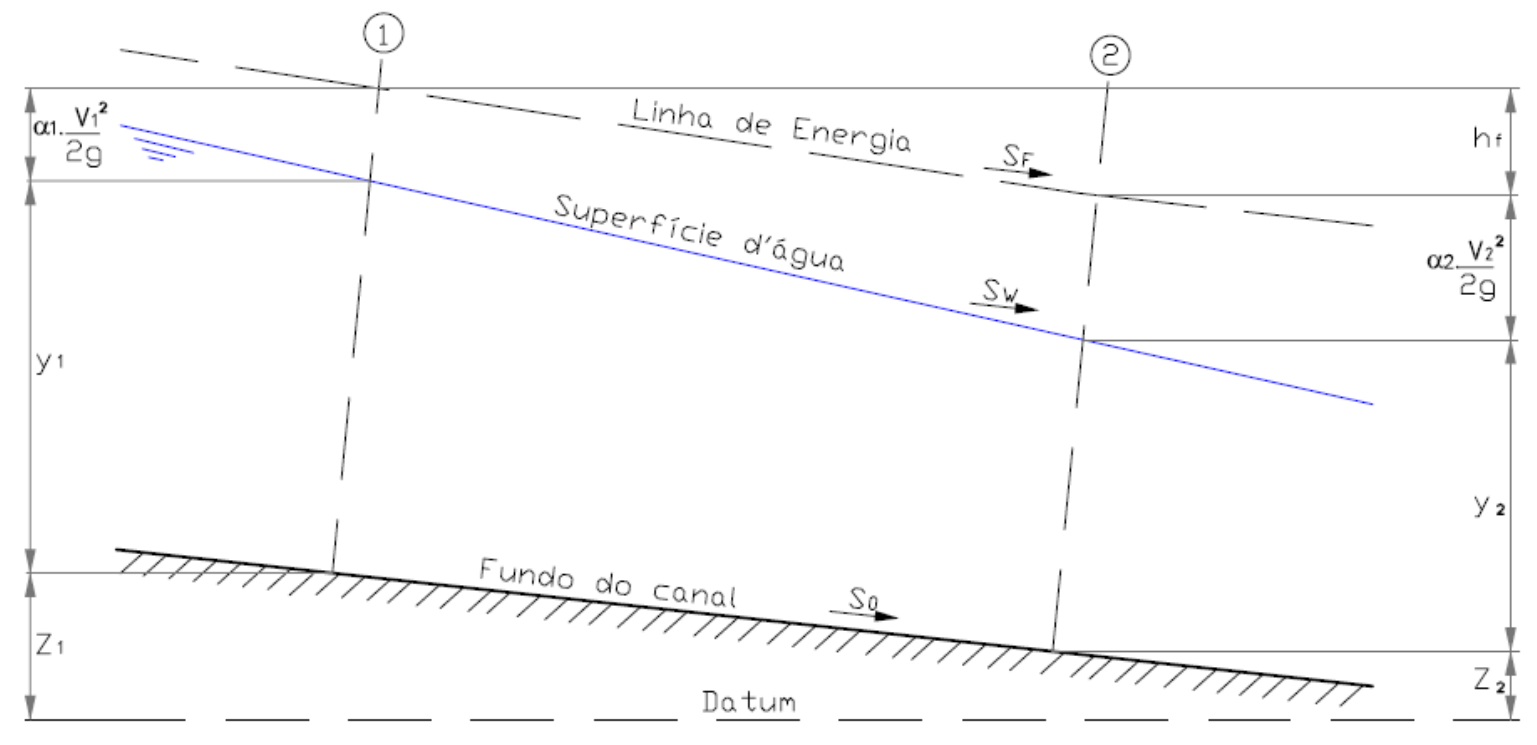

Figura 3.3 - Princípio da Energia em Canais.

$z_{1}+y_{1}+\alpha_{1} \cdot \frac{v_{1}^{2}}{2 \cdot g}=z_{2}+y_{2}+\alpha_{2} \cdot \frac{v_{2}^{2}}{2 \cdot g}+h_{f}$

As seções 1 e 2 são representadas na figura 3.3. Sendo $z$ a elevação do ponto acima do datum; $y$ a profundidade da água no canal; $v$ a velocidade média do escoamento na seção; $g$ a aceleração da gravidade; $\alpha$ o coeficiente de Coriolis, e $h f$ a perda de carga no trecho do canal. Esta equação é conhecida como Equação da Energia. 
A carga específica é definida como a distância vertical entre o fundo do canal e a linha de energia. Este conceito é extremamente importante para estudar os problemas de escoamento através de singularidades em canais, como mudança de declividade, de seção, de direção do escoamento ou alteração da cota de fundo. A energia específica para uma determinada seção de um canal, em escoamento retilíneo, pode ser representada pela expressão 3.8:

$$
E=y+\alpha \cdot \frac{v^{2}}{2 \cdot g}
$$

Portanto, a energia específica em uma seção do canal é a soma da altura d'água com a carga cinética.

Pode-se notar na figura 3.4 , que para uma vazão constante a energia específica varia com a profundidade. Para pequenos valores de y, a curva aproximase $\mathrm{o}$ infinito do eixo $\mathrm{E}$, enquanto que, para grandes valores de $\mathrm{y}$, o termo referente à carga cinética é desprezível e a curva aproxima-se da linha a $45^{\circ}$, onde $y=E$, assintoticamente. A profundidade onde ocorre a mínima energia específica é chamada de profundidade ou altura crítica (STREETER; WYLIE, 1982). Porto (2004) definiu o escoamento crítico como sendo o estágio em que a energia específica é mínima para uma dada vazão ou o estágio em que a vazão é máxima para uma dada energia específica.
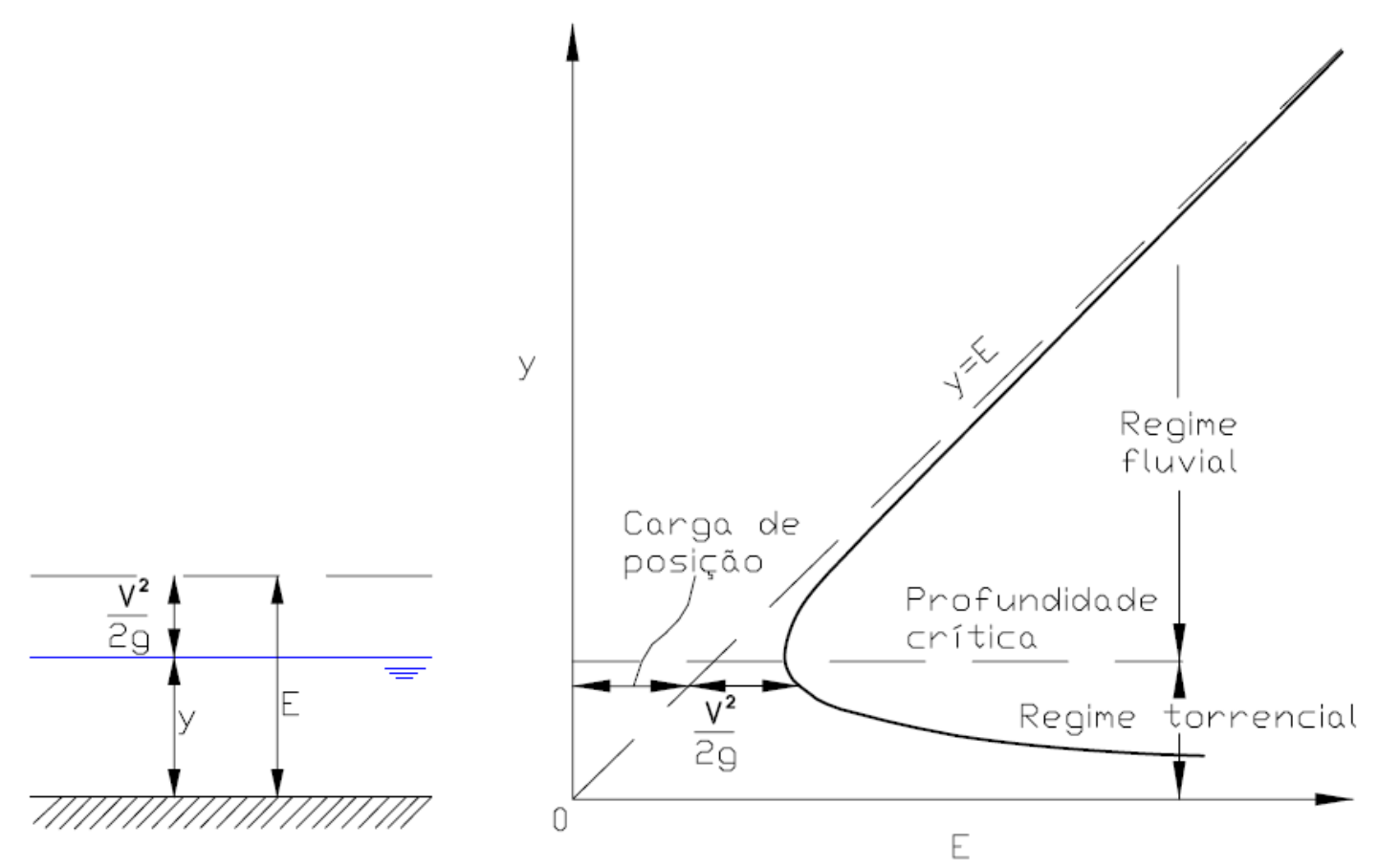

Figura 3.4 - Energia específica para o escoamento, adaptado de Streeter e Wylie (1982). 
Pode-se observar no gráfico da Figura 3.4 que para cada nível de energia prefixado, existem duas possibilidades de veicular uma vazão. $O$ escoamento pode apresentar o regime fluvial ou regime torrencial, estes dois escoamentos têm características bem diferentes, enquanto o fluvial é chamado de lento ou subcrítico o torrencial é chamado de rápido ou supercrítico.

O escoamento é subcrítico quando a velocidade do escoamento for menor que a velocidade de propagação de um pequeno distúrbio, e sua onda propaga-se para montante, sendo sujeito a um controle de jusante. Já em um escoamento supercrítico a onda provocada por um distúrbio é propagado apenas para a jusante, sendo sujeito a um controle de montante. O controle caracteriza-se pelo estabelecimento de uma relação entre a profundidade e a vazão em suas vizinhanças. A seção do canal em que esta relação é estabelecida chama-se seção de controle. Portanto, um controle transforma o escoamento a montante em subcrítico e a jusante em supercrítico (SOUZA, 2005).

\subsection{VERTEDORES}

Os vertedores são dispositivos utilizados para medição e/ ou controle de vazão em escoamentos em canais. Por definição, trata-se de um orifício de grandes dimensões no qual foi suprimida a aresta de topo, isto é, na passagem pela estrutura a parte superior da veia líquida está em contato com a pressão atmosférica (PORTO, 2004).

A estrutura de um vertedor resume-se em uma parede com abertura de determinada forma geométrica, alocada em sua maioria, perpendicularmente à corrente, elevando o nível d'água de montante até que este nível atinja uma cota suficiente para produzir uma lâmina líquida sobre o obstáculo, compatível com a vazão descarregada (PORTO, 2004).

Os vertedores são estruturas relativamente simples e de grande importância prática. Eles são utilizados em numerosas construções hidráulicas, como: sistema de macro drenagem, barragens, medição de vazão, sistemas de irrigação, entre outros. 


\subsubsection{Características dos vertedores}

As principais partes de um vertedor são apresentadas a seguir e podem ser visualizadas na Figura 3.5:

- Crista ou soleira: é a parte superior da parede em que há o contato com a lâmina vertente;

- Carga geométrica sobre a soleira (h): é a diferença de cota entre o nível d'água a montante e o nível da soleira, fora da região de curvatura da lâmina, uma distância a montante de no mínimo seis vezes a carga;

- Altura do vertedor $(\mathrm{P})$ : é a diferença de cotas entre a soleira e o fundo do canal de chegada;

- Largura da Soleira (L): é a dimensão da soleira onde ocorre o escoamento.
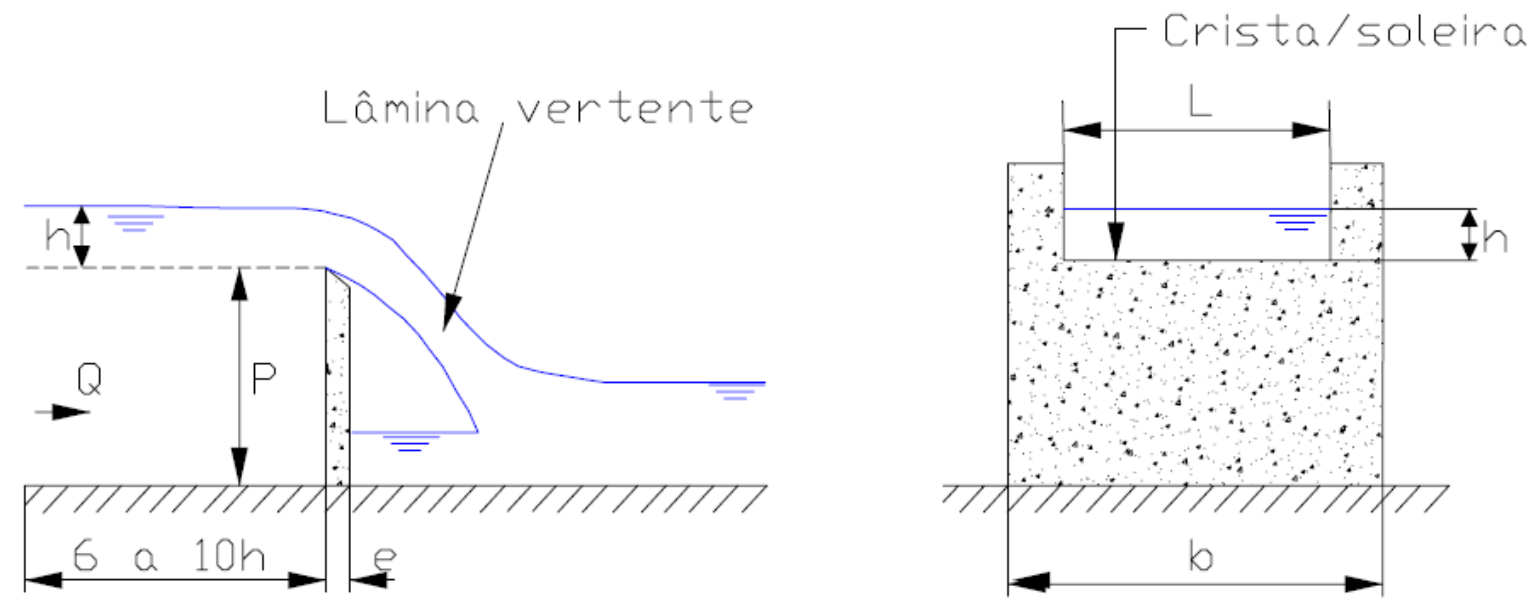

Figura 3.5 - Vertedor de parede delgada, adaptado de Porto (2004).

Os vertedores são classificados em relação à:

- Forma geométrica da abertura: retangulares, trapezoidais, triangulares, circulares, etc;

- Altura relativa da soleira: descarga livre e descarga submersa;

- Natureza da parede: parede delgada, se a espessura da parede for inferior a dois terços da carga, ou parede espessa;

- Largura relativa da soleira: sem contrações laterais ou com contrações; 
- Natureza da lâmina: livre, se a região abaixo da lâmina for suficientemente arejada, deprimida, se a pressão abaixo da lâmina for menor que a pressão atmosférica, aderente, onde não há bolsa de ar abaixo da lâmina;

- Inclinação da parede: vertical ou inclinado;

- Geometria da crista: crista retilínea, circular e poligonal.

\subsubsection{Principais tipos de vertedores}

Serão apresentados os principais tipos de vertedores e suas características predominantes:

\section{a) Vertedor retangular de parede fina}

Esse vertedor (Figura 3.5) é o mais estudado ao longo dos anos, sendo constituído por uma placa delgada, com soleira horizontal e biselada, instalada perpendicularmente ao escoamento, ocupando toda a largura do canal, e com o espaço sob a lâmina vertente ocupado com ar à pressão atmosférica. Geralmente esse dispositivo é utilizado para medidas de vazão, fornecendo resultados com boa precisão. Este vertedor é denominado como descarregador Bazin (PORTO, 2004).

A vazão do vertedor retangular de parede fina pode ser obtida através da equação (3.9).

$$
Q=\frac{2}{3} \cdot C_{d} \cdot \sqrt{2 g} \cdot L \cdot h^{3 / 2}
$$

Sendo:

$Q$ a vazão, em $\left[\mathrm{m}^{3} / \mathrm{s}\right]$;

$\mathrm{C}_{\mathrm{d}}$ o coeficiente de descarga;

$\mathrm{g}$ a aceleração da gravidade, em $\left[\mathrm{m} / \mathrm{s}^{2}\right]$;

L a largura da soleira, em [m];

h a carga hidráulica sobre a soleira, em [m]. 
Existem diversos estudos para a determinação do coeficiente de descarga para tipo de vertedor, entretanto, para o desenvolvimento desse trabalho será utilizada a equação de Rehbock (1929), citada por Porto (2004), que é representada pela equação (3.10). Porto (2004) afirma que, devido a condições e limites de parâmetros experimentais, e do ponto de vista prático na engenharia, é perfeitamente aceitável a variação de resultados na faixa de $5 \%$.

$$
C_{d}=\left[0,6035+0,0813 \cdot\left(\frac{h+0,0011}{P}\right)\right] \cdot\left[1+\frac{0,0011}{h}\right]^{3 / 2}
$$

Sendo:

$\mathrm{P}$ a altura do vertedor, em [m].

A equação (3.10) é válida para a faixa de parâmetros de $0,03<\mathrm{h}<0,75 \mathrm{~m}$, $L>0,30 m, P>0,30 m$ e $h<P$.

Em campo, nas medições de vazões em córregos naturais ou canais artificiais é comumente utilizado um vertedor com a largura da soleira menor do que a largura do curso d'água, ocorrendo à influência de contrações laterais, sendo necessário aplicar um fator de correção para a largura da soleira nas equações utilizadas para a determinação da vazão (NETTO; ALVAREZ, 1982).

\section{b) Vertedor triangular}

Os vertedores triangulares (Figura 3.6) possibilitam uma maior precisão na medida de cargas correspondentes a vazões reduzidas. São geralmente trabalhados em chapas metálicas. Em aplicações práticas, somente são utilizados os de forma isósceles, sendo os mais usuais os de $90^{\circ}$ (NETTO; ALVAREZ, 1982). 


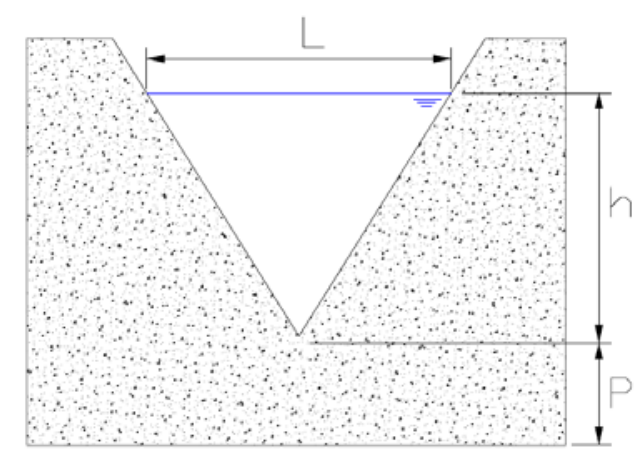

Figura 3.6 - Vertedor triangular, adaptado de Porto (2004).

Para vertedores triangulares com ângulos de abertura de $90^{\circ}$, a fórmula mais utilizada é a de Thomson (equação (3.11)):

$Q=1,4 \cdot h^{5 / 2}$

Sendo:

$\mathrm{Q}$ a vazão, em $\left[\mathrm{m}^{3} / \mathrm{s}\right]$

h a carga hidráulica sobre a soleira, em [m].

c) Vertedor trapezoidal

O vertedor tipo trapezoidal não desperta tanto interesse de aplicação como os vertedores retangulares e triangulares. Entretanto, o vertedor chamado Cipoletti (Figura 3.7), que possui a forma de um trapézio isósceles, a sua geometria é obtida de maneira que as inclinações laterais compensem a diminuição da vazão, isso ocorre devido ao efeito da contração lateral do vertedor retangular de mesma largura da soleira (PORTO, 2004).

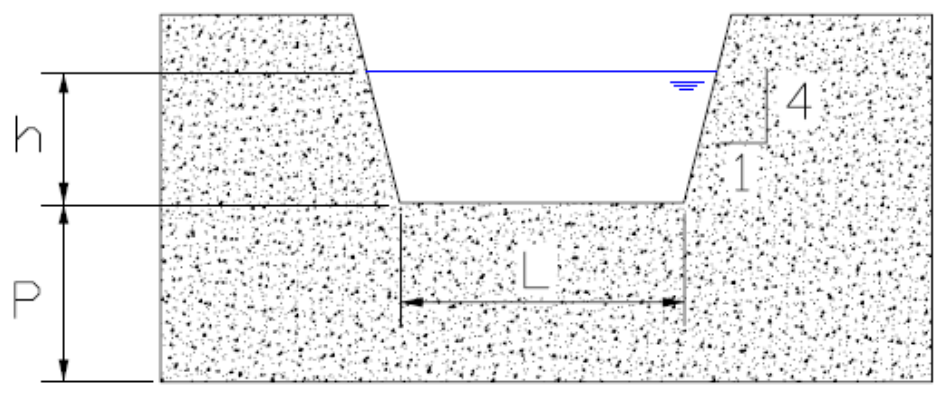

Figura 3.7 - Vertedor Cipoletti, adaptado de Porto (2004). 
A sua vazão pode ser determinada pela equação:

$Q=1,861 \cdot L \cdot h^{3 / 2}$

Sendo:

$\mathrm{Q}$ a vazão, em $\left[\mathrm{m}^{3} / \mathrm{s}\right]$

$\mathrm{L}$ a largura da soleira, em [m];

h a carga hidráulica sobre a soleira, em [m].

d) Vertedor de soleira espessa horizontal

Esse vertedor (Figura 3.8) é uma elevação no fundo do canal com uma determinada altura, largura e comprimento, suficiente para produzir a elevação do nível d'água a montante. A veia líquida apresenta uma depressão nas proximidades do bordo de montante e o escoamento desenvolve-se praticamente paralelo à crista (PORTO, 2004).

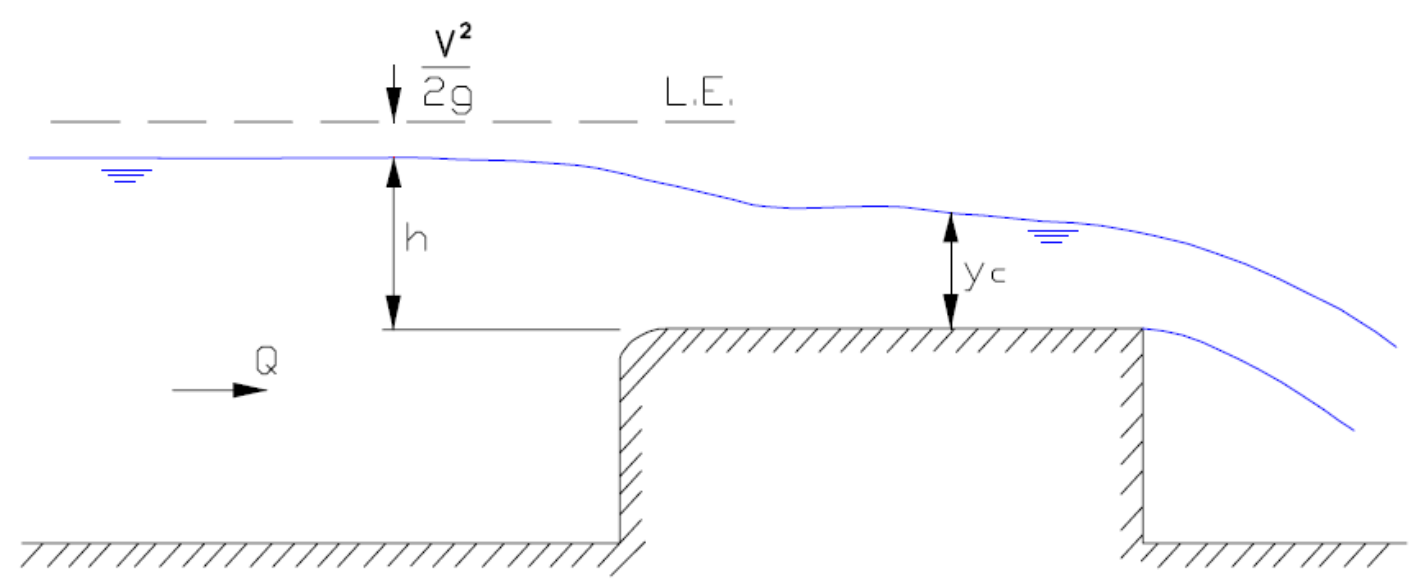

Figura 3.8 - Vertedor de soleira espessa horizontal, adaptado de Porto (2004).

A sua vazão pode ser determinada pela fórmula de Bélanger (NETTO; ALVAREZ, 1982):

$Q=1,71 \cdot L \cdot h^{3 / 2}$

Sendo:

$\mathrm{Q}$ a vazão, em $\left[\mathrm{m}^{3} / \mathrm{s}\right]$ 
$\mathrm{L}$ a largura da soleira, em [m];

h a carga hidráulica sobre a soleira, em [m].

\section{e) Vertedores de Soleira Normal}

O vertedor de soleira Normal (Figura 3.9) corresponde a uma forma geométrica, cujo perfil vertente a jusante da crista se assemelha com a lâmina vertente a jusante de uma soleira delgada livre. Este conceito visa acomodar melhor a lâmina vertente, com favorecimento do coeficiente de vazão e reduzir ou mesmo eliminar as pressões negativas na face inferior da lâmina, que podem provocar a cavitação do concreto (RAIMUNDO, 2007).

Diversos estudos analíticos e experimentais foram desenvolvidos para esse perfil, sendo os mais comuns os perfis Creager e Scimeni (PORTO, 2004). Este tipo de vertedor é mais utilizado em usinas hidrelétricas, barragens de regulação e para abastecimento de água.

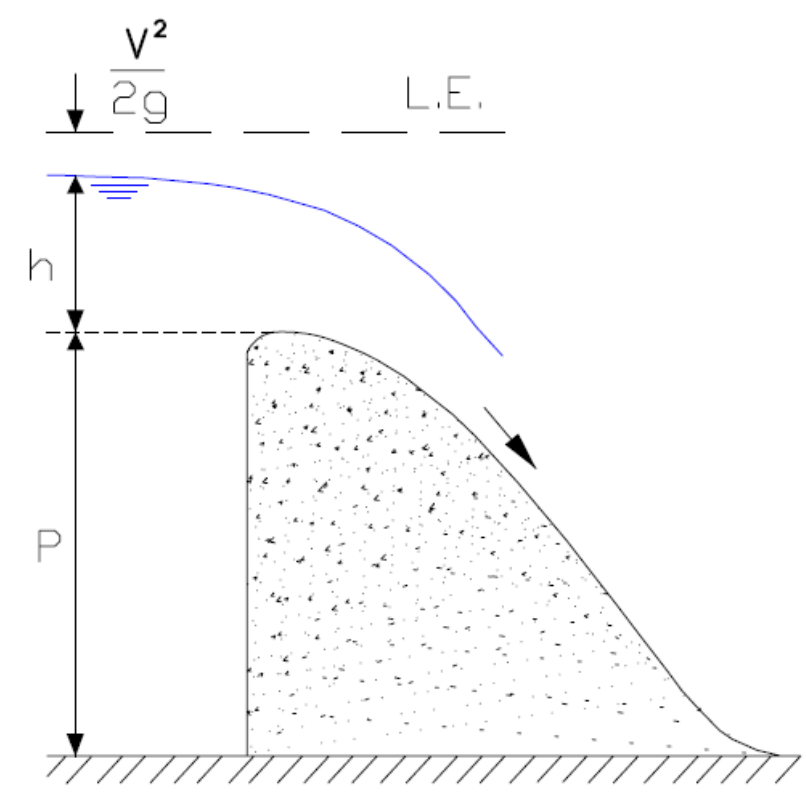

Figura 3.9 - Vertedor de soleira normal, adaptado de Porto (2004).

A fórmula genérica para a determinação da vazão desse tipo de vertedor é representada por:

$Q=2,2 \cdot L \cdot h^{3 / 2}$ 
Sendo:

$\mathrm{Q}$ a vazão, em $\left[\mathrm{m}^{3} / \mathrm{s}\right]$

$\mathrm{L}$ a largura da soleira, em [m];

h a carga hidráulica sobre a soleira, em [m].

\subsubsection{Considerações Gerais sobre o Vertedor Lateral}

A utilização comum de vertedores em obras hidráulicas é aquela em que o dispositivo hidráulico é instalado perpendicularmente ao sentido da corrente, nessa situação, a vazão unitária é essencialmente constante. Entretanto, quando os vertedores são instalados paralelamente ao escoamento, devido a uma necessidade de alívio de um sistema de drenagem, ou a partição de vazão em um projeto de irrigação, entre outros casos, o escoamento sobre a soleira desses dispositivos não mantém uma vazão unitária constante e são do tipo espacialmente variado, sendo conhecidos como vertedores laterais (PORTO, 2004).

Os vertedores laterais possuem um comportamento complexo, pois o fluxo varia ao longo do vertedor, o que não ocorre nos vertedores transversais tradicionais, cuja modelagem teórica é um campo bem conhecido da engenharia hidráulica e onde as condições de fluxo podem ser determinadas por equações relativamente simples (SOUZA, 2005). Alguns dos fatores que dificultam a análise do comportamento do escoamento em um vertedor lateral são:

- O escoamento é tridimensional, sendo desviado próximo à crista do vertedor, enquanto que no lado oposto do canal e nas camadas próximas ao leito o escoamento praticamente não sofre influência do vertedor lateral;

- O escoamento passa através dos vertedores laterais em ângulos oblíquos, ângulos que variam com a velocidade do escoamento;

- A carga atuante no vertedor lateral varia ao longo da crista do mesmo, causando uma mudança na sua vazão específica. 
Devido às dificuldades existentes para o vertedor lateral, torna-se necessário à utilização de resultados experimentais ou numéricos para o projeto desses dispositivos.

\subsubsection{Característica do escoamento}

O escoamento do vertedor lateral caracteriza-se pela complexidade. Para o projeto desse dispositivo os engenheiros buscam métodos de cálculos práticos e fáceis de aplicar. Desta forma, os métodos existentes, excluindo os pacotes de programas de Dinâmica dos Fluidos Computacional (CFD), são baseados na simplificação do escoamento, considerando o escoamento unidimensional, utilização dos coeficientes de correção da quantidade de movimento e de correção de energia cinética para compensar a não-uniformidade da distribuição de velocidades, e a utilização do coeficiente de descarga para compensar o ângulo oblíquo que a água passa através do vertedor lateral.

Para representar de forma satisfatória e prática a capacidade de descarga do vertedor lateral é utilizada a equação unidimensional do escoamento espacialmente variado com o decréscimo da vazão. Esta equação pode ser apresentada através de duas formas, que dependem se a mesma foi derivada a partir da conservação da quantidade de movimento ou da energia no canal principal (MAY et al., 2003)

\subsubsection{Equação da Energia}

A equação da energia torna-se uma alternativa para a dedução da equação do escoamento espacialmente variado, onde ocorre o escoamento com decréscimo de vazão. São determinadas algumas suposições para a derivação dessa equação (MAY et al., 2003):

a) O escoamento é unidirecional;

b) O efeito da não-uniformidade da distribuição de velocidades no canal principal é corrigido pelo coeficiente de Coriolis ( $\alpha$ ); 
c) A distribuição de pressões no escoamento é hidrostática;

d) O efeito do arrastamento de ar não é considerado;

e) A superfície de água é horizontal em qualquer seção transversal do canal, mas considera-se a variação com a distância ao longo do canal;

f) Não há perda de energia do escoamento ao longo da soleira.

Segundo May et al. (2003), a variação da profundidade do escoamento "y" em relação à distância ao longo da soleira do vertedor lateral a partir do seu início, " $x$ ", considerando as suposições citadas anteriormente e que o canal seja retangular, pode ser representada da seguinte forma:

$$
\frac{d y}{d x}=\frac{S_{0}-S_{F}-\alpha \cdot \frac{q \cdot Q}{g \cdot A^{2}}}{1-\frac{\alpha \cdot b \cdot Q^{2}}{g \cdot A^{3}}}
$$

Sendo:

$S_{0}$ a inclinação do fundo do canal principal;

$\mathrm{S}_{\mathrm{F}}$ a inclinação da linha de carga total do canal principal;

a o coeficiente de Coriolis;

q a vazão por unidade de largura no vertedor lateral;

Q a vazão do canal;

g a aceleração da gravidade;

A a área da seção transversal do escoamento no canal;

b a largura do canal.

Para canais não retangulares tem-se:

$$
\frac{d y}{d x}=\frac{S_{0}-S_{F}-\alpha \cdot \frac{q \cdot Q}{g \cdot A^{2}}}{1-\frac{\alpha \cdot Q^{2}}{g \cdot A^{2} \cdot D}}
$$


Sendo:

D a profundidade hidráulica, que é a relação entre a área molhada e a largura da seção na superfície livre.

Porto (2004) apresenta o caso mais comum na prática (Figura 3.10), vertedor lateral retangular de altura $\mathrm{P}$ e comprimento $\mathrm{L}$, de soleira delgada ou espessa, canal principal retangular de largura b e escoamento de aproximação fluvial.

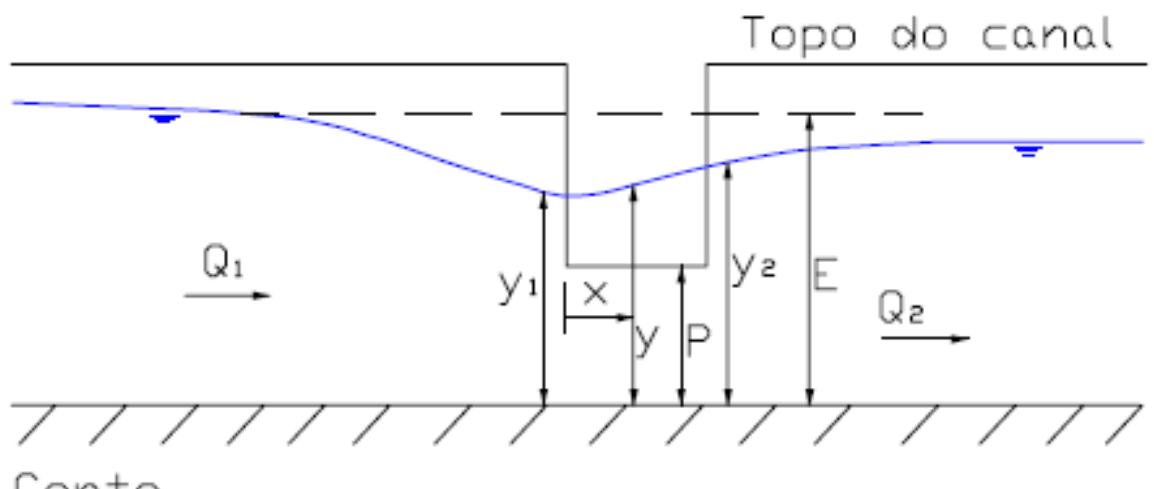

Corte

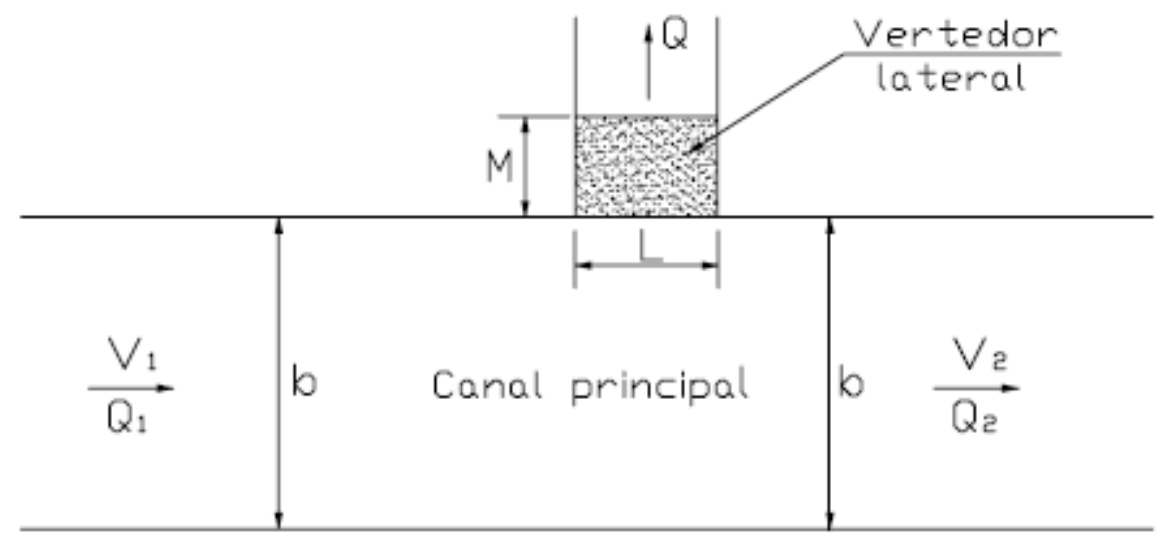

Planta

Figura 3.10 - Vertedor lateral (fonte: Porto, 2004).

A vazão unitária de um vertedor retangular, parede fina, sem contrações laterais, em que $\mathrm{C}_{d}$ (coeficiente de descarga) é considerado constante, é dada por: $q(x)=\frac{2}{3} \cdot C_{d} \cdot \sqrt{2 \cdot g} \cdot(y(x)-P(x))^{3 / 2}$ 
Sendo:

$q(x)$ a vazão unitária;

$\mathrm{C}_{\mathrm{d}}$ o coeficiente de descarga;

g a aceleração da gravidade;

y(x) o nível d’água sobre a soleira do vertedor lateral;

$P(x)$ a altura soleira.

Considerando que a energia específica é constante ao longo de todo o vertedor lateral, onde o coeficiente de Coriolis é igual à unidade e o canal sendo horizontal, onde a inclinação do fundo do canal e a inclinação da linha de energia são iguais a zero $\left(S_{0}=S_{F}=0\right)$, obtém-se a equação diferencial da linha d'água:

$$
\frac{d y}{d x}=-\frac{4}{3} \cdot \frac{C_{d}}{b} \cdot\left[\sqrt{\frac{\left(E_{0}-y\right) \cdot(y-P)^{3}}{\left(2 \cdot E_{0}-3 \cdot y\right)}}\right]
$$

Sendo:

$E_{0}$ a energia específica.

Porto (2004) afirma que, está equação foi integrada por Giulio de Marchi em 1932, para $x=0$ até $x=L$, onde foi considerado que $C_{d}$ é independente de $x$.

$$
L=\frac{3}{2} \cdot \frac{b}{C_{d}} \cdot\left(\Phi_{2}-\Phi_{1}\right)
$$

com:

$\Phi=\frac{2 \cdot E_{0}-3 \cdot P}{E_{0}-P} \cdot \sqrt{\frac{E_{0}-y}{y-P}}-3 \cdot \operatorname{arcsen} \sqrt{\frac{E_{0}-y}{y-P}}$

A equação 3.19 corresponde à largura da soleira do vertedor lateral, onde o início e o final do dispositivo são representados, respectivamente, pelos sufixos 1 e 2. 
Estudou-se por alguns pesquisadores a hipótese da constância da energia específica ao longo do vertedor lateral, utilizada para a dedução realizada por Giulio de Marchi, sendo verificada uma variação da energia específica entre as extremidades do vertedor de $2 \%$ a $5 \%$. Estes resultados mostram que essa hipótese pode ser considerada válida para o escoamento subcrítico. Entretanto, a hipótese de que o coeficiente de Coriolis é igual à unidade não é válido, porque a retirada de água do canal através do vertedor torna o perfil de velocidades absolutamente nãouniforme nas vizinhanças do dispositivo (SOUZA, 2005).

\subsubsection{Equação da Quantidade de Movimento}

A equação da quantidade de movimento também é utilizada para analisar o comportamento hidráulico do vertedor lateral. Esta equação não leva em consideração as perdas internas, evitando quaisquer erros associados à hipótese de que a energia é constante ao longo do vertedor lateral, considerando apenas as perdas devido às forças de atrito junto às paredes do canal. São determinadas algumas suposições para a derivação dessa equação (MAY et al., 2003):

a) O escoamento é unidirecional;

b) O efeito da não-uniformidade da distribuição de velocidades no canal principal é corrigido pelo coeficiente de Boussinesq $(\beta)$;

c) A distribuição de pressões no escoamento é hidrostática;

d) O efeito do arrastamento de ar não é considerado;

e) A superfície de água é horizontal em qualquer seção transversal do canal, mas considera-se a variação com a distância ao longo do canal;

Conforme May et al. (2003), a equação da quantidade de movimento utilizada para analisar o comportamento hidráulico do vertedor lateral, considerando as suposições citadas anteriormente, é representada pela equação 3.21. 
$\frac{d y}{d x}=\frac{S_{0}-S_{F}-\left(2 \cdot \beta-\frac{U}{V}\right) \cdot \frac{q \cdot Q}{g \cdot A^{2}}}{1-\frac{\beta \cdot b \cdot Q^{2}}{g \cdot A^{3}}}$

Sendo:

$S_{0}$ a inclinação do fundo do canal principal;

$\mathrm{S}_{\mathrm{F}}$ a inclinação da linha de carga total do canal principal;

$\beta$ o coeficiente de Boussinesq;

U a componente da velocidade do escoamento lateral na direção longitudinal do canal;

$\checkmark$ a velocidade média no canal;

q a vazão por unidade de largura no vertedor lateral;

$Q$ a vazão do canal;

g a aceleração da gravidade;

A a área da seção transversal do escoamento no canal;

b a largura do canal.

Para canais não retangulares a equação é representada por:

$$
\frac{d y}{d x}=\frac{S_{0}-S_{F}-\left(2 \cdot \beta-\frac{U}{V}\right) \cdot \frac{q \cdot Q}{g \cdot A^{2}}}{1-\frac{\beta \cdot Q^{2}}{g \cdot A^{2} \cdot D}}
$$

Sendo:

D a profundidade hidráulica, que é a relação entre a área molhada e a largura da seção na superfície livre. 
As equações unidimensionais do escoamento espacialmente variado que utilizam os princípios da energia e da quantidade de movimento são equivalentes se a distribuição de velocidades no canal principal for assumida uniforme, senão, as equações podem apresentar resultados diferentes (MAY et al., 2003).

\subsubsection{Efeito do Número de Froude}

No canal principal as condições do escoamento a montante e jusante influenciam diretamente o perfil longitudinal da água ao longo do vertedor lateral. São apresentados na figura 3.11 quatro tipos básicos de comportamento do perfil longitudinal que podem ocorrer, em função do número de Froude de montante e de jusante (MAY et al., 2003).

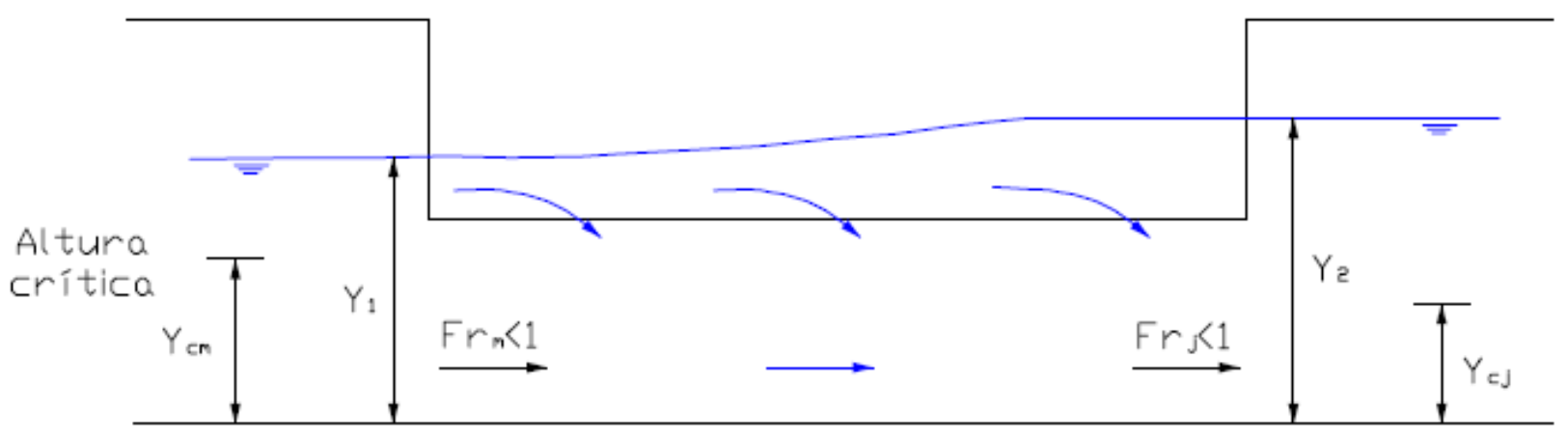

(a)

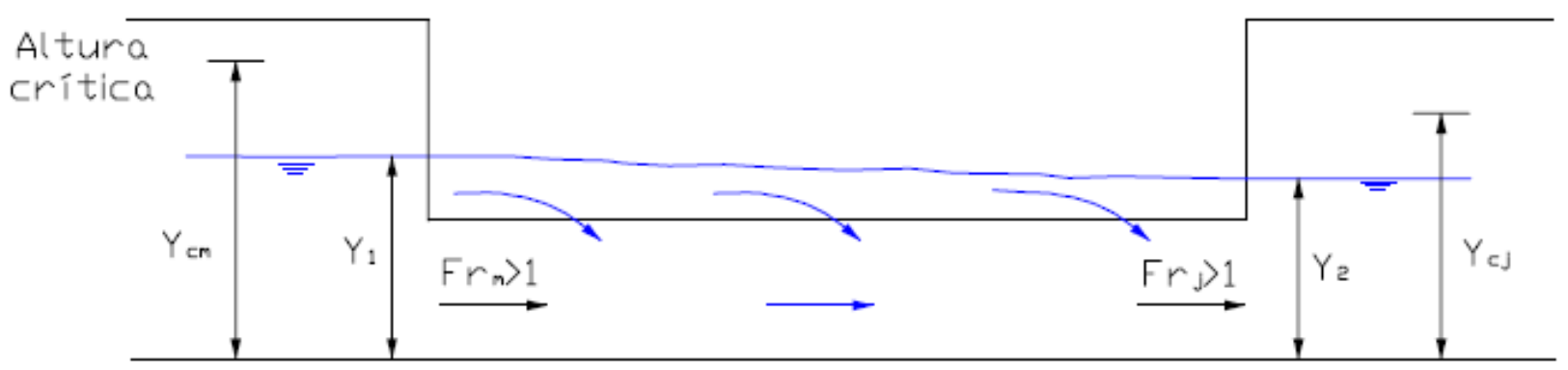

(b) 


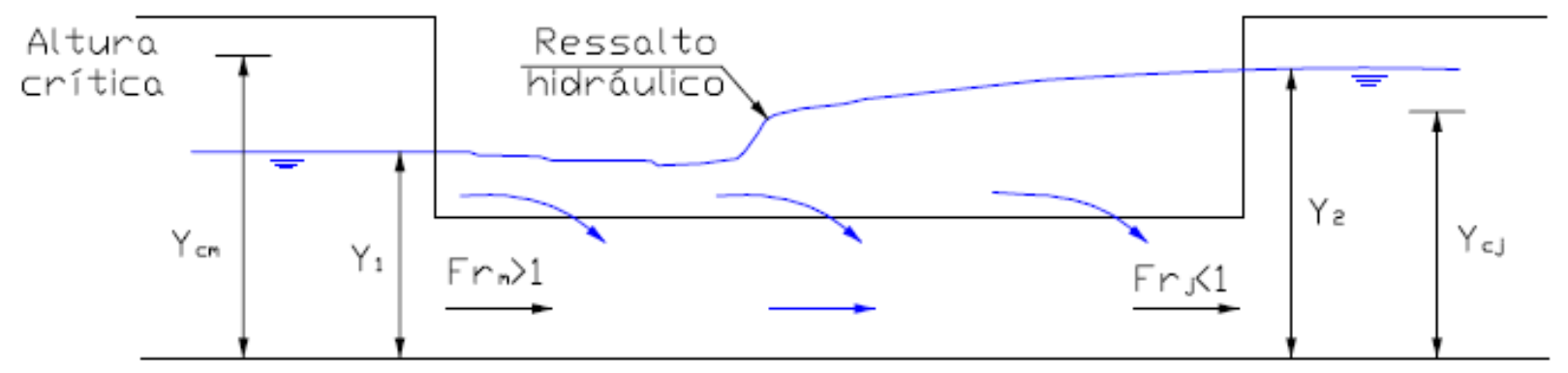

(c)

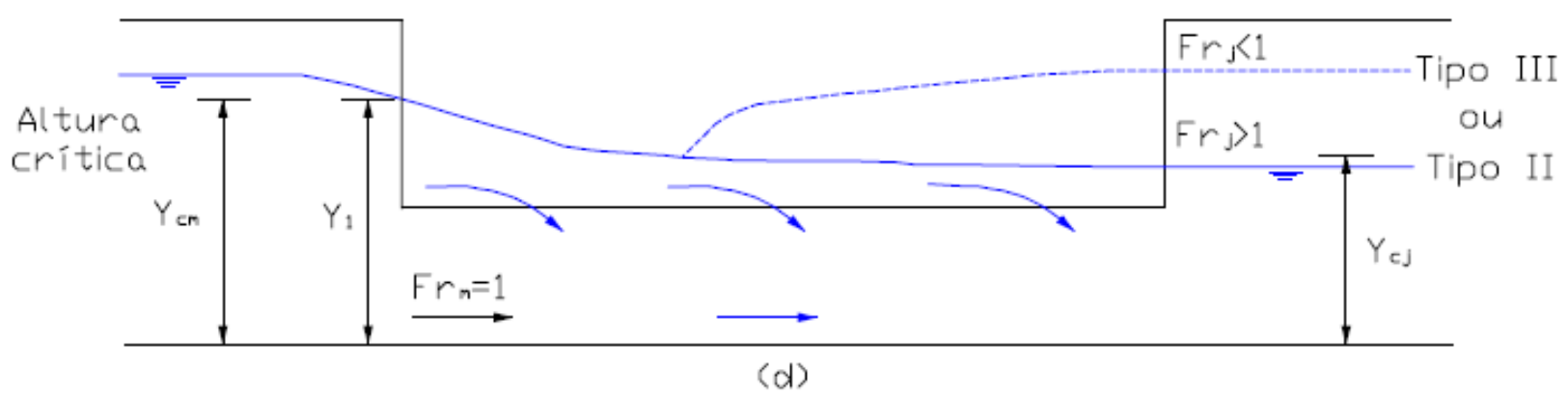

Figura 3.11 - Tipos de perfis longitudinais em vertedores laterais (fonte: MAY et al., 2003).

A simbologia apresentada na Figura 3.11 é definida como: $\mathrm{Fr}_{\mathrm{m}}$ é o número de Froude de montante; $\mathrm{Fr}_{\mathrm{j}}$ é o número de Froude de jusante; $\mathrm{Y}_{1}$ é a profundidade a montante do vertedor lateral; $Y_{2}$ é a profundidade a jusante do vertedor lateral; $Y_{c m}$ é a profundidade crítica a montante e $\mathrm{Y}_{\mathrm{cj}}$ é a profundidade crítica a jusante do vertedor lateral.

Os quatro tipos básicos de perfis que podem ocorrer são definidos como:

a) Tipo I - O escoamento mantém-se subcrítico, apresentado o número de Froude menor que um, ao longo de toda a extensão do vertedor lateral. Esse tipo de escoamento ocorre geralmente em canais horizontais ou com pequenas declividades. A sua característica principal é que o nível de água aumenta ao longo do vertedor lateral. Isso pode ser notado quando as equações (3.15), (3.16), (3.21) e (3.22) são analisadas, o último termo do denominador corresponde ao número de Froude, que quando apresenta valores inferiores a um e com um canal de baixa declividade, onde a inclinação de fundo é semelhante a declividade da linha de carga total, a 
relação dy/dx é positiva, correspondendo a uma elevação do nível d'água no sentido de jusante.

b) Tipo II - O escoamento mantém-se supercrítico, com o número de Froude maior que um, ao longo de toda a extensão do vertedor lateral. Esse tipo de escoamento pode ocorrer em um canal com alta declividade que não esteja sujeito a um controle de jusante. Ao contrário que ocorre no Tipo I e analisando as equações que foram mencionadas no item a), verifica-se que a relação dy/dx é negativa, portanto o nível de água decresce ao longo do vertedor lateral.

c) Tipo III - Ocorre um misto dos casos Tipo I e II, a montante do vertedor lateral o escoamento é supercrítico ( $F r>1)$, enquanto que a jusante o escoamento é subcrítico $(\mathrm{Fr}<1)$. Deste modo, ocorre um ressalto hidráulico em algum pondo ao longo do vertedor. Esse tipo de escoamento pode ocorrer em um canal com uma declividade elevada e sujeito a um controle de jusante.

d) Tipo IV - Ocorre uma variação entre o Tipo II e III. O escoamento de montante do vertedor lateral é supercrítico, embora apresente uma tendência a crítico, onde o número de Froude é igual a um, à medida que se aproxima do início do vertedor. A partir deste ponto, o escoamento aumenta a velocidade e pode seguir conforme o Tipo II ou III, dependendo da declividade do canal ou da presença de um controle de jusante.

\subsection{ESTUDOS EXPERIMENTAIS EM VERTEDORES LATERAIS}

A vazão pode ser calculada pela integração do escoamento total sobre 0 vertedor, mas diversos pesquisadores desenvolveram equações teóricas para facilitar a determinação da vazão. O coeficiente de descarga é um parâmetro decisivo para a determinação da vazão do vertedor lateral coerente com o fenômeno físico.

A determinação do coeficiente de descarga para um vertedor lateral de parede fina ou espessa tem sido objeto de trabalhos experimentais, os quais mostram a influência da presença de paredes no canal lateral sobre a trajetória das linhas de corrente. O coeficiente de descarga é, basicamente, função do tipo de escoamento a 
montante do vertedor, através do número de Froude do escoamento de aproximação (PORTO, 2004).

Diversos trabalhos experimentais apresentaram resultados para a geometria retangular, como Hager (1987), Subramanya e Awasthy (1972), Ranga Raju, Prassad e Gupta (1979), Swamme et al. (1994) e Singh, Manivannan e Satuamarayana (1994), entre outros.

No caso de um vertedor lateral convencional, sem estar conectado a um canal lateral, os dados de Subramanya e Awasthy (1972) fornecem uma expressão do coeficiente de vazão, função do número de Froude no canal principal, a montante do vertedor, dado pela equação (3.23) que é válida para a aproximação subcrítica ou supercrítica:

$C_{d}=0,622-0,222 \cdot F r_{m}$

para $0 \leq P \leq 0,60 m$

No caso da presença de um canal lateral, Ranga Raju, Prassad e Gupta (1979) recomendam a equação abaixo para o coeficiente de vazão.

$C_{d}=0,81-0,60 \cdot F r_{m}$

Para $0,20 \leq P \leq 0,50 m$.

Para o caso de um vertedor de parede espessa com canal lateral, a equação (3.24) é modificada pela introdução de um parâmetro K, que leva em conta o efeito do comprimento $\mathrm{M}$ da crista do vertedor, na forma:

$C_{d}=\left(0,81-0,60 \cdot F r_{m}\right) \cdot K$

Sendo:

$$
\begin{aligned}
& K=1 \text { para }\left(y_{1}-P\right) \geq 2 \cdot M \\
& K=0,80+0,10 \cdot\left(y_{1}-P\right) / M \text { para }\left(y_{1}-P\right)<2 \cdot M
\end{aligned}
$$


Singh, Manivannan e Satuamarayana (1994), apresentaram para um vertedor retangular de parede fina com canal lateral, uma expressão para o coeficiente de vazão $C_{d}$, em função de ambos, $F r_{m}$ e da relação $P / y_{1}$ :

$C_{d}=0,33-0,18 \cdot F r_{m}+0,49 \cdot P / y_{1}$

Para $0,06 \leq P \leq 0,12 m$ e $0,10 \leq L \leq 0,20 m$.

Diversos pesquisadores estabeleceram, através de trabalhos experimentais, uma relação para o coeficiente de descarga $C_{d}$ na condição de escoamento subcrítico, tomando o parâmetro $\mathrm{Fr}_{\mathrm{m}}$ como a variável principal. Porém Borghei, Jalili e Ghodsian (1999), analisaram diversos resultados experimentais considerando a influência da altura da soleira $P$, do seu comprimento $L$ e da inclinação do fundo $S_{0}$, e chegaram a propor a seguinte expressão:

$C_{d}=\left(0,687-0,46 \cdot F r_{m}-0,30 \cdot \frac{P}{y_{1}}+0,06 \cdot \frac{L}{b}+1,20 \cdot S_{0}\right)$

Os autores buscaram por uma expressão mais prática, na qual a influência da declividade longitudinal do canal pudesse ser desprezada, resultando na expressão (3.28), de onde se verifica a notável dependência das condições de aproximação, representada pelo número de Froude e pelo comprimento da soleira.

$C_{d}=\left(0,70-0,48 \cdot F r_{m}-0,30 \cdot \frac{P}{y_{1}}+0,06 \cdot \frac{L}{b}\right)$

Outras expressões encontradas na bibliografia que relacionam o coeficiente de descarga das soleiras laterais são apresentadas a seguir:

Singh et al. (1994): $C d=0,33-0,18 \cdot F r_{m}+0,49 \cdot \frac{P}{y_{1}}$

A equação (3.29) é válida para a faixa de parâmetros de $0,06 \leq P \leq 0,12 m$ e $0,10 \leq L \leq 0,20 \mathrm{~m}$, onde Singh et al (1994) verificaram que, a avaliação do coeficiente 
de descarga associando o número de Froude de montante e a relação de $\mathrm{P} / \mathrm{y}_{1}$ apresentou o melhor resultado, com erro entre o valor obtido através da equação e do ensaio experimental inferior à $12 \%$.

Jalili e Borghei (1996): $C_{d}=0,71-0,41 \cdot F r_{m}-0,22 \cdot\left(\frac{P}{y_{1}}\right)$

Jalili e Borghei (1996) obtiveram a equação (3.30) a partir de uma série de ensaios experimentais, sendo válida para a faixa de parâmetros de $0,01 \leq \mathrm{P} \leq 0,19 \mathrm{~m}$ e $0,20 \leq \mathrm{L} \leq 0,75 \mathrm{~m}$. Essa equação apresentou um erro de aproximadamente $7,6 \%$ quando comparada com os ensaios experimentais.

May et al. (2003): $C_{d}=0,65-0,149 \cdot\left(\frac{y_{2}-P}{P}\right)^{0,0868} \cdot\left(\frac{L}{y_{2}-P}\right)^{-0,303} \cdot\left(\frac{y_{2}}{P}\right)^{0,149}$

Para a determinação da equação (3.31), May et al. (2003) utilizaram a equação unidimensional do fluxo espacialmente variado baseada no princípio da quantidade de movimento (equação (3.21)) e a ajustaram com dados de ensaios experimentais.

Anchieta (2006): $C_{d}=0,66-0,173 \cdot F r_{m}-0,05 \cdot\left(\frac{y_{1}}{P}\right)$

Anchieta (2006) determinou a equação (3.32) a partir de 68 testes realizados,

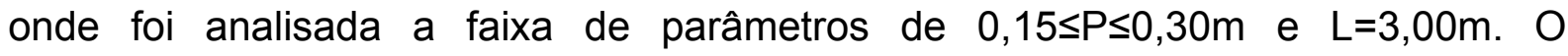
pesquisador representou os resultados do estudo (Figura 3.12) em função do número de Froude de montante e do coeficiente de descarga $\left(\mathrm{C}_{\mathrm{d}}\right)$. Na Figura (3.12) nota-se uma variação de $C_{d}$ entre 0,26 e 0,50 para o intervalo estudado, entretanto, ocorre uma variação maior em relação aos demais parâmetros, indicando que a altura e o comprimento da soleira, a carga hidráulica e a energia específica influem significativamente sobre o coeficiente de descarga. 


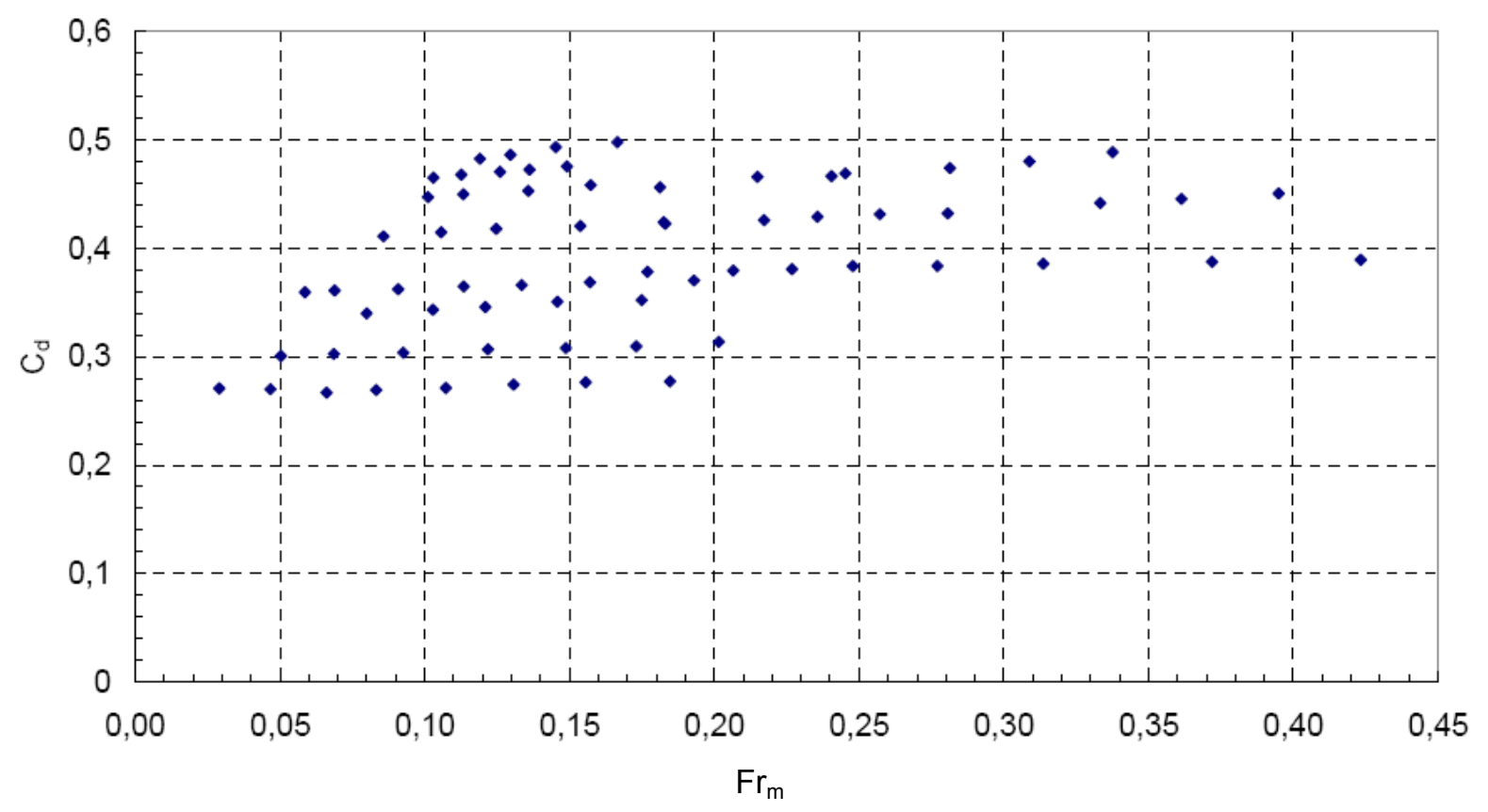

Figura 3.12 - Representação dos dados experimentais em função $C_{d}$ e $F r_{m}$ (fonte: ANCHIETA, 2006).

Raimundo (2007), a partir da re-análise dos dados experimentais do estudo em modelo físico reduzido realizado por Anchieta (2006), estabeleceu uma nova relação para o coeficiente de descarga para a soleira lateral, levando em conta um maior conjunto de fatores, como: a altura e o comprimento da soleira, carga hidráulica, etc. Raimundo (2007) desenvolveu a equação (3.33), que se apresentou mais adequada quando comparada com dados reais levantados para o reservatório Aricanduva $\mathrm{V}$, situado na cidade de São Paulo.

Raimundo (2007): $C_{d}=7,53 \cdot F r_{m}^{0,026} \cdot\left(\frac{P}{y_{1}}\right)^{1,028} \cdot\left(\frac{y_{1}-P}{P}\right)^{0,817} \cdot\left(\frac{P}{L}\right)^{0,655} \cdot\left(\frac{H}{P}\right)^{0,466}$

Sendo:

H a carga hidráulica sobre a soleira do vertedor lateral.

Das equações apresentadas para o coeficiente de descarga, a maioria dos pesquisadores relaciona esse coeficiente com o número de Froude de montante $\left(\mathrm{Fr}_{\mathrm{m}}\right)$ e a profundidade de montante $\left(\mathrm{Y}_{1}\right)$, exceto May et al. (2003), que utilizou a equação unidimensional do escoamento espacialmente variado, confrontando com 
dados experimentais, e obteve uma relação do coeficiente de descarga, principalmente, com a profundidade de jusante $\left(\mathrm{Y}_{2}\right)$.

Os estudos de 1972 a 2007 mostraram que vários parâmetros influem na determinação do coeficiente de descarga da soleira lateral. Em 1972 o $C_{d}$ era determinado a partir do número de Froude de montante, já em 2007 a sua equação era dependente de vários parâmetros, como altura e o comprimento da soleira, carga hidráulica, entre outros. A evolução natural dos estudos do $C_{d}$, e suas respectivas equações, evidenciam a complexidade de sua análise e determinação.

Existem diversos estudos experimentais realizados ao longo dos anos envolvendo os vertedores laterais, dentre eles, a determinação do coeficiente de descarga foi um dos mais estudados pelos pesquisadores. A seguir serão apresentadas algumas das outras pesquisas experimentais dos vertedores laterais.

Tan, Wang e Gilbreth (2001) propuseram um método geral para o vertedor lateral, onde apresentaram a concepção que o escoamento subcrítico é governado pelas condições de jusante do escoamento, como a profundidade e o número de Froude, e parâmetros geométricos do canal e do vertedor. Os estudos foram baseados na análise dos parâmetros da equação de De Marchi. Para os pesquisadores, os parâmetros do escoamento subcrítico do vertedor lateral são somente controlados pelas condições de jusante e as equações desenvolvidas para representar o comportamento do escoamento devem contém vários parâmetros, para uma melhor representação do fenômeno físico.

Oliveto, Biggiero e Fiorentino (2001), estudaram as características localizadas ao longo de um vertedor lateral em um canal circular (Figura 3.13), na condição de escoamento supercrítico sobre a soleira e escoamento subcrítico à montante. $\mathrm{O}$ estudo foi baseado em trabalhos experimentais e dados disponíveis na literatura, avaliando as vazões vertidas pelo vertedor lateral, enfatizando o ângulo de escoamento e a sua velocidade, e por fim, apresentaram uma teoria para determinar a perda de carga devido à divisão do escoamento na estrutura. Os autores afirmaram que, com os resultados experimentais foi possível entender melhor o comportamento do escoamento sobre o vertedor lateral, onde apresentaram uma relação em função do comprimento da soleira e a vazão vertida com uma precisão de $\pm 5 \%$. 

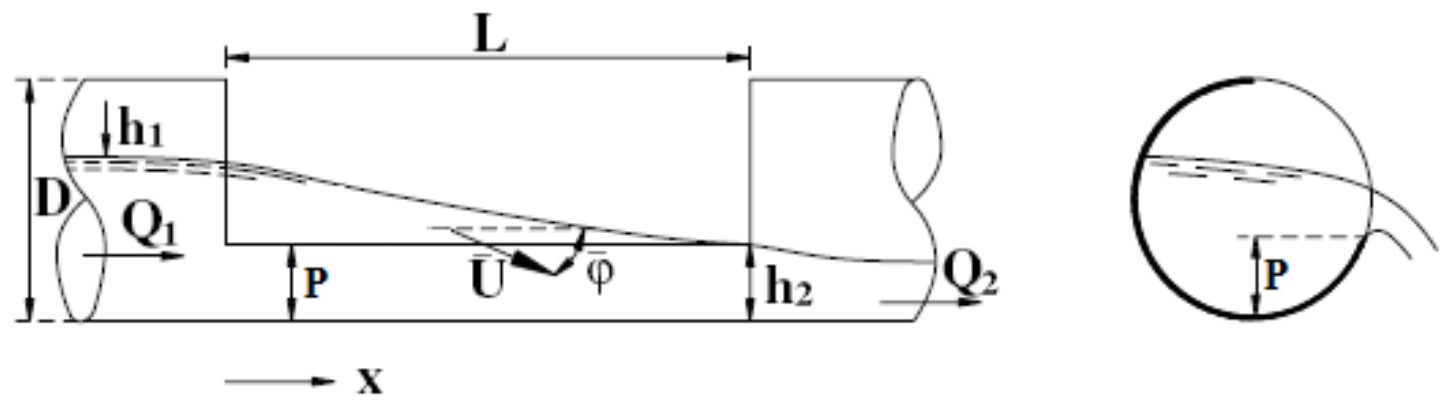

Figura 3.13 - Vertedor lateral em canal circular (fonte: OLIVETO; BIGGIERO; FIORENTINO, 2001).

Tan, Einhellig e Pugh (2001), criaram em laboratório um modelo reduzido na escala 1:30 (Figura 3.14) para o vertedor lateral do riacho San Sevaine em San Bernadino County, Califórnia, com objetivo de estudar a performance do dispositivo, que possui a altura de 1,83 m e comprimento de $853 \mathrm{~m}$ em escala real, na condição de escoamento subcrítico. Os pesquisadores utilizaram a semelhança de Froude como a condição de semelhança entre o modelo e a estrutura real, e estudaram os efeitos da variação da geometria do modelo. No modelo foi utilizado um medidor Venturi à montante do vertedor lateral e um vertedor Cipoletti à jusante, sendo a diferença entre os medidores a vazão do vertedor lateral. Variando o comprimento da soleira e a sua forma verificaram a eficiência com a variação da vazão vertida. Os estudos comprovaram que o comprimento do vertedor poderia ser reduzido para aproximadamente 744 metros, que a eficiência do dispositivo seria a mesma, com um custo de obra significativamente menor. Também foi verificado pelos pesquisadores que a eficiência do vertedor lateral está diretamente relacionada com o comprimento da soleira e a sua forma. Para comprimentos maiores e formas mais arredondadas tem-se uma maior eficiência do dispositivo. 


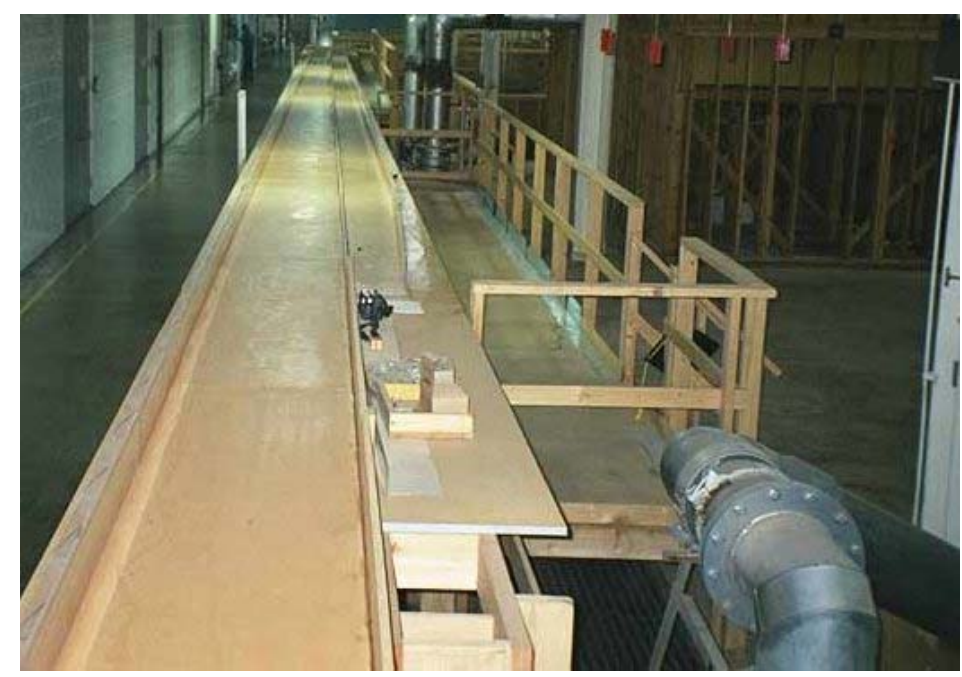

Figura 3.14 - Modelo do canal San Sevaine com vertedor lateral e coletor (fonte: TAN;

EINHELLIG; PUGH, 2001).

Gert, Guido e Jean (2002), estudaram a eficiência de diferentes modelos físicos de uma estrutura combinada com transbordamento de esgoto (CSO), que utiliza um vertedor lateral, conforme a Figura (3.15), com Q e q sendo respectivamente, as vazões de entrada e saída pelo canal principal, e as demais indicações são as dimensões características. Realizaram um estudo detalhado com a influência de diferentes parâmetros geométricos do modelo, definiram uma fórmula geral de eficiência de remoção de partículas e compararam com estudos da literatura para a validação. Na comparação entre os dados experimentais obtidos e os resultados calculados pela fórmula, verificaram uma boa correlação da eficiência de remoção de partículas $\left(R^{2}=0,95\right)$.

Os pesquisadores afirmaram que a fórmula geral de eficiência é uma ferramenta muito útil para comparar diferentes estruturas de transbordamento em fase de desenvolvimento. Entretanto, eles concluíram que não se pode definir uma fórmula geral para os diferentes dispositivos, porque cada tipo possui um fator de geometria particular. 


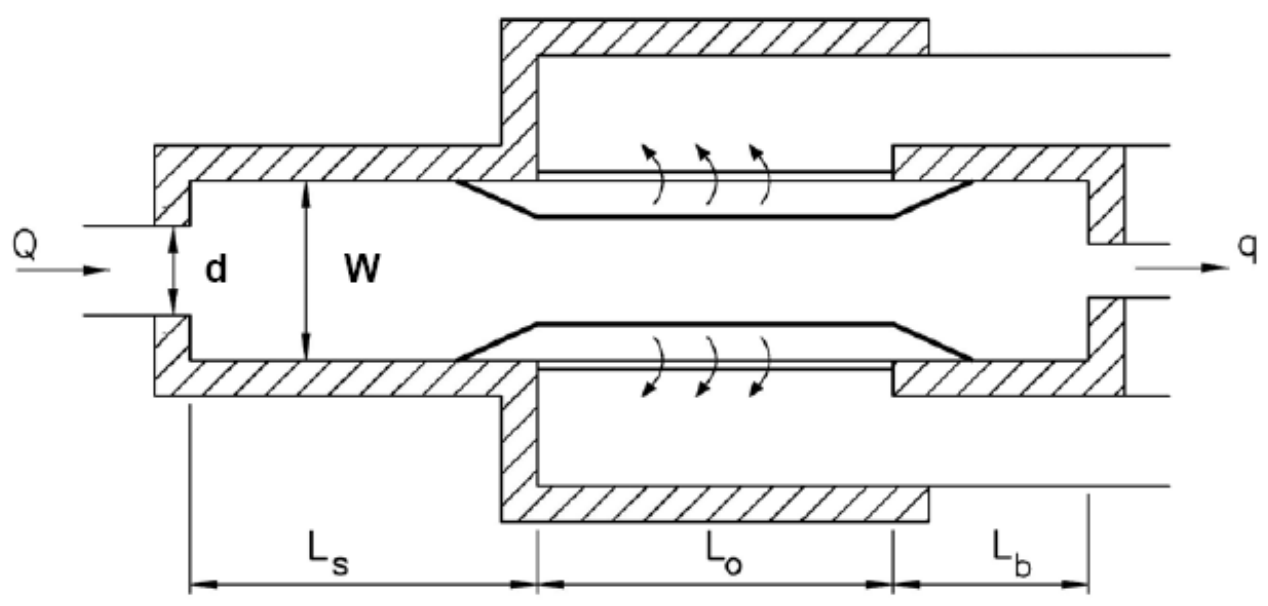

Figura 3.15 - Vista em planta da estrutura de transbordamento pelo vertedor lateral (fonte: GERT; GUIDO; JEAN, 2002).

Souza (2005) estudou através de ensaios em modelo reduzido (Figura 3.16) a viabilidade de reduzir o nível de água no canal de adução de uma Pequena Central Hidrelétrica $(\mathrm{PCH})$, utilizando estruturas fixas no início do canal, como vertedores laterais, que não necessitam de operação humana. O pesquisador objetivou reduzir o custo na construção da usina com a respectiva redução dos muros laterais do canal de adução e diminuir os riscos operacionais de comportas, que segundo ele, são caracterizadas com um alto risco em $\mathrm{PCH}$, que apresenta um reservatório com volume reduzido e num evento pluviométrico de grande magnitude pode ocorrer a rápida elevação no nível da água. Souza (2005) realizou vários ensaios com diferentes condições em seu estudo, como a variação do comprimento do vertedor lateral, adicionando uma soleira de fundo no canal, defletores à montante ou à jusante e contrações no canal, e para cada ensaio verificava o nível da água. Ele não concluiu qual seria a condição mais favorável para redução dos muros laterais, por não ter realizado uma análise de custo sobre possíveis variações na geração de energia devido às intervenções propostas no canal de adução, deixando aos projetistas e construtores do ramo, decidirem qual seria a condição mais adequada para o seu caso em particular. 


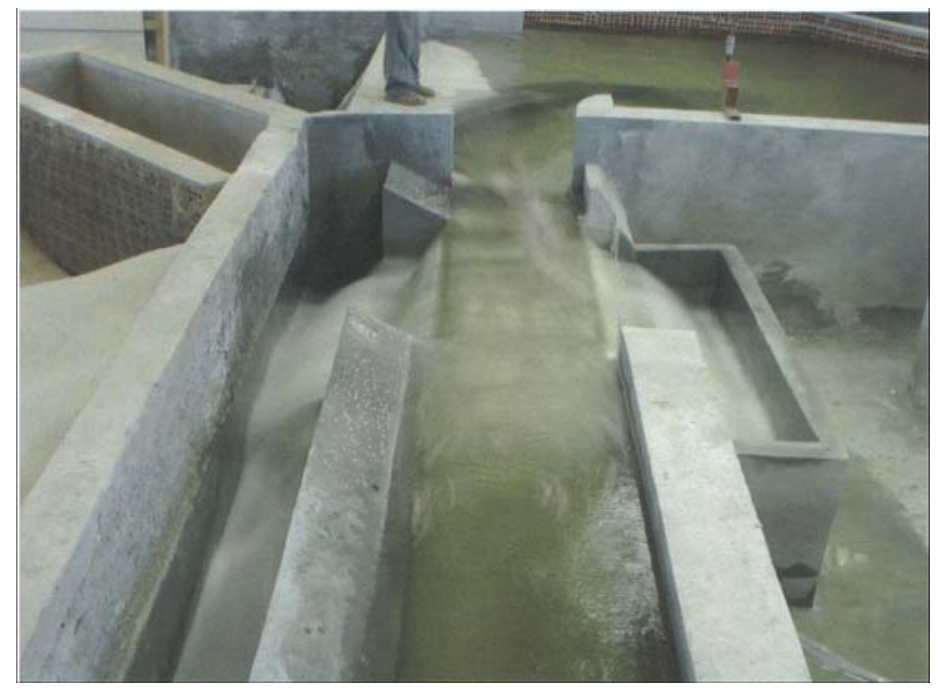

Figura 3.16 - Modelo do canal de adução com vertedores laterais (fonte: SOUZA, 2005).

\subsection{ESTUDOS NUMÉRICOS DO ESCOAMENTO EM VERTEDORES LATERAIS}

Alguns estudos numéricos envolvendo vertedores laterais são apresentados a seguir, no entanto, verifica-se nesses estudos a importância de realização de trabalhos experimentais ou a utilização de dados experimentais presentes na literatura para a validação dos modelos numéricos.

Uyumaz (1997) estudou numericamente o comportamento do escoamento do vertedor lateral em um canal em forma de $U$ (Figura 3.17). O modelo numérico proposto pelo pesquisador foi baseado no Princípio da Energia e resolvido pelo método de diferenças finitas. As vazões do vertedor lateral e o perfil da linha d'água ao longo do canal, para os regimes subcrítico e supercrítico, obtidos através do modelo numérico foram comparados com resultados experimentais. $O$ autor determinou equações práticas para uso da engenharia, que descrevem o comportamento da linha d'água sobre a soleira lateral com boa precisão.

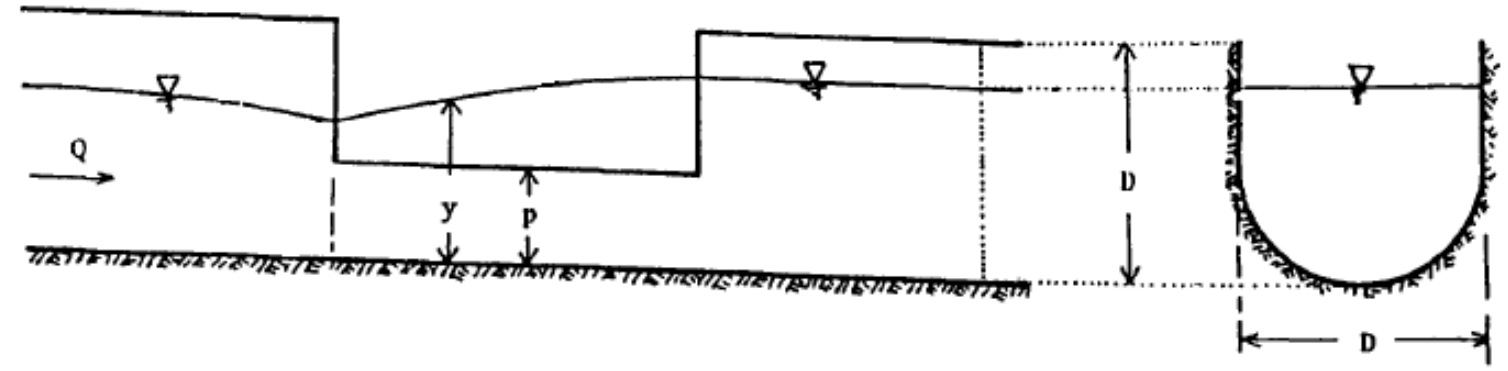

Figura 3.17 - Vertedor lateral em um canal em forma de U (fonte: UYUMAZ, 1997). 
Burt et al. (2002), utilizaram a ferramenta CFD em um vertedor lateral combinado com transbordamento de esgoto (CSO) (Figura 3.18). Eles verificaram a técnica de cálculo da eficiência de retenção de sólido em uma câmara estabelecida. A eficiência foi calculada através da porcentagem de partículas que se atrasam na câmara, aquelas que não escoam através do vertedor. Na modelagem foi considerada uma vazão de $675 \mathrm{l} / \mathrm{s}$ na entrada da estrutura, $100 \mathrm{l} / \mathrm{s}$ na saída e o restante escoando através do vertedor lateral. Os pesquisadores compararam os resultados dos modelos Eureliano e Lagrangiano multi-fase, utilizados para predizer a eficiência da retenção de sólidos, para uma mesma configuração de CSO e validaram os resultados com experimentos em modelo físico. Segundo Burt et al. (2002), a conclusão mais importante do estudo é que o Método de Lagrange não prevê a eficiência de retenção na câmara do CSO com precisão. Já o Modelo de Euler representa bem a tendência das partículas observadas no experimento de validação.

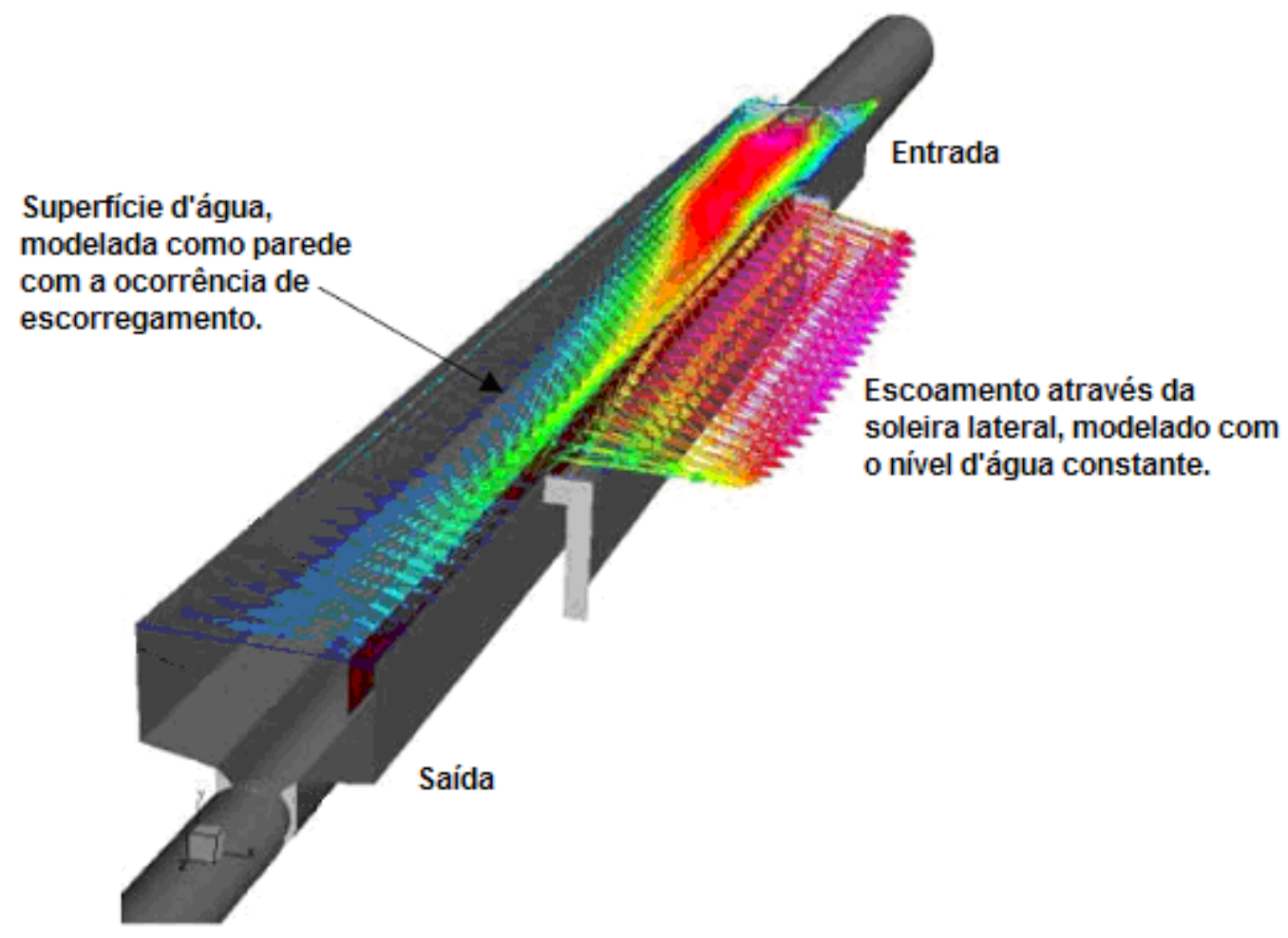

Figura 3.18 - Simulação em CFD da distribuição da velocidade do vertedor lateral combinado com transbordamento de esgoto (fonte: BURT et al., 2002). 
Muslu (2002) analisou hidraulicamente o fluxo sobre o vertedor lateral, utilizando para o seu estudo métodos numéricos. Ele definiu dois parâmetros $\theta$ e $\psi$, onde $\Psi$ representa a inclinação da superfície d'água na direção lateral, e $\theta$ é o ângulo do escoamento sobre o vertedor com relação ao canal retangular (Figura 3.19). Os parâmetros foram expressos em relação ao número de Froude e $L / b$, e foram substituídos na equação da energia. As equações foram resolvidas através de técnicas computacionais e foi utilizada a análise gráfica para ajuste das curvas. $O$ modelo apresentou bons resultados, podendo ser utilizado para a determinação do coeficiente de descarga. Muslu (2002) validou o seu modelo numérico com dados existentes na literatura.

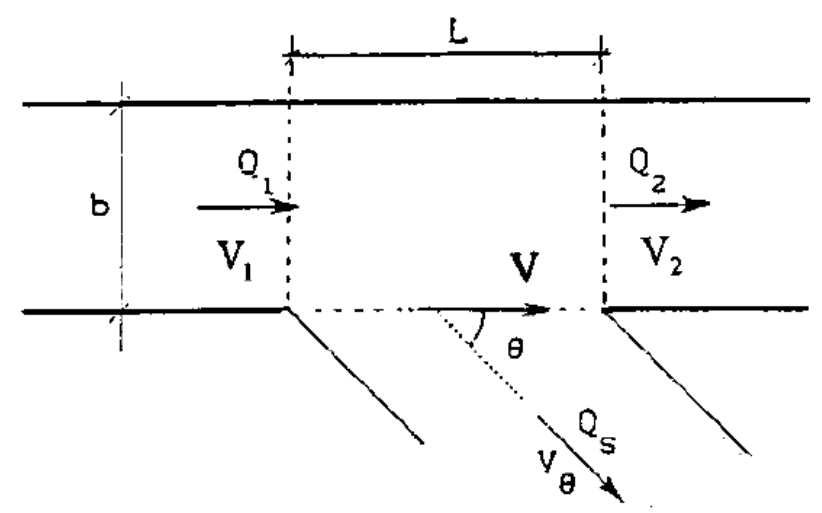

Figura 3.19 - Parâmetros do vertedor lateral em canal retangular (fonte: MUSLU, 2002).

Muslu, Tozluk e Yüksel (2003), estudaram a influência do comprimento do vertedor lateral, em um canal retangular com base constante, no comportamento do perfil d'água ao longo da soleira. Desenvolveram um modelo numérico com princípios hidrodinâmicos, onde o comprimento do vertedor era dividido em segmentos computacionais menores e obtiveram a aproximação do perfil da superfície d'água. Os resultados do modelo eram comparados e validados com dados experimentais, entretanto, alguns parâmetros foram comparados com dados disponíveis na literatura.

Venutelli (2008) utilizou um método de passo iterativo para resolver equações diferenciais ordinárias não-lineares, verificando o desenvolvimento espacial do escoamento sobre um vertedor lateral. Venutelli (2008) utilizou como condição de contorno uma profundidade conhecida. Os perfis de superfície d'água e as vazões 
escoadas sobre o vertedor lateral foram estudados para canais retangulares, comparando os dados obtidos com dados experimentais para as condições de escoamento subcrítico e supercrítico. A validação do método proposto é realizada pela comparação com a solução obtida pela hipótese clássica De Marchi, onde a energia específica é constante ao longo do vertedor lateral. 


\section{DINÂMICA DOS FLUIDOS COMPUTACIONAL}

A utilização de técnicas numéricas para a solução de problemas complexos da engenharia e da física é uma realidade atualmente, devido ao desenvolvimento de computadores que possuem grande capacidade de processamento $e$ armazenamento. Em função desse potencial computacional, cresce o desenvolvimento de algoritmos para a solução desses problemas (MALISKA, 1995).

Para resolução de um determinado problema de engenharia, têm-se basicamente três ferramentas: métodos analíticos, métodos numéricos e experimentos em laboratório.

Os métodos analíticos e os numéricos são os métodos teóricos, porque ambos objetivam resolver equações diferenciais e também podem ser utilizados na solução de equações integrais, que não possuem solução direta baseada em formulações conhecidas. A diferença entre eles é a capacidade de resolução de equações complexas. Os métodos analíticos são utilizados normalmente para resolução de problemas que envolvam geometria e condições de contorno simples, sendo a sua principal desvantagem as hipóteses simplificativas que os distanciam do fenômeno físico real. Sua vantagem significativa é a obtenção do resultado em forma fechada, necessitando de um tempo computacional menor. As soluções analíticas são utilizadas para validar casos limites de modelos numéricos e auxiliar no desenvolvimento de modelos mais robustos (MALISKA, 1995).

Os experimentos em laboratório possuem a grande vantagem de tratar com a configuração quase real do fenômeno físico, porém apresentam um alto custo e em alguns casos não podem ser utilizados, como no estudo da cavitação em dispositivos hidráulicos.

Os métodos numéricos podem resolver problemas com complexas condições de contorno, com geometrias arbitrárias e apresentando resultados com rapidez, mas não estão imunes as limitações computacionais. Entretanto, os resultados obtidos devem ser confiáveis, para isso deve-se evitar a ocorrência de dois níveis de erros que podem ocorrer quando comparado com o fenômeno real. O primeiro são os erros numéricos, resultantes da má solução das equações diferenciais e o segundo são os erros resultantes do uso de equações diferenciais que não representam adequadamente o fenômeno estudado. Por isso, a ferramenta 
numérica é adequada e confiável, quando se tem um método numérico que resolva corretamente as equações diferenciais, e um modelo matemático que represente com fidelidade o fenômeno físico (MALISKA, 1995).

Maliska (1995) afirma que, a simulação numérica utilizando a ferramenta CFD teve um desenvolvimento impressionante a partir da década de 80 . No princípio era utilizada para análise de problemas físicos em nível de investigação científica, e atualmente é utilizada para a solução de importantes problemas aplicados da engenharia. O avanço na área de CFD ocorreu devido à relativa facilidade de aplicação dos métodos numéricos, mesmo em problemas complexos, e o grande desenvolvimento tecnológico dos computadores.

A Dinâmica dos Fluidos Computacional (CFD) é uma ferramenta baseada em computadores, a qual é utilizada para simular o comportamento de sistemas envolvendo o escoamento de fluidos, transferência de calor, entre outros processos físicos; permitindo a solução das equações do escoamento de fluidos sobre uma região de interesse, para uma determinada condição de contorno. Fortuna (2000) define CFD como a área da computação científica que estuda métodos computacionais para simulação de fenômenos que envolvem fluidos em movimento com ou sem trocas de calor.

Ao longo dos anos vem aumentando o uso dos computadores para resolver problemas de escoamentos de fluidos, devido ao aumento de sua capacidade de processamento, à evolução dos recursos gráficos e à interatividade na manipulação de imagens 3-D, tornando a ferramenta CFD menos onerosa, reduzindo o tempo de simulação e, conseqüentemente, o seu custo de uso. Hoje essa ferramenta é utilizada pelas indústrias como uma alternativa mais econômica em novos projetos (LOMBARDI, 2005).

O usuário de CFD, basicamente, está interessado em obter as distribuições de velocidades, pressões e temperatura na região do escoamento. Com esses dados, o engenheiro pode otimizar projetos, reduzindo os custos operacionais e melhorando o desempenho do item desenhado, por exemplo, a redução no arrasto aerodinâmico de uma aeronave permite reduzir o seu consumo de combustível (FORTUNA, 2000).

Wendt (2009) afirma que, uma das aplicações da ferramenta de CFD é reduzir o número de experimentos e explorar fenômenos que não poderiam ser estudados em laboratório de maneira prática. E acrescenta que, essa ferramenta possui grande 
facilidade para alterar parâmetros geométricos, condições de contornos, entre outros.

\subsection{APLICAÇÃO DA FERRAMENTA CFD}

A ferramenta CFD possui diversas aplicações na área profissional e acadêmica, dentre elas pode-se destacar (ANSYS, 2006):

- Processos Industriais: tanques para mistura, reatores químicos;

- Indústria Automotiva: desenvolvimento da aerodinâmica dos carros, modelagem de sistemas de combustão;

- Indústria Aeronáutica e Espacial;

- Óleo e gás;

- Segurança: propagação e efeitos de fogo e fumaça;

- Previsão do Tempo;

- Meio Ambiente: Dispersão de poluentes no ar ou na água;

- Medicina: comportamento do escoamento de sangue;

- Turbomáquinas: simulação de bombas, turbinas, ventiladores, etc;

- Processos Químicos;

- Hidráulica: Análise de escoamentos em tubulação e superfícies livres.

\subsection{ESCOLHA DO PACOTE COMERCIAL}

Existem diversas ferramentas computacionais de CFD, como o ANSYS CFX, FLUENT, STAR-CD, FLOW-3D, PHOENICS CFD, NUMECA, entre outras. Arantes (2007) afirma que, muitos fornecedores da ferramenta de CFD utilizam o Método de Volumes Finitos ou o Método dos Elementos Finitos, e apresentam soluções de problemas complexos, incluindo desde sistemas de definição da geometria e de geração de malhas estruturadas ou não-estruturadas, até diferentes modelos de 
turbulência, modelagem de escoamento multifásico e ferramentas de visualização científica.

Devido o programa ANSYS CFX apresentar um pacote robusto e completo de solução, desde a definição do problema, resolução, análise e apresentação dos resultados, juntamente com a boa experiência obtida utilizando essa ferramenta (DIAS et al., 2009) e a disponibilidade da mesma na Escola Politécnica da USP, com respaldo da licença de uso junto ao fornecedor ANSYS, essa ferramenta foi escolhida para o desenvolvimento desse trabalho.

\subsection{METODOLOGIA CFD}

A ferramenta CFD pode ser utilizada para validar um componente no estágio de projeto ou pode ser utilizado para encontrar meios para melhorar as características de componentes já implementados. A Dinâmica dos Fluidos Computacional é prática, podendo alterar característica de projeto com simples e rápidas alterações na geometria do modelo. Ela é dividida em quatro partes:

a) Geração da geometria e da malha - é o estágio do pré-processamento, onde será criada a geometria da região de estudo. A partir da geometria, definem-se o fluxo do fluido, regiões sólidas e nomeiam-se as respectivas superfícies. Após a definição e classificação da geometria, gera-se a malha, cujo refinamento está diretamente relacionado com a precisão dos resultados apresentados pela simulação.

b) Condições de simulação - é o primeiro estágio do processamento, onde se definem o domínio, as condições de contorno da região de estudo, as propriedades do fluido e as condições iniciais e de convergência para o processamento.

c) Acompanhamento da resolução - é o segundo estágio do processamento; nessa fase ocorre a resolução das equações diferenciais parciais no espaço e no tempo, onde as mesmas são 
integradas nos volumes de controle dentro da região de interesse. As equações são definidas como Conservação da Massa, Quantidade de Movimento e da Energia, representadas num formato geral utilizada pela ferramenta CFX ${ }^{\circledR}$, respectivamente, pelas equações (4.1), (4.2) e (4.3). Essas equações integradas são convertidas em um sistema de equações algébricas pela geração de um conjunto de aproximações para os termos das equações integrais. Segundo Lombardi (2005), as equações algébricas são resolvidas iterativamente por causa da natureza não-linear das equações e, na medida em que a solução se aproxima da solução exata, assume-se que ela está convergindo. Em cada iteração há um erro ou resíduo que é comparado a uma precisão estabelecida e, o cálculo é realizado até alcançar a convergência ou o número de iteração estabelecida.

d) Visualização dos resultados - é a fase do pós-processamento, onde se pode visualizar e apresentar os resultados de forma interativa, e também, obter valores de grandezas físicas de qualquer região do volume de controle.

Equação da Conservação da Massa:

$$
\frac{\partial \rho}{\partial t}+\nabla \cdot(\rho \cdot \vec{u})=0
$$

Sendo:

$\frac{\partial \rho}{\partial t} \quad$ a taxa de variação da massa no volume considerado; 
$\nabla \cdot(\rho \cdot \vec{u})$ o fluxo líquido de massa através da superfície do volume considerado, onde $\vec{u}$ é o vetor velocidade.

Equação da Conservação da Quantidade de Movimento (Equações de NavierStokes), para escoamento incompressível e propriedades físicas constantes:

$$
\frac{\partial \vec{u}}{\partial t}+(\vec{u} \cdot \nabla) \cdot \vec{u}=-\frac{1}{\rho} \cdot \nabla p+v \cdot \nabla^{2} \cdot \vec{u}+\vec{g}
$$

Sendo:

$\frac{\partial \vec{u}}{\partial t} \quad$ a taxa de variação da quantidade de movimento;

$(\vec{u} \cdot \nabla) \cdot \vec{u} \quad$ o fluxo convectivo da quantidade de movimento;

$-\frac{1}{\rho} \cdot \nabla p \quad$ a força resultante devida ao gradiente de pressão;

$v \cdot \nabla^{2} \cdot \vec{u} \quad$ o fluxo líquido difusivo da quantidade de movimento ou dissipação de energia cinética dependendo das escalas em questão, onde $v$ é a viscosidade cinemática;

$\vec{g} \quad$ o vetor da aceleração da gravidade.

Equação da Conservação da Energia

$$
\frac{\partial T}{\partial t}+(\vec{u} \cdot \nabla) \cdot T=\alpha \cdot \nabla^{2} \cdot T+\Phi e
$$

Sendo:

$\frac{\partial T}{\partial t} \quad$ a taxa de acumulo de energia interna no volume considerado, onde 
T é a temperatura;

$(\vec{u} \cdot \nabla) \cdot T \quad$ o fluxo líquido convectivo de energia interna;

$\alpha \cdot \nabla^{2} \cdot T$ o fluxo líquido difusivo de energia interna, $\operatorname{com} \alpha$ sendo a condutividade térmica;

Фe o termo fonte de energia interna devido à dissipação de energia interna.

Lombardi (2005) afirma que, soluções analíticas para as equações de NavierStokes existem apenas para os fluxos mais simples e condições ideais. Em casos reais de escoamentos a obtenção da solução requer um método numérico. Desta forma, as equações são substituídas por aproximações algébricas que podem ser resolvidas por um método numérico. O programa ANSYS CFX utiliza o Método dos Volumes Finitos.

A idéia principal dos modelos numéricos é transformar um conjunto de equações diferenciais parciais (EDP's) em um sistema de equações algébricas correspondente, e sua solução fornece o resultado do sistema de equações originais em instantes e coordenadas espaciais determinadas. Antes de montar o conjunto de equações é preciso discretizar o domínio de solução, dividindo o mesmo em regiões (volumes) menores, ou em pontos. No caso de problemas transientes o tempo também é dividido em um número finito de intervalos (CASTRO, 2006).

No Método dos Volumes Finitos, uma superfície pode ser dividida por quadriláteros ou triângulos, e uma região tridimensional em volumes, que podem ser de uma forma poliédrica qualquer, com um número variável de vizinhos, criando uma malha não estruturada, ou por um número fixo de vizinhos, o que se classifica como malha estruturada. Para malhas não estruturadas os volumes mais usados são pirâmides, prismas e tetraedros (CASTRO, 2006).

A resolução do sistema de equações pode ser realizada com uma matriz, de forma acoplada, ou de maneira segregada, em que as equações algébricas são resolvidas uma por vez, e há uma equação adicional de acoplamento entre a pressão e a velocidade, que é resolvida de forma independente. Já os termos não lineares das EDP's devem ser linearizados (CASTRO, 2006). 
O Método dos Volumes Finitos (MVF) é utilizado largamente na resolução de problemas envolvendo transferência de calor e massa em mecânica dos fluidos. $\mathrm{O}$ MVF permite a solução numérica de equações diferenciais parciais baseado no balanço de massa, energia e quantidade de movimento, para um determinado volume de meio contínuo (MALISKA, 1995). Fortuna (2000) afirma que, a interpretação física direta das equações resultantes da aplicação do método de volumes finitos, bem como a possibilidade de aplicá-lo diretamente sobre malhas com espaçamentos não uniformes, são duas das razões que explicam a sua popularidade.

Para um melhor entendimento e aprofundamento no assunto de métodos numéricos, principalmente no Método dos Volumes Finitos, ver Maliska (1995) ou Fortuna (2000).

\subsection{TIPOS DE MALHAS}

O domínio geométrico é dividido por meio de uma malha, que consiste em um conjunto de pontos distribuídos sobre a região de cálculo. A malha pode ser geralmente, estruturada, não estruturada (Figura 4.1) ou híbrida. Cada volume é definido por um conjunto de faces planas e cada face é normalmente compartilhada por apenas dois volumes (CASTRO, 2006).

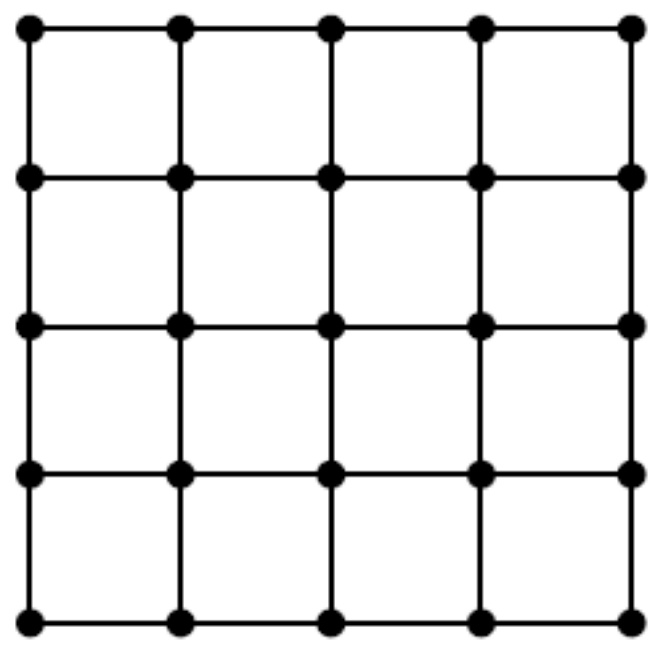

a) Malha Estruturada

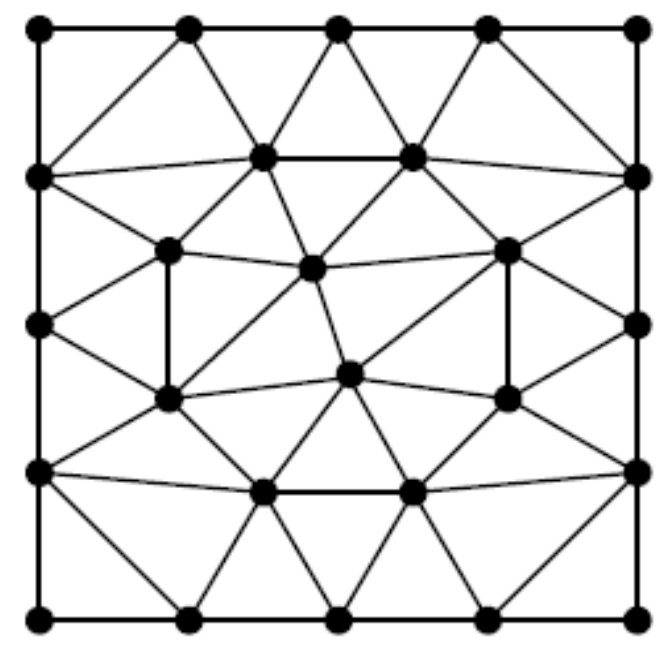

b) Malha Não estruturada

Figura 4.1 - Tipos de Malha (fonte: BATISTA, 2005). 
a) Malhas estruturadas: são geradas de modo que cada coordenada espacial do domínio geométrico de cálculo seja transformada em uma coordenada computacional equivalente, em uma malha regular. As linhas que definem as coordenadas são geradas de modo a acompanharem a geometria das fronteiras, e ter o máximo de ortogonalidade entre elas.

b) Malhas não estruturadas: não há a transformação de um sistema de coordenadas cartesiano para um sistema de coordenadas computacional. Também não ocorre uma adaptação suave da distribuição dos pontos no interior do domínio computacional, às fronteiras. Os elementos formados, no caso tridimensional, tampouco têm a forma quadrada ou cúbica, podendo apresentar um número variável de faces, como os do tipo: tetraédrico (4 faces), pirâmide ou prisma (5 faces), etc. O número de vizinhos de um elemento no interior do domínio computacional também pode variar, ao contrário das malhas estruturadas, que no caso 3D terão sempre seis elementos adjacentes. Esta falta de regularidade demanda uma estrutura lógica de controle dos relacionamentos dos elementos mais complexa (feito por meio de uma matriz de relacionamentos), aumentando o custo computacional e a necessidade de memória. As grandes vantagens das malhas não-estruturadas são a simplicidade, o que facilita a automação, e sua adaptabilidade a geometrias complexas, que reduz o tempo gasto na geração da malha (CASTRO, 2006).

c) Malhas híbridas: são criadas ao se mesclar regiões onde a malha é estruturada em regiões de malha não-estruturada. A utilização desse tipo de malha deve-se as vantagens de um método compensar as desvantagens do outro, reciprocamente. As malhas estruturadas produzem elementos de boa qualidade a um custo relativamente baixo, para geometrias não muito complexas, e melhoram a precisão e eficiência dos algoritmos de solução devido à direcionalidade da malha. Entretanto, apresentam limitações em modelos tridimensionais complexos. Esta limitação das malhas estruturadas é justamente a maior qualidade das malhas não-estruturadas que tem, contudo, as desvantagens da falta de direcionalidade e aumento do custo computacional. O uso de malhas híbridas possibilita reduzir o uso de 
malhas não-estruturadas ao mínimo, devido a complexidade geométrica ou necessidade de refinamento adaptativo (CASTRO, 2006).

As malhas podem ser ortogonais ou não ortogonais. As malhas não ortogonais podem ser tetraédricas ou hexaédricas, com faces triangulares ou quadrangulares. Existe a possibilidade de gerar malhas prismáticas nas faces que representam paredes, de forma a representar de forma mais adequada o comportamento da camada limite. Desta forma, alguns elementos piramidais são criados na adaptação da malha prismática com a tetraédrica. O programa para geração de malha permite determinar o grau de refinamento da malha para determinadas faces ou contornos, possibilitando a construção de malhas mais refinadas em regiões de interesse e mais grosseira em regiões de menor valia para os resultados da simulação, sempre estando de acordo com as condições de angulação da malha e da diferenciação do tamanho das malhas adjacentes (ARANTES, 2007).

Castro (2006) afirma que, nem sempre é possível obter uma malha com a qualidade ideal, pois isto significaria, na maioria dos casos, uma discretização tão refinada que tornaria a solução do problema extremamente demorada. Mas deve-se garantir que nas regiões onde o escoamento é submetido a gradientes maiores e sobre superfícies, a malha seja refinada, e nas demais regiões do domínio, tenha um refinamento apenas suficiente.

Analisando a qualidade da malha, não basta apenas garantir o grau de refinamento adequado, também é necessário garantir que os elementos da malha tenham formas regulares e com o mínimo de distorção (CASTRO, 2006).

O pesquisador Ludwig Prandtl em 1904 foi o primeiro a demonstrar que, ao redor da superfície de corpos em movimento imersos, em um fluido, há uma fina região na qual o gradiente de velocidade normal à superfície do corpo é significativo. Portanto, nessas regiões, as tensões de cisalhamento não podem ser desprezadas. Essa região é conhecida como camada limite (FORTUNA, 2000).

Na camada limite a velocidade varia desde zero, na superfície sólida, até a velocidade do escoamento livre na fronteira da camada limite. Além disso, quanto maior a velocidade relativa entre o fluido e o corpo, mais fina é a camada limite.

O conceito da camada limite forneceu a ligação que estava faltando entre a teoria e a prática. Além do mais, tal conceito permitiu a solução de problemas de escoamento viscoso que seria impossível de resolver através da aplicação das 
equações de Navier-Stokes para a totalidade do campo do escoamento. Assim, a introdução do conceito da camada limite marcou o início da era moderna da mecânica dos fluidos (FOX; MCDONALD, 1981).

A camada limite é representada por elementos prismáticos nas proximidades de todas as paredes na metodologia do ANSYS CFX. Na região de interface entre a malha principal do modelo e a malha prismática da camada limite, ocorre uma adaptação das malhas para que ocorra a conexão entre elas.

\subsection{MODELO DE TURBULÊNCIA}

Lombardi (2005) afirma que, os casos reais de escoamento de água em condutos forçados, desde os mais simples aos mais complexos, tornam-se instáveis em regimes acima de certo número de Reynolds, aproximadamente 2300. A maioria dos escoamentos estudados pela engenharia é turbulenta.

O número de Reynolds de um escoamento fornece a relação entre as forças de inércia (associadas com os efeitos convectivos) e as forças viscosas. Em experimentos observa-se que, para número de Reynolds abaixo de um valor crítico, cerca de 2300, o escoamento é suave e camadas adjacentes de fluido deslizam uma pela outra de forma ordenada e, se as condições de contorno não mudam com o tempo, o escoamento é estável. Este regime é conhecido como laminar. Com números de Reynolds acima desse valor crítico, uma série de eventos acontece e leva a mudanças radicais nas características do escoamento, como aleatoriedade. Este regime é conhecido como turbulento (VERSTEEG; MALALASEKERA, 1995). As principais propriedades da turbulência são:

- Irregularidade - os escoamentos turbulentos são de difícil predição determinística e o uso de ferramentas estatísticas é importante para a análise;

- Alta difusibilidade - a experiência mostra que o processo de mistura de todas as propriedades ligadas a um escoamento (quantidade de movimento, energia, contaminantes, etc.) é maior no regime turbulento que no regime laminar; porque no regime turbulento, tem-se a presença de flutuações térmicas e de concentração, o que cria fortes e numerosos gradientes locais, tornando o processo de difusão turbulenta mais eficiente;

- A turbulência ocorre a altos números de Reynolds; 
- Flutuações tridimensionais de vorticidade - a experiência mostra que qualquer escoamento é tridimensional;

- A turbulência é um fenômeno altamente dissipativo;

- A turbulência é um fenômeno contínuo - qualquer escoamento de fluidos newtonianos pode ser modelado utilizando-se as equações de Navier-Stokes. Se o fluido for não newtoniano estas equações devem ser modificadas no seu termo viscoso.

- A turbulência é um fenômeno imprevisível - sendo incapaz de reprodução ou repetição de um dado experimento.

A turbulência consiste na flutuação das características do escoamento no tempo e no espaço, sendo um processo complexo, principalmente porque é tridimensional, instável e composto de muitas escalas, provocando efeitos significantes na característica do escoamento. A turbulência ocorre quando as forças de inércia no fluido se tornam significantes comparadas às forças viscosas. Em princípio, as equações de Navier-Stokes descrevem tanto fluxos laminares como turbulentos sem a necessidade de informações adicionais. Entretanto, escoamentos turbulentos produzem regimes que, em algumas situações, exigem o uso de malhas tão refinadas para capturar as peculiaridades do fluxo que se torna dispendiosa a análise numérica do fenômeno. Para considerar os efeitos da turbulência nos estudos, pesquisas em CFD têm concentrado esforços na obtenção de métodos que utilizem modelos de turbulência, evitando a necessidade do uso de malhas extremamente refinadas ou o uso de Simulação Numérica Direta (DNS), que requer um grande poder computacional. Esses modelos são geralmente modelos estatísticos (LOMBARDI, 2005).

Um modelo de turbulência é um procedimento computacional para a resolução das Tensões de Reynolds. Em geral, modelos de turbulência modificam as equações originais de Navier-Stokes pela introdução de quantidades médias e flutuantes, produzindo as equações de Navier-Stokes pelas médias de Reynolds (RANS). Estas equações representam as quantidades médias do escoamento, modelando os efeitos da turbulência sem a necessidade de resolver as flutuações turbulentas, reduzindo consideravelmente o esforço computacional. Os modelos de turbulência baseados nas equações de RANS são conhecidos como Modelos Estatísticos de 
Turbulência, devido ao procedimento de médias estatísticas empregado para obter as equações. Entretanto, o procedimento das médias introduz termos desconhecidos formados por produtos cruzados das quantidades flutuantes, que agem como tensão adicional no fluido. Estes termos são conhecidos como turbulentos ou tensões de Reynolds, que são difíceis de determinar diretamente e se tornam incógnitas adicionais. Estas tensões precisam ser modeladas e as equações utilizadas para fechar o sistema definem o tipo de modelo de turbulência (ANSYS CFX, 2006).

Arantes (2007) afirma que, os modelos de turbulência muito utilizados em mecânica dos fluidos são:

- Modelos de Uma Equação: Modelo Spalart-Allmaras;

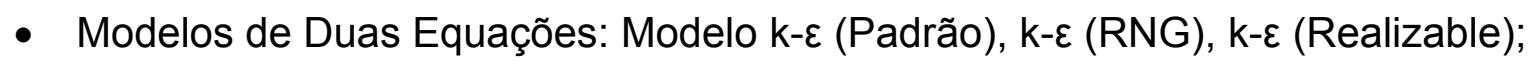

- Modelo de Tensões de Reynolds (RSM);

- Modelo de Simulação de Grandes Escalas “Large Eddy Simulation” (LES);

- Modelos de Simulação Híbridos “Detached Eddy Simulation” (DES).

Ocorre um aumento do esforço computacional nos modelos de turbulência citados de cima para baixo, devido ao acréscimo de variáveis físicas.

Segundo Arantes (2007), os modelos k- $\varepsilon$ possuem formas semelhantes, com equação de transporte para k (energia cinética turbulenta) e $\varepsilon$ (taxa de dissipação da energia cinética turbulenta). As suas principais diferenças são:

- O método para calcular a viscosidade turbulenta;

- O número de Prandtl turbulento que governa a difusão turbulenta de k e $\varepsilon$;

- Os termos de geração e dissipação na equação para $\varepsilon$.

Os modelos de turbulência utilizados nesse trabalho são o Modelo $k-\varepsilon, k-\varepsilon$ (RNG) e SST k- $\omega$ (“Shear Stress Model”). Alencar (2007) afirma que, entre os modelos de escoamento turbulento utilizados pelo CFD, os modelos utilizados nesse trabalho, juntamente com o RSM ("Reynolds Stress Model"), podem ser destacados em diversos estudos envolvendo CFD. O modelo $k-\varepsilon$ é o mais usado devido à sua estabilidade numérica, robustez e menor custo computacional, porém tem limitações 
da simulação de escoamentos que apresentem separação da camada limite e em superfícies curvas. Para suprir esta deficiência, o modelo k- $\varepsilon$ (RNG) permite rastrear as menores escalas de turbulência junto com as demais escalas. O modelo SST k- $\omega$ tem merecido maior atenção recentemente por sua maior precisão para prever o comportamento do escoamento em regiões com gradientes de pressão adversos, como por exemplo, nas regiões com descolamento do escoamento em perfis aerodinâmicos e palhetas ou perfis para turbo máquinas (ALENCAR, 2007).

\subsubsection{Modelo k- $\varepsilon$}

O modelo k- $\varepsilon$ (padrão) é um modelo semi-empírico baseado nas equações do modelo de transporte para a energia cinética $(k)$ e sua taxa de dissipação $(\varepsilon)$. A equação do modelo de transporte para k é derivada da equação de Navier-Stokes, enquanto que a equação do modelo de transporte para $\varepsilon$ foi obtida usando raciocínio físico e sustenta pouca semelhança em relação a k (ARANTES, 2007).

Esse modelo é indicado para escoamentos completamente turbulentos com altas taxas de turbulência. Sua limitação é não conseguir resultados precisos em escoamentos com baixas escalas de turbulência envolvendo geometrias complexas.

Para este modelo, o Tensor de Reynolds $\left(U_{i} \cdot U_{j}\right)$, pode ser representado pela seguinte expressão (ALENCAR, 2007):

$-\rho \cdot\left(U_{i} \cdot U_{j}\right)=2 \cdot \mu_{t} \cdot S_{I J}-\frac{2}{3} \cdot \rho \cdot k \cdot \delta_{I J}$

Onde $\delta_{I J}$ é a função Delta de Dirac; $S_{I J}$ é o Tensor de Cisalhamento Médio calculado pela expressão (4.5):

$$
S_{I J}=\frac{1}{2} \cdot\left(\frac{\partial U_{i}}{\partial x_{j}}+\frac{\partial U_{j}}{\partial x_{i}}\right)
$$

A viscosidade turbulenta é calculada através da equação (4.6): 
$\mu_{t}=\rho \cdot C_{\mu} \cdot \frac{k^{2}}{\varepsilon}$

Sendo:

$\mathrm{C}_{\mu}$ uma constante;

$k=\frac{1}{2} \cdot\left(U_{i} \cdot U_{j}\right) \quad$ e $\quad \varepsilon=v \cdot \frac{\partial U_{i}}{\partial x_{j}} \cdot \frac{\partial U_{j}}{\partial x_{i}}$

Onde $v$ a viscosidade cinemática do fluido.

Estas expressões satisfazem as seguintes equações de transporte em cada ponto de domínio do escoamento:

$$
\begin{aligned}
& \frac{\partial(\rho k)}{\partial t}+\frac{\partial\left(\rho k u_{i}\right)}{\partial x_{i}}=\frac{\partial}{\partial x_{j}}\left[\left(\mu+\frac{\mu_{t}}{\sigma_{k}}\right) \cdot \frac{\partial k}{\partial x_{j}}\right]+G_{k}+G_{b}-\rho \varepsilon-Y_{M} \\
& \frac{\partial(\rho \varepsilon)}{\partial t}+\frac{\partial\left(\rho \varepsilon u_{i}\right)}{\partial x_{i}}=\frac{\partial}{\partial x_{j}}\left[\left(\mu+\frac{\mu_{t}}{\sigma_{\varepsilon}}\right) \cdot \frac{\partial \varepsilon}{\partial x_{j}}\right]+C_{1 \varepsilon} \frac{\varepsilon}{k} \cdot\left(G_{k}+C_{3 \varepsilon} G_{b}\right)-C_{2 \varepsilon} \rho \frac{\varepsilon^{2}}{k}
\end{aligned}
$$

Onde:

$G_{k} \quad$ representa a geração de energia cinética turbulenta devido aos gradientes de velocidade média;

$G_{b} \quad$ é a geração de energia cinética turbulenta devido às flutuações das velocidades;

$Y_{M}$ representa a contribuição na taxa de dissipação total devido à variação volumétrica para o caso compressível;

$\sigma_{k} \quad$ é o número de Prandtl turbulento para k;

$\sigma_{\varepsilon} \quad$ é o número de Prandtl turbulento para $\varepsilon$;

$C_{1 \varepsilon}, C_{2 \varepsilon}, C_{3 \varepsilon}$ são constantes;

$\mu_{t} \quad$ é a viscosidade turbulenta. 
Launder e Spalding (1972) definiram, a partir de experimentos com variados escoamentos em duto sob pressão e superfície livre, os valores para as constantes:

$C_{1 \varepsilon}=1,44, C_{2 \varepsilon}=1,92, C_{\mu}=0,09, \sigma_{k}=1,00$ e $\sigma_{\varepsilon}=1,30$.

\subsubsection{Modelo k- $\varepsilon$ (RNG)}

O modelo $k-\varepsilon$ (RNG) de turbulência é derivado das equações instantâneas de Navier-Stokes, onde $(k)$ é a energia cinética turbulenta e $(\varepsilon)$ é a sua taxa de dissipação, usando uma técnica matemática chamada de métodos de "Renormalização de Grupo" (RNG). A derivação analítica resulta em um modelo com constantes diferentes do modelo $k-\varepsilon$ (padrão), e termos e funções adicionais nas equações de transporte para $\mathrm{k}$ e $\varepsilon$ (ARANTES, 2007). Para um melhor entendimento da teoria RNG e sua aplicação para turbulência pode-se buscar em Lesieur (2008).

A principal diferença entre o modelo $k-\varepsilon$ (padrão) e o k- $\varepsilon$ (RNG) são os valores das constantes utilizadas em cada modelo. O modelo $k-\varepsilon$ (RNG) é uma forma melhorada do modelo $k-\varepsilon$, pois é capaz de rastrear baixas escalas de turbulência em geometrias complexas. As equações de transporte para o modelo $k-\varepsilon$ (RNG) são expressas por:

$$
\begin{aligned}
& \frac{\partial(\rho k)}{\partial t}+\frac{\partial\left(\rho k u_{i}\right)}{\partial x_{i}}=\frac{\partial}{\partial x_{j}}\left[\alpha_{k} \mu_{\text {eff }} \frac{\partial k}{\partial x_{j}}\right]+G_{k}+G_{b}+\rho \varepsilon-Y_{M} \\
& \frac{\partial(\rho \varepsilon)}{\partial t}+\frac{\partial\left(\rho \varepsilon u_{i}\right)}{\partial x_{i}}=\frac{\partial}{\partial x_{j}}\left[\alpha_{\varepsilon} \mu_{\text {eff }} \frac{\partial \varepsilon}{\partial x_{j}}\right]+C_{1 \varepsilon} \frac{\varepsilon}{k}\left(G_{k}+C_{3 \varepsilon} G_{b}\right)-C_{2 \varepsilon} \rho \frac{\varepsilon^{2}}{k}-R_{\varepsilon}
\end{aligned}
$$

Onde:

$G_{k} \quad$ representa a geração de energia cinética turbulenta devido aos gradientes de velocidade média;

$G_{b} \quad$ é a geração de energia cinética turbulenta devido às flutuações das velocidades; 


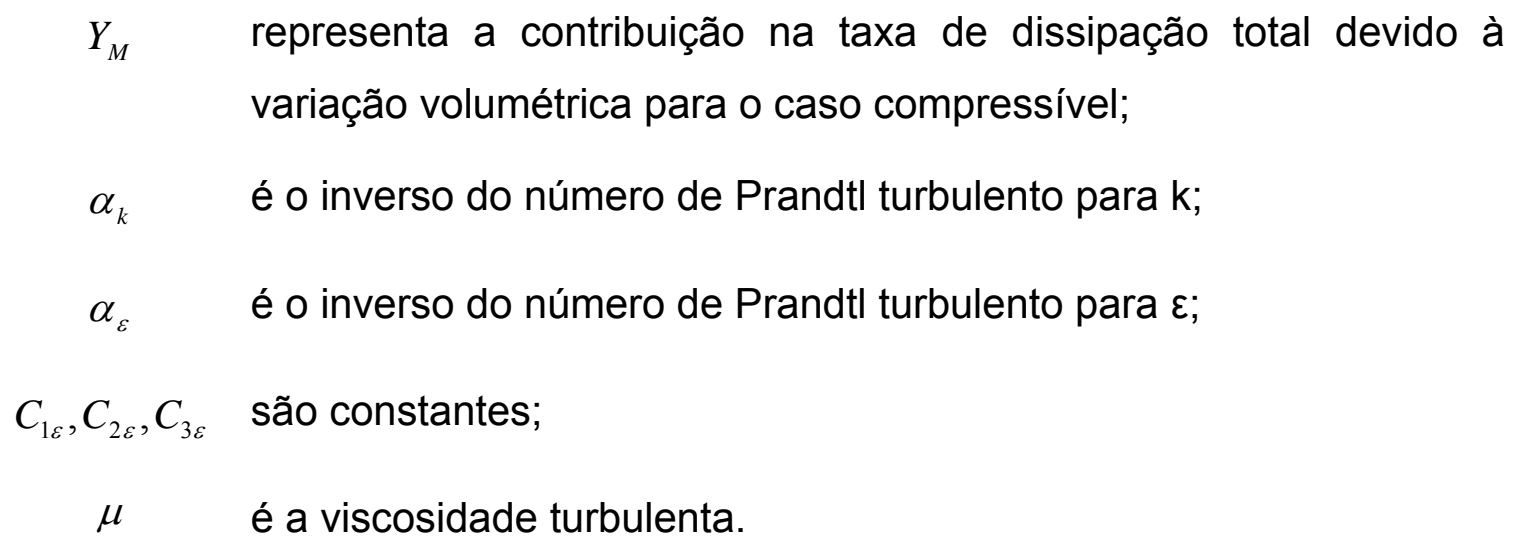

Os valores típicos médio para as constantes são:

$C_{1 \varepsilon}=1,42, C_{2 \varepsilon}=1,68, C_{\mu}=0,085, \sigma_{k}=0,72$ e $\sigma_{\varepsilon}=0,72$.

\subsubsection{Modelo SST $k-\omega$}

Este modelo tem sido utilizado para descrever escoamentos onde ocorre a separação da camada limite ou a inversão de escoamento, sujeitos a gradientes de pressão adversos, os quais podem ser encontrados, por exemplo, nos projetos aerodinâmicos das asas de aviões (ALENCAR, 2007).

De maneira geral, o modelo SST k- $\omega$ pode ser utilizado para descrever o comportamento do escoamento na região da camada limite, enquanto o modelo k- $\varepsilon$ (padrão) para a descrição do escoamento fora da camada limite. Com isso, esse modelo é capaz de rastrear o comportamento do escoamento envolvendo tanto as grandes quanto as pequenas escalas de turbulência num escoamento. Para escoamentos com superfícies livres, o modelo SST k- $\omega$ pode apresentar o

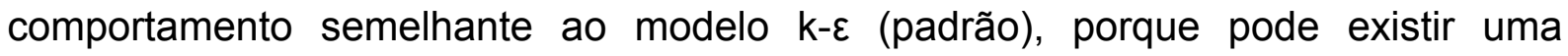
interface bem definida entre fluidos de densidade específica diferente (ar+água), considerando que o modelo é homogêneo (ALENCAR, 2007).

A idéia básica deste modelo em relação à turbulência associada com a vorticidade $\omega$ de Von Karman pode ser representada pela equação:

$$
\omega=c \cdot \frac{k^{2}}{l}
$$


Onde $k$ é definido pela equação (4.7); 1 é o comprimento de mistura de Prandtl ao longo da coordenada y, dado por $\mathrm{l}=\kappa . \mathrm{y}$, onde $\mathrm{\kappa}$ é a constante de Von Karman, cujo valor experimental é $\mathrm{k}=0,41$; e $c$ é uma constante de proporcionalidade.

A viscosidade no escoamento turbulento é representada pela equação:

$$
\mu_{t}=\rho \cdot \frac{k}{\omega}
$$

Desta forma, substituindo as equações (4.12) e (4.13) nas equações de transporte, obtém as duas equações de $\mathrm{k}$ e $\omega$ do modelo SST k- $\omega$ :

$$
\begin{aligned}
& \frac{\partial(\rho k)}{\partial t}+(\rho \cdot k) \frac{\partial V_{i}}{\partial x_{i}}=\frac{\partial}{\partial x_{i}}\left[\mu_{k} \cdot \frac{\partial k}{\partial x_{i}}\right]+\frac{\partial}{\partial x_{i}}\left(\frac{\partial \tau_{i}}{\partial x_{j}} \cdot V_{j}\right)-\beta^{*} \cdot \rho \cdot k \cdot \omega \\
& \frac{\partial(\rho \omega)}{\partial t}+\frac{\partial\left(\rho \cdot \omega \cdot V_{i}\right)}{\partial x_{i}}=\frac{\partial}{\partial x_{i}}\left[\mu_{\varepsilon} \cdot \frac{\partial \omega}{\partial x_{i}}\right]+\alpha \cdot \frac{\omega}{k} \cdot \frac{\partial}{\partial x_{i}}\left(\frac{\partial \tau_{i}}{\partial x_{j}} \cdot V_{j}\right)-\beta \cdot \rho \cdot \omega^{2}
\end{aligned}
$$

Onde:

$\omega \quad$ vorticidade associada a vorticidade $\omega$ de Von Karman;

$\alpha, \beta, \beta^{*}$ são constantes;

$\mu \quad$ é a viscosidade turbulenta.

Os valores típicos para as constantes são: $\alpha=0,556, \beta=0,075, \beta^{*}=0,09, \sigma_{k}=0,50$ e $\sigma_{\varepsilon}=0,50$.

Para uma melhor compreensão e aprofundamento nos estudos de modelos de turbulência, pode-se buscar em Cebeci (2003) e ANSYS CFX (2006). 


\subsection{MODELOS MULTIFÁSICOS}

Os modelos multifásicos são utilizados em simulações de CFD, representando as diferentes fases ou misturas dos fluidos presentes nos escoamentos. Estes modelos são divididos, geralmente, em modelos multifásicos euleriano-euleriano ou euleriano-lagrangeano (ANSYS CFX, 2006). Para representar o escoamento em superfície livre, água/ ar, será utilizado o modelo multifásico euleriano-euleriano, que pode ser dividido em dois outros sub-modelos: homogêneo e não-homogêneo (modelo de transferência entre fluidos).

As diferentes fases de fluidos podem ser denotadas pelas seguintes letras gregas minúsculas: $\alpha, \beta, \gamma$, etc. A fração de volume de $\alpha$ é denotado por $r_{\alpha}$. Assim, volume $\mathrm{Vol}_{\alpha}$ ocupado pela fase $\alpha$ em um pequeno volume $\mathrm{Vol}$ ao redor de um ponto de fração de volume $r_{\alpha}$ é determinado por:

$\mathrm{Vol}_{\alpha}=r_{\alpha} \cdot \mathrm{Vol}$

O total de número de fases é $N p$. A fração de volume de cada fase é denotada por $r_{\alpha}$, em que a varia de 1 a $N p$. Também é importante distinguir entre a massa específica do fluido e a massa específica efetiva do fluido $\alpha$, conforme a fração de volume de cada fase.

- Modelo não-homogêneo: cada fluido é processado com o seu próprio campo de escoamento e as interações entre as fases são calculadas por meio de um termo de transferência. Desta forma, nesse modelo há um campo de solução em separado para cada fase. Como exemplo: duas fases podem ter campos de velocidade e temperatura separados, mas há uma tendência para que ele fique em equilíbrio na interface através do termo de arrasto e de transferência de calor (ANSYS CFX, 2006);

- Modelo homogêneo: um campo de escoamento comum é compartilhado por todos os fluidos, como também outros campos relevantes como a temperatura e a turbulência. Isto permite algumas simplificações para construção do modelo multifásico. Para um dado processo de transporte, o modelo homogêneo assume que as quantidades transportadas para aquele processo 
(com exceção da fração de volume) são as mesmas para todas as fases (ANSYS CFX, 2006);

A transferência de massa na interface ocorre quando a massa é transmitida de uma fase para outra. Este modelo de transferência de massa é aplicado em ambos os modelos multifásicos, não homogêneo ou homogêneo.

O Modelo de Mistura é o modelo mais simples, pois trata ambas as fases $\alpha$ e $\beta$ de forma simétrica. A área de superfície por unidade de volume é calculada por:

$$
A_{\alpha \beta}=\frac{r_{\alpha} \cdot r_{\beta}}{d_{\alpha \beta}}
$$

Sendo:

$r_{\alpha}$ a fração de volume de $\alpha$;

$r_{\beta}$ a fração de volume de $\beta$;

$d_{\alpha \beta}$ uma escala de comprimento na interface, que é especificado por (em caso de duas fases):

$d_{\alpha \beta}=\frac{r_{\alpha} \cdot d_{\beta}+r_{\beta} \cdot d_{\alpha}}{6}$

Os coeficientes adimensionais de transferência interfases podem ser correlacionados em termo do número de Reynolds de mistura e o número de Prandtl (ANSYS CFX, 2006).

O Modelo de Superfície Livre descreve a teoria do escoamento que é a aplicação mais comum em escoamentos homogêneos multifásicos. Esse modelo tem o propósito de solucionar a interface entre os fluidos (ANSYS CFX, 2006). 


\section{MÉTODO DE TRABALHO}

O método de trabalho empregado nesta pesquisa consistiu na realização de ensaios em modelo físico e a modelagem do problema, utilizando a Dinâmica dos Fluidos Computacional (CFD).

\subsection{ENSAIOS EXPERIMENTAIS EM MODELO FÍSICO}

Os ensaios experimentais no modelo reduzido bidimensional de um vertedor lateral (Figuras 5.1 a 5.5), criado por Armelin (2010) no hall externo do Laboratório de Hidráulica da Escola Politécnica da Universidade de São Paulo, foram realizados durante o mês de julho de 2010. O ensaio consistiu na obtenção de parâmetros como vazões e profundidade de lâmina d'água, posteriormente utilizados para alimentar o modelo matemático e validar os resultados por ele gerados. Na Figura 5.1 tem-se uma visão geral do modelo físico, podendo visualizar o canal retangular e o vertedor lateral. Já a Figura 5.2 mostra uma vista de jusante, onde se pode ver a comporta reguladora de nível e a alimentação do sistema.

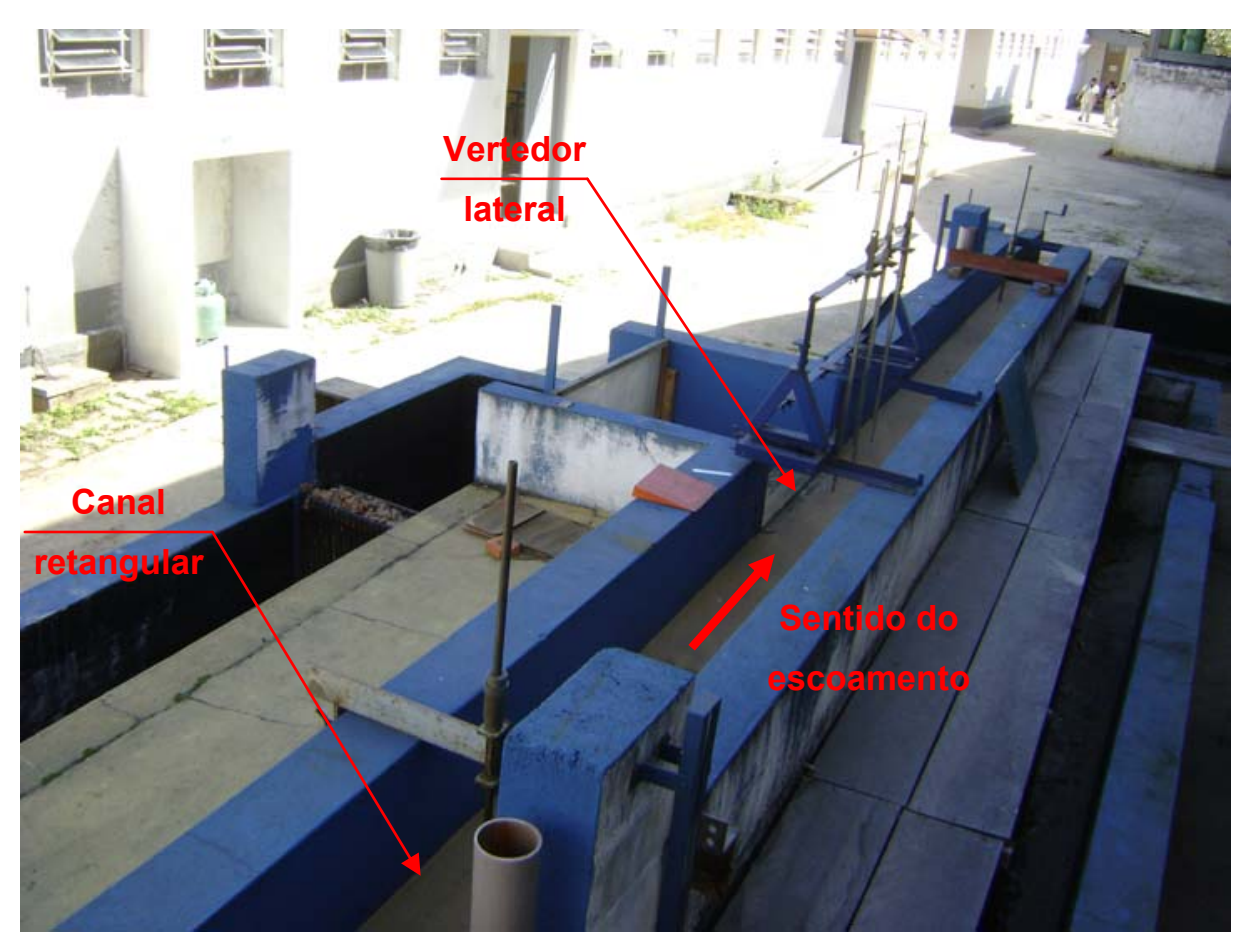

Figura 5.1 - Vista à montante do modelo do vertedor lateral. 


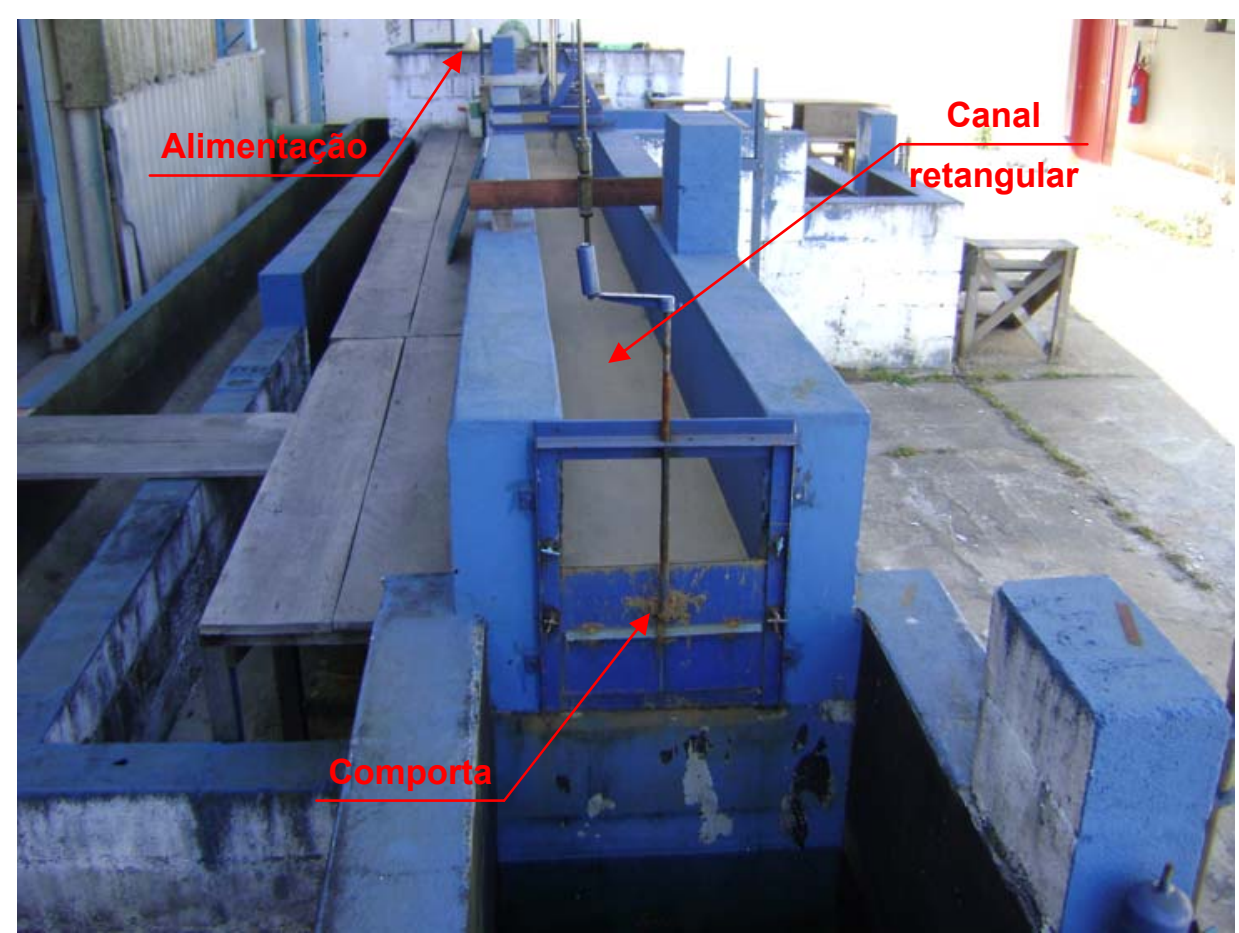

Figura 5.2 - Vista à jusante do modelo do vertedor lateral.

O detalhe da soleira lateral pode ser visto na Figura 5.3, enquanto nas Figuras 5.4 e 5.5 , pode-se visualizar o escoamento através do dispositivo lateral em dois ângulos diferentes.

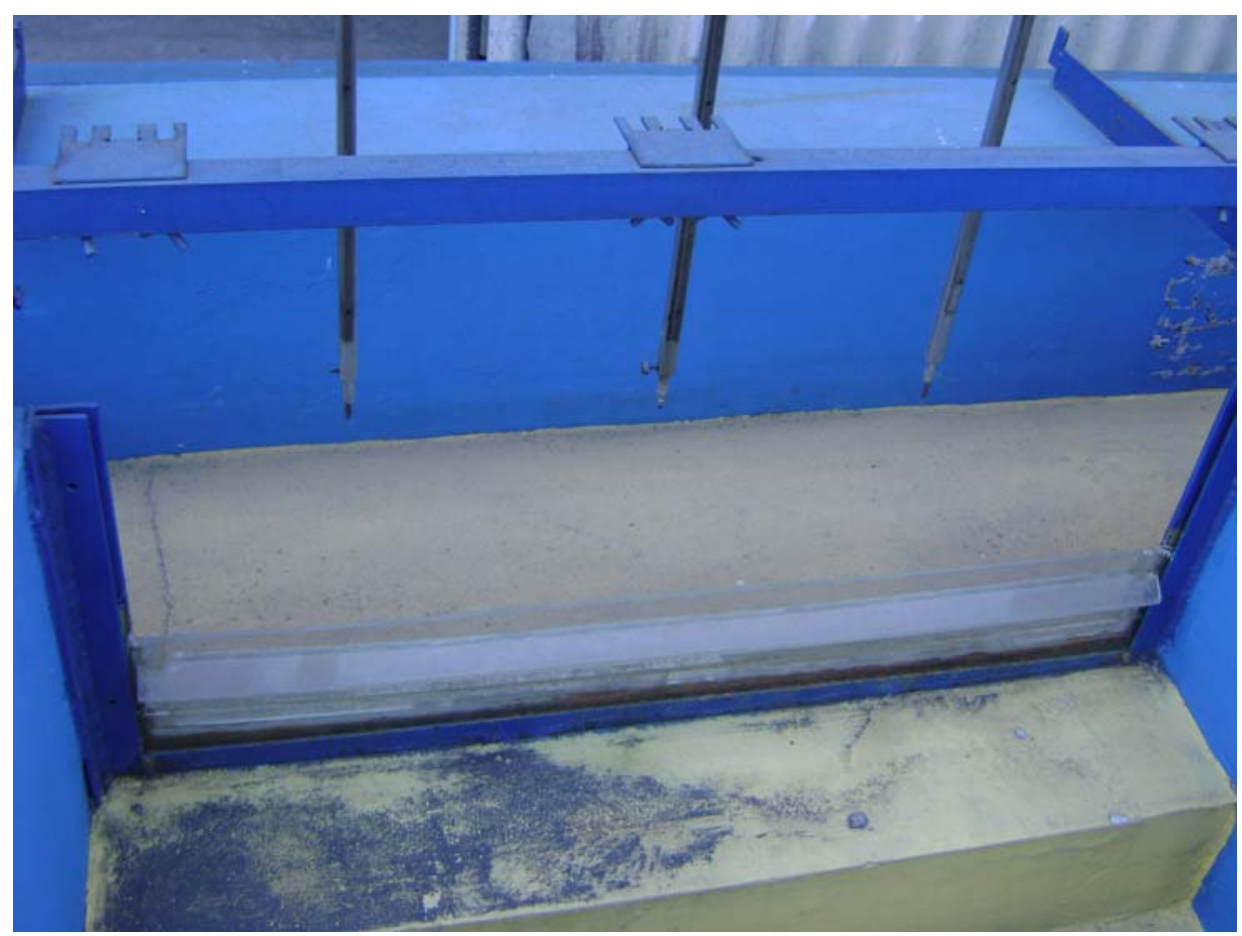

Figura 5.3 - Detalhe da soleira do vertedor lateral. 


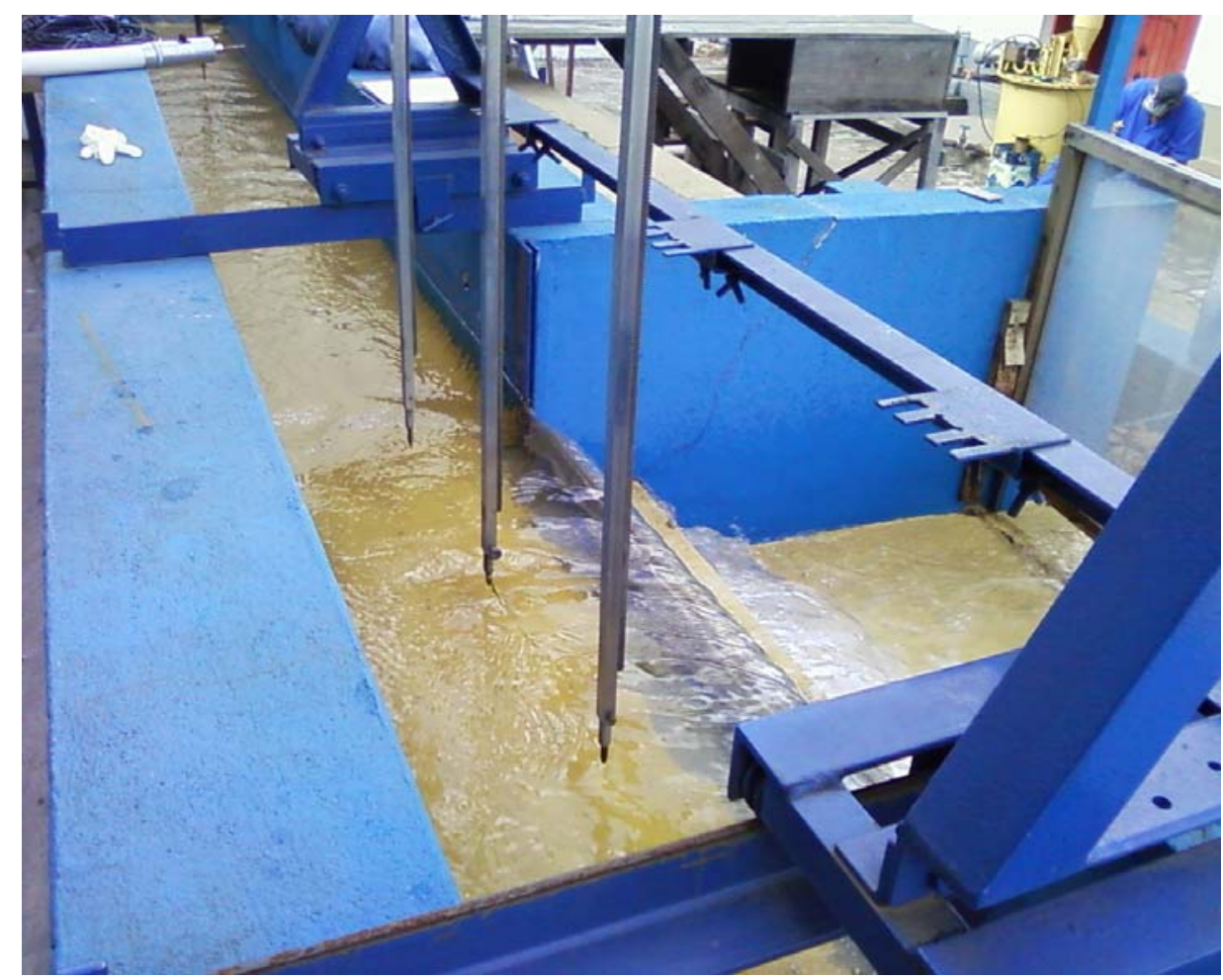

Figura 5.4 - Vista à jusante do vertedor lateral estudado.

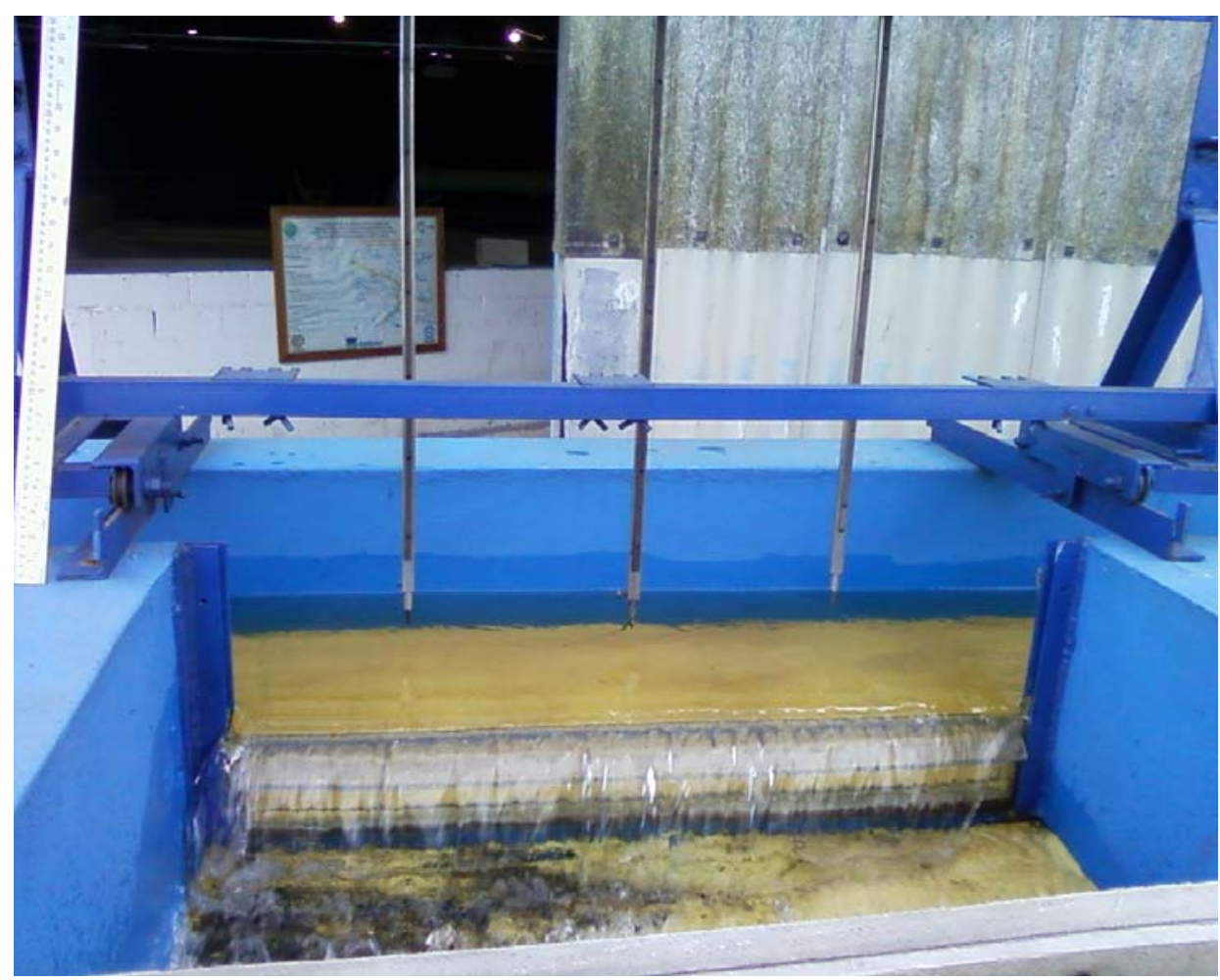

Figura 5.5 - Vista frontal do vertedor lateral estudado. 
O sistema de funcionamento do modelo é representado na Figura (5.6), e suas principais características são:

- Canal retangular principal: 0,40m x 0,40m;

- Vertedor lateral:

o Comprimento: $1,00 \mathrm{~m}$;

o Altura média da soleira: 0,125m (declividade longitudinal $\cong 0,004 \mathrm{~m} / \mathrm{m}$ );

- Declividade longitudinal do canal: $0,005 \mathrm{~m} / \mathrm{m}$;

- Comprimento aproximado do canal: $10 \mathrm{~m}$.

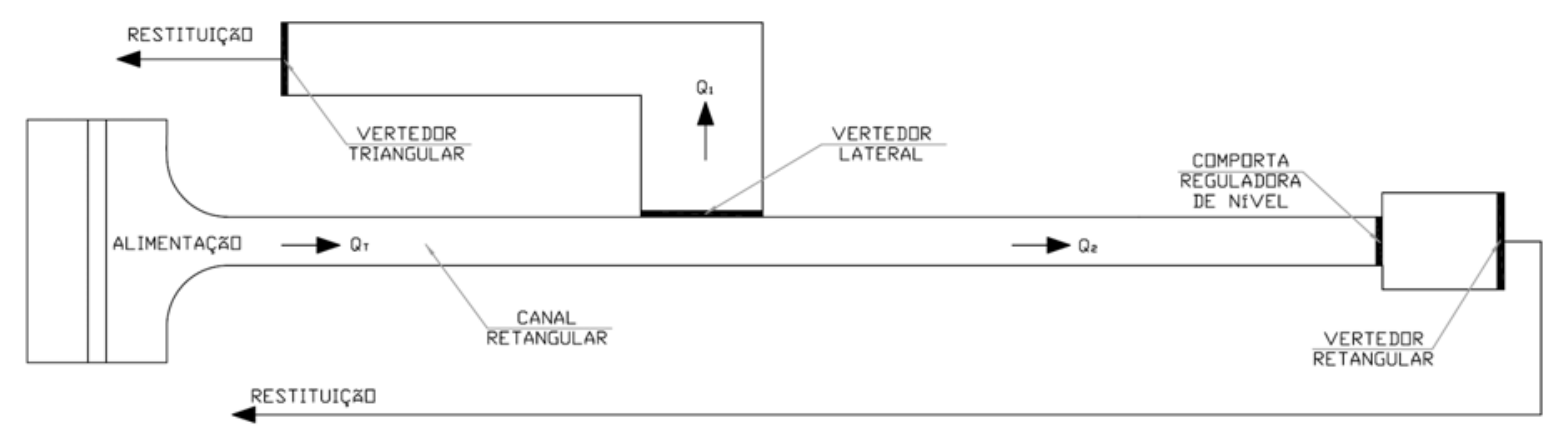

Figura 5.6 - Sistema de funcionamento do modelo.

O modelo é alimentado por um sistema motor-bomba com tubulação de ferro fundido de $300 \mathrm{~mm}$ a partir de um reservatório de nível constante. Essa tubulação chega a uma câmara tranqüilizante (Alimentação da Figura 5.6), que encaminha o escoamento para o canal retangular.

$A$ vazão total $Q_{\mathrm{T}}$ do escoamento através do canal é dividida em $Q_{1}$ que escoa através do vertedor lateral e $Q_{2}$ que segue pelo canal principal. Essas vazões são medidas, respectivamente, no vertedor triangular (Figura 5.7) e vertedor retangular (Figura 5.8). Posteriormente as águas são restituídas ao reservatório de nível constante. 


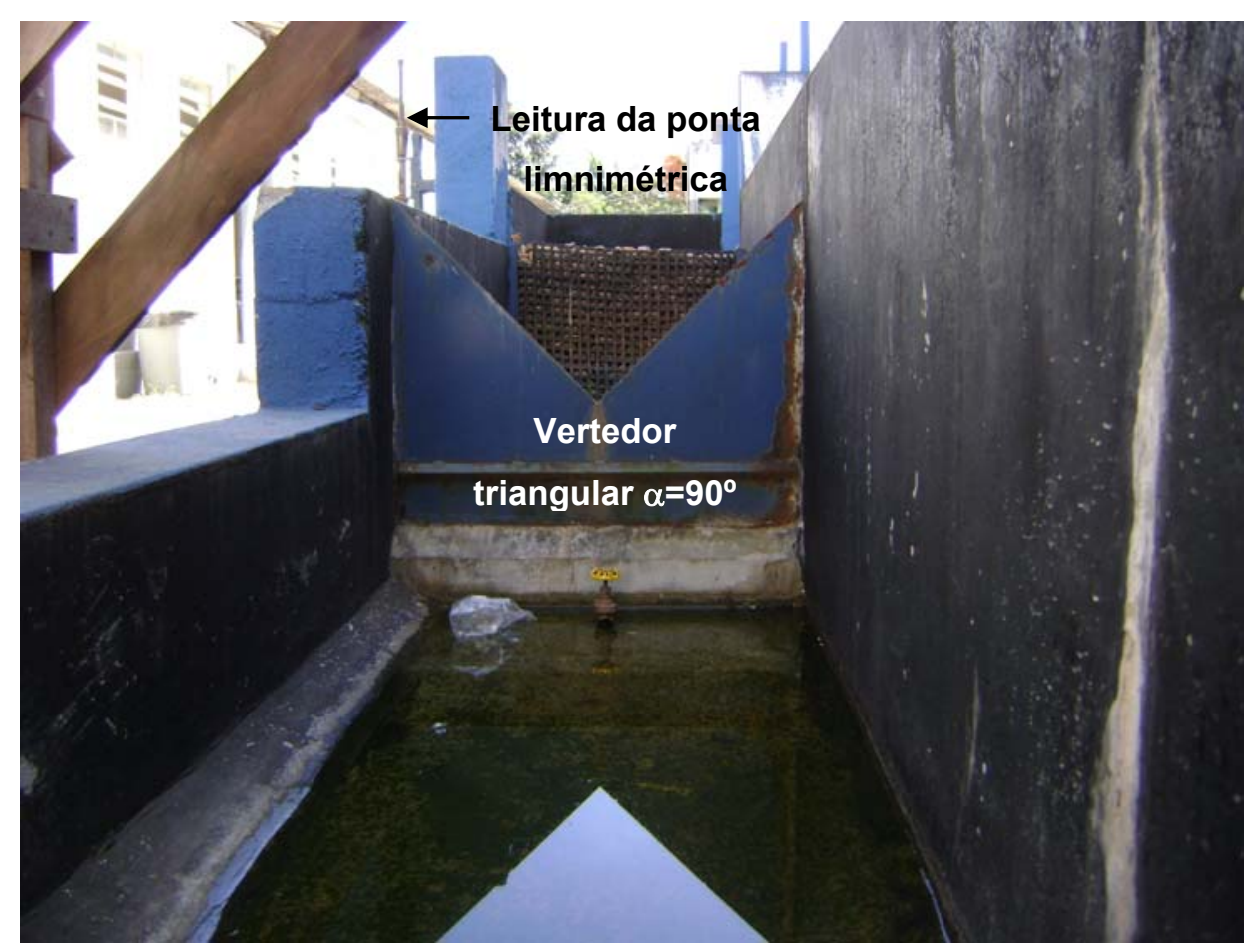

Figura 5.7 - Vista frontal do vertedor triangular.

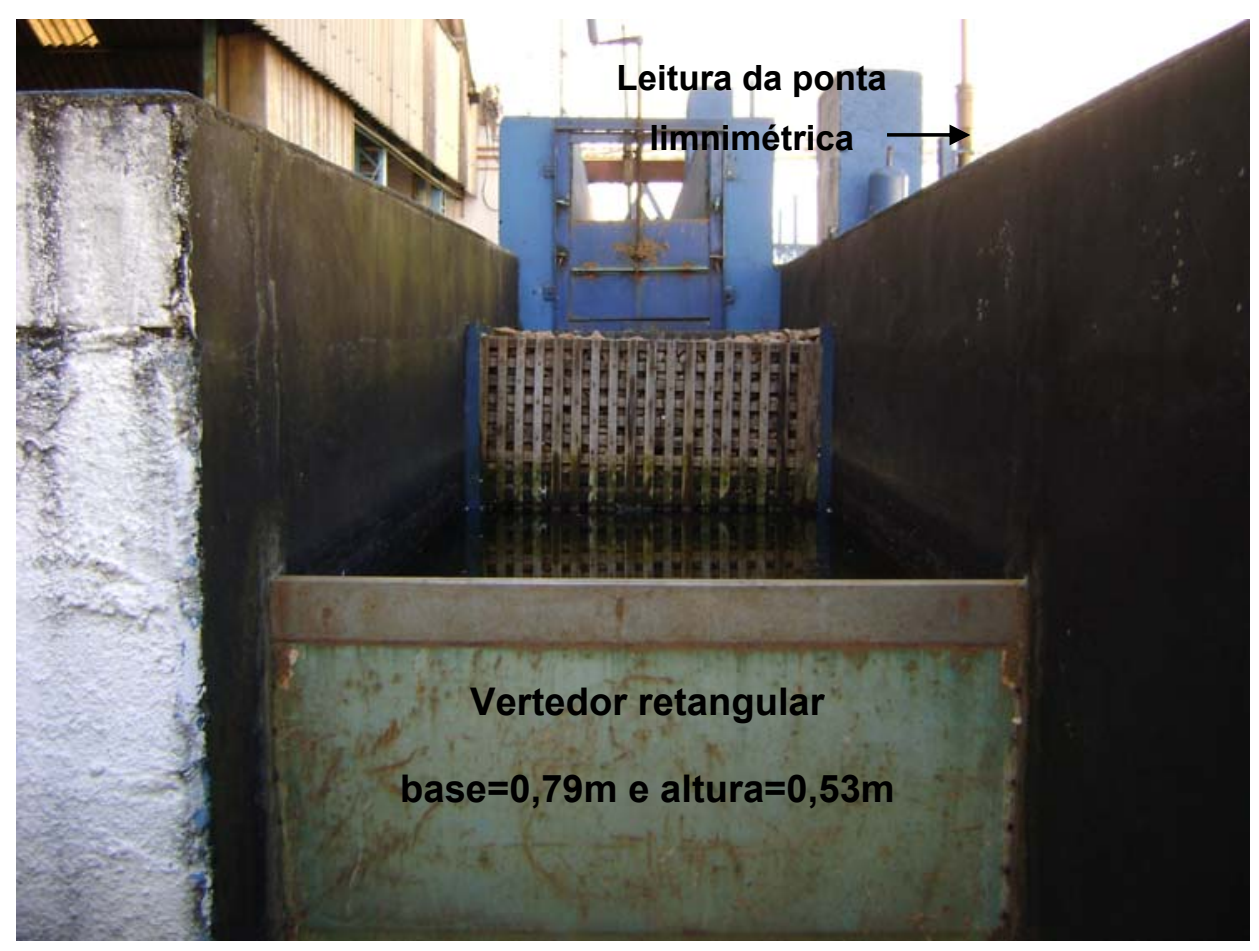

Figura 5.8 - Vista frontal do vertedor retangular.

Nos ensaios experimentais realizaram-se as leituras das pontas limnimétricas dos vertedores triangular e retangular, através de copos estabilizadores de escoamento, que mantém o nível d'água em seu interior praticamente constante. $A$ 
sua leitura representa a carga hidráulica sobre a soleira. $A$ vazão $Q_{1}$ foi determinada a partir da equação (3.11) e vazão $Q_{2}$ através da equação (3.9).

Ao final do canal principal há uma comporta reguladora de nível, com a função de controlar a variação da vazão no vertedor lateral. Quanto maior o nível da comporta, maior será a vazão através do vertedor lateral.

Nas Figuras 5.9 e 5.10 são apresentadas as regiões de interesse para o estudo deste trabalho. Apesar do modelo físico estudado possuir aproximadamente 10 metros de comprimento, modelou-se com CFD 3,5 metros, assim pode-se apresentar um maior refinamento da malha com um menor custo computacional.

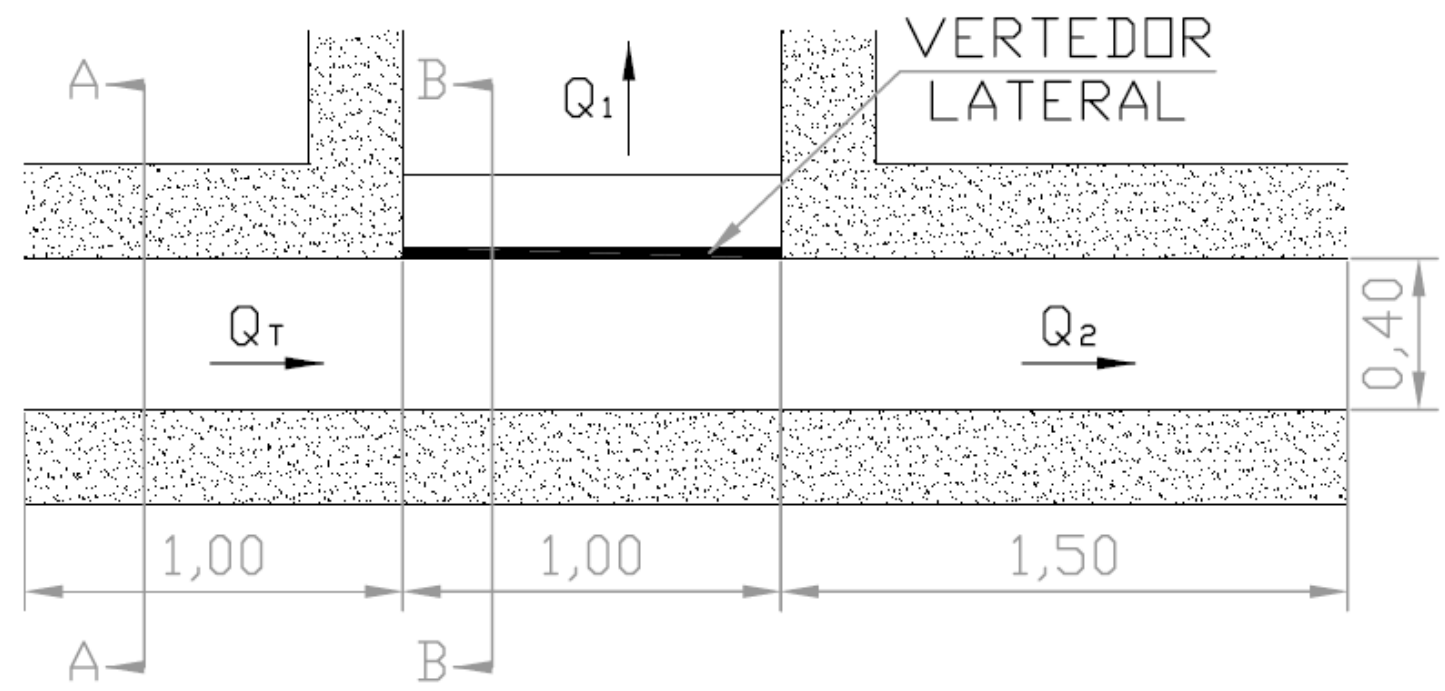

Figura 5.9 - Vista em planta do modelo físico simulado.
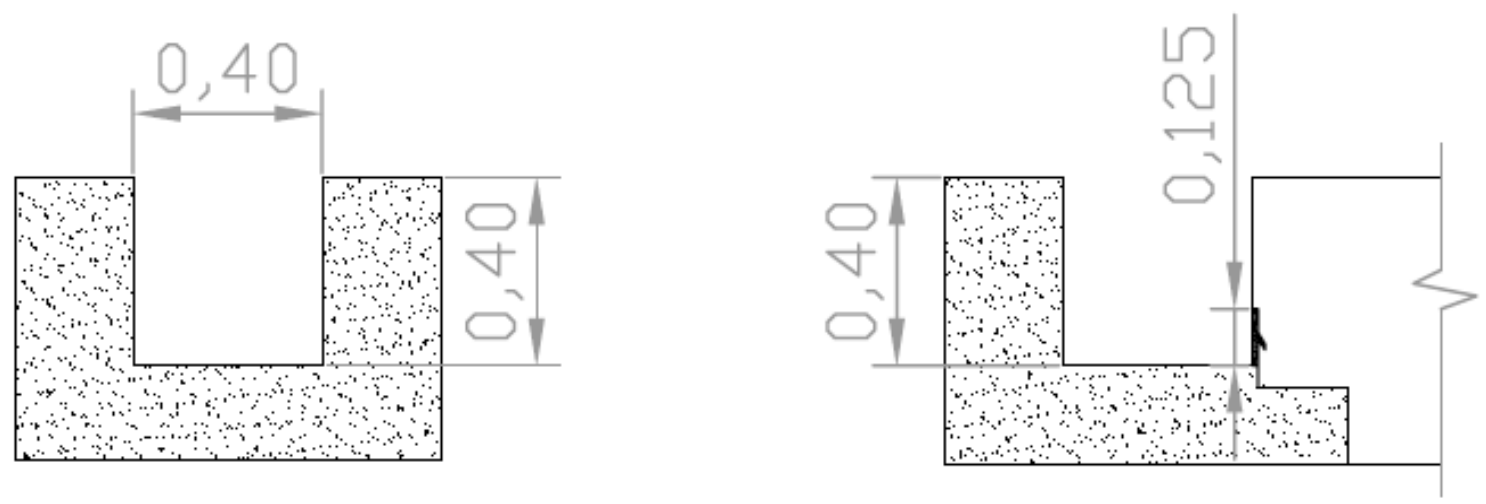

Corte AA

Corte BB

Figura 5.10 - Detalhes do modelo físico. 
No ensaio mediram-se os níveis d'água, através de réguas de medição direta (Figura 5.11), a 1 metro a montante do início do vertedor lateral, 1,5 metros a jusante do final do dispositivo, essas medidas foram obtidas no eixo do canal retangular principal, e 20 pontos sobre a soleira do vertedor, espaçados de 5 centímetros. Também se mediu a temperatura da água e do ambiente com o auxílio de um termômetro, ambas as temperaturas ficaram em torno de $20^{\circ} \mathrm{C}$.

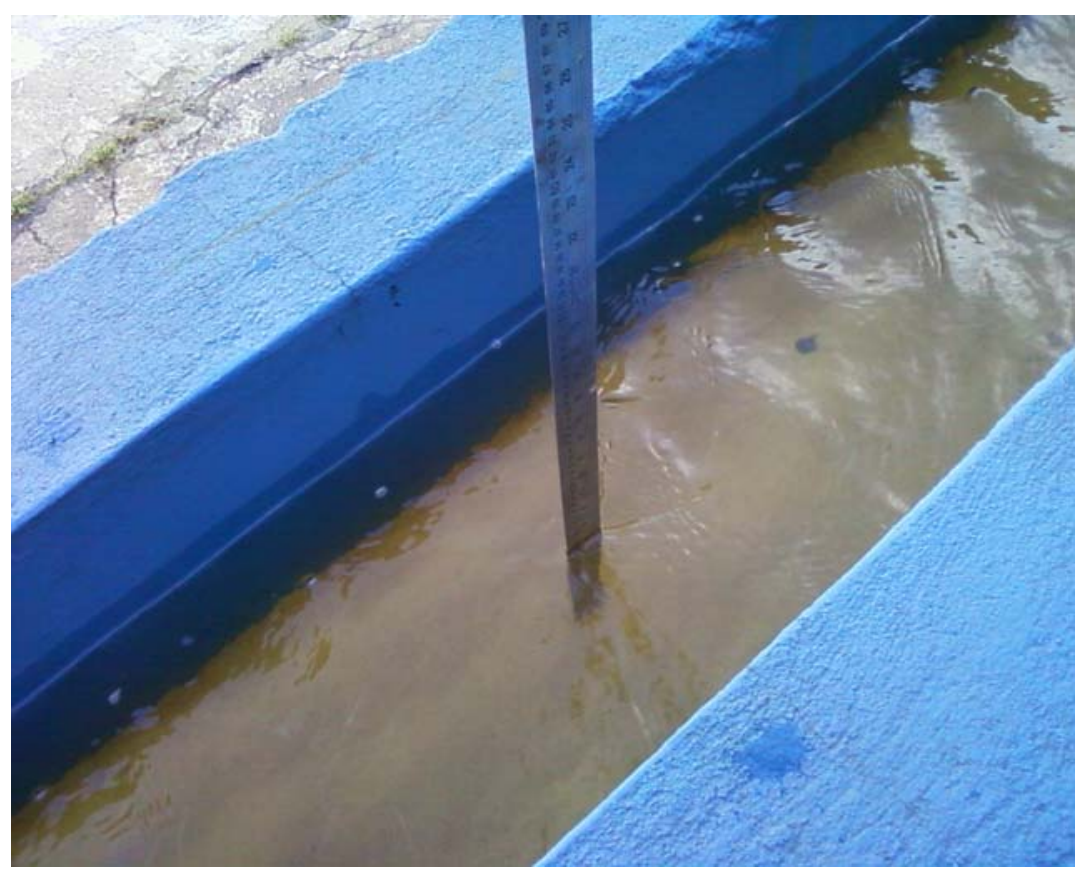

Figura 5.11 - Medição do nível d’água com régua metálica.

Ensaiou-se três arranjos hidráulicos, que consistem na variação da altura da comporta reguladora de nível, para as alturas de $10 \mathrm{~cm}, 8 \mathrm{~cm}$ e $6 \mathrm{~cm}$, e para cada arranjo foi ajustada uma vazão (Q1, Q2 e Q3) no sistema de alimentação do modelo, com isso, são 9 situações diferentes. Cada situação é representada através da vazão volumétrica do canal principal e altura da comporta, "Q1-C8" significa, por exemplo, a vazão volumétrica do ensaio 1 e altura de comporta igual a $8 \mathrm{~cm}$.

Os dados medidos dos níveis d'água do canal retangular e a leitura das pontas limnimétricas, juntamente com as respectivas vazões calculadas são representados na Tabela 5.1. A Tabela 5.2 apresenta os dados medidos dos NA's sobre a soleira do vertedor lateral. 
Tabela 5.1 - Níveis d'água do ensaio e vazões calculadas.

\begin{tabular}{cccccccc}
\hline Ensaios & $\begin{array}{c}\text { Montante } \\
{[\mathbf{c m}]}\end{array}$ & $\begin{array}{c}\text { Jusante } \\
{[\mathbf{c m}]}\end{array}$ & $\begin{array}{c}\text { Vertedor } \\
\text { Retangular } \\
{[\mathbf{c m}]}\end{array}$ & $\begin{array}{c}\text { Vertedor } \\
\text { Triangular } \\
{[\mathbf{c m}]}\end{array}$ & $\begin{array}{c}\text { Vazão } \\
\text { Canal de } \\
\text { Saída } \\
{[\mathrm{L} / \mathbf{s}]}\end{array}$ & $\begin{array}{c}\text { Vazão } \\
\text { Vertedor } \\
\text { Lateral } \\
{[\mathrm{L} / \mathbf{s}]}\end{array}$ & $\begin{array}{c}\text { Vazão } \\
\text { Canal de } \\
\text { Entrada } \\
{[\mathrm{L} / \mathbf{s}]}\end{array}$ \\
\hline Q1-C6 & 13,50 & 14,50 & 7,83 & 4,20 & 32,13 & 0,51 & 32,64 \\
Q1-C8 & 14,50 & 16,50 & 6,73 & 11,85 & 25,62 & 6,77 & 32,39 \\
Q1-C10 & 14,00 & 15,75 & 5,83 & 14,90 & 20,69 & 12,00 & 32,69 \\
Q2-C6 & 13,50 & 15,50 & 8,27 & 9,49 & 34,88 & 3,88 & 38,76 \\
Q2-C8 & 15,50 & 17,75 & 6,82 & 14,96 & 26,14 & 12,12 & 38,26 \\
Q2-C10 & 16,25 & 18,50 & 6,50 & 16,00 & 24,33 & 14,34 & 38,67 \\
Q3-C6 & 14,50 & 17,00 & 9,26 & 11,88 & 41,34 & 6,81 & 48,15 \\
Q3-C8 & 16,50 & 18,25 & 8,01 & 16,46 & 33,25 & 15,39 & 48,64 \\
Q3-C10 & 17,00 & 19,00 & 7,20 & 18,32 & 28,34 & 20,11 & 48,45 \\
\hline
\end{tabular}

$\mathrm{Na}$ medição dos níveis d'água no canal retangular, montante e jusante, observou-se durante um minuto para cada leitura, uma variação do NA de $-0,6 \mathrm{~cm}$ a $+0,6 \mathrm{~cm}$, portanto, essa será a incerteza utilizada para alimentar o modelo matemático criado.

As leituras das pontas limnimétricas, que foram utilizadas na determinação das vazões, não apresentaram uma variação significativa durante o ensaio, mas devido uma questão de segurança, por exemplo: não garantir o posicionamento preciso das tomadas de nível, a sua incerteza foi considerada como $\Delta \mathrm{H}=0,0002 \mathrm{~m}$, sendo $\mathrm{H} \mathrm{o}$ NA lido na ponta limnimétrica.

O erro do modelo físico na medição de vazão foi determinado para a vazão escoada no vertedor lateral $\left(Q_{1}\right)$ e no canal de saída $\left(Q_{2}\right)$.

Para $Q_{1}$ derivou-se a equação 3.11 em função de $\mathrm{H}$ e posteriormente determinou-se o $\Delta Q_{1}$, o erro considerado é $\Delta Q_{1} / Q_{1}$. Dentre as condições ensaiadas, o erro médio foi aproximadamente $0,5 \%$. 
$A$ vazão $Q_{2}$ foi determinada a partir de método numérico, traçou-se uma curva de $\mathrm{Q}_{2} \times \mathrm{H}$, onde foram determinadas barras de erros de $\pm \Delta \mathrm{H}=0,0002 \mathrm{~m}$ para cada medida de $\mathrm{H}$, e conseqüentemente determinou-se o $\Delta \mathrm{Q}_{2}$, o erro considerado foi $\Delta Q_{2} / Q_{2}$. Para as condições ensaiadas, o erro médio foi aproximadamente $1,0 \%$.

Conforme ABNT NBR 13403, que trata de medições de vazões em escoamentos livres, os vertedores podem apresentar erros de até $3 \%$, desde que estejam corretamente instalados, bem operados e com boa manutenção.

Na medição dos NA's sobre a soleira do vertedor lateral também não foram observadas variações significativas, porém, devido à utilização da régua metálica e dos pequenos valores, a sua incerteza foi considerada como $\Delta \mathrm{H}=0,0005 \mathrm{~m}$. O erro considerado foi $\Delta \mathrm{H} / \mathrm{H}$, sendo $\mathrm{H}$ os níveis d'água sobre a soleira. As condições ensaiadas resultaram em um erro médio de aproximadamente 4,0\%.

Os erros do ensaio experimental serão considerados para determinar o erro admitido para a comparação com o modelo criado através da ferramenta de CFD, onde serão comparadas as vazões escoadas através do vertedor lateral com as vazões obtidas através da simulação. O erro admitido será considerado bom quando a comparação entre as vazões forem inferiores a $2 \%$, já que o erro somado das vazões ensaiadas ficou em torno $1,5 \%$ e mais os $4,0 \%$ obtido para os níveis d'água, que serão utilizados para alimentar o modelo matemático. Para os níveis d'água sobre a soleira lateral, a sua comparação será admitida razoável para erros inferiores a $6 \%$, com base na técnica de medição e seus erros apresentados. 
Tabela 5.2 - Níveis d’água sobre a soleira do vertedor lateral.

\begin{tabular}{|c|c|c|c|c|c|c|c|c|c|c|c|c|c|c|c|c|c|c|c|c|}
\hline & & & & & & & NA & lerte & or L & teral & $\mathrm{cm}]$ & & & & & & & & & \\
\hline $\begin{array}{c}\text { bordo de } \\
\text { montante da } \\
\text { soleira lateral }\end{array}$ & 5 & 10 & 15 & 20 & 25 & 30 & 35 & 40 & 45 & 50 & 55 & 60 & 65 & 70 & 75 & 80 & 85 & 90 & 95 & 100 \\
\hline Q1-C6 & 0,2 & 0,6 & 0,7 & 0,6 & 0,7 & 0,8 & 0,8 & 0,8 & 0,7 & 0,7 & 0,9 & 0,9 & 0,9 & 0,8 & 0,8 & 1,0 & 1,0 & 1,0 & 1,0 & 1,0 \\
\hline Q1-C8 & 1,4 & 2,0 & 2,1 & 2,1 & 2,1 & 2,3 & 2,3 & 2,5 & 2,5 & 2,6 & 2,6 & 2,6 & 2,4 & 2,4 & 2,5 & 2,5 & 2,7 & 2,7 & 2,8 & 3,5 \\
\hline Q1-C10 & 2,3 & 3,1 & 3,1 & 3,1 & 3,1 & 3,2 & 3,4 & 3,3 & 3,4 & 3,5 & 3,6 & 3,6 & 3,7 & 3,7 & 3,8 & 3,8 & 3,8 & 4,0 & 4,0 & 4,6 \\
\hline Q2-C6 & 0,7 & 0,7 & 0,9 & 1,0 & 1,0 & 1,2 & 1,1 & 1,2 & 1,2 & 1,3 & 1,3 & 1,4 & 1,3 & 1,4 & 1,4 & 1,5 & 1,6 & 1,5 & 1,6 & 2,0 \\
\hline Q2-C8 & 1,8 & 2,5 & 2,8 & 3,0 & 3,0 & 3,2 & 3,4 & 3,3 & 3,4 & 3,4 & 3,5 & 3,5 & 3,4 & 3,5 & 3,5 & 3,5 & 3,7 & 3,7 & 4,0 & 5,0 \\
\hline Q2-C10 & 2,0 & 2,8 & 3,4 & 3,8 & 3,6 & 3,6 & 3,7 & 3,9 & 3,7 & 3,8 & 3,8 & 3,9 & 4,0 & 4,0 & 4,0 & 4,0 & 4,3 & 4,4 & 4,5 & 5,5 \\
\hline Q3-C6 & 0,5 & 0,9 & 1,1 & 1,9 & 1,9 & 1,7 & 1,6 & 1,7 & 1,7 & 2,0 & 2,2 & 2,4 & 2,3 & 2,3 & 2,1 & 2,5 & 2,5 & 3,0 & 3,0 & 3,0 \\
\hline Q3-C8 & 2,0 & 2,5 & 3,0 & 3,3 & 3,4 & 3,4 & 3,0 & 3,4 & 3,6 & 4,0 & 3,5 & 4,0 & 3,8 & 4,0 & 4,5 & 4,0 & 4,0 & 4,2 & 4,3 & 5,0 \\
\hline Q3-C10 & 2,5 & 3,0 & 3,5 & 4,0 & 4,0 & 4,3 & 4,0 & 4,3 & 4,3 & 4,2 & 4,4 & 4,4 & 4,3 & 4,5 & 4,6 & 4,6 & 4,8 & 5,0 & 5,2 & 6,0 \\
\hline
\end{tabular}


Para determinação da vazão mássica utiliza-se a equação (5.1):

Qmas $=\rho \cdot Q$

Sendo:

Qmas a vazão mássica, em [kg/s];

$\rho$ a massa específica da água, para $20^{\circ} \mathrm{C}$ igual a $998,2\left[\mathrm{~kg} / \mathrm{m}^{3}\right]$;

$Q$ a vazão volumétrica, em $\left[\mathrm{m}^{3} / \mathrm{s}\right]$.

A estimativa da espessura da camada limite é obtida através da equação:

$\delta=\frac{5,48 \cdot L}{\sqrt{\operatorname{Re}_{L}}}$

Sendo:

$\delta$ a espessura da camada limite [m];

$\mathrm{Re}_{\llcorner}$o número de Reynolds para o comprimento de desenvolvimento;

L o comprimento de desenvolvimento do escoamento, em [m].

Fox e Mcdonald (1981) afirmam que, o comprimento de desenvolvimento do escoamento $(L)$ é uma referência, que pode ser baseada nas distâncias que os instrumentos de medida se posicionam à montante do dispositivo a ser ensaiado. Nesse trabalho foi admitido 1,5 vezes o diâmetro hidráulico da seção de montante do canal para o comprimento de desenvolvimento do escoamento.

Para representar um valor seguro da espessura da camada limite foi escolhida a equação (5.2), que é indicada para escoamentos laminares, onde o $\operatorname{Re}_{\mathrm{L}}$ é inferior a 500.000 , condição observada nos ensaios experimentais realizados da soleira lateral.

O material do canal retangular é concreto, segundo Porto (2004), esse material com acabamento normal apresenta a rugosidade absoluta equivalente $(\varepsilon)$ entre 0 intervalo de 1 a 3 milímetros. Como a espessura da camada limite $(\delta)$ calculada é 
maior do que a rugosidade absoluta do material do canal, o mesmo pode ser considerado hidraulicamente liso.

$\mathrm{Na}$ Tabela 5.3 são apresentados cálculos iniciais do ensaio que serão utilizados para análise e construção do modelo de CFD.

Tabela 5.3 - Cálculos iniciais do ensaio experimental.

\begin{tabular}{cccccccc}
\hline Ensaios & $\begin{array}{c}\mathbf{y} \\
\text { Montante } \\
{[\mathrm{m}]}\end{array}$ & $\begin{array}{c}\text { Vazão } \\
\text { Mássica } \\
{[\mathbf{k g} / \mathbf{s}]}\end{array}$ & $\begin{array}{c}\text { Área } \\
{\left[\mathbf{m}^{2}\right]}\end{array}$ & $\begin{array}{c}\text { Velocidade } \\
{[\mathrm{m} / \mathbf{s}]}\end{array}$ & Froude $_{\mathbf{M}}$ & Reynolds $_{\mathbf{M}}$ & $\delta$ [mm $]$ \\
\hline Q1-C6 & 0,135 & 32,58 & 0,054 & 0,604 & 0,53 & 193514 & 6,0 \\
Q1-C8 & 0,145 & 32,33 & 0,058 & 0,558 & 0,47 & 186466 & 6,4 \\
Q1-C10 & 0,140 & 32,63 & 0,056 & 0,584 & 0,50 & 190940 & 6,2 \\
Q2-C6 & 0,135 & 38,69 & 0,054 & 0,718 & 0,62 & 229822 & 5,5 \\
Q2-C8 & 0,155 & 38,19 & 0,062 & 0,617 & 0,50 & 214024 & 6,2 \\
Q2-C10 & 0,163 & 38,59 & 0,065 & 0,595 & 0,47 & 211834 & 6,4 \\
Q3-C6 & 0,145 & 48,07 & 0,058 & 0,830 & 0,70 & 277205 & 5,2 \\
Q3-C8 & 0,165 & 48,55 & 0,066 & 0,737 & 0,58 & 264651 & 5,8 \\
Q3-C10 & 0,170 & 48,37 & 0,068 & 0,713 & 0,55 & 260091 & 5,9 \\
\hline
\end{tabular}




\subsection{MODELAGEM MATEMÁTICA DO PROBLEMA}

O presente trabalho propõe a validação do modelo do vertedor lateral criado com o programa ANSYS CFX v. 12.0. Serão estudados três tipos de malhas e três modelos de turbulência, e será analisada a precisão dos resultados da vazão volumétrica vertida na simulação com o experimento, esse será o parâmetro de validação. Posteriormente serão comparados os níveis d'água sobre a soleira do vertedor lateral para visualização do comportamento do escoamento modelado.

Serão utilizados quatro módulos do programa ANSYS CFX v. 12.0 para a realização do estudo proposto:

- ANSYS ICEM CFD - Criação da geometria e da malha;

- CFX-Pre 12.0 - Condições de cálculo (Domínio, condições de contorno, dados iniciais para a simulação, etc.);

- CFX-Solver 12.0 - Execução do cálculo;

- CFX-Post 12.0 - Determinação e visualização tridimensional do escoamento.

Nas Figuras 5.12 e 5.13 são apresentados em vermelho os domínios do modelo matemático proposto. Nos próximos itens, mostra-se em detalhes a modelagem do vertedor lateral utilizando o programa ANSYS CFX v. 12.0, desde a criação da geometria até a visualização dos resultados. 


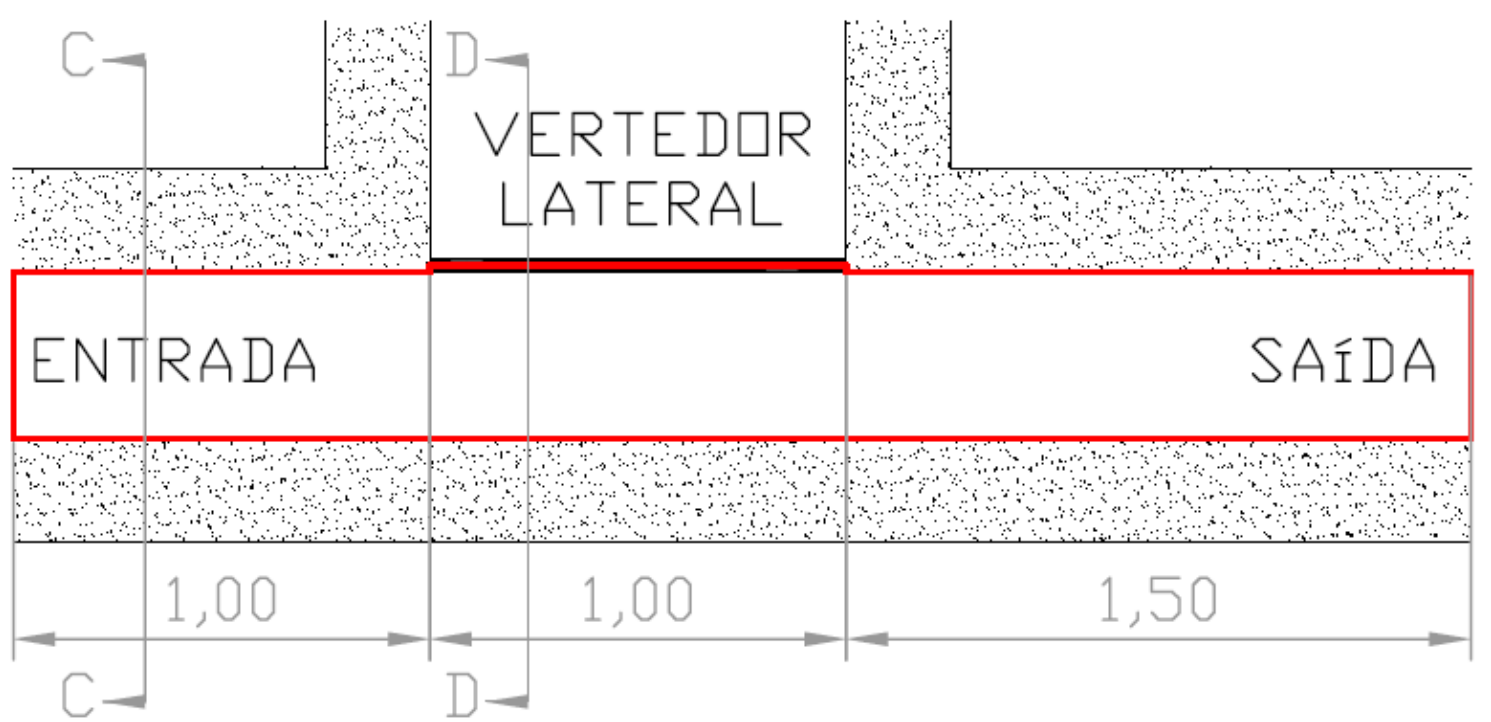

Figura 5.12 - Vista em planta do domínio do modelo.

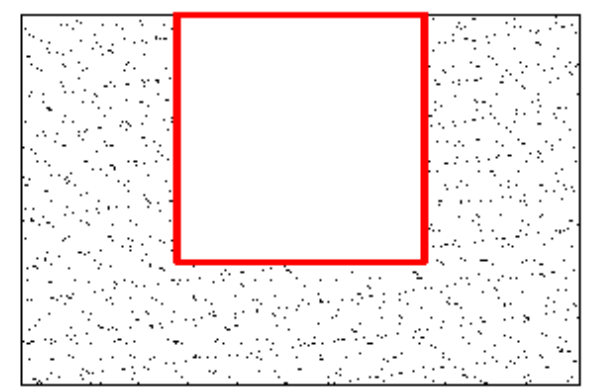

Corte CC

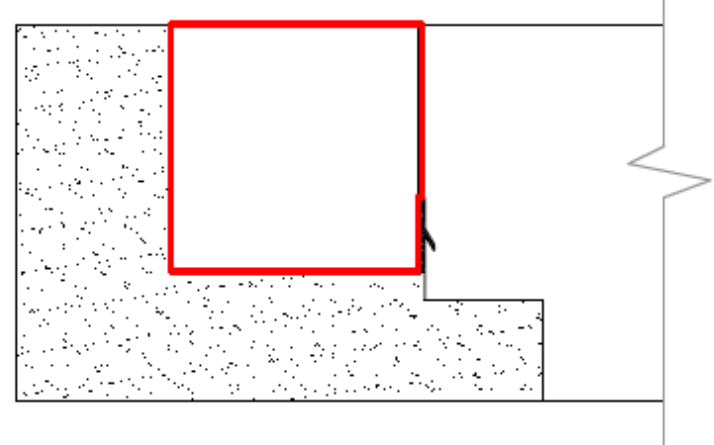

Corte DD

Figura 5.13 - Detalhes do domínio do modelo.

A modelagem do trabalho está representada no fluxograma (Figura 5.14). 
Simulação Fluido

Dinâmica Computacional<smiles>C1=CCCC1</smiles>

Pré - Processamento

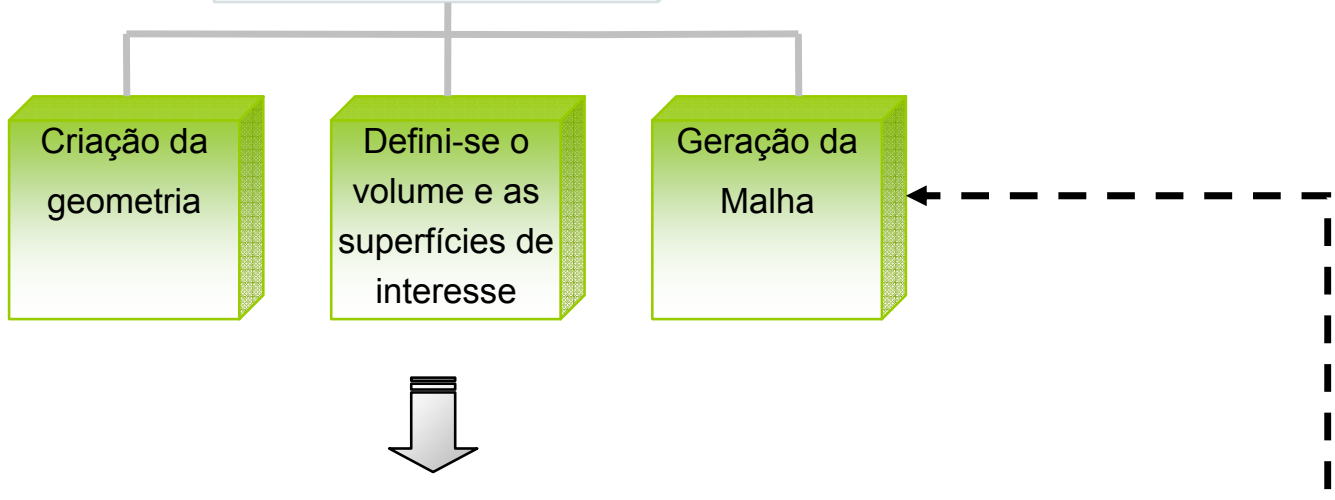

Processamento

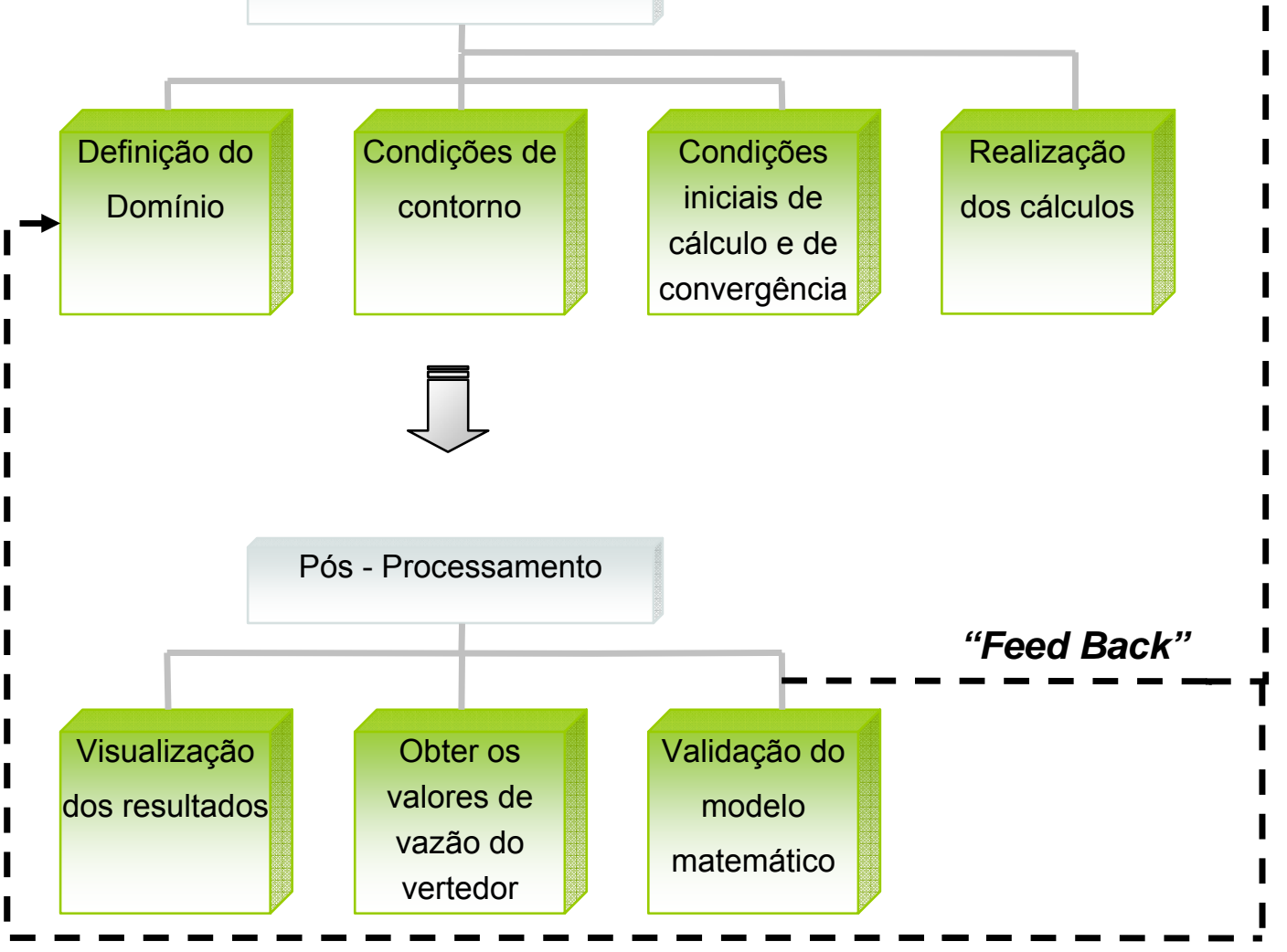

Figura 5.14 - Esquema básico para a modelagem do problema. 


\subsubsection{Pré-Processamento}

No ANSYS ICEM CFD, na opção "Geometry" cria-se a geometria da região de estudo a partir de um conjunto de pontos, que estão representados na Tabela 5.4, com as medidas em milímetros:

Tabela 5.4 - Pontos em coordenadas da geometria do vertedor lateral.

\begin{tabular}{|c|c|c|c|}
\hline Ponto & $x$ & $\bar{Y}$ & $\mathbf{Z}$ \\
\hline 1 & 0 & 20 & 0 \\
\hline 2 & 0 & 420 & 0 \\
\hline 3 & 400 & 420 & 0 \\
\hline 4 & 400 & 20 & 0 \\
\hline 5 & 0 & 17,5 & 500 \\
\hline 6 & 0 & 417,5 & 500 \\
\hline 7 & 400 & 417,5 & 500 \\
\hline 8 & 400 & 17,5 & 500 \\
\hline 9 & 0 & 15 & 1000 \\
\hline 10 & 0 & 415 & 1000 \\
\hline 11 & 400 & 415 & 1000 \\
\hline 12 & 400 & 138,5 & 1000 \\
\hline 13 & 400 & 15 & 1000 \\
\hline 14 & 0 & 10 & 2000 \\
\hline 15 & 0 & 410 & 2000 \\
\hline 16 & 400 & 410 & 2000 \\
\hline 17 & 400 & 137,5 & 2000 \\
\hline 18 & 400 & 10 & 2000 \\
\hline 19 & 0 & 7,5 & 2500 \\
\hline 20 & 0 & 407,5 & 2500 \\
\hline 21 & 400 & 407,5 & 2500 \\
\hline 22 & 400 & 7,5 & 2500 \\
\hline 23 & 0 & 2,5 & 3500 \\
\hline 24 & 0 & 402,5 & 3500 \\
\hline 25 & 400 & 402,5 & 3500 \\
\hline 26 & 400 & 2,5 & 3500 \\
\hline 27 & 405 & 415 & 1000 \\
\hline 28 & 405 & 138,5 & 1000 \\
\hline 29 & 405 & 410 & 2000 \\
\hline 30 & 405 & 137,5 & 2000 \\
\hline
\end{tabular}


Os pontos criados são unidos com curvas e podem ser visualizados na Figura 5.15. O modelo é construído de montante para jusante ao longo do eixo $Z$, usando a tolerância de 1 milímetro, a qual evita o aparecimento de "gaps", que são deficiências da geometria que impendem a geração da malha. A superfície é criada partir de duas ou quatro curvas, posteriormente gera-se o sólido com base em dois pontos internos da geometria. A Figura 5.16 mostra uma visão geral do vertedor lateral e a Figura 5.17 o detalhe da soleira.

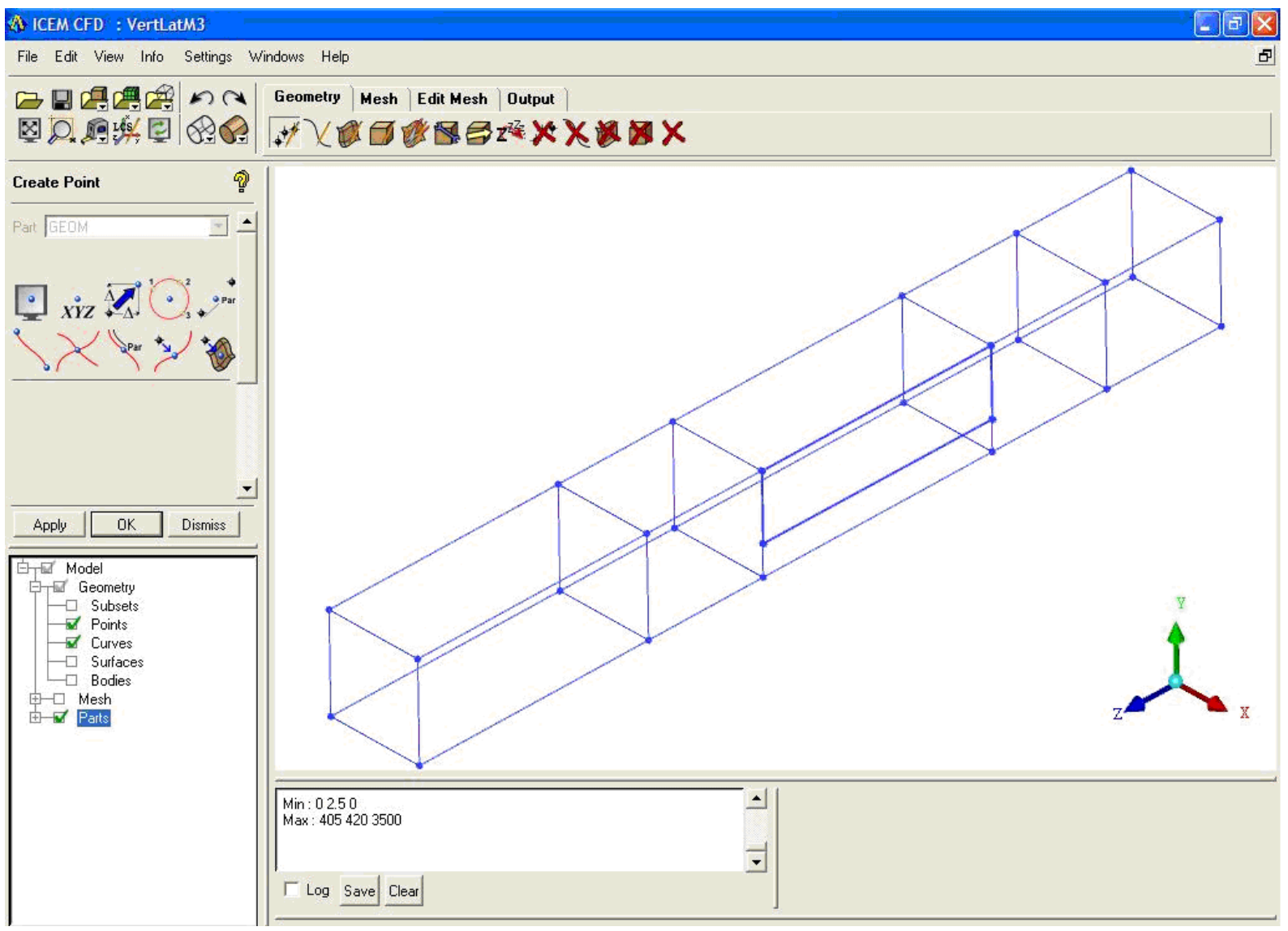

Figura 5.15 - Pontos e curvas da geometria do vertedor lateral.

A partir do sólido gerado, criam-se as definições das superfícies da geometria, no item "Parts". As definições são principalmente: Entrada, Saída, Saída Vertedor Lateral, Parede, Fundo e Topo (Figura 5.18), com algumas subdivisões, montante, jusante e região do vertedor lateral. Essas subdivisões serão utilizadas para um maior refinamento da malha na região próxima a soleira do vertedor. 
As definições das superfícies são importantes, porque são utilizadas como referência para a próxima etapa da modelagem, onde são estabelecidas as condições de contorno do problema em estudo.

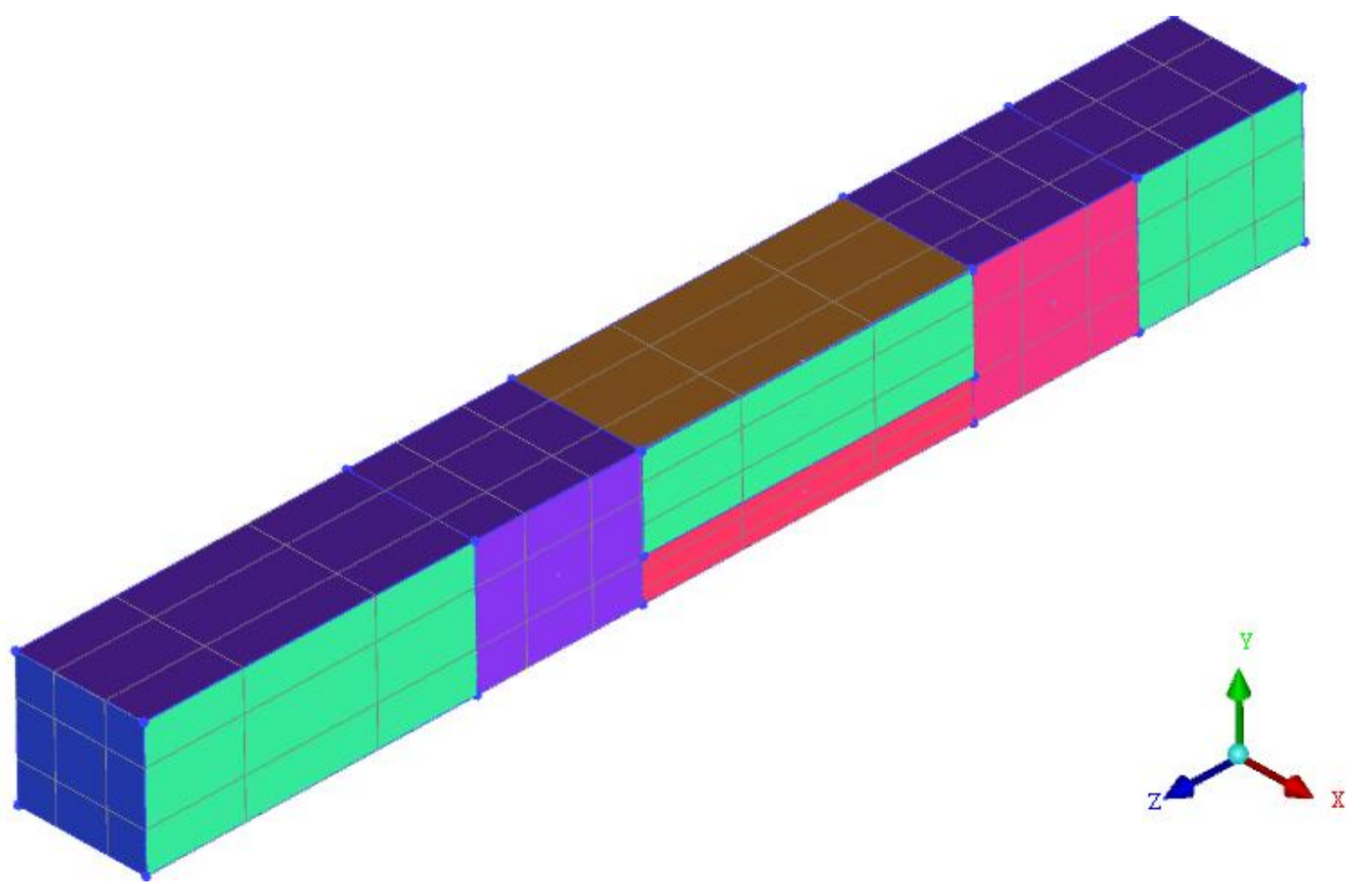

Figura 5.16 - Visão geral do vertedor lateral, visualizado no modo "Solid/ Wireflame".

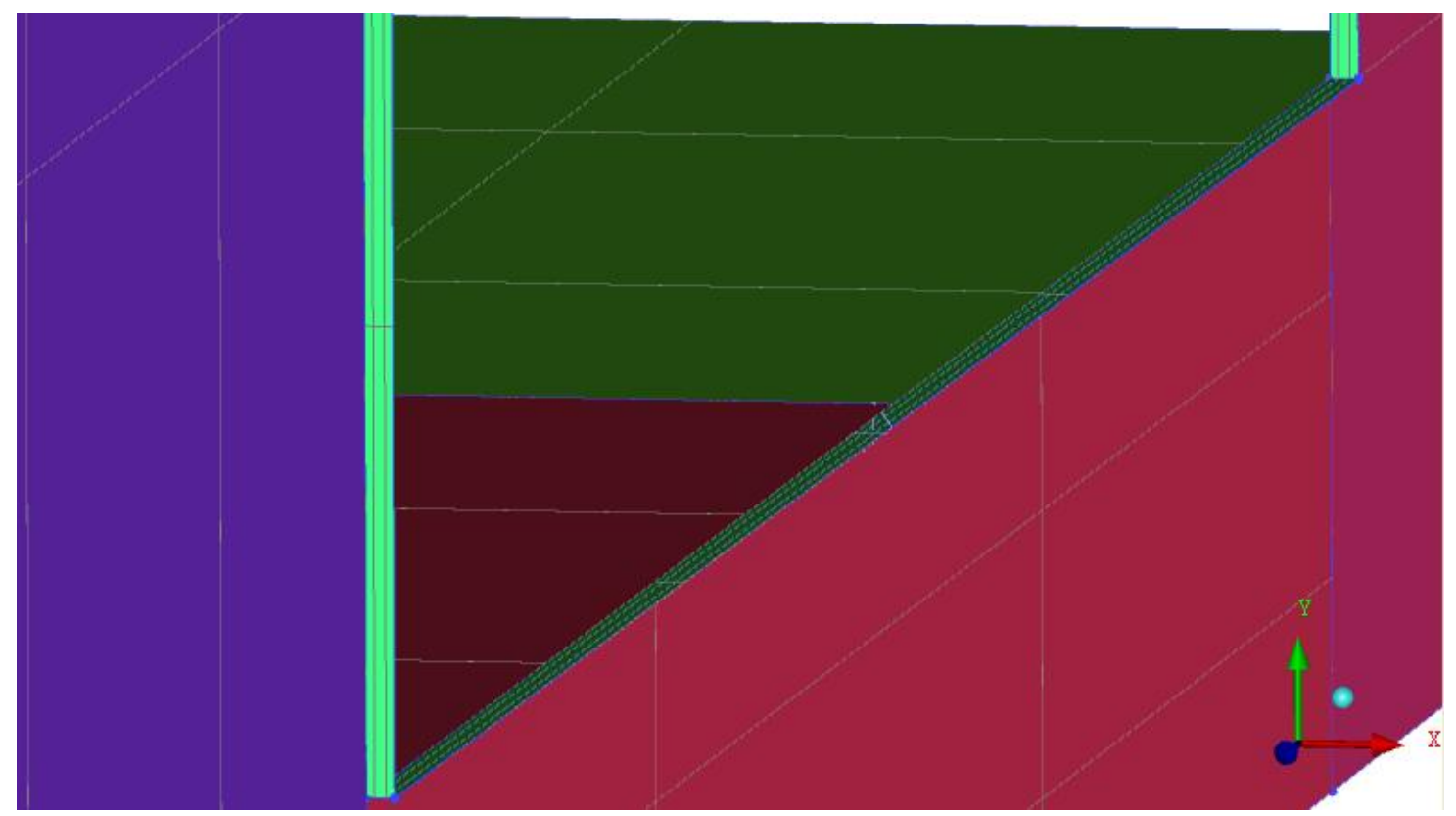

Figura 5.17 - Detalhe da soleira do vertedor lateral, visualizado no modo "Solid/ Wireflame". 


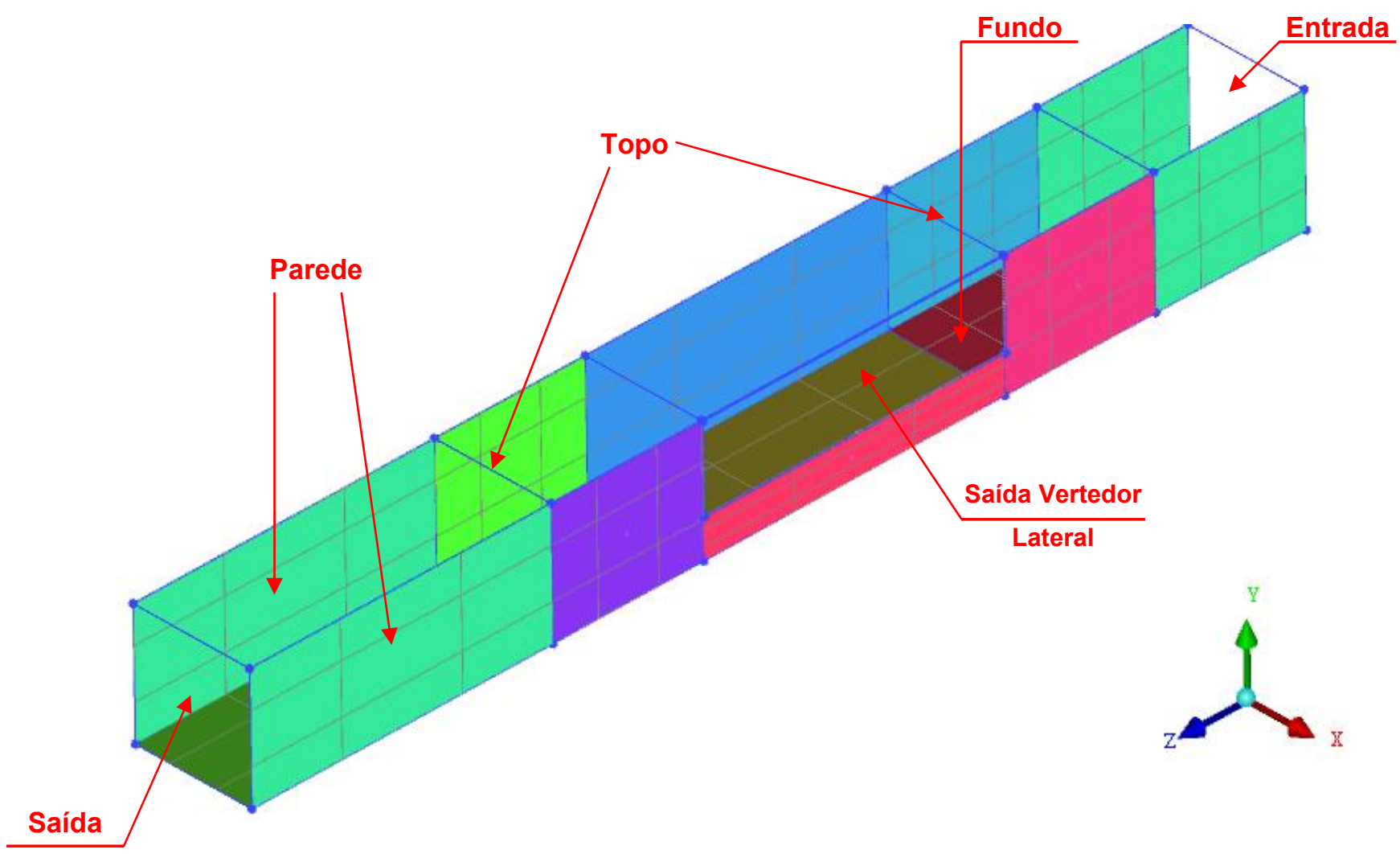

Figura 5.18 - Definições da superfície do vertedor lateral.

A seguir, gera-se a malha (Figura 5.19) a partir do sólido. A malha predominante utilizada é do tipo hexaédrica, estruturada, com elementos prismáticos nas proximidades de todas as paredes e fundo, para representar a camada limite.

Inicialmente realiza-se a setagem padrão do tamanho dos elementos da malha, quanto mais refinada a malha, geralmente, melhores serão os resultados, porém, maior será o custo computacional. Por esse motivo, deve-se encontrar o nível de refinamento que ofereça dados confiáveis com um tempo de simulação computacional coerente.

Como a região próxima a soleira é o objeto de estudo desse trabalho, essa região será mais refinada, verificando assim, o comportamento do escoamento com uma maior precisão.

Para o presente trabalho a camada limite está dividida em 3 camadas, sendo criada nas paredes internas e no fundo do modelo. Depois de criada a malha, exporta-a para o CFX-Pre. 


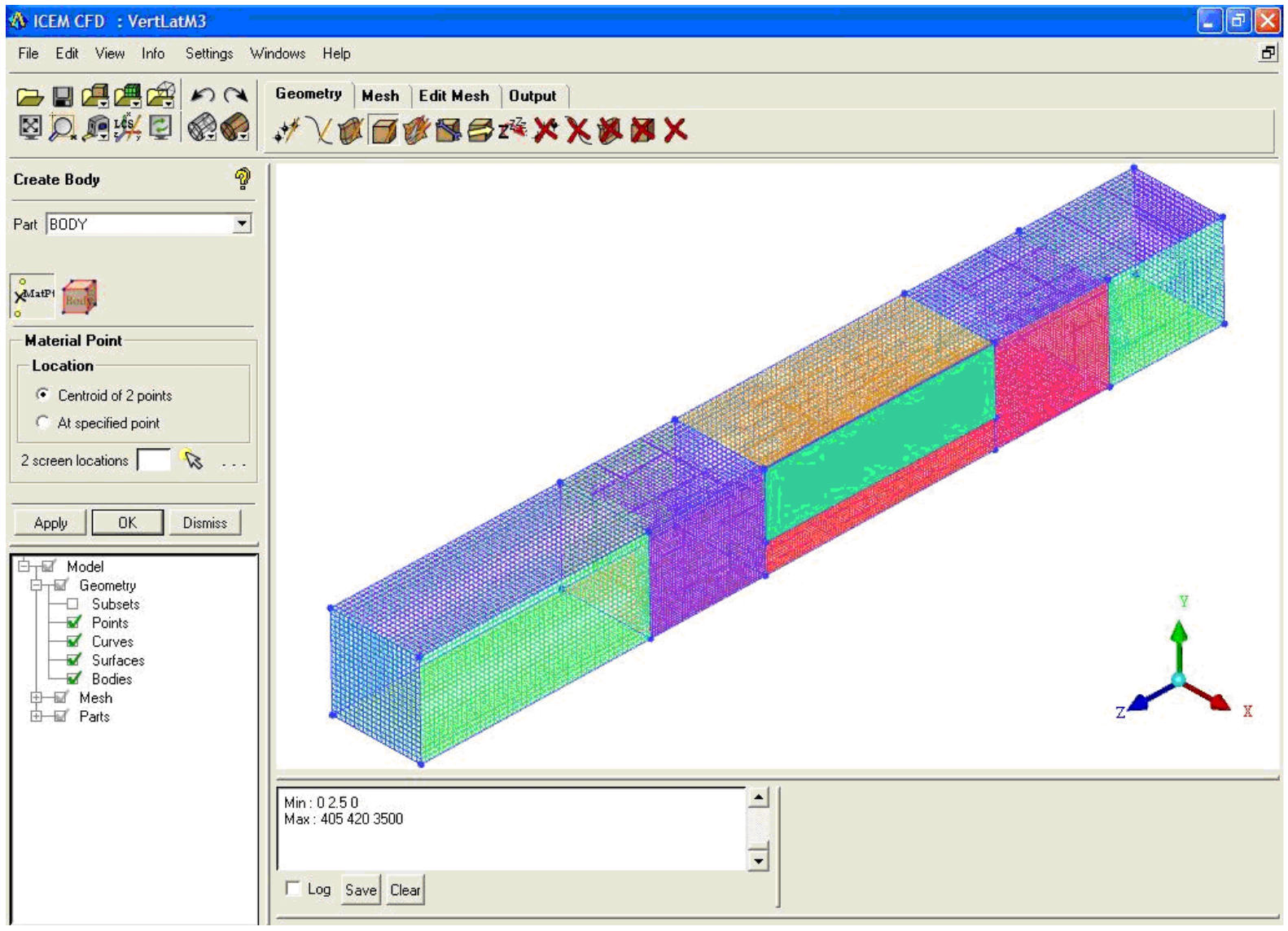

Figura 5.19 - Malha típica do vertedor lateral, formada por elementos hexaédricos.

\subsubsection{Processamento}

A primeira parte do processamento é realizada no CFX-Pre, onde são definidas as condições de cálculo. Para condição do experimento, o regime do escoamento é permanente.

O domínio é definido como VertLatM (Figura 5.20), sendo estático, os fluidos de trabalho são água e ar, a pressão de referência é 1 atm, as temperaturas ambiente e do fluido são aproximadamente $20^{\circ} \mathrm{C}$, a densidade do ar considerada é $1,204 \mathrm{~kg} / \mathrm{m}^{3}$, o fluido foi considerado isotérmico e os modelos de turbulência

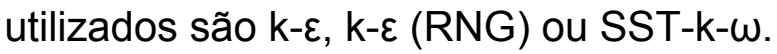

Para as propriedades do sistema água/ ar, deve-se especificar as condições de multi-fase, utilizou-se o modelo homogêneo, que busca manter a menor taxa de transferência entre as frações volumétricas e assim preservar a definição da interface. Esse modelo é indicado para escoamentos que possuem uma interface bem definida, como o escoamento de um canal de superfície livre. 


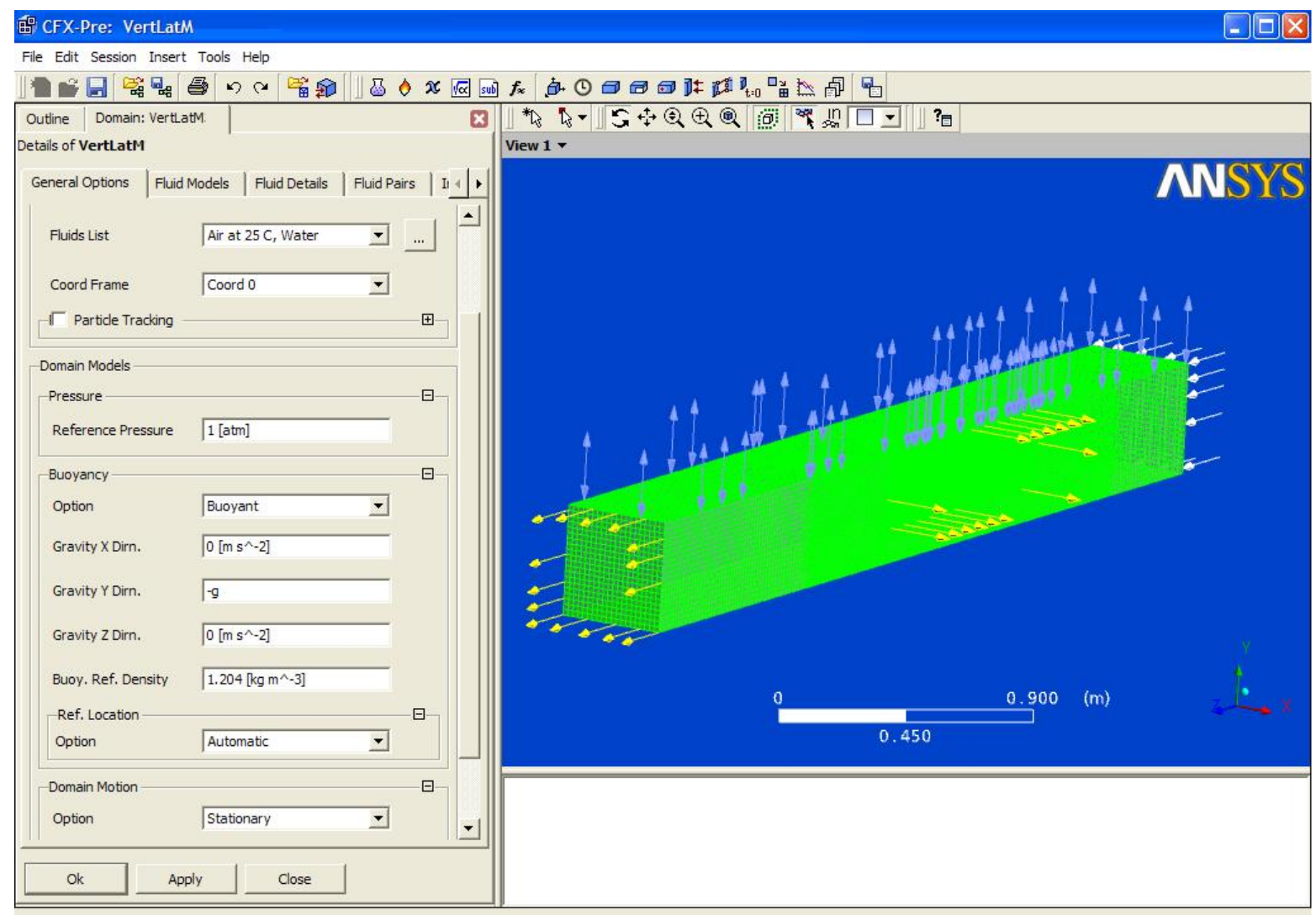

Figura 5.20 - Definições do domínio.

A simulação do escoamento de superfície livre, geralmente, requer definições apropriadas das condições iniciais de cálculo e de contorno, no caso da pressão e da fração volumétrica de cada fluido. Para isso, é necessário criar expressões usando a ferramenta CEL (CFX Expression Language) para definir essas condições.

Para determinar como o domínio é ocupado por cada fluido, altura e disposição da interface, utilizou-se expressões adimensionais que permitem calcular a fração volumétrica (Expressão 5.3 e 5.4), onde a função STEP é uma função interna do CEL, cujo traçado assemelha-se a uma função escada. Quando a fração volumétrica está acima da superfície livre a função STEP é unitária para o ar e nula para a água, e quando está abaixo é nula para o ar e unitária para a água.

$\operatorname{VFAr}=\operatorname{step}\left(\frac{(y-N A)}{1[m]}\right)$ 
VFAgua $=1-V F A r$

Sendo:

VFAr a fração volumétrica do ar;

VFAgua a fração volumétrica da água;

y a variável altura;

NA o nível d'água do escoamento.

Para representar a pressão hidrostática no escoamento livre do domínio, utilizou-se a Expressão (5.5):

Pres $=$ DenAgua $\cdot g \cdot$ VFAgua $\cdot(N A-y)$

Sendo:

Pr es a pressão hidrostática;

DenAgua a densidade da água, para $20^{\circ} \mathrm{C}$ igual a $998,2\left[\mathrm{~kg} / \mathrm{m}^{3}\right]$;

g a aceleração da gravidade;

VFAgua a fração volumétrica da água;

y a variável altura;

NA o nível d'água do escoamento.

As condições de contorno foram definidas para as regiões de Entrada, Saída, Saída Vertedor Lateral, Parede, Fundo e Topo, sendo apresentadas a seguir:

a) Entrada: definida como INLET, onde o fluido escoa somente para dentro do domínio. Inseriu-se a vazão mássica total do canal $\left(\mathrm{Q}_{\mathrm{MT}}\right)$ e o nível d'água de montante (NAMont), Tabela 5.5, para representar a fração volumétrica do ar 
e da água, inseriu-se a expressão 5.3 e 5.4, respectivamente, para o NAMont.

b) Saída: definida como OUTLET, onde o fluido escoa somente para fora do domínio. Inseriu-se como condição de contorno para a pressão relativa a expressão 5.5 para o nível d’água de jusante (NAJus).

c) Saída Vertedor Lateral: definida como OUTLET. Inseriu-se como condição de contorno a pressão relativa igual a zero, representando a "queda livre" do escoamento após passar pela soleira.

d) Parede: definida como WALL, onde representa impermeável para o escoamento. Definiu-se a parede como lisa e não ocorre escorregamento.

e) Fundo: definida como WALL. Definiu-se o fundo como liso e não ocorre escorregamento.

f) Topo: definida como OPENING (aberto), onde o fluido pode escoar para fora ou para dentro do domínio, simultaneamente, dependendo das condições do escoamento. Inseriu-se como condição de contorno a pressão estática (Entrain) igual a zero, turbulência gradiente zero e a fração volumétrica unitária para o ar e nula para a água.

Tabela 5.5 - Valores utilizados nas condições de contorno.

\begin{tabular}{ccccc}
\hline Ensaios & $\begin{array}{c}\text { NAMont } \\
{[\mathrm{m}]}\end{array}$ & $\begin{array}{c}\text { NAJus } \\
{[\mathbf{m}]}\end{array}$ & $\begin{array}{c}\mathbf{Q}_{\mathbf{M T}} \\
{[\mathbf{k g} / \mathbf{s}]}\end{array}$ & $\begin{array}{c}\text { Velocidade } \\
{[\mathbf{m} / \mathbf{s}]}\end{array}$ \\
\hline Q1-C6 & 0,129 & 0,139 & 32,58 & 0,633 \\
Q1-C8 & 0,143 & 0,160 & 32,33 & 0,566 \\
Q1-C10 & 0,146 & 0,163 & 32,63 & 0,560 \\
Q2-C6 & 0,130 & 0,152 & 38,69 & 0,745 \\
Q2-C8 & 0,155 & 0,175 & 38,19 & 0,617 \\
Q2-C10 & 0,157 & 0,179 & 38,59 & 0,618 \\
Q3-C6 & 0,140 & 0,166 & 48,07 & 0,860 \\
Q3-C8 & 0,165 & 0,185 & 48,55 & 0,737 \\
Q3-C10 & 0,175 & 0,192 & 48,37 & 0,692 \\
\hline
\end{tabular}


No CFX-Pre também se definem as condições iniciais para o cálculo e as condições de convergência:

- Condições iniciais: Inseriu-se para a condição inicial de montante a velocidade do escoamento no eixo $Z$, para a pressão relativa utilizou-se a expressão 5.5 para o NAMont, que representa a pressão hidrostática, e para a fração volumétrica do ar e da água, utilizou-se a expressão 5.3 e 5.4, respectivamente, para o NAMont.

- Condições de convergência: o cálculo do ANSYS CFX é um processo iterativo, a convergência dos cálculos é quantificada através de um erro (Erro Médio Quadrático), sendo calculada sobre as projeções da velocidade do escoamento no sistema de coordenada cartesiano, vazão mássica, turbulência, energia dissipada pela turbulência e fração volumétrica da água. O valor objetivo de convergência desse trabalho é $10^{-4}$. Admitiu-se o número máximo de 700 iterações no cálculo. Quando uma das duas condições é atendida, o cálculo é finalizado.

$\mathrm{Na}$ segunda parte do processamento, representado pelo CFX-Solver, é realizada a resolução da simulação. O cálculo foi realizado por um computador com um processador INTEL Pentium 4 HT 3,2 Ghz e 1,5 GBytes de memória RAM. O processo numérico da simulação é apresentado durante o cálculo, sendo possível acompanhar a convergência e o relatório dos resultados, conforme é exemplificado pela Figura 5.21. 


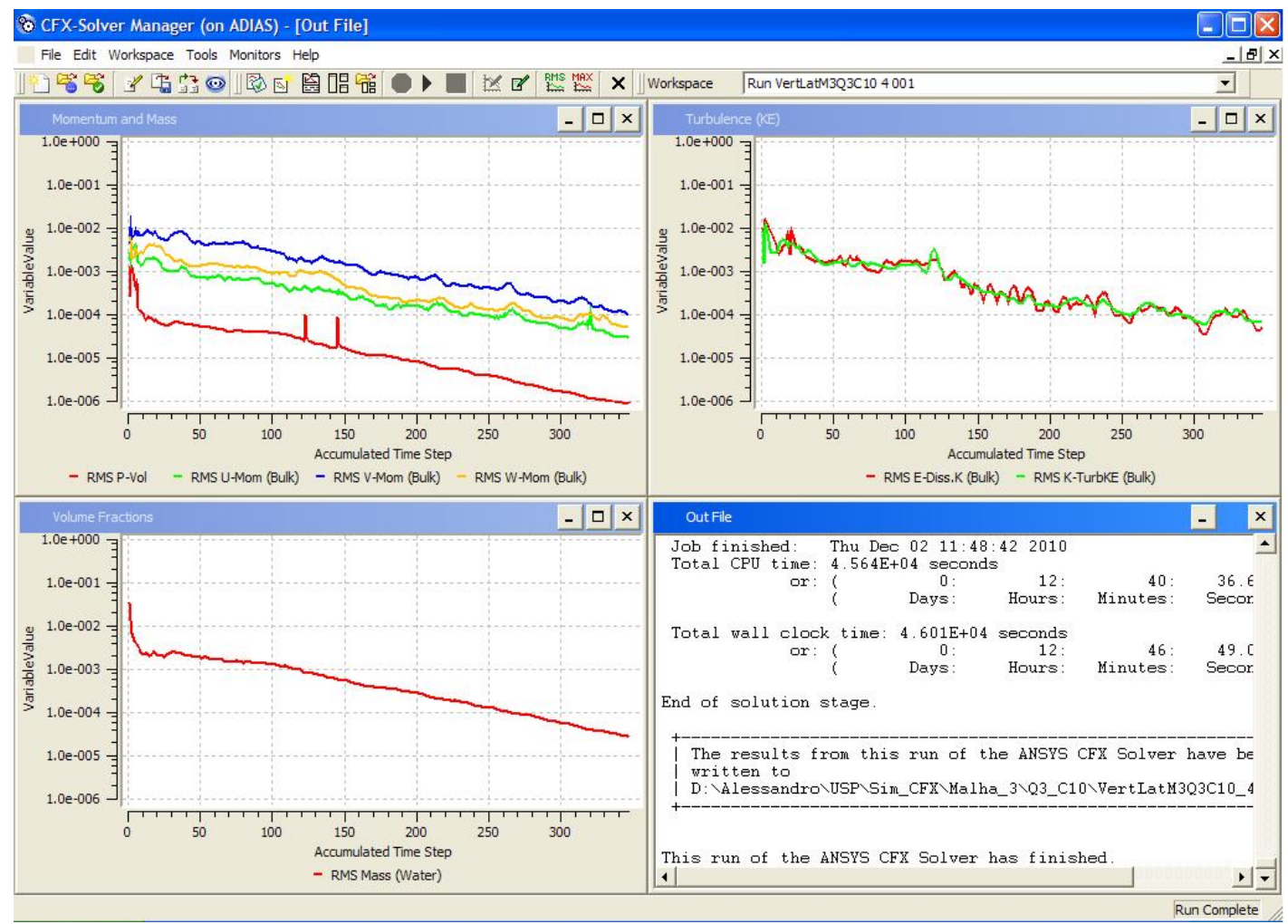

Figura 5.21 - CFX-Solver após a execução dos cálculos.

\subsubsection{Pós-Processamento}

Após o término dos cálculos, quando alcançada a convergência da simulação ou o número máximo de iterações, utilizou-se o CFX-Post para visualização e aquisição dos resultados. Com essa ferramenta, pode-se criar pontos, retas, vetores de velocidades, planos, iso-superfícies e volumes de referência longitudinais e transversalmente ao sentido do escoamento, que facilitam a análise tridimensional dentro do domínio. Além disso, existe a possibilidade de criar gráficos com as diversas variáveis estudadas na região de interesse.

Para a validação dos resultados, utilizou-se a função "massFlow" na Saída do Vertedor Lateral para o fluido água, que fornece a vazão mássica calculada pelo modelo matemático. Obtida a vazão mássica do modelo, transforma-a em vazão volumétrica e posteriormente compara-a com a vazão volumétrica do ensaio experimental.

Posteriormente em relação à validação da vazão volumétrica, comparou-se os níveis d'água sobre a soleira do vertedor lateral para visualização do comportamento 
do escoamento modelado. Para isso, criou-se uma iso-superfície que permite mostrar a interface água/ ar, utilizando a variável da fração volumétrica da água. Também foi criada uma superfície no plano YZ na Saída do Vertedor Lateral, na posição $X$ igual a 402 milímetros, e utilizou-se a mesma variável da iso-superfície, que facilitou a visualização da interface. A partir disso, criaram-se pontos (pretos) com o mesmo espaçamento do ensaio experimental na interface água/ ar, e com isso, obteve-se os níveis d'água sobre a soleira (Figura 5.22).

Após o processo de validação, pode-se visualizar e obter parâmetros importantes dentro do domínio, que facilitam a análise hidráulica do dispositivo em estudo.

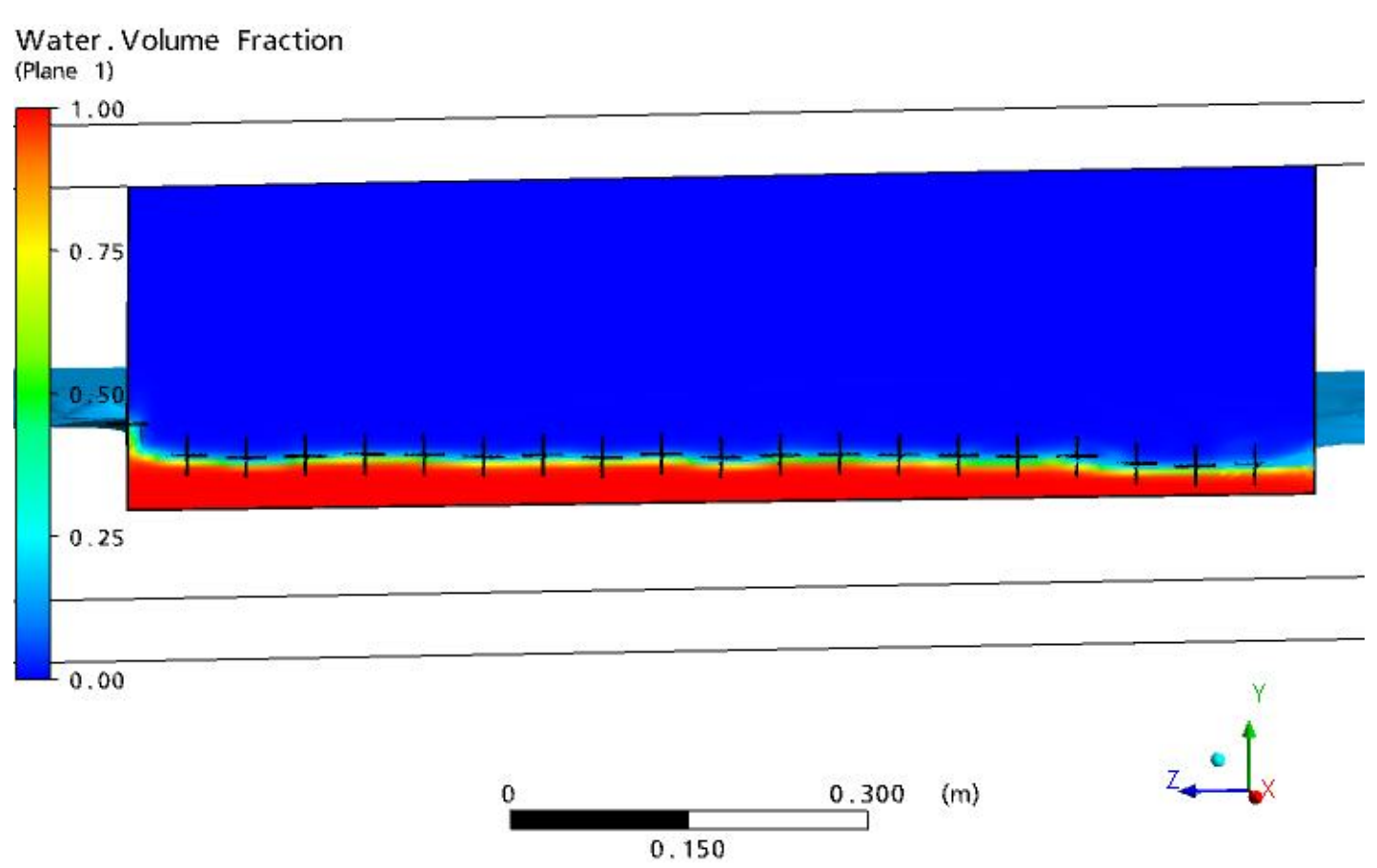

Figura 5.22 - Obtenção dos níveis d'água sobre a soleira no CFX-Post. 


\section{RESULTADOS E DISCUSSÕES}

Os resultados e discussões apresentam as validações da malha e do modelo de turbulência, o comportamento do escoamento e a comparação do modelo do vertedor lateral com equações experimentais do coeficiente de descarga $\left(C_{d}\right)$.

\subsection{VALIDAÇÃO}

A validação da malha e do modelo de turbulência foi realizada para três das noves condições ensaiadas (Q1-C8, Q2-C8 e Q3-C8), sendo uma para cada vazão volumétrica do canal principal, abrangendo as três situações possíveis, e na condição média do ensaio, que é a comporta com altura de $8 \mathrm{~cm}$.

\subsubsection{Malha}

Para a validação da malha será utilizado o modelo de turbulência $k-\varepsilon$ (RNG), o qual foi proposto inicialmente para o desenvolvimento desse trabalho. A malha que apresentar a maior precisão será utilizada para a validação do modelo de turbulência.

\section{a) Malha 1}

A malha 1 (Figura 6.1) apresenta um refinamento com 6370 nós e 6194 elementos (hexaédricos (predominante), tetraédricos, prismáticos e piramidais), e o comprimento do maior lado do elemento na malha de volume igual a 50 milímetros. O tempo médio de simulação para o intervalo estudado foi de 15 minutos com um número aproximado de 300 iterações, onde foi alcançada a convergência de $1 \times 10^{-4}$. Caso a simulação não alcance a convergência estipulada e dependendo do aspecto da sua curva, pode-se aumentar o número de iterações e o refinamento da malha. Neste caso, a qualificação da malha não está somente em obter o menor erro possível, mas conseguir este objetivo em 
um tempo de cálculo satisfatório. No presente trabalho, optou-se por realizar 700 iterações devido às características da geometria e condições do escoamento.

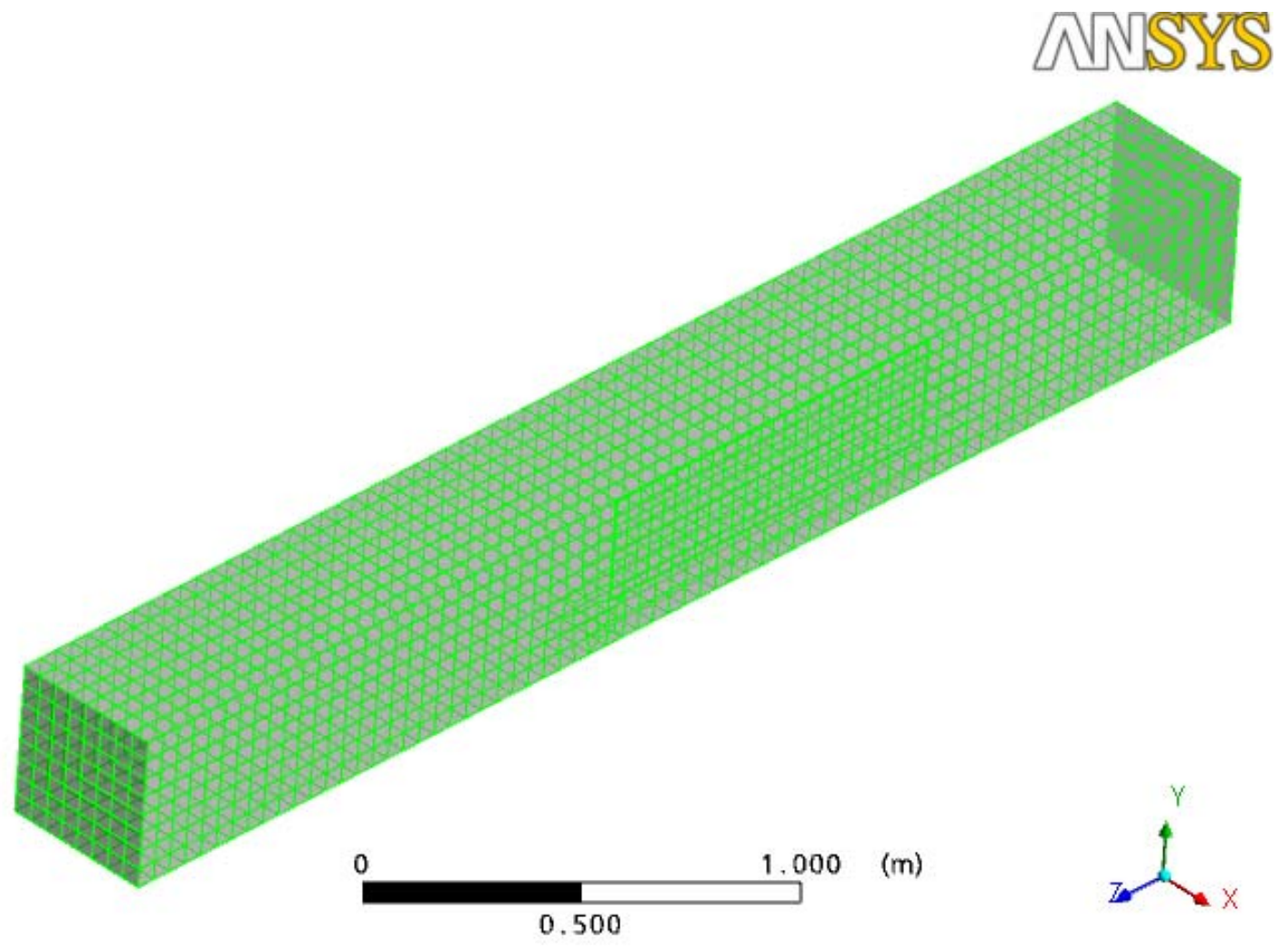

Figura 6.1 - Vista isométrica da malha 1.

Na Figura 6.2 apresenta-se a comparação entre os resultados da vazão volumétrica obtida através da simulação computacional com os resultados do ensaio experimental. O gráfico apresenta no eixo das abscissas a vazão total $\left(Q_{T}\right)$ escoada pelo canal principal e no eixo das ordenadas a vazão escoada pelo vertedor lateral $\left(\mathrm{Q}_{\mathrm{VL}}\right)$. Admitiu-se nesse trabalho como bons resultados da simulação erros inferiores a $2 \%$ para a vazão do vertedor lateral e satisfatório quando são inferiores a $6 \%$ para o nível d'água sobre a soleira, com base nos erros do modelo físico e erros inerentes ao modelo matemático. Para determinar o erro será utilizada a equação 6.1 .

$$
\text { Erro }=\frac{\mid \text { Knum }-K \exp \mid}{\text { Knum }} \cdot 100
$$


Sendo:

Erro o erro entre a simulação computacional e o ensaio experimental, em [\%];

Knum o valor obtido através da simulação;

Kexp o valor obtido através do ensaio experimental.

Esta forma de obtenção de erro é genérica. Para uma grande quantidade de dados pode-se utilizar a teoria estatística. Contudo, optou-se por esta forma de cálculo, uma vez que o número de amostras foi considerado pequeno.

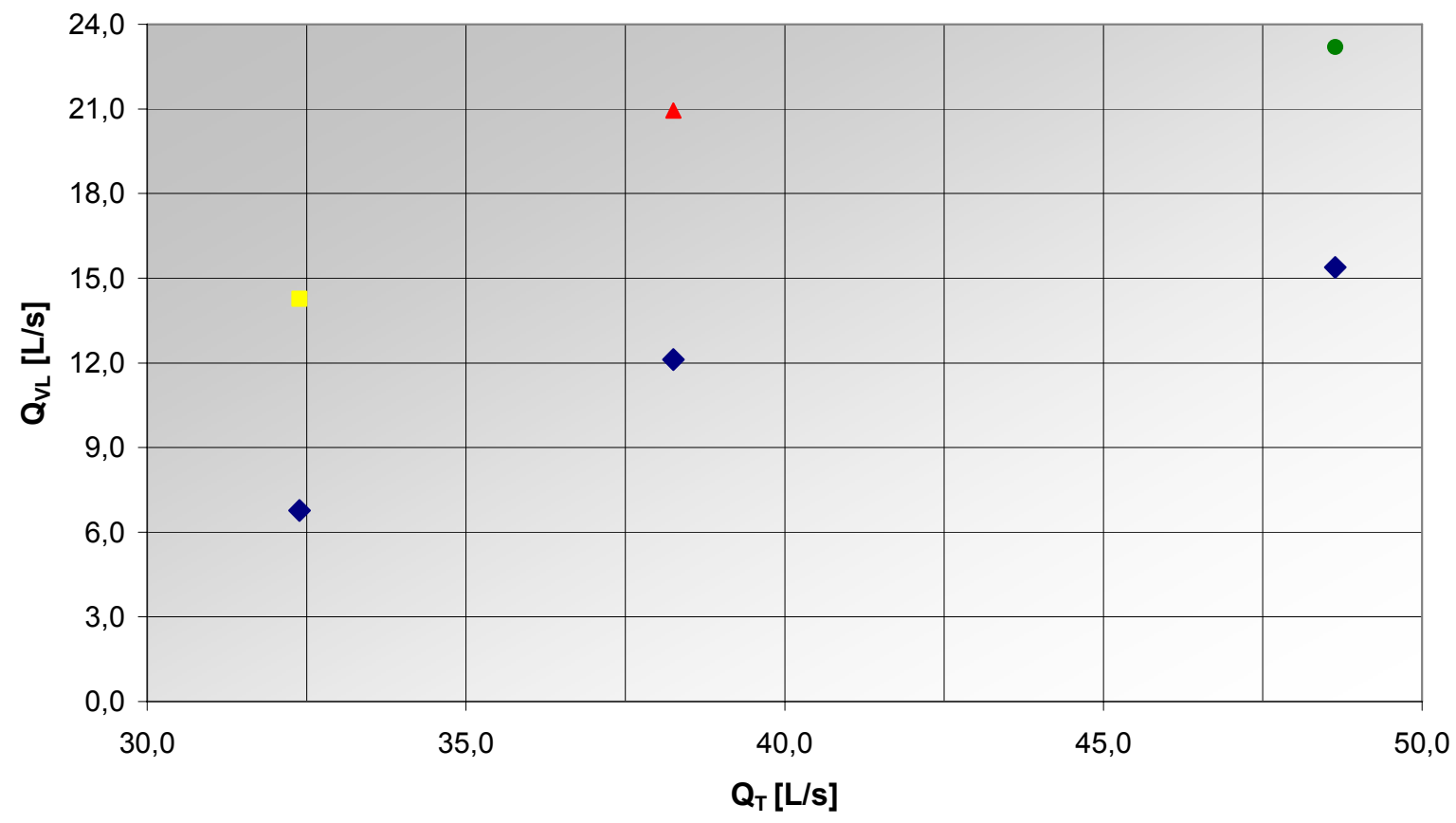

$\bullet$ Ensaio $\triangle$ Q1-C8 $\triangle$ Q2-C8 $\bullet$ Q3-C8

Figura 6.2 - Comparação da simulação para a malha 1.

Na Figura 6.2, nota-se que os resultados da simulação apresentaram valores distantes do ensaio experimental, com erros acima de $33 \%$, alcançado para a condição Q1-C8 um erro de aproximadamente 53\%. Esses valores estão bem acima do esperado nesse trabalho. 


\section{b) Malha 2}

A malha 2 (Figura 6.3) apresenta um refinamento com 29420 nós e 27456 elementos (hexaédricos (predominante), tetraédricos, prismáticos e piramidais), e o comprimento do maior lado do elemento na malha de volume igual a 30 milímetros. O tempo médio de simulação para o intervalo estudado foi de 1,2 horas com um número aproximado de 450 iterações, onde foi alcançada a convergência de $1 \times 10^{-4}$.

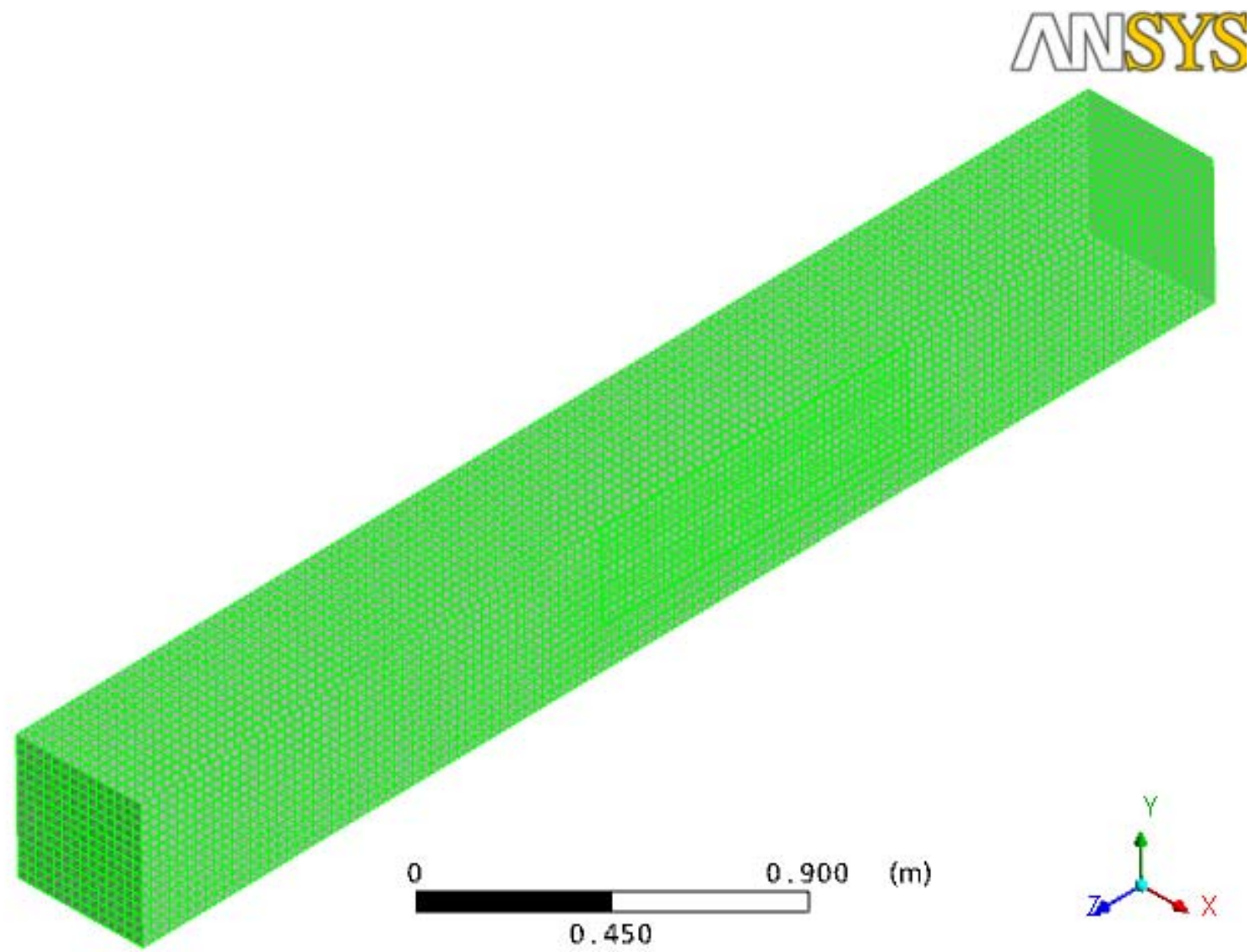

Figura 6.3 - Vista isométrica da malha 2.

Essa malha também não apresentou bons resultados (Figura 6.4), entretanto, é visível a melhora dos resultados quando comparadas as Figuras 6.2 e 6.4. Os erros reduziram, mas ficaram entre 14\% e 19\%. Novamente a condição Q1-C8 apresentou o maior erro. Os valores dos resultados da simulação ainda estão acima do esperado. 


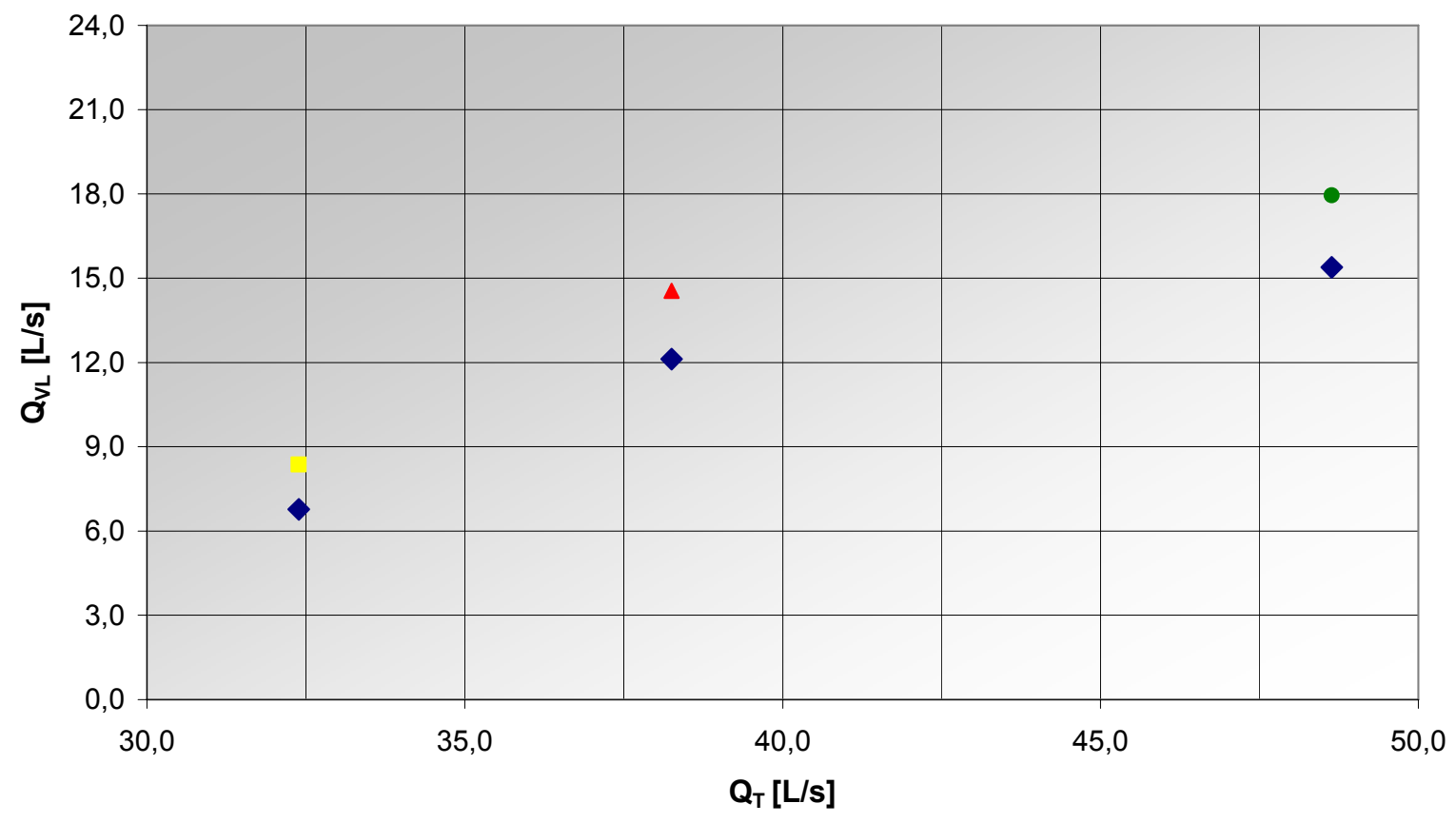

$\bullet$ Ensaio $\quad$ Q1-C8 $\triangle$ Q2-C8 $\bullet$ Q3-C8

Figura 6.4 - Comparação da simulação para a malha 2.

\section{c) Malha 3}

A malha 3 (Figura 6.5 e 6.6) apresenta um refinamento com 298760 nós e 341885 elementos (hexaédricos (predominante), tetraédricos, prismáticos e piramidais), e o comprimento do maior lado do elemento na malha de volume igual a 20 milímetros, já na região do vertedor lateral os elementos possuem a medida de 5 milímetros. O tempo médio de simulação para o intervalo estudado foi de 18,5 horas com um número aproximado de 550 iterações, onde foi alcançada a convergência de $1 \times 10^{-4}$.

Na Figura 6.7, observa-se bons resultados, com uma redução acentuada dos erros da simulação, quando comparado com as Figuras 6.2 e 6.4, onde os mesmos estão entre $0,9 \%$ e $1,55 \%$. Para a malha 3 a condição Q2-C8 apresentou o maior erro. Os valores obtidos estão dentro do esperado para esse trabalho. 


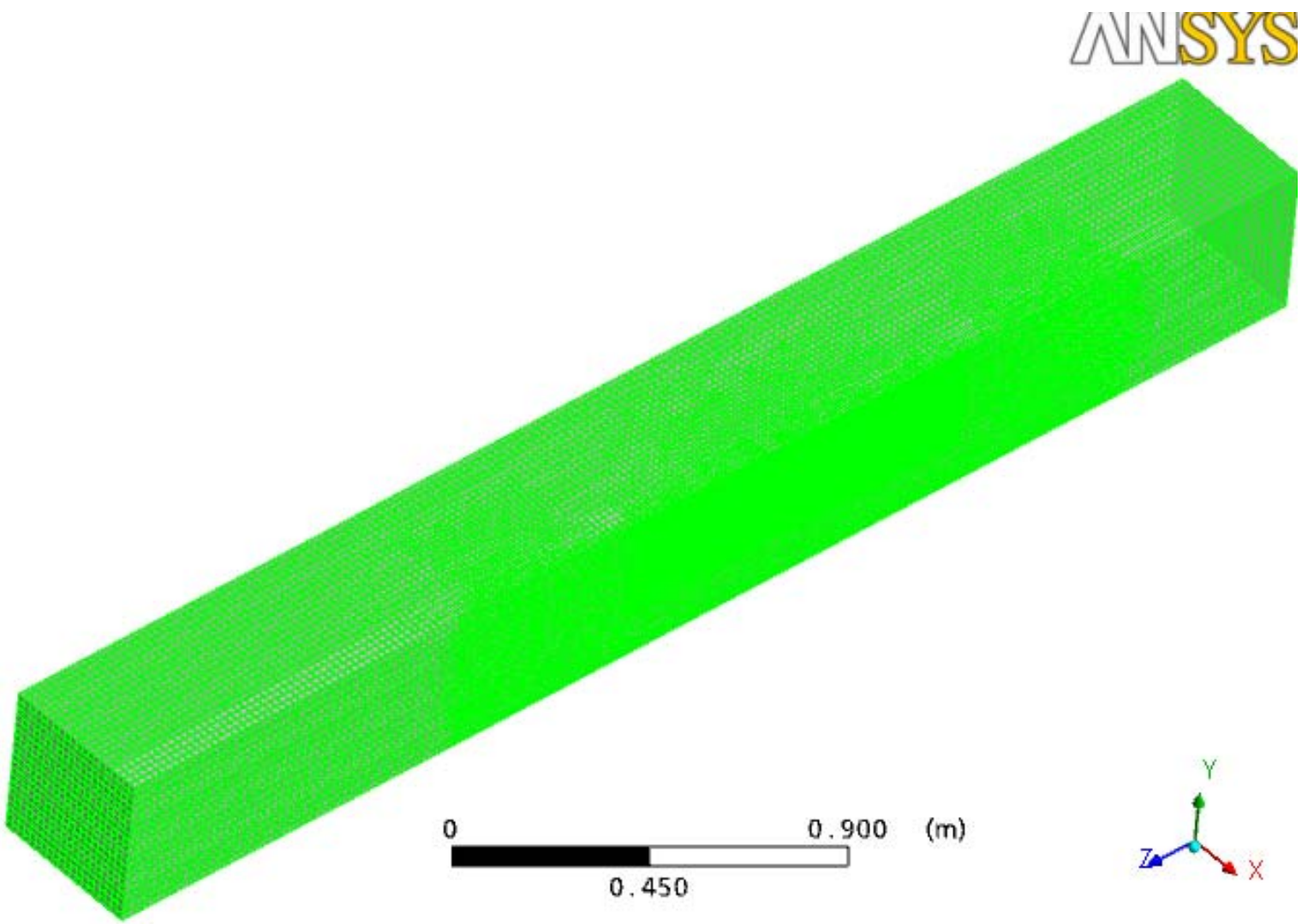

Figura 6.5 - Vista isométrica da malha 3.

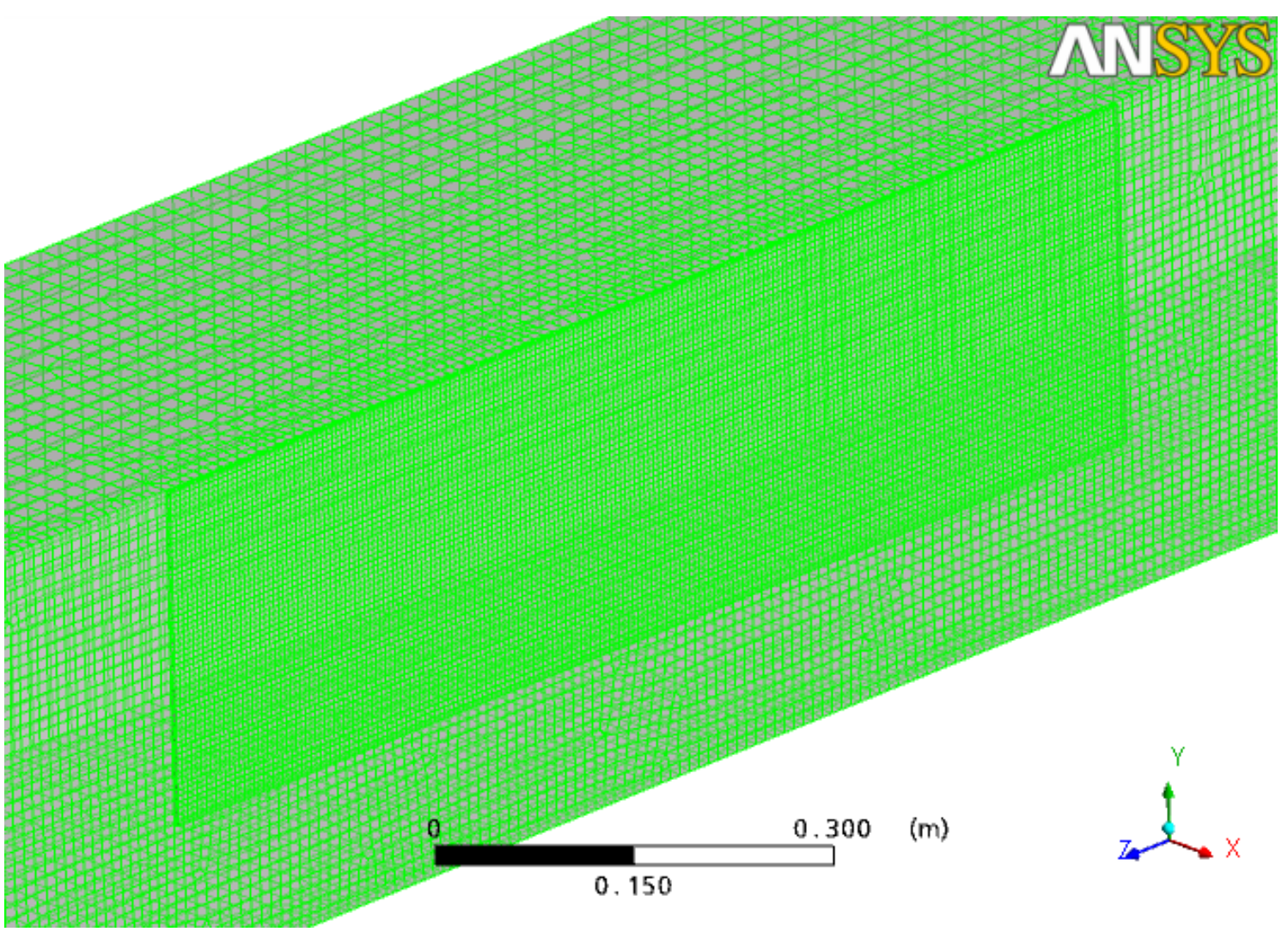

Figura 6.6 - Detalhe do vertedor lateral da malha 3. 


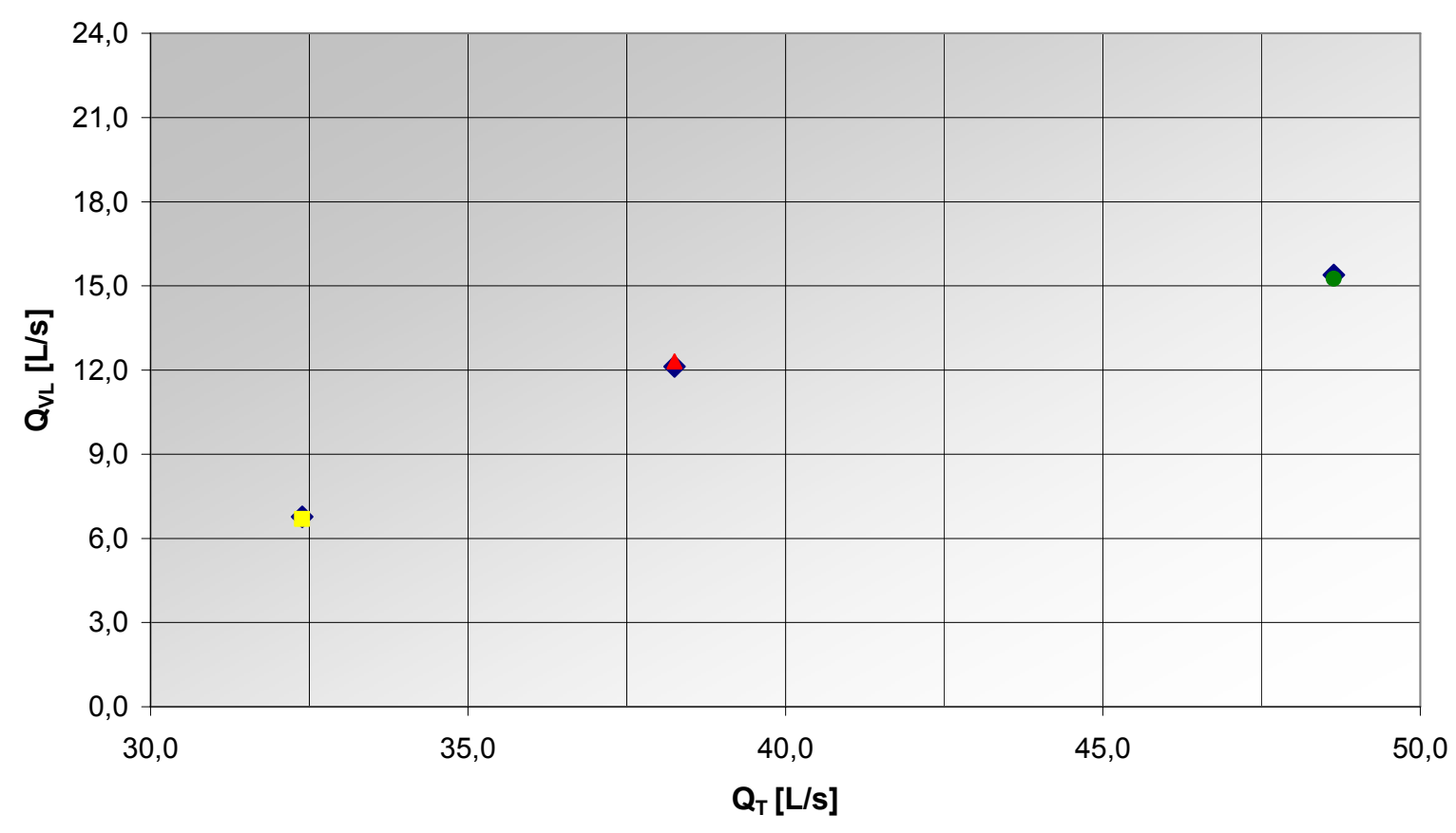

$\bullet$ Ensaio $\triangle \mathrm{Q} 1-\mathrm{C} 8 \Delta \mathrm{Q} 2-\mathrm{C} 8 \bullet \mathrm{Q} 3-\mathrm{C} 8$

Figura 6.7 - Comparação da simulação para a malha 3.

\section{d) Comparação das Malhas}

A malha 3 apresentou a maior precisão dos resultados, com erros inferiores a $1,55 \%$, por isso, essa será a malha escolhida para a validação da simulação computacional do vertedor lateral.

Os resultados de vazões do vertedor lateral obtidos na simulação (Tabela 6.1), apresentaram erros significativos para as diversas malhas estudadas, sendo visível a melhora dos resultados com o maior refinamento da malha.

Tabela 6.1 - Comparação das vazões do vertedor lateral entre as malhas.

\begin{tabular}{ccccc}
\hline Ensaios & $\begin{array}{c}\text { Experimental } \\
{[\mathrm{L} / \mathbf{s}]}\end{array}$ & $\begin{array}{c}\text { Malha 1 } \\
{[\mathrm{L} / \mathbf{s}]}\end{array}$ & $\begin{array}{c}\text { Malha 2 } \\
{[\mathrm{L} / \mathbf{s}]}\end{array}$ & $\begin{array}{c}\text { Malha 3 } \\
{[\mathrm{L} / \mathbf{s}]}\end{array}$ \\
\hline Q1-C8 & 6,77 & 14,27 & 8,36 & 6,69 \\
Q2-C8 & 12,12 & 20,94 & 14,55 & 12,31 \\
Q3-C8 & 15,39 & 23,19 & 17,95 & 15,25 \\
\hline
\end{tabular}


$\mathrm{Na}$ Figura 6.8 tem-se a comparação do erro da simulação para as vazões escoadas pelo vertedor lateral, no intervalo de $Q_{T}$ estudado, para as três malhas. A linha verde tracejada representa o erro esperado de $2 \%$, que foi atendido somente pela malha 3. Apesar do refinamento de cada malha, as três apresentaram os menores erros para a condição Q3-C8, que possui a maior vazão do canal principal e vertida pelo dispositivo estudado, mostrando a possibilidade do modelo computacional criado ser menos sensível ao erro para as vazões maiores.

A maior precisão dos resultados do estudo, malha mais refinada, é diretamente proporcional ao custo computacional, tempo de simulação. Antes da modelagem é importante definir o grau de precisão, requerido dos resultados do modelo, para o nível e tipo do estudo ou projeto, com isso, evita-se onerá-lo demasiadamente acima da necessidade.

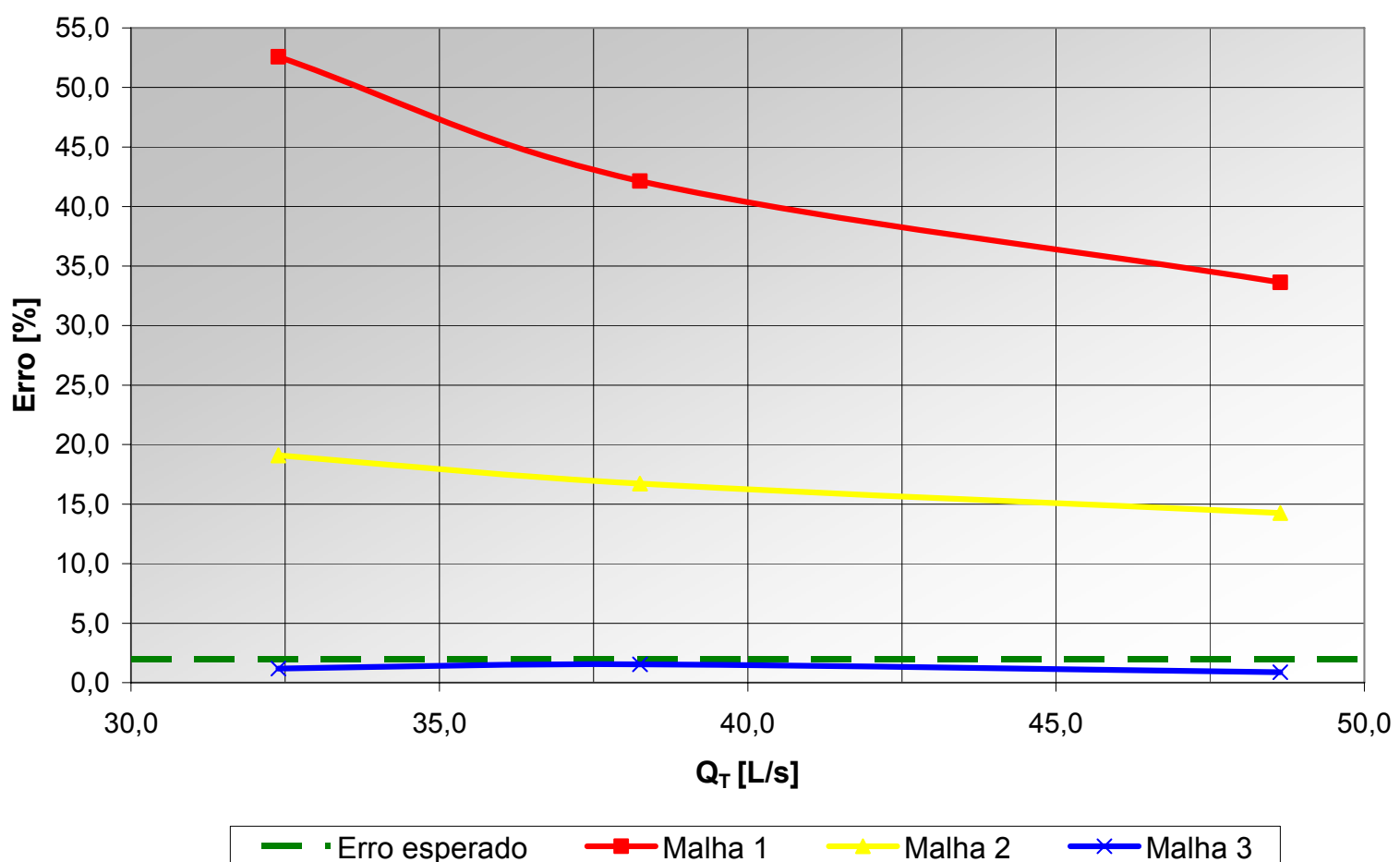

Figura 6.8 - Comparação do erro da simulação entre as malhas. 


\subsubsection{Modelos de Turbulência}

Utiliza-se a malha 3 para a validação dos modelos de turbulência, devido apresentar a maior precisão dos resultados obtidos no item 6.1.1.

\section{a) Modelo k- $-\varepsilon$}

O tempo médio de simulação para o intervalo estudado de vazões foi de 18,3 horas com o número médio de 500 iterações, onde foi alcançada a convergência. Na Figura 6.9, verifica-se bons resultados, exceto para a condição Q1-C8, onde o erro apresentado foi aproximadamente 7,8\%, valor acima do esperado. Para as outras condições, Q2-C8 e Q3-C8, o erro obtido ficou dentro do valor esperado.

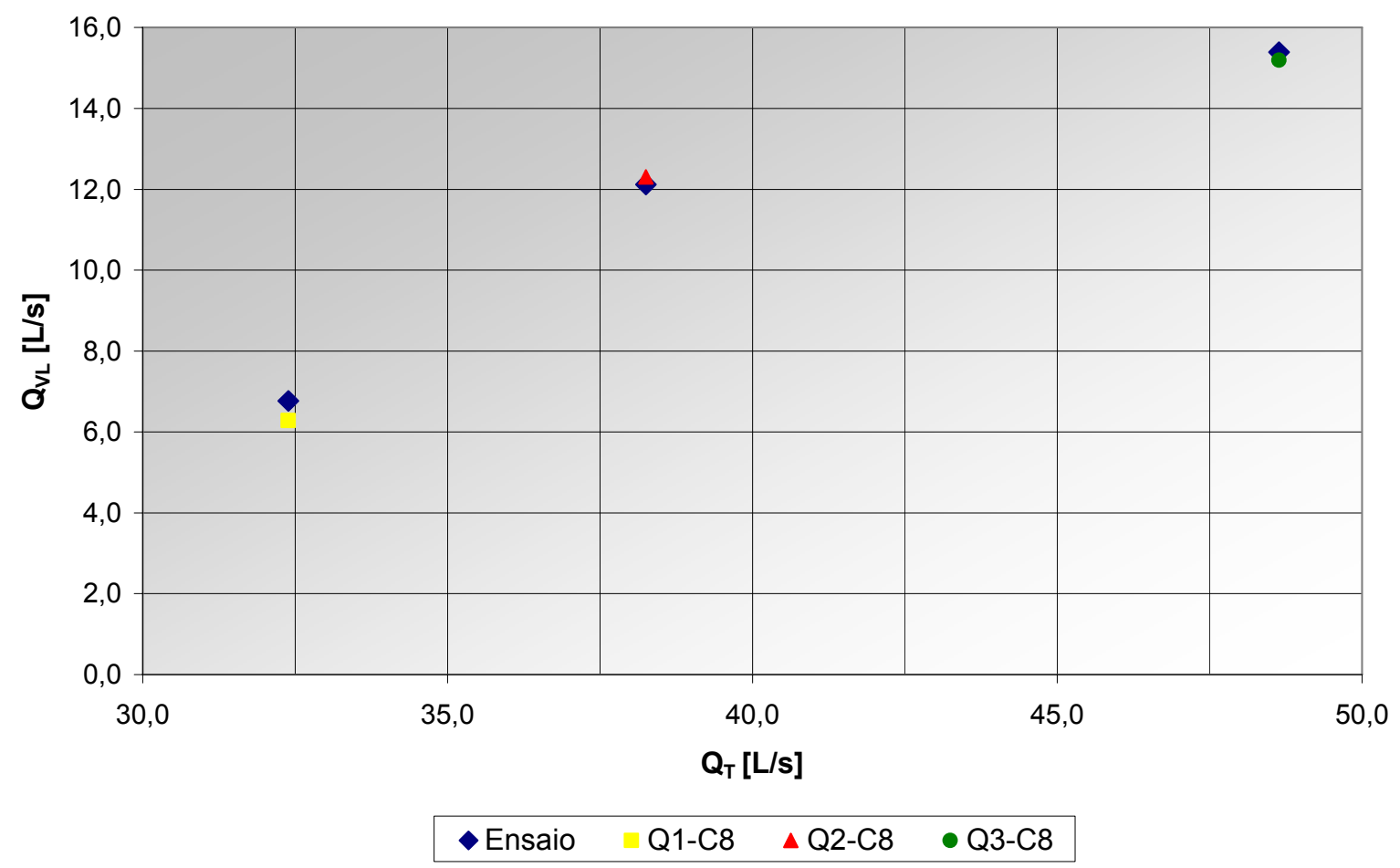

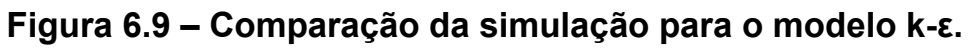




\section{b) Modelo k- $\varepsilon$ (RNG)}

O tempo médio de simulação para o intervalo estudado de vazões foi de 18,5 horas com o número médio de 550 iterações, onde foi alcançada a convergência.

Os erros apresentados por esse modelo estão dentro do intervalo proposto, com valores inferiores a $1,55 \%$. A Figura 6.10 mostra a proximidade dos resultados da simulação computacional com o ensaio experimental.

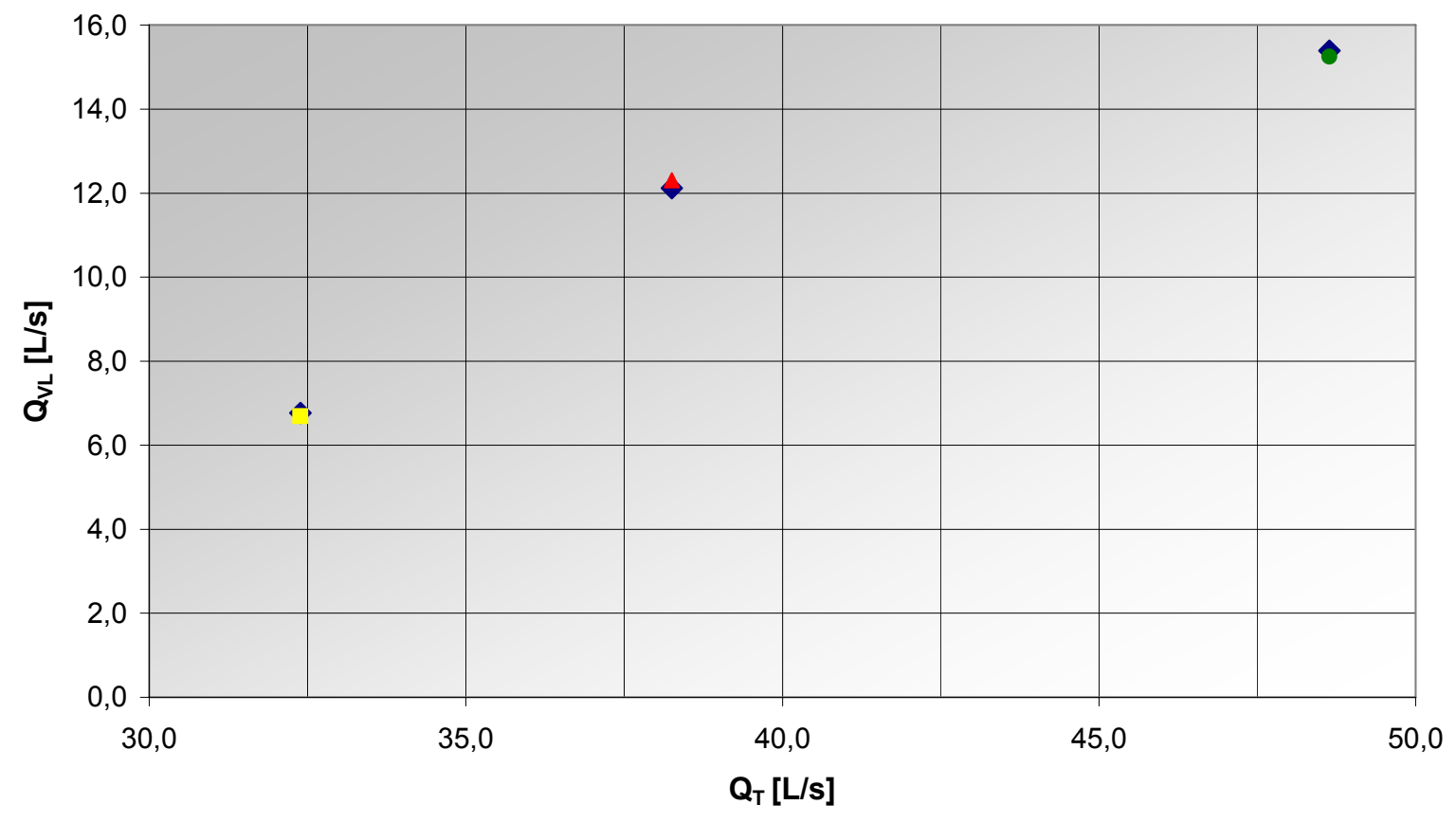

$\bullet$ Ensaio $\backsim$ Q1-C8 $\triangle$ Q2-C8 $\bullet$ Q3-C8

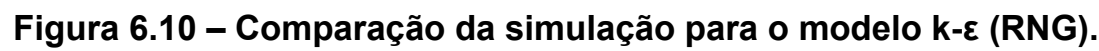

\section{c) Modelo SST k-w}

O tempo médio de simulação para o intervalo estudado de vazões foi de 20,3 horas com o número médio de 560 iterações, onde foi alcançada a convergência. Na Figura 6.11, verifica-se bons resultados, com exceção para a condição Q1C8, onde o erro apresentado foi aproximadamente $6 \%$, valor acima do intervalo proposto. Já as outras condições, o erro obtido ficou dentro do intervalo proposto. 


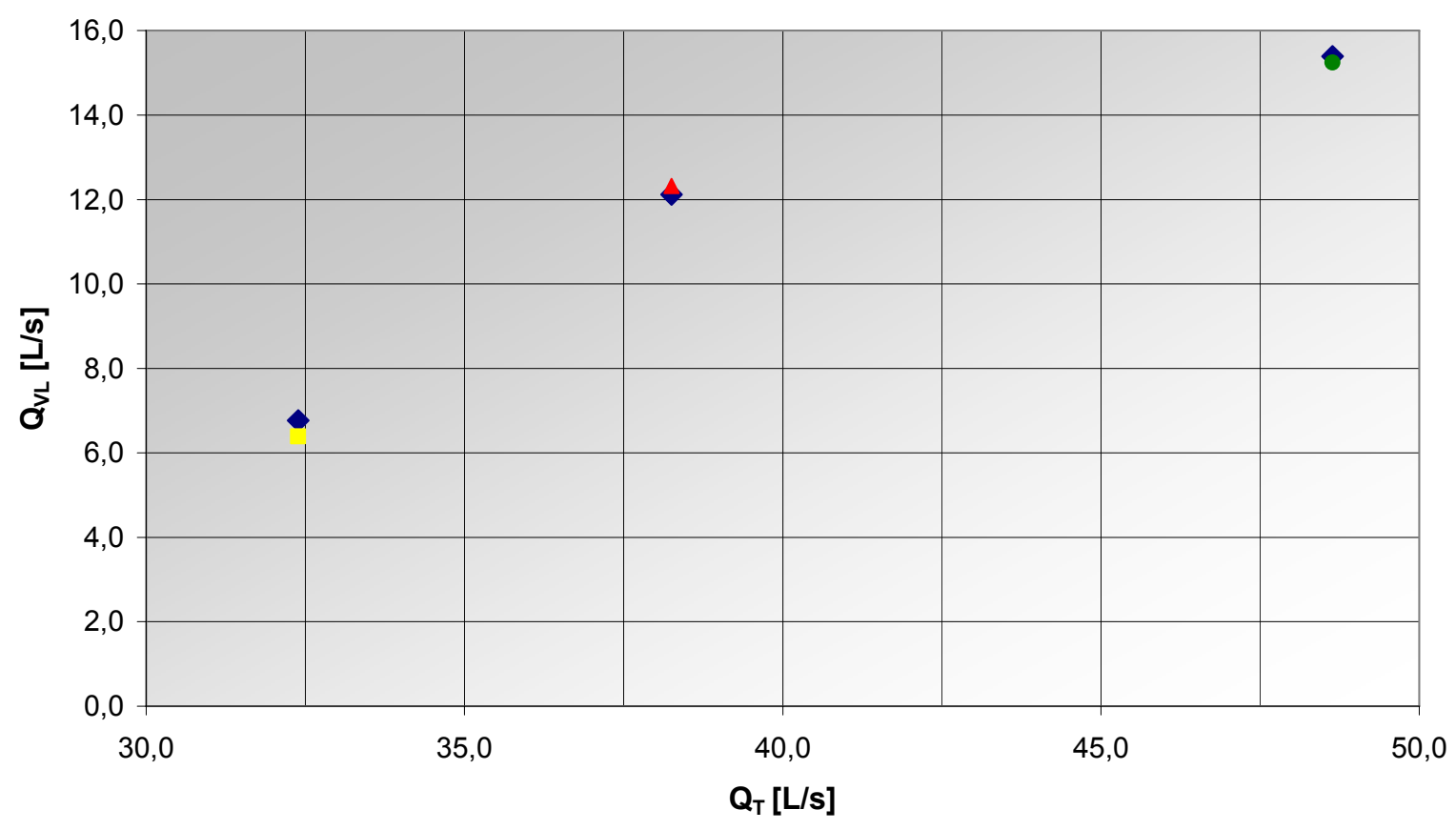

$\bullet$ Ensaio $\triangle$ Q1-C8 $\triangle$ Q2-C8 $\bullet$ Q3-C8

Figura 6.11 - Comparação da simulação para o modelo SST k-w.

\section{d) Comparação dos Modelos de Turbulência}

Somente a vazão do vertedor lateral para a condição Q1-C8 apresentou um erro significativo para os modelos de turbulência estudados (Tabela 6.2), onde os modelos k- $\varepsilon$ e SST k- $\omega$ apresentaram erros acima do intervalo proposto.

Tabela 6.2 - Comparação das vazões do vertedor lateral entre os modelos de turbulência.

\begin{tabular}{ccccc}
\hline Ensaios & $\begin{array}{c}\text { Experimental } \\
{[\mathrm{L} / \mathbf{s}]}\end{array}$ & $\begin{array}{c}\mathbf{k - \varepsilon} \\
{[\mathrm{L} / \mathbf{s}]}\end{array}$ & $\begin{array}{c}\mathbf{k - \varepsilon}(\mathbf{R N G}) \\
{[\mathrm{L} / \mathbf{s}]}\end{array}$ & $\begin{array}{c}\text { SST k- } \boldsymbol{\omega} \\
{[\mathrm{L} / \mathbf{s}]}\end{array}$ \\
\hline Q1-C8 & 6,77 & 6,28 & 6,69 & 6,39 \\
Q2-C8 & 12,12 & 12,31 & 12,31 & 12,32 \\
Q3-C8 & 15,39 & 15,19 & 15,25 & 15,24 \\
\hline
\end{tabular}


A Figura 6.12 apresenta a comparação do erro da simulação para as vazões escoadas pelo vertedor lateral, no intervalo de $Q_{T}$ estudado, para os três modelos de turbulência.

O modelo de turbulência k- $\varepsilon$ (RNG) apresentou a maior precisão dos resultados, com erros inferiores a 1,55\%. Nas três condições estudadas (Q1-C8, Q2-C8 e Q3-C8) obteve, praticamente, os menores erros quando comparado com os outros dois modelos de turbulência. Por isso, o modelo k- $\varepsilon$ (RNG) foi escolhido para a validação do modelo computacional do vertedor lateral.

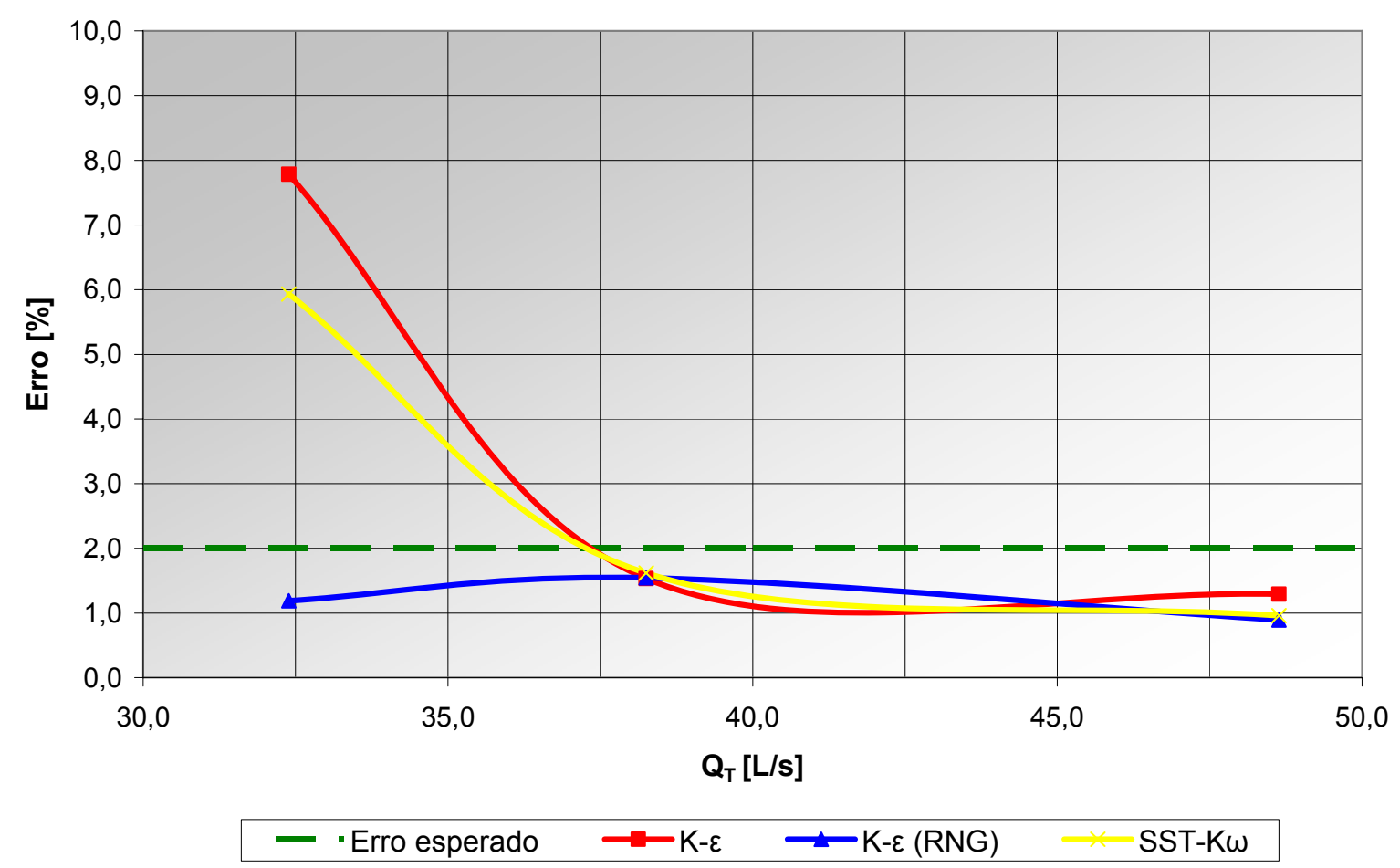

Figura 6.12 - Comparação do erro da simulação entre os modelos de turbulência.

Analisando a Figura 6.12, é satisfatoriamente aceitável que o modelo k- $\varepsilon$ (RNG) tenha obtido, aparentemente, melhor resultado do que o modelo SST k- $\omega$, porque o modelo SST, apesar dos resultados da condição Q2-C8 e Q3-C8, é mais indicado para fluidos com massa específica próxima ao do ar, e o fluido principal desse trabalho é a água. Já com relação ao modelo k- $\varepsilon$, o mesmo não representa com eficiência pequenas escalas de turbulência, que para a condição Q1-C8, pode ter ocorrido na região do vertedor lateral.

Apesar da escolha do modelo $k-\varepsilon$ (RNG) pelo critério de validação, e sendo a análise do nível d'água (NA) sobre a soleira parte da proposta desse trabalho, 
serão comparados os NA's para os modelos de turbulência e verificado o desempenho do modelo escolhido.

No gráfico da Figura 6.13 é representado no eixo das abscissas o comprimento da soleira, sendo a posição 0 , montante e a posição 100 , jusante, e no eixo das ordenadas o nível d'água sobre a soleira. Para condição Q1-C8 o modelo de turbulência k- $\varepsilon$ (RNG) apresentou o erro médio, para o conjunto de 19 pontos medidos, de $5,98 \%$, já os outros dois modelos apresentaram o erro médio acima de $7,0 \%$.

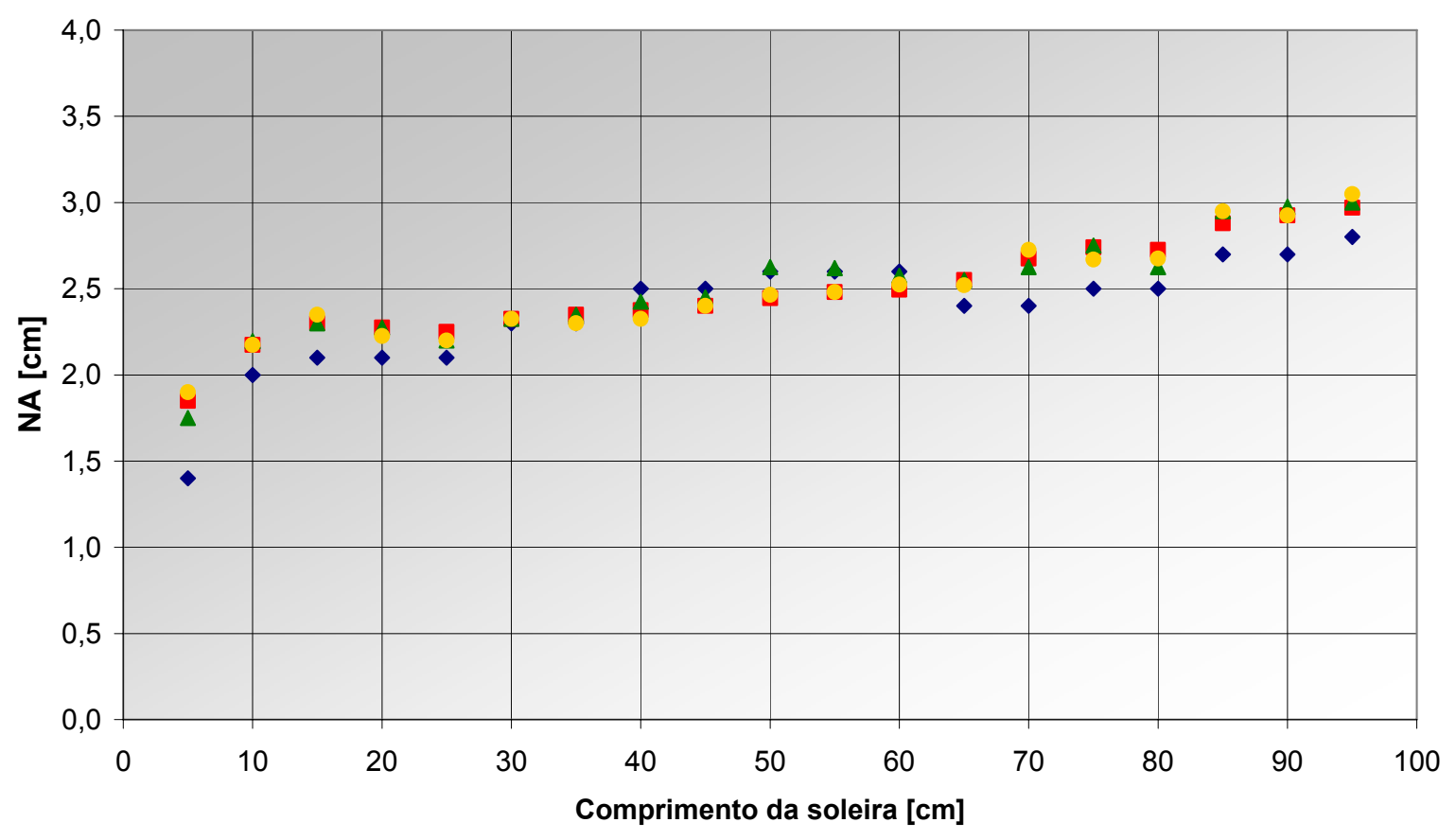

- Ensaio $\square \mathrm{k}-\varepsilon \Delta \mathrm{k}-\varepsilon(\mathrm{RNG}) \odot \mathrm{SST}-\mathrm{k} \omega$

Figura 6.13 - Comparação do nível d'água sobre a soleira para a condição Q1-C8.

O modelo k- $\varepsilon$ (RNG) apresentou melhor resultado para a condição Q2-C8 (Figura 6.14), onde o erro médio obtido foi de $4,60 \%$, contra $5,10 \%$ para o modelo $k-\varepsilon$ e $5,50 \%$ para o modelo SST-kw.

A condição Q3-C8 (Figura 6.15) também apresentou a maior precisão para o modelo k- $\varepsilon$ (RNG), confirmando a escolha do modelo como o mais indicado para representar o estudo proposto, dentro do intervalo de erro esperado. Nessa condição o modelo k- $\varepsilon$ (RNG) apresentou erro médio de $5,35 \%$, já os outros dois modelos apresentaram o erro médio acima de $7,50 \%$. 


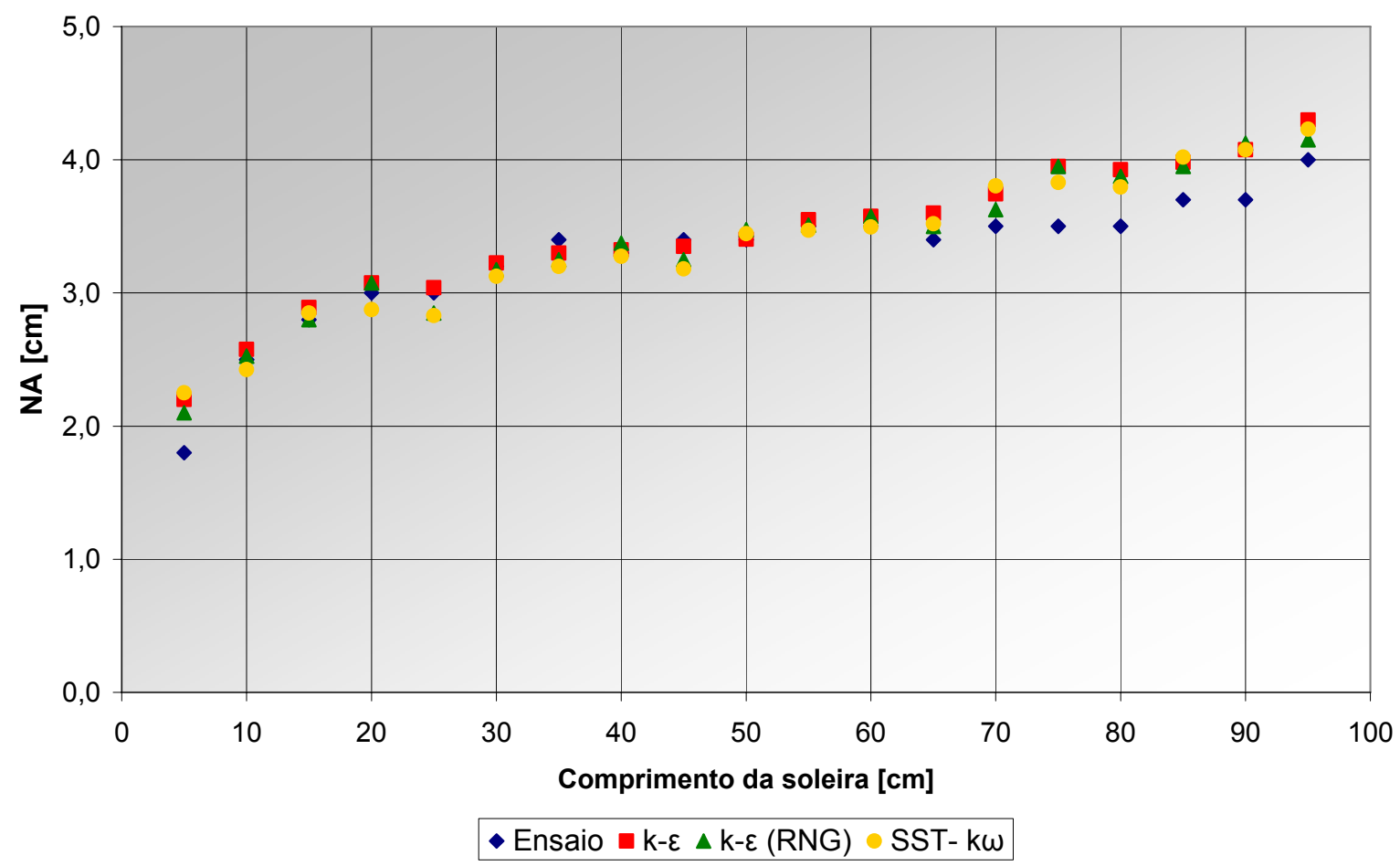

Figura 6.14 - Comparação do nível d’água sobre a soleira para a condição Q2-C8.

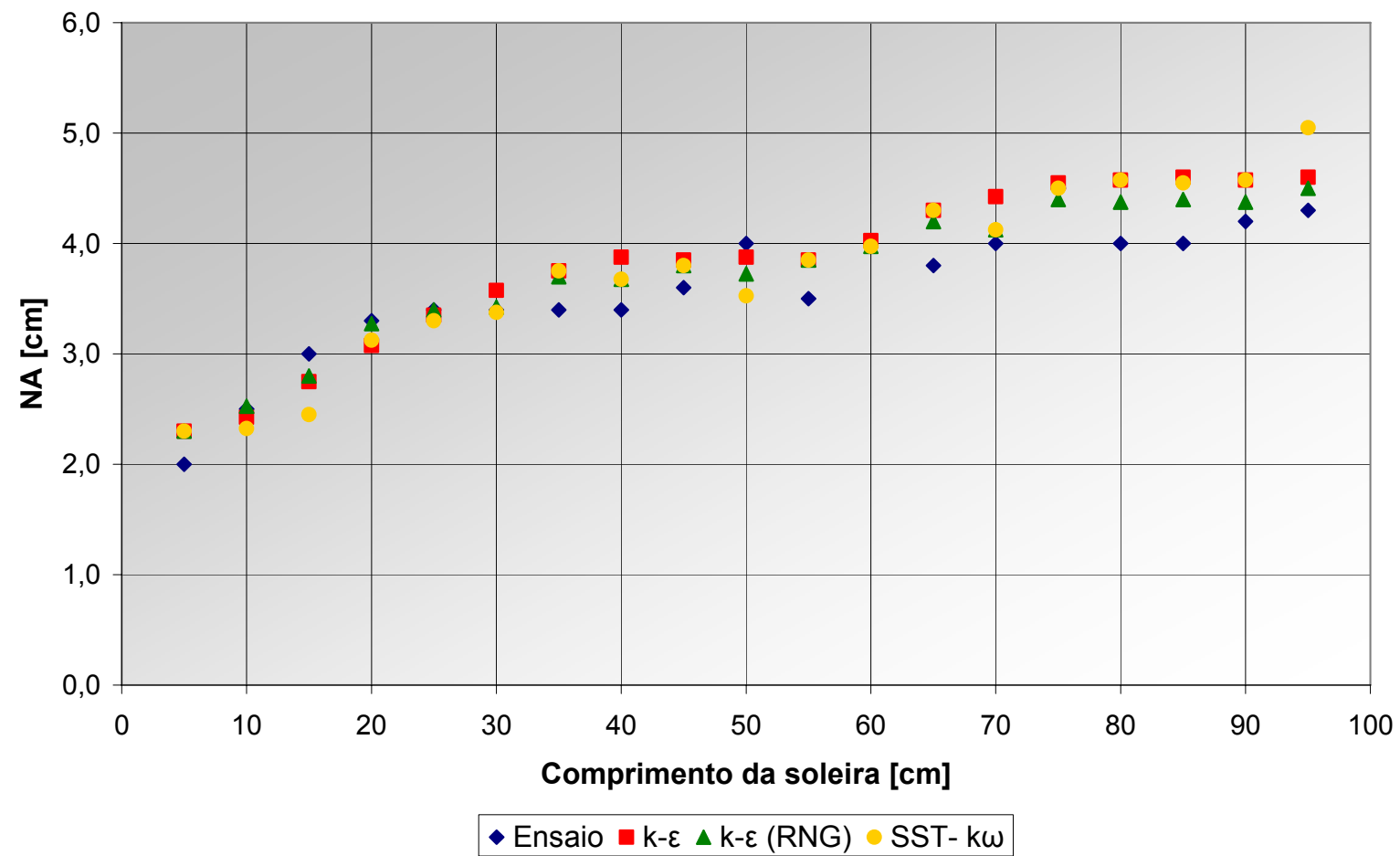

Figura 6.15 - Comparação do nível d’água sobre a soleira para a condição Q3-C8.

Nesse item foi possível identificar a malha e o modelo de turbulência mais indicados para realizar os estudos hidráulicos da soleira lateral. 


\subsection{ANÁLISE DO ESCOAMENTO NO VERTEDOR LATERAL}

O modelo computacional validado é composto pela malha 3 e o modelo de

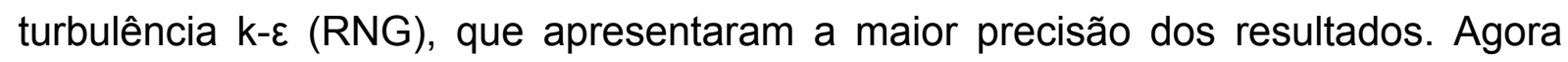
serão apresentadas todas as condições simuladas para o modelo validado.

O tempo médio de simulação para o intervalo estudado de vazões foi de 19,5 horas com o número médio de 550 iterações, onde foi alcançada a convergência, exceto para a condição Q3-C6, que terminou o cálculo com 700 iterações.

A Tabela 6.3 apresenta a comparação dos resultados da simulação com o ensaio experimental para todas as condições estudadas. Para melhor visualização dos resultados os mesmos estão representados na Figura 6.16. O gráfico apresenta no eixo das abscissas a vazão total $\left(Q_{T}\right)$ escoada pelo canal principal e no eixo das ordenadas a vazão escoada pelo vertedor lateral $\left(Q_{\mathrm{VL}}\right)$.

Tabela 6.3 - Comparação das vazões do vertedor lateral.

\begin{tabular}{ccc}
\hline Ensaios & $\begin{array}{c}\text { Experimental } \\
\text { [L/s] }\end{array}$ & $\begin{array}{c}\text { Simulação } \\
\text { [L/s] }\end{array}$ \\
\hline Q1-C6 & 0,51 & 0,51 \\
Q1-C8 & 6,77 & 6,69 \\
Q1-C10 & 12,00 & 11,83 \\
Q2-C6 & 3,88 & 3,82 \\
Q2-C8 & 12,12 & 12,31 \\
Q2-C10 & 14,34 & 14,57 \\
Q3-C6 & 6,81 & 6,92 \\
Q3-C8 & 15,39 & 15,25 \\
Q3-C10 & 20,11 & 19,81 \\
\hline
\end{tabular}

O intervalo estudado para a vazão total escoada pelo canal principal foi de aproximadamente $32,5 \mathrm{~L} / \mathrm{s}$ a $48,5 \mathrm{~L} / \mathrm{s}$, já a vazão escoada pelo vertedor lateral foi de aproximadamente $0,50 \mathrm{~L} / \mathrm{s}$ a $20,0 \mathrm{~L} / \mathrm{s}$. Observa-se na Figura 6.16 a proximidade dos resultados entre o ensaio e a simulação, praticamente, para todas as condições. 


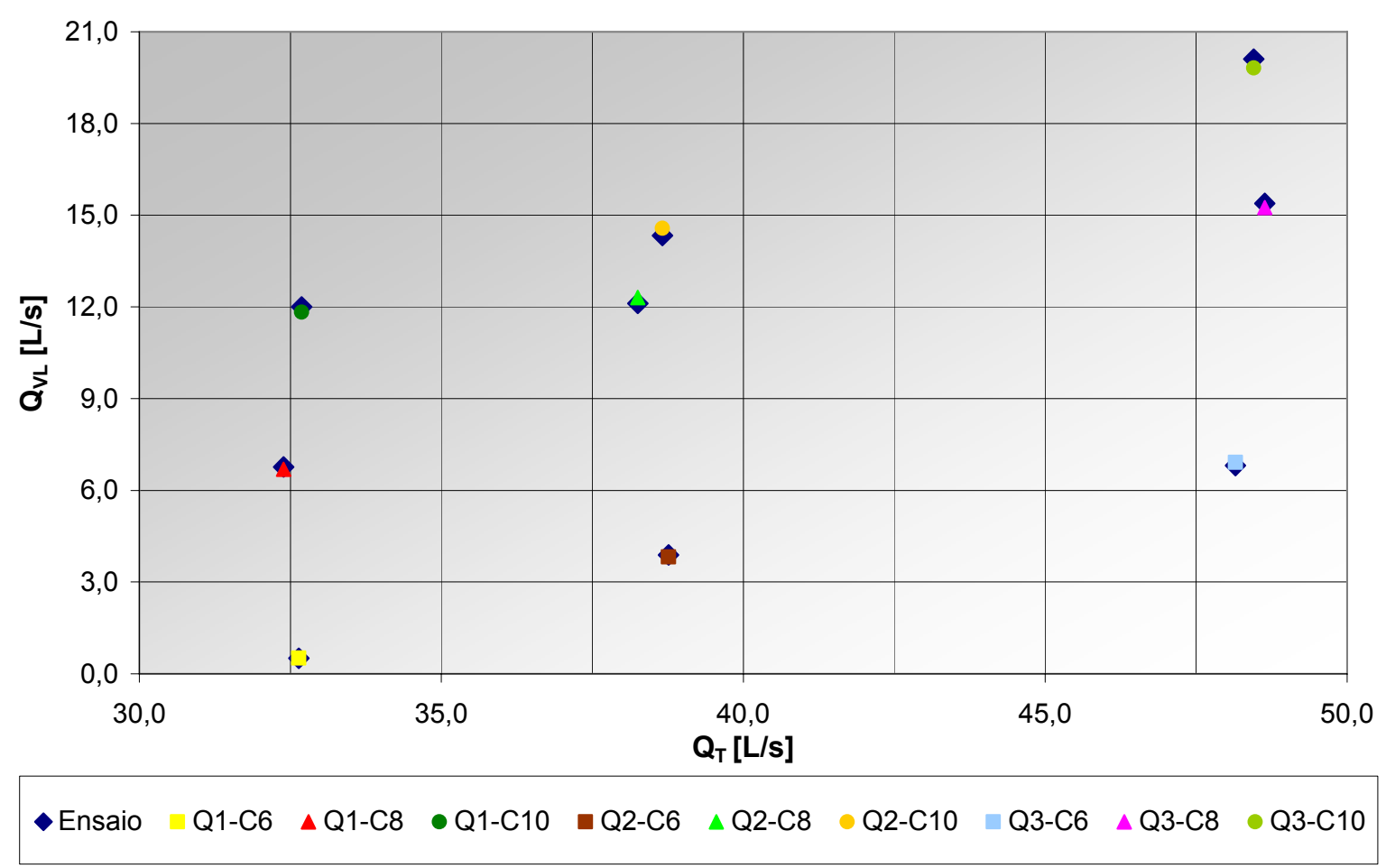

Figura 6.16 - Comparação da simulação para todas as condições.

O erro médio observado na Figura 6.17 foi de aproximadamente $1,5 \%$, com uma exceção visível, Q3-C8, que apresentou o erro inferior a 1,0\%. No geral, os resultados das vazões escoadas pelo dispositivo apresentaram-se constante, sem mostrar uma sensibilidade maior ao erro para uma faixa de vazão.

A análise do escoamento do modelo em CFD será realizada em relação ao seu comportamento, verificando a fração volumétrica do ar e da água, a distribuição de velocidades, distribuição de pressões relativas e os níveis d'água sobre a soleira, para as diversas condições estudadas, conforme a Tabela 6.3. 


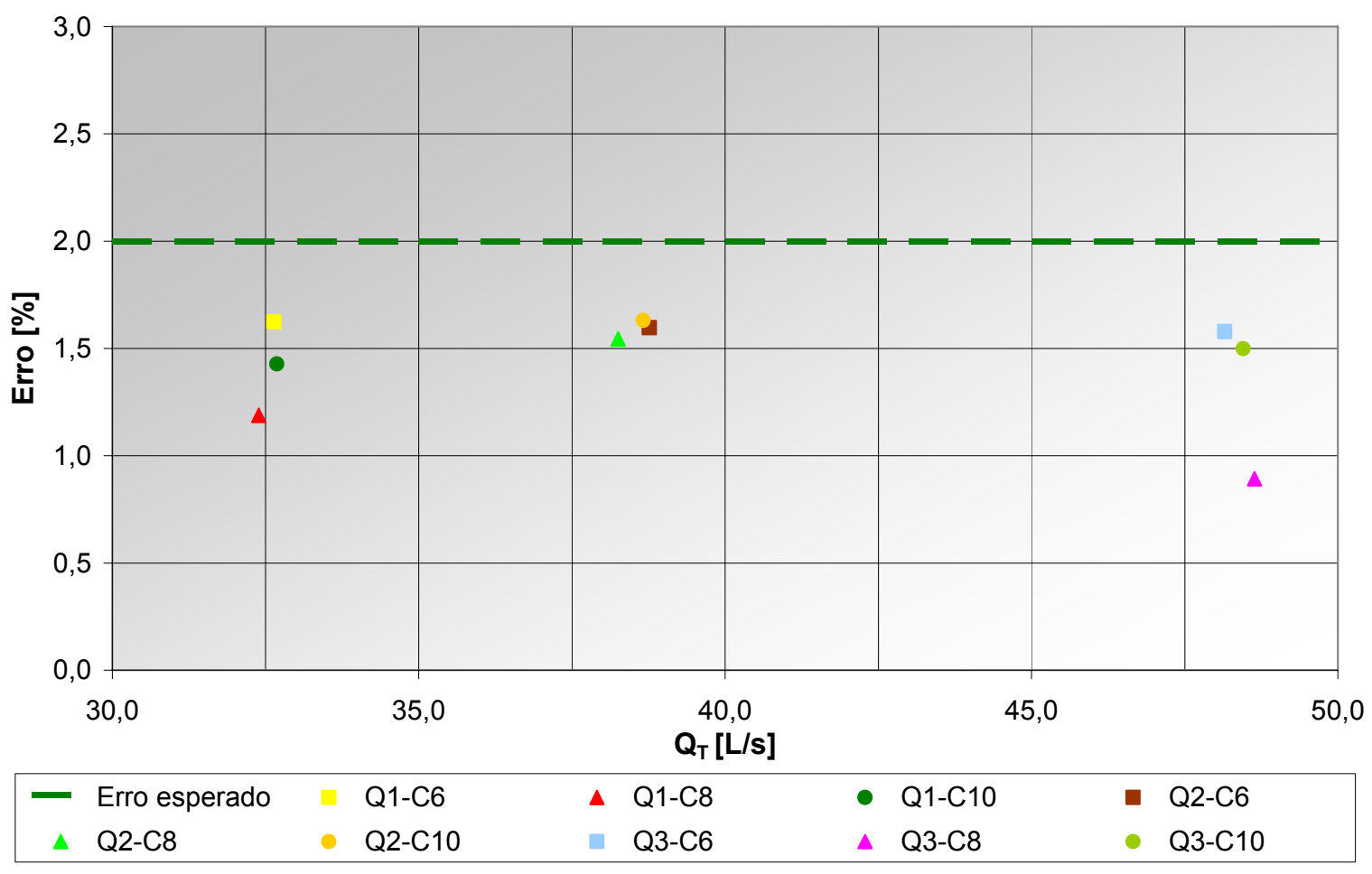

Figura 6.17 - Comparação do erro da simulação para todas as condições.

\subsubsection{Condição Q1}

A condição Q1 representa a vazão escoada no canal principal $\left(Q_{T}\right)$ de aproximadamente $32,5 \mathrm{~L} / \mathrm{s}$. Serão apresentados os resultados e análises das três condições de variação da comporta Q1-C6, Q1-C8 e Q1-C10.

A fração volumétrica do ar e da água pode ser visualizada nas Figuras 6.18 a 6.20, onde a interface entre ambos define a superfície d'água, que está representada de azul claro. Acima se tem a fração de ar e abaixo, inclusive a superfície, tem-se a fração volumétrica de água. Observam-se pequenas perturbações no canal principal, tanto a montante como a jusante, devido à influência do vertedor lateral. Essas perturbações aumentam conforme aumenta a vazão escoada através do dispositivo lateral.

Para a condição Q1-C6 é pequena a amplitude das perturbações, devido à baixa vazão escoada pelo dispositivo lateral, que é aproximadamente 0,51 L/s. Já a condição Q1-C8 apresenta um aumento das perturbações da água no canal 
principal, quando comparada com a condição Q1-C6, sendo a sua vazão da soleira lateral de $6,77 \mathrm{~L} / \mathrm{s}$.

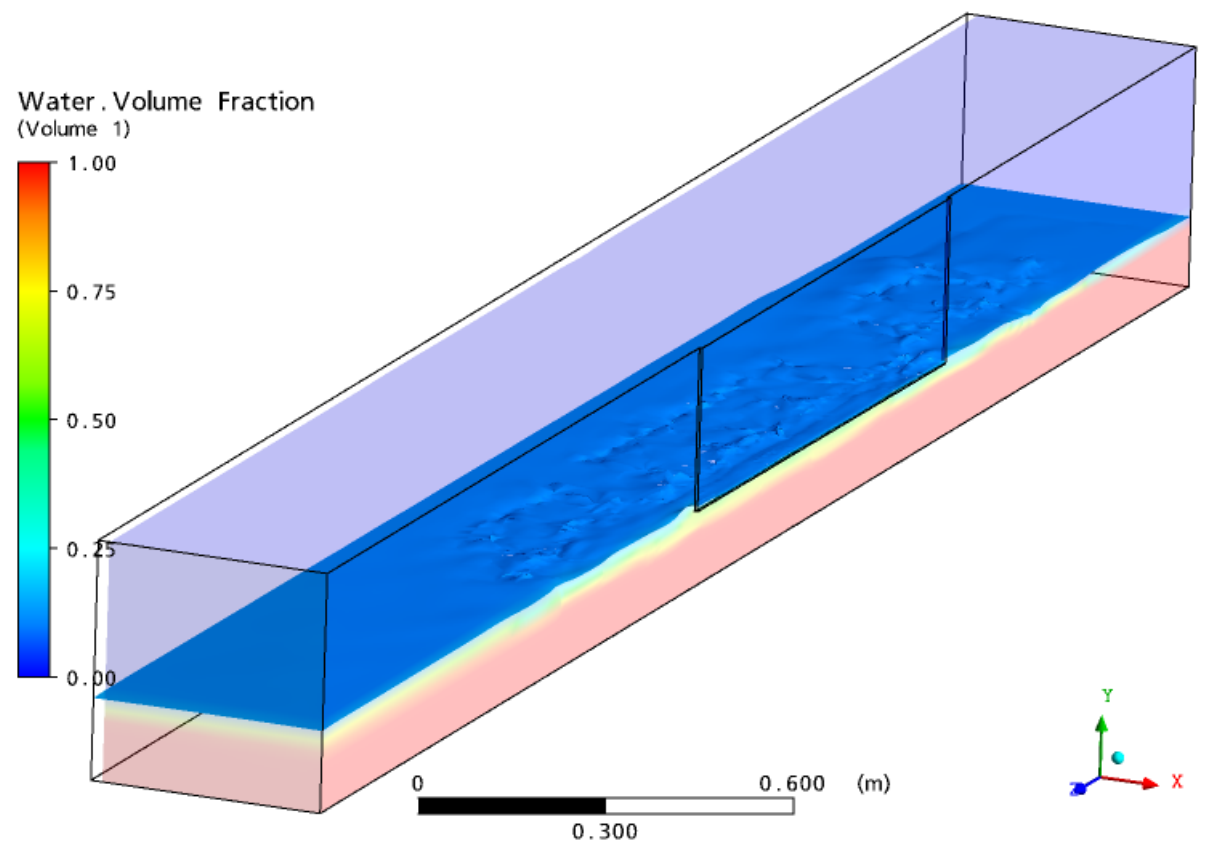

Figura 6.18 - Vista isométrica da superfície d'água para condição Q1-C6.

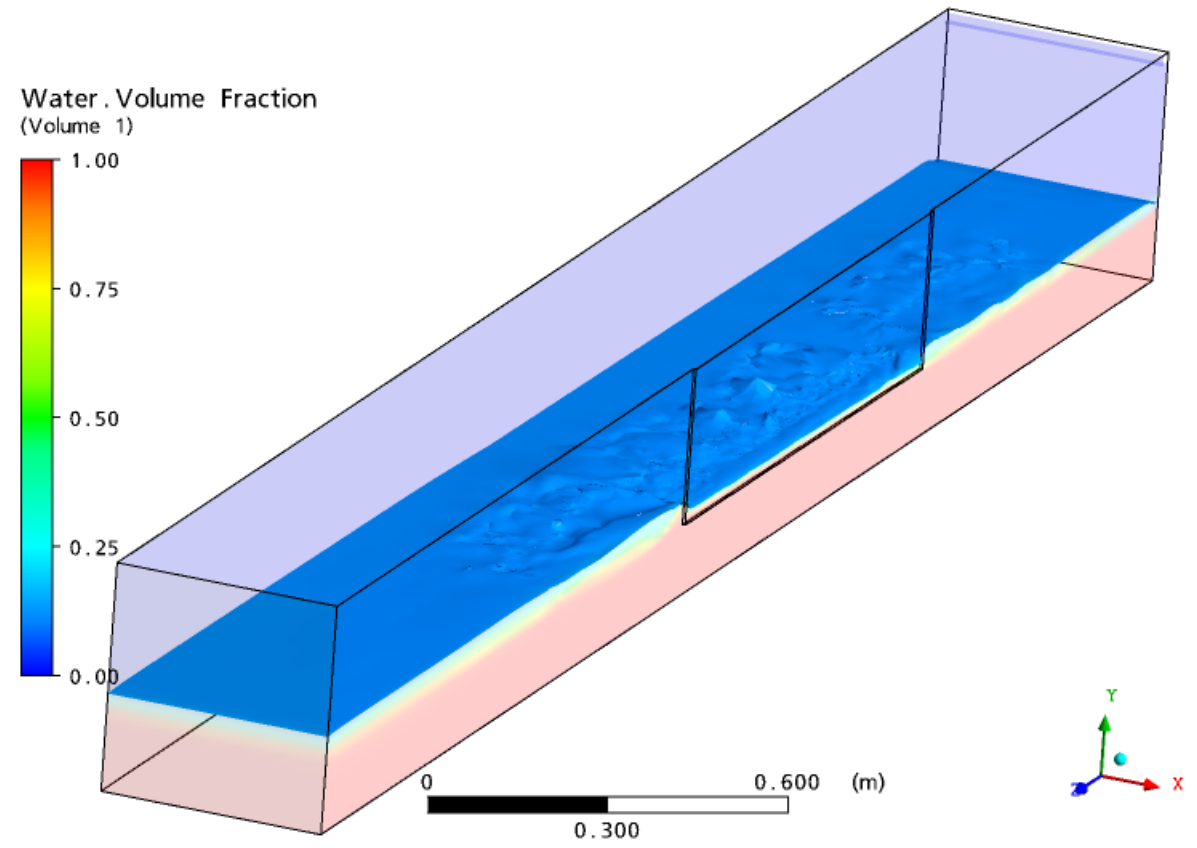

Figura 6.19 - Vista isométrica da superfície d'água para a condição Q1-C8. 
Para a condição Q1-C10 (Figura 6.20) a vazão escoada na soleira lateral é 12,00 L/s. Observa-se nessa condição o aumento da influência do dispositivo lateral, tanto a montante como a jusante, sobre o canal principal.

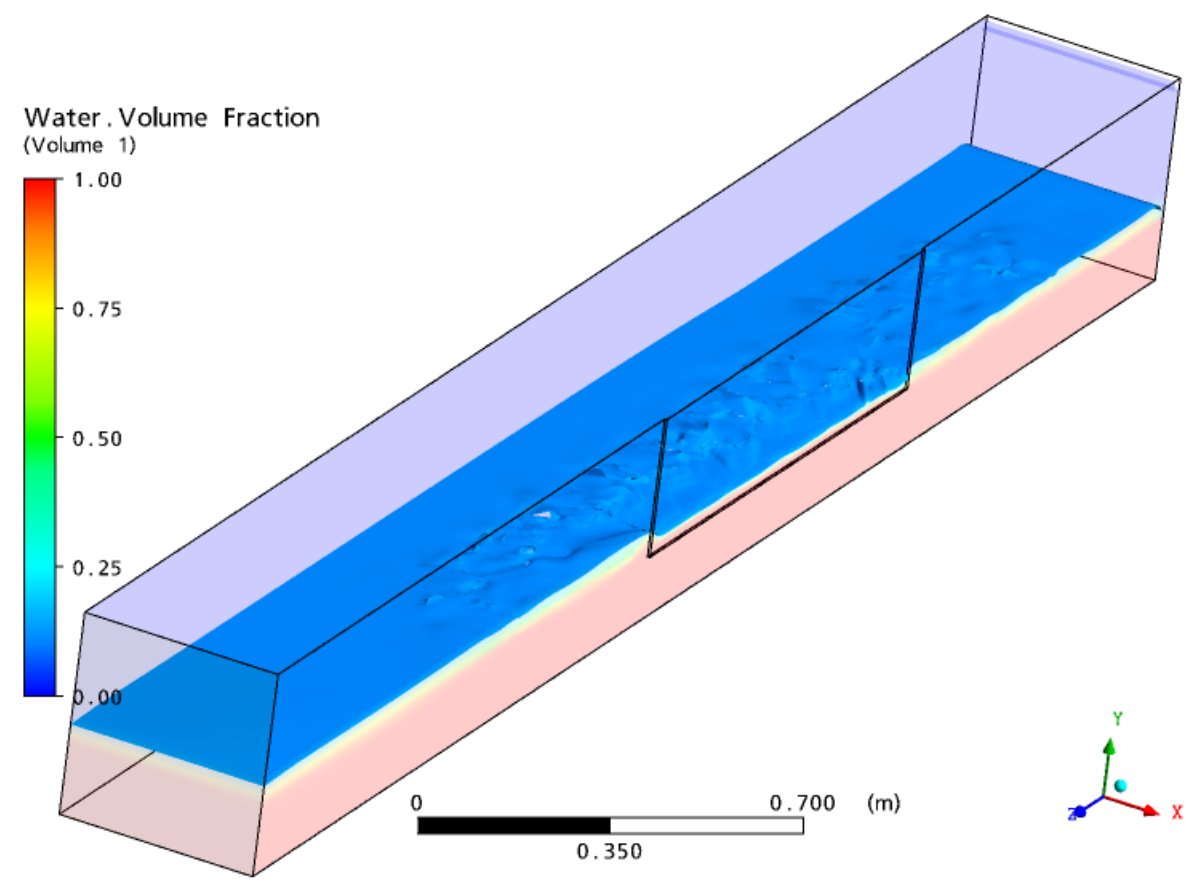

Figura 6.20 - Vista isométrica da superfície d'água para a condição Q1-C10.

Nas Figuras 6.21 a 6.23 , tem-se a vista frontal do vertedor lateral (direita representa montante), podendo-se visualizar o nível d'água (NA) sobre a soleira e suas perturbações em detalhe. A variação mínima e máxima do NA sobre a soleira é representada na Tabela 6.4 .

Tabela 6.4 - Variação do NA sobre a soleira lateral.

\begin{tabular}{ccc}
\hline Ensaios & NA $_{\text {mín. }}$ [cm] & NA $_{\text {máx. }}$ [cm] \\
\hline Q1-C6 & 0,30 & 1,25 \\
Q1-C8 & 1,75 & 3,00 \\
Q1-C10 & 2,60 & 4,05 \\
\hline
\end{tabular}




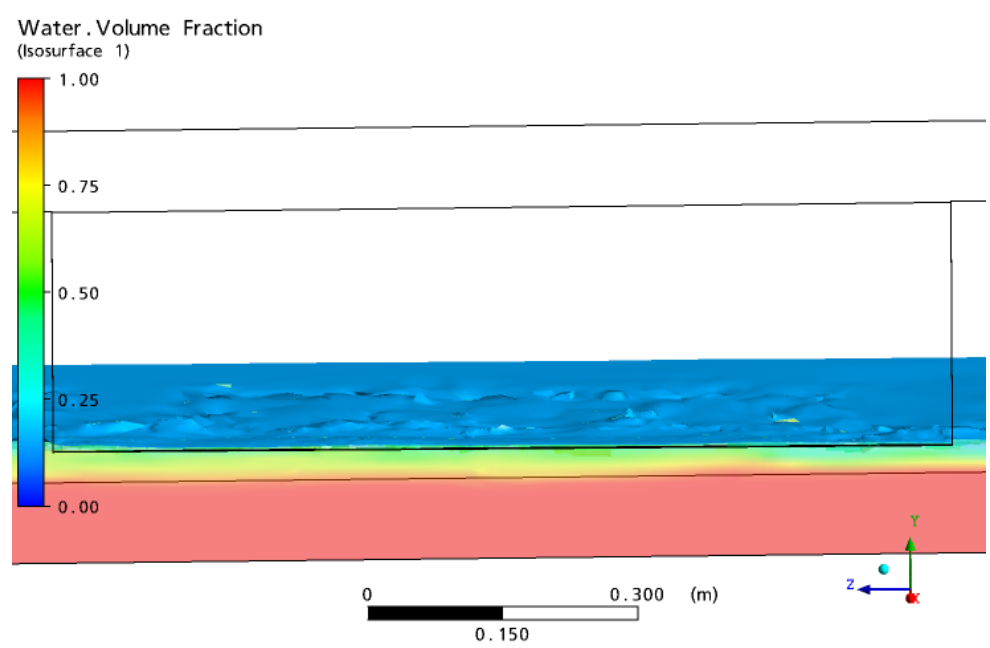

Figura 6.21 - Vista frontal da superfície d'água do vertedor lateral para a condição Q1-C6.

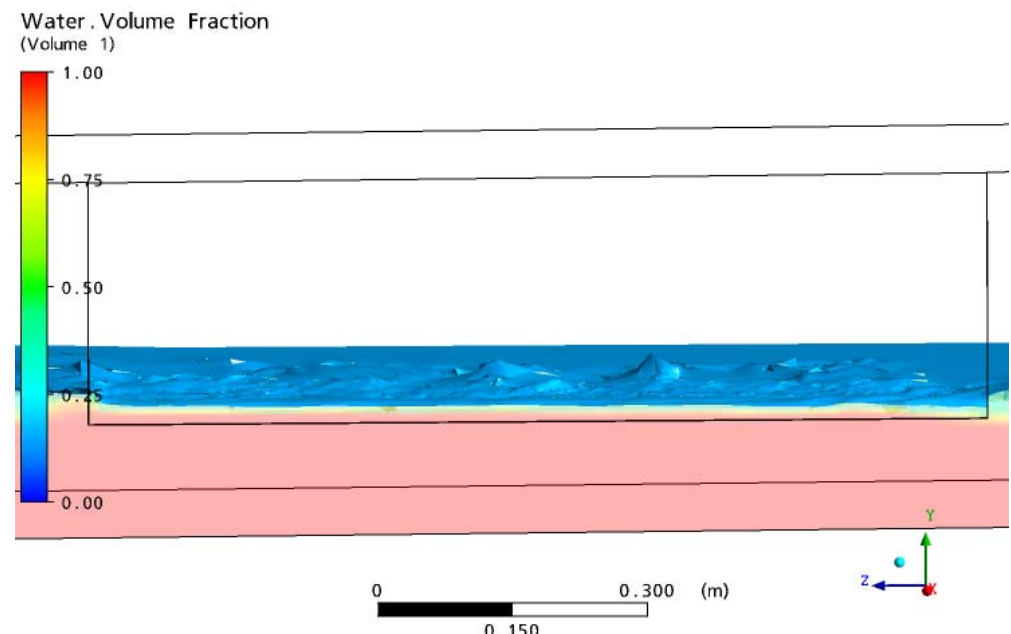

Figura 6.22 - Vista frontal da superfície d'água do vertedor lateral para a condição Q1-C8.

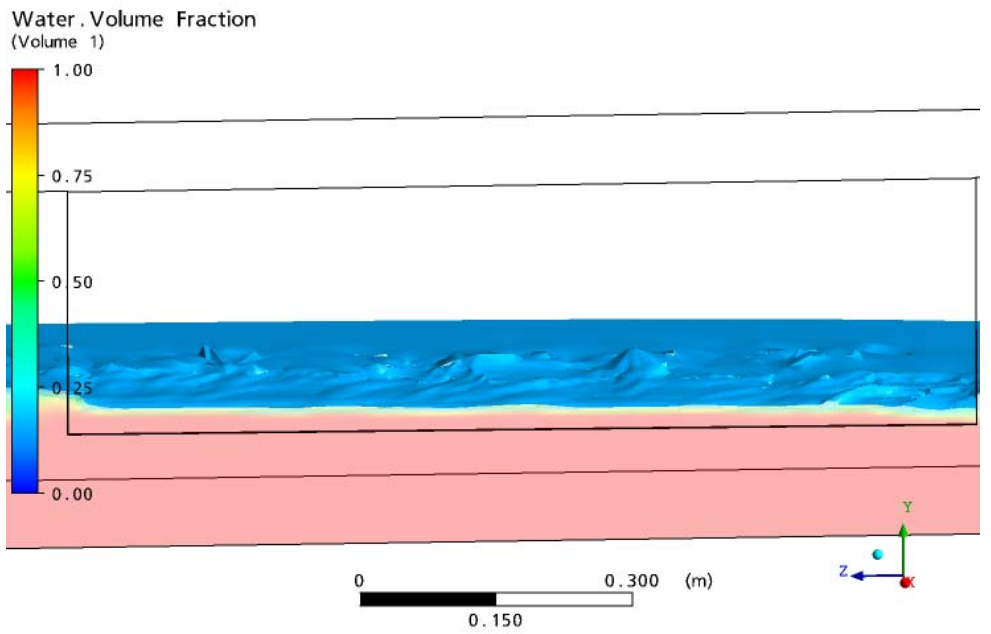

Figura 6.23 - Vista frontal da superfície d'água do vertedor lateral para a condição Q1-C10. 
Nos gráficos das Figuras 6.24, 6.26 e 6.27 é representado no eixo das abscissas o comprimento da soleira, sendo a posição 0 montante, e a posição 100 jusante, e no eixo das ordenadas o nível d'água sobre a soleira. Para condição Q1C6 o modelo matemático apresentou o erro médio, para o conjunto de 19 pontos medidos, de $12,87 \%$, ficando fora do valor esperado como satisfatório $6 \%$. Essa discrepância pode estar associada a defeitos e imperfeições do modelo físico (Figura 6.25), como desgaste prematuro do material da parede e fundo, e acabamento e impermeabilização não uniforme do vertedor lateral. Essas imperfeições, provavelmente, são mais influentes em pequenas vazões, como é o caso da condição Q1-C6. Apesar do erro estar acima do esperado, nota-se uma semelhança no comportamento do NA entre o resultado do modelo com o ensaio experimental.

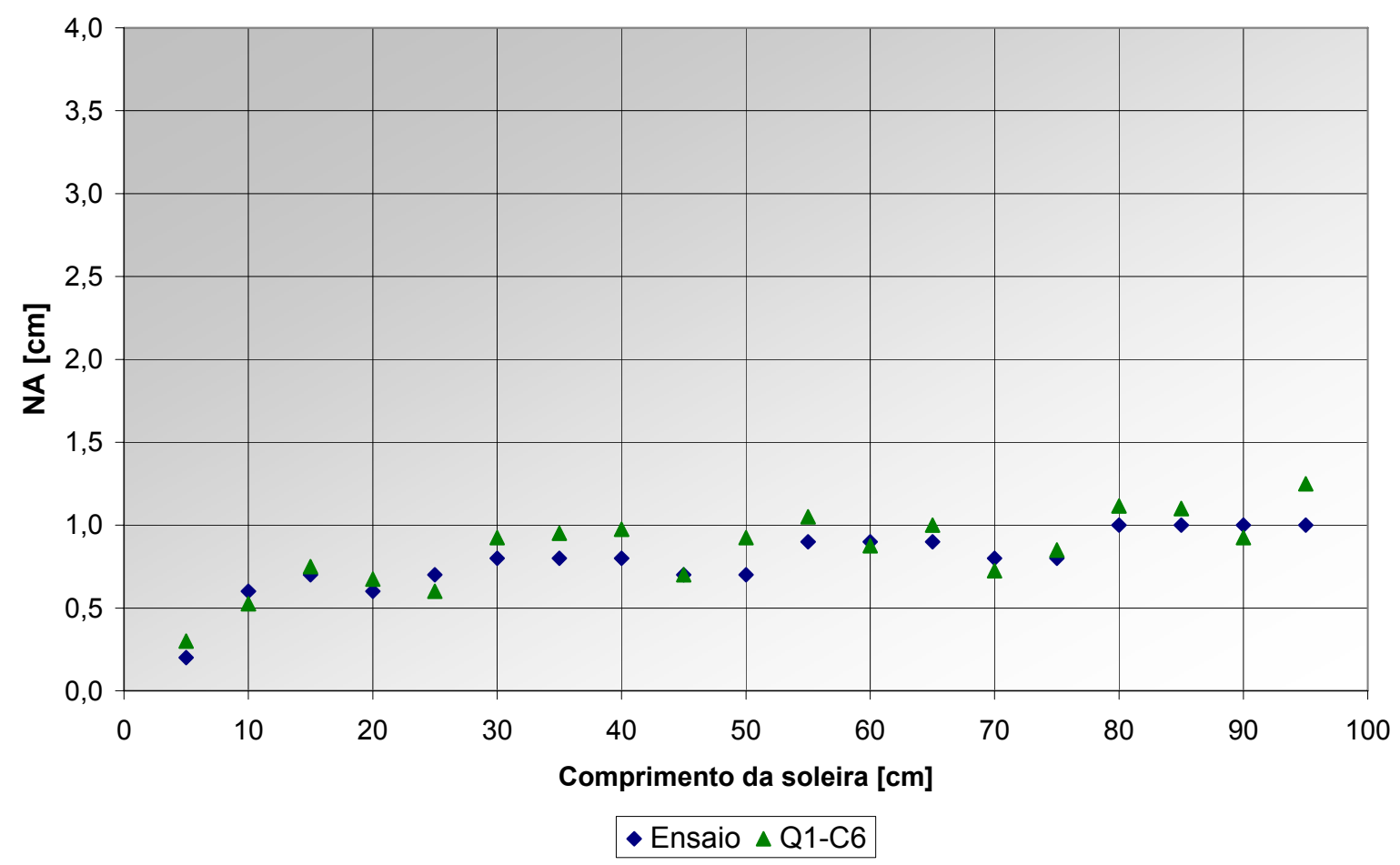

Figura 6.24 - Comparação do nível d'água sobre a soleira para a condição Q1-C6.

No gráfico da Figura 6.26, nota-se uma boa aderência dos pontos do resultado da simulação com os pontos do ensaio experimental, principalmente na região central, da posição 25 a $65 \mathrm{~cm}$, onde são menores as influências de imperfeições do modelo físico. O erro médio da simulação para essa condição foi de $5,94 \%$, dentro do esperado para esse trabalho. 


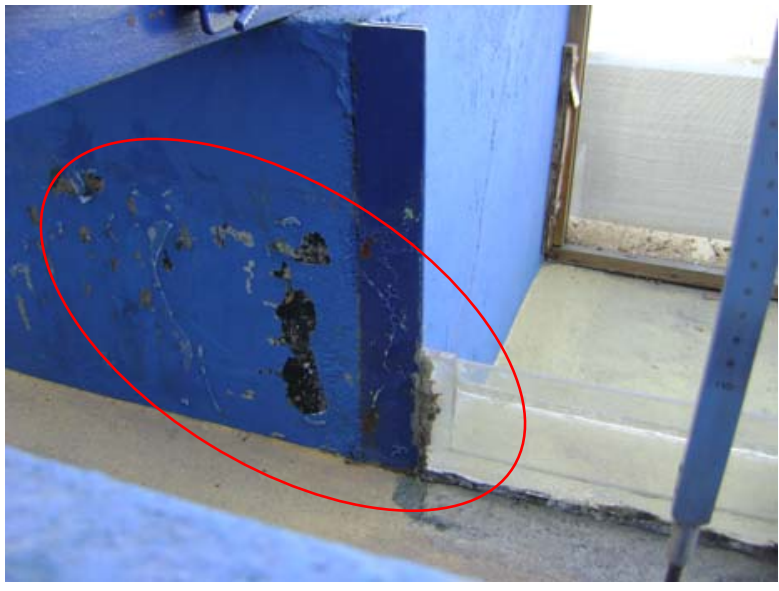

(a) Montante

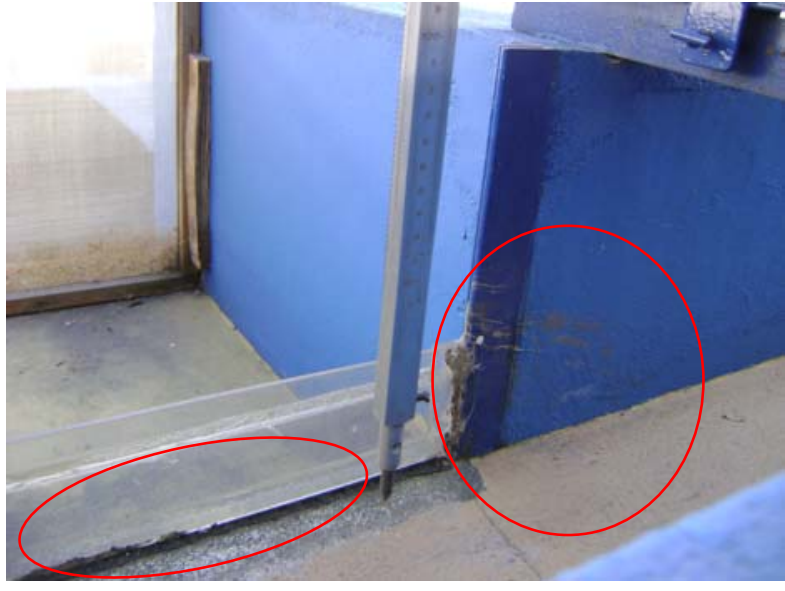

(b) Jusante

Figura 6.25 - Vista em detalhe do vertedor lateral.

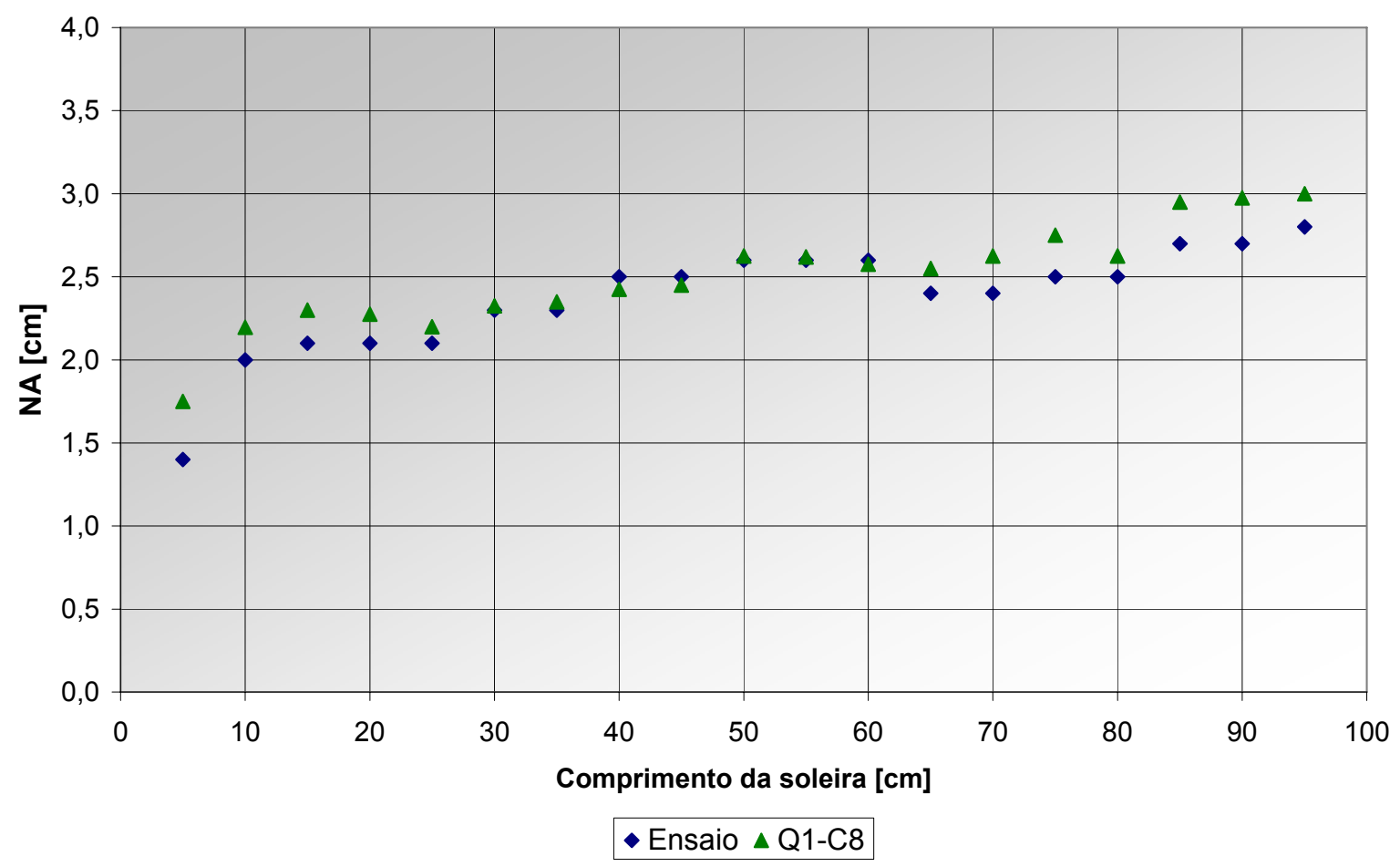

Figura 6.26 - Comparação do nível d’água sobre a soleira para a condição Q1-C8.

$\mathrm{Na}$ Figura 6.27 também nota-se uma boa aderência dos pontos do resultado da simulação com os pontos do ensaio experimental, principalmente na região de 15 a $50 \mathrm{~cm}$ e na extremidade de jusante, de 80 a $95 \mathrm{~cm}$. O erro médio da simulação para essa condição foi de $3,91 \%$. 


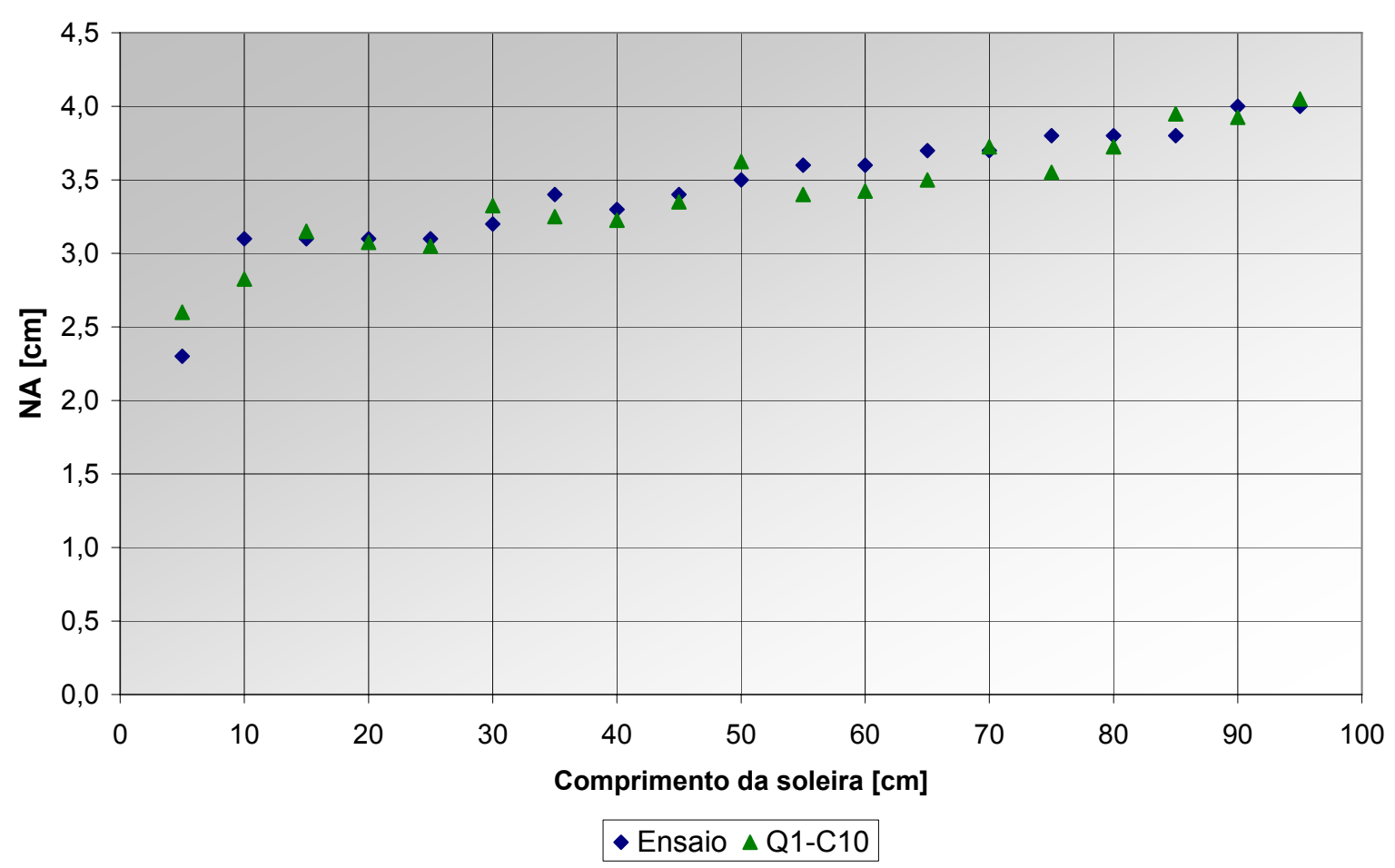

Figura 6.27 - Comparação do nível d'água sobre a soleira para a condição Q1-C10.

A Figura 6.28 apresenta a distribuição longitudinal de pressão estática relativa no eixo do canal principal para a condição Q1-C6, onde essa distribuição é igual à distribuição hidrostática de pressões. Observa-se que a distribuição de pressões não apresenta uma variação significativa ao longo do canal principal, e o seu escoamento pode ser classificado como paralelo, onde as linhas de corrente são retas paralelas. Essa situação também foi observada para as condições Q1-C8 e Q1-C10.

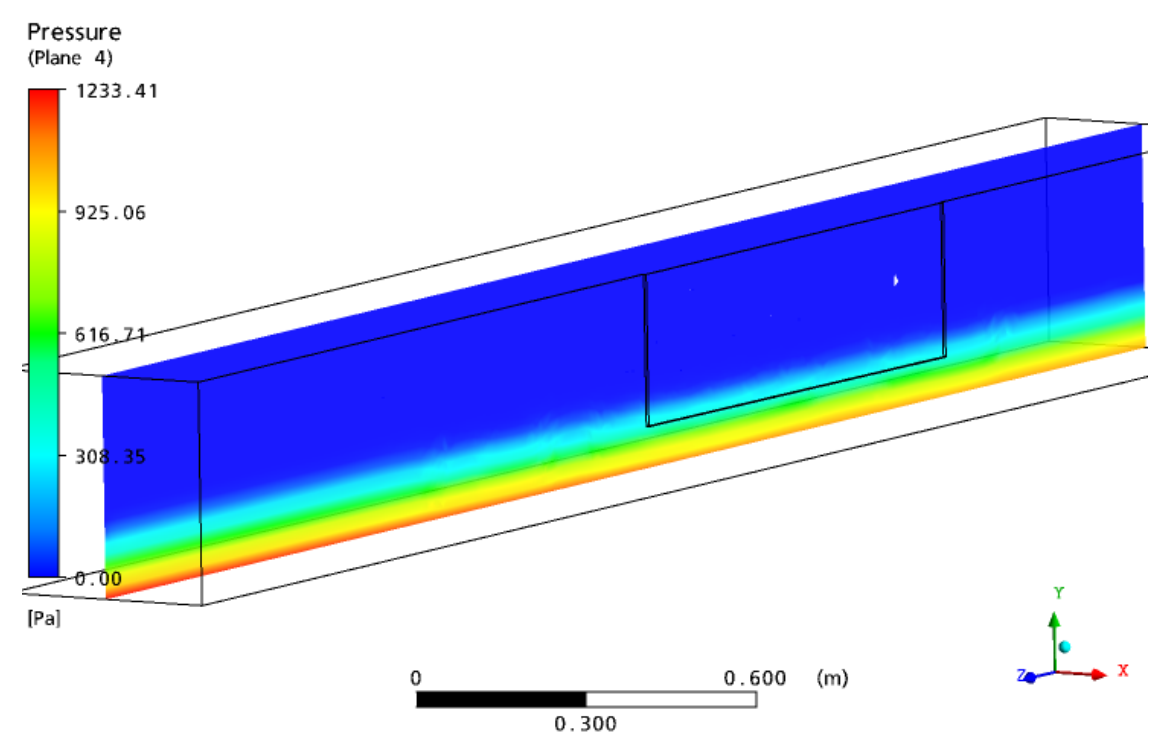

Figura 6.28 - Distribuição longitudinal da pressão estática relativa para a condição Q1-C6. 
As distribuições longitudinais da velocidade no eixo do canal principal são representadas pelas Figuras 6.29 a 6.31. Essas distribuições são afetadas logo a montante do vertedor lateral, onde a linhas de fluxo do escoamento direcionam-se para o dispositivo lateral.

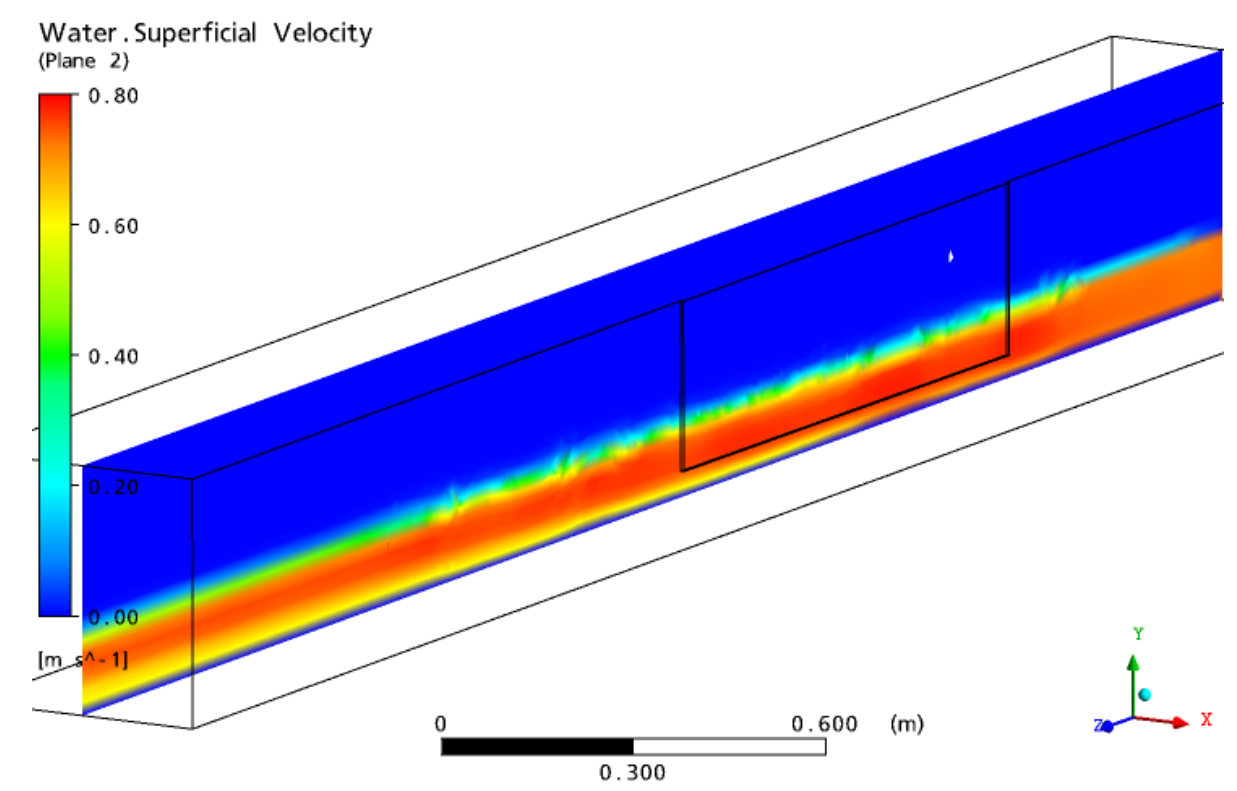

Figura 6.29 - Distribuição longitudinal da velocidade para a condição Q1-C6.

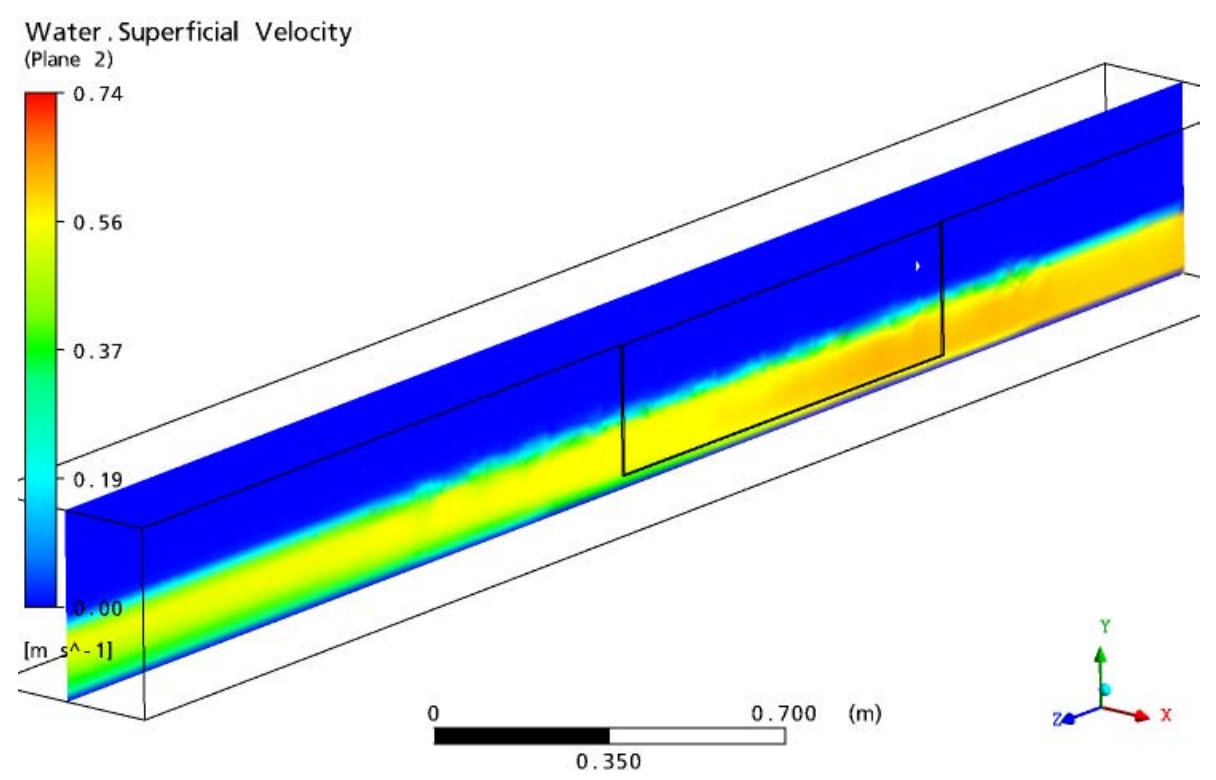

Figura 6.30 - Distribuição longitudinal da velocidade para a condição Q1-C8.

As velocidades máximas observadas para as três condições são aproximadamente: $\mathrm{Q} 1-\mathrm{C} 6=0,80 \mathrm{~m} / \mathrm{s}, \mathrm{Q} 1-\mathrm{C} 8=0,70 \mathrm{~m} / \mathrm{s}$ e $\mathrm{Q} 1-\mathrm{C} 10=0,65 \mathrm{~m} / \mathrm{s}$. 


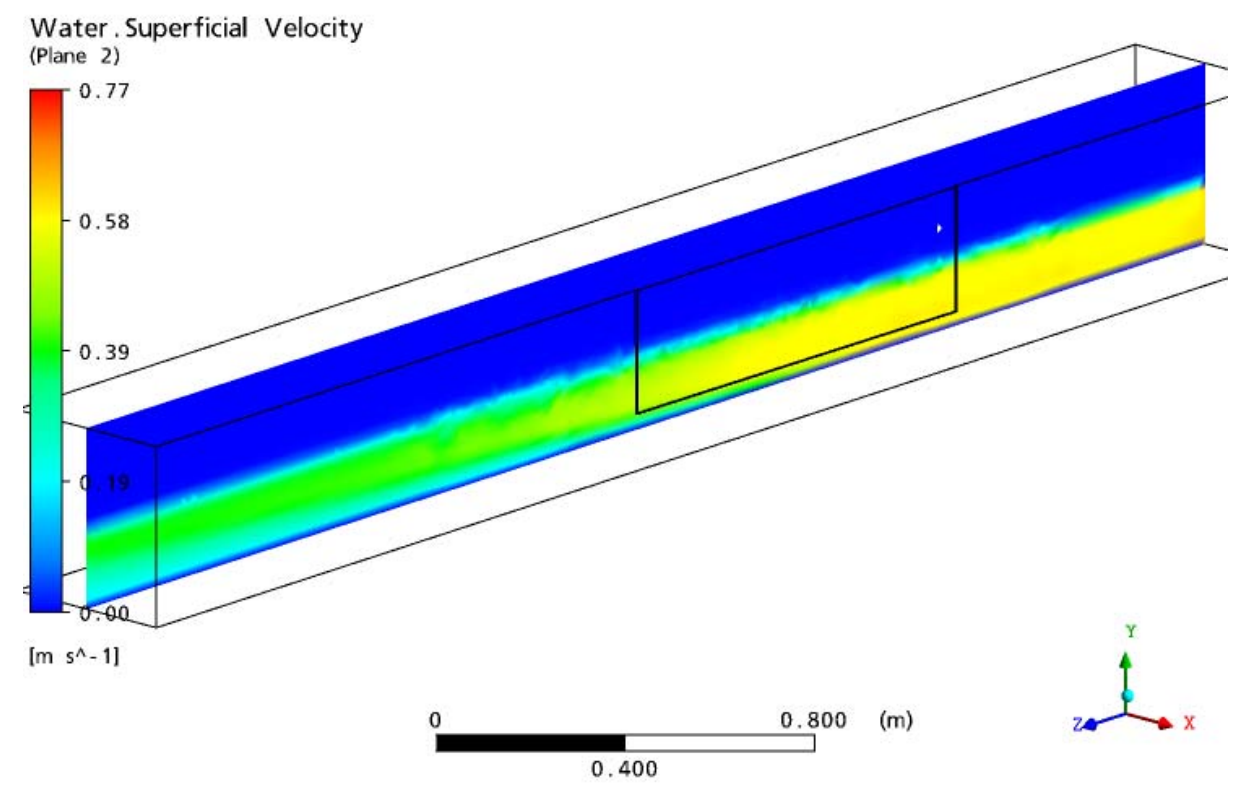

Figura 6.31 - Distribuição longitudinal da velocidade para a condição Q1-C10.

A distribuição vertical da velocidade é aproximadamente parabólica, com valores decrescentes com a profundidade e a máxima velocidade ocorre um pouco abaixo da superfície livre. Isso pode ser verificado nas Figuras 6.32 a 6.34, onde são apresentadas três seções transversais do canal principal na região do vertedor lateral para as três condições de Q1, a posição está referenciada ao eixo Z. No início do vertedor lateral $(Z=1,00 \mathrm{~m})$ nota-se a velocidade mais distribuída no canal principal, verificando também a influência da camada limite, com velocidades tendendo a zero próximo as paredes.

A condição $Z=1,50 \mathrm{~m}$ refere-se ao meio do vertedor lateral, onde a distribuição de velocidade altera-se devido ao escoamento do dispositivo lateral, e essa alteração é propagada para a condição $Z=2,0 \mathrm{~m}$, fim do vertedor, onde se observa a diminuição da velocidade em sua distribuição nas três condições de Q1. Porém, para a condição Q1-C6 a velocidade média observada, de $0,71 \mathrm{~m} / \mathrm{s}$, no meio do vertedor foi aproximadamente 5\% e 7\% superior a velocidade, respectivamente, em seu início e fim, mostrando a influência positiva do vertedor lateral em sua região de tomada d'água.

Na Figura 6.32 no item (d), tem-se o vetor velocidade, que representa as linhas de fluxo do escoamento, na seção transversal $Z=1,50 \mathrm{~m}$, onde se pode observar o direcionamento dessas linhas para o vertedor lateral e a maior velocidade é 
observada em sua proximidade no canal principal. O canal principal possui a base de $0,40 \mathrm{~m}$, o lado oposto ao dispositivo lateral, não apresenta uma perturbação visível do escoamento nos $0,15 \mathrm{~m}$ da parede oposta ao eixo do canal.

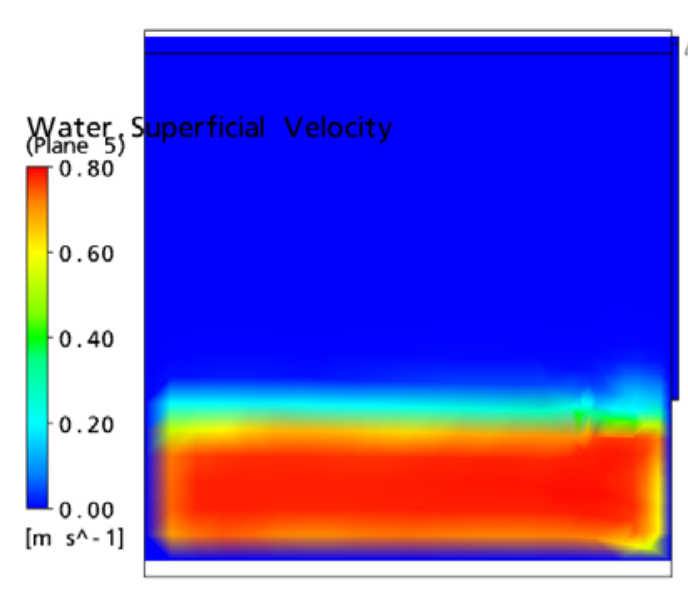

(a) $Z=1,00 \mathrm{~m}$.

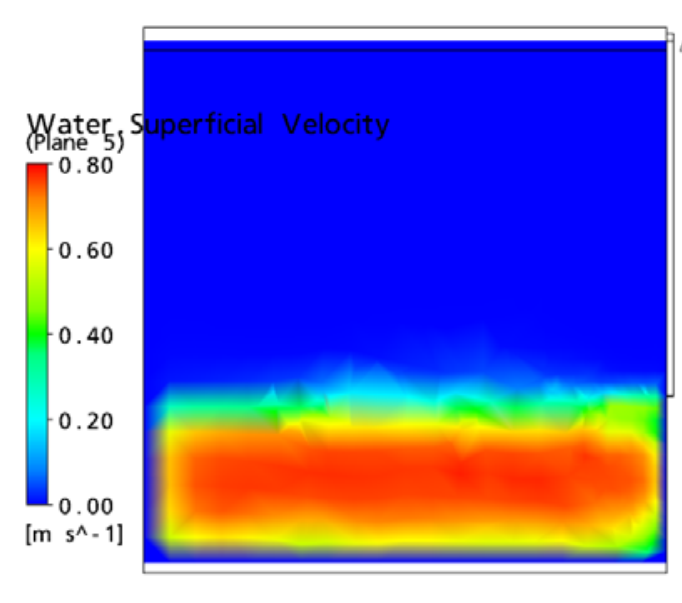

(c) $Z=2,00 \mathrm{~m}$.
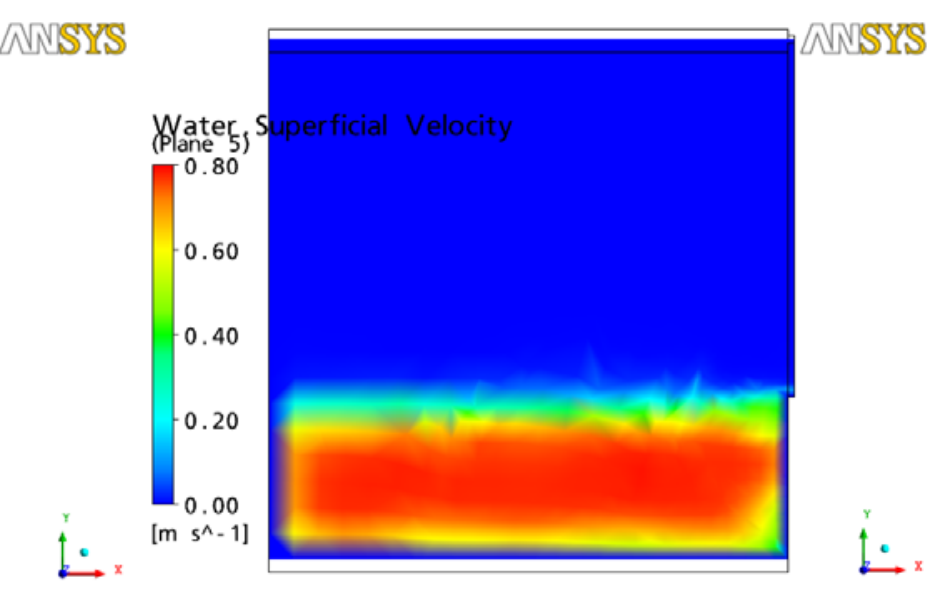

(b) $Z=1,50 \mathrm{~m}$.
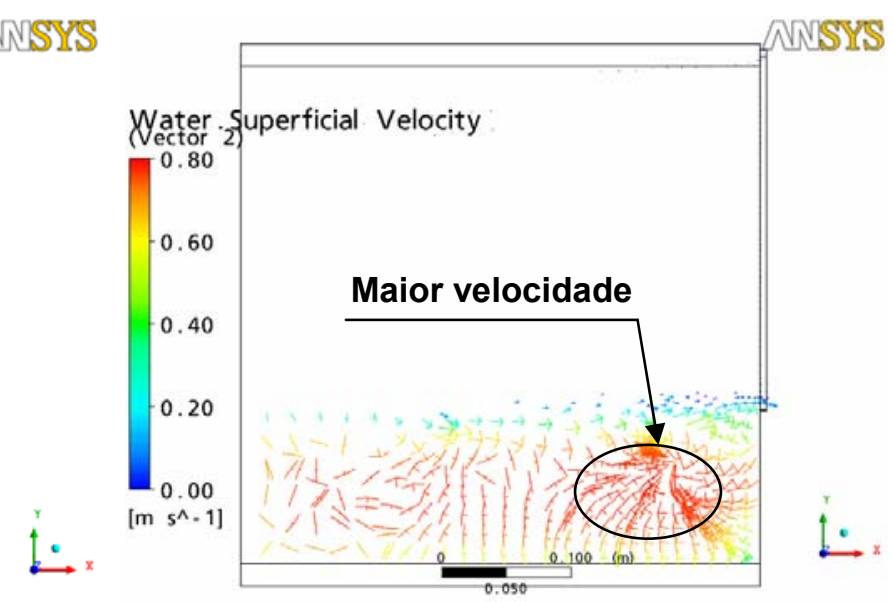

(d) Vetor $Z=1,50 \mathrm{~m}$.

Figura 6.32 - Distribuição transversal da velocidade ao longo do vertedor lateral para a condição Q1-C6.

A condição Q1-C8 (Figura 6.33) apresentou uma velocidade média de 0,58 $\mathrm{m} / \mathrm{s}$, no meio do vertedor foi aproximadamente $5 \%$ e $30 \%$ superior a velocidade, respectivamente, em seu início e fim, mostrando a influência positiva do vertedor lateral em sua região de tomada d'água. No item (d) dessa condição, o vetor velocidade apresentou o direcionamento dos vetores com os maiores valores para o 
vertedor lateral. O canal principal de base $0,40 \mathrm{~m}$, não apresentou uma perturbação visível do escoamento nos $0,10 \mathrm{~m}$ da parede oposta ao eixo do canal.

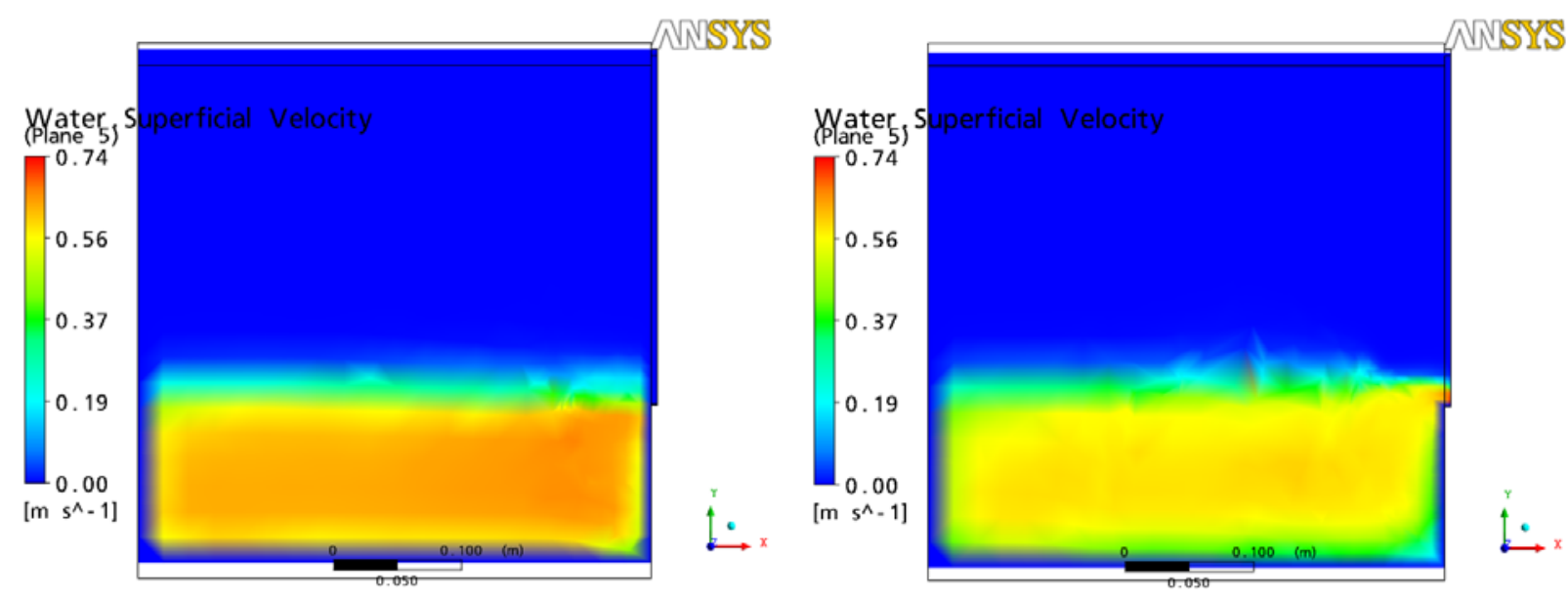

(a) $Z=1,00 \mathrm{~m}$

(b) $Z=1,50 \mathrm{~m}$.

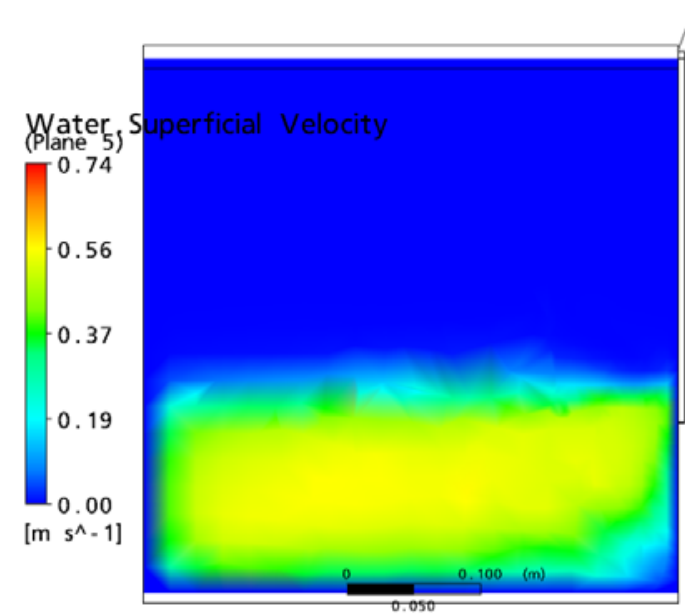

(c) $Z=2,00 \mathrm{~m}$.

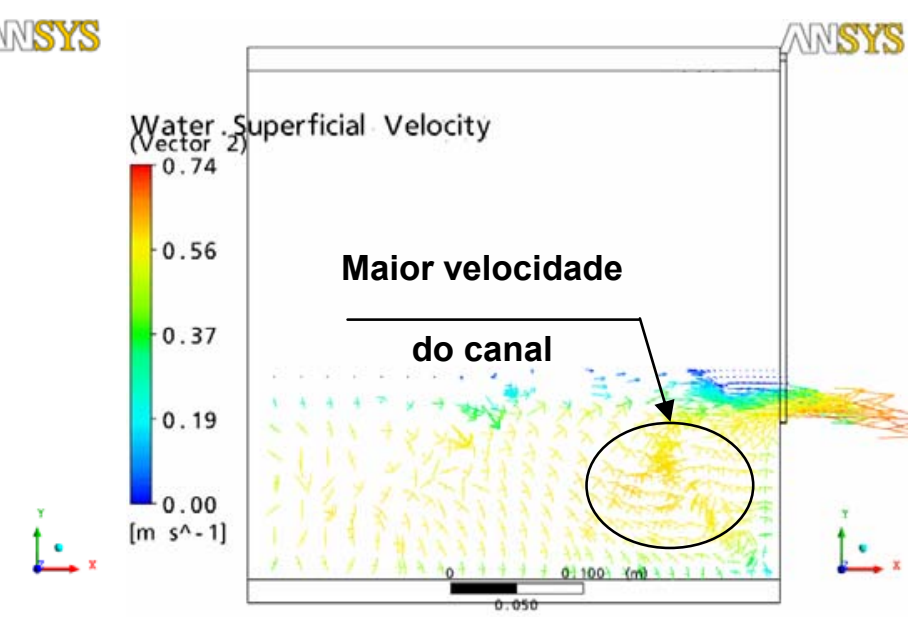

(d) Vetor $Z=1,50 \mathrm{~m}$

Figura 6.33 - Distribuição transversal da velocidade ao longo do vertedor lateral para a condição Q1-C8.

Já a condição Q1-C10 (Figura 6.34) nos itens (b) e (c) se observou a diminuição da velocidade em sua distribuição e o desenvolvimento de uma região de mínima velocidade abaixo da soleira. Entretanto, a velocidade média observada no meio do vertedor foi de $0,60 \mathrm{~m} / \mathrm{s}$, aproximadamente $3 \%$ e $50 \%$ superior a velocidade, respectivamente, em seu início e fim. Verifica-se que quanto maior a vazão escoada pelo vertedor lateral, maior é a diminuição da velocidade a sua jusante no canal principal. 
Com o aumento da vazão escoada pelo dispositivo lateral, maior é a sua influência no canal principal, para a condição Q1-C10 somente $0,05 \mathrm{~m}$ do lado oposto não sofre interferência do dispositivo, onde o escoamento segue sem perturbações aparentes.

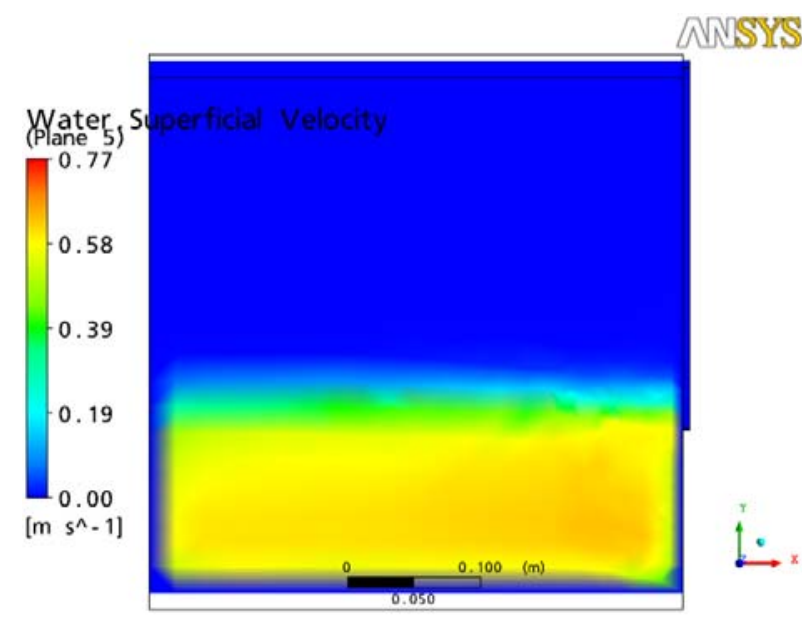

(a) $Z=1,00 \mathrm{~m}$.

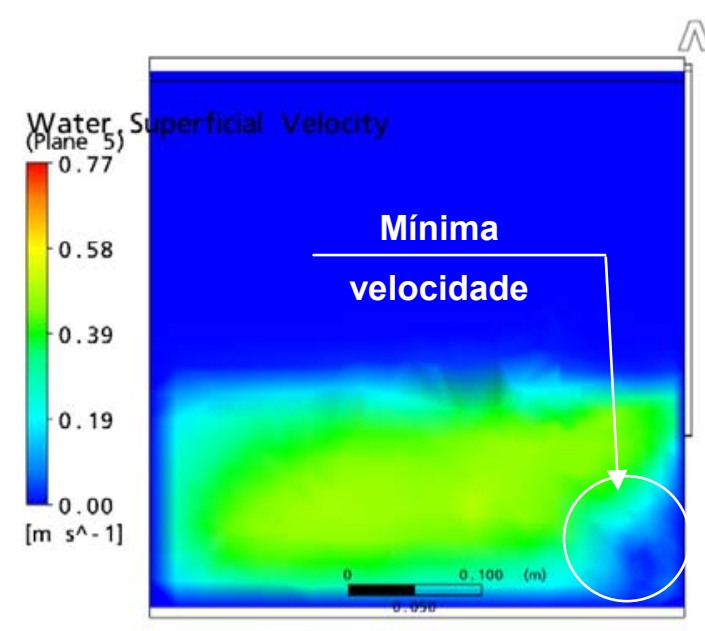

(c) $Z=2,00 \mathrm{~m}$.

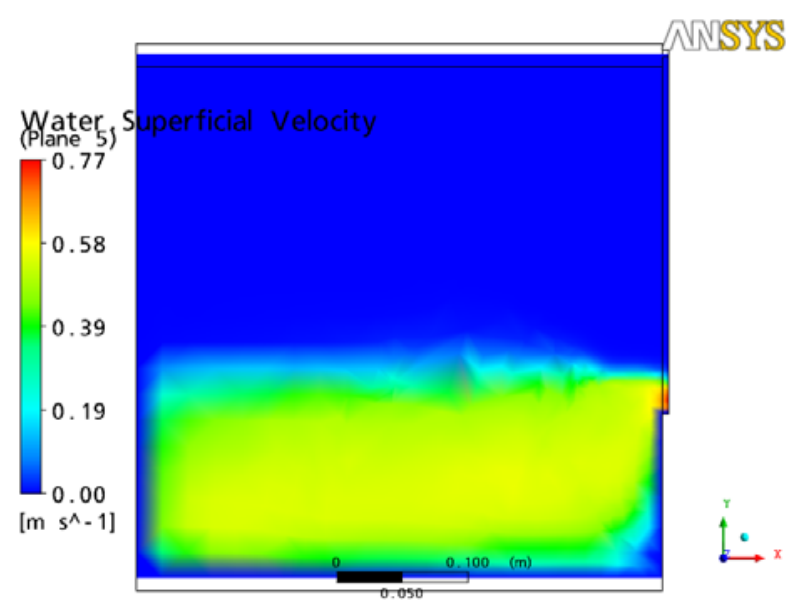

(b) $Z=1,50 \mathrm{~m}$.

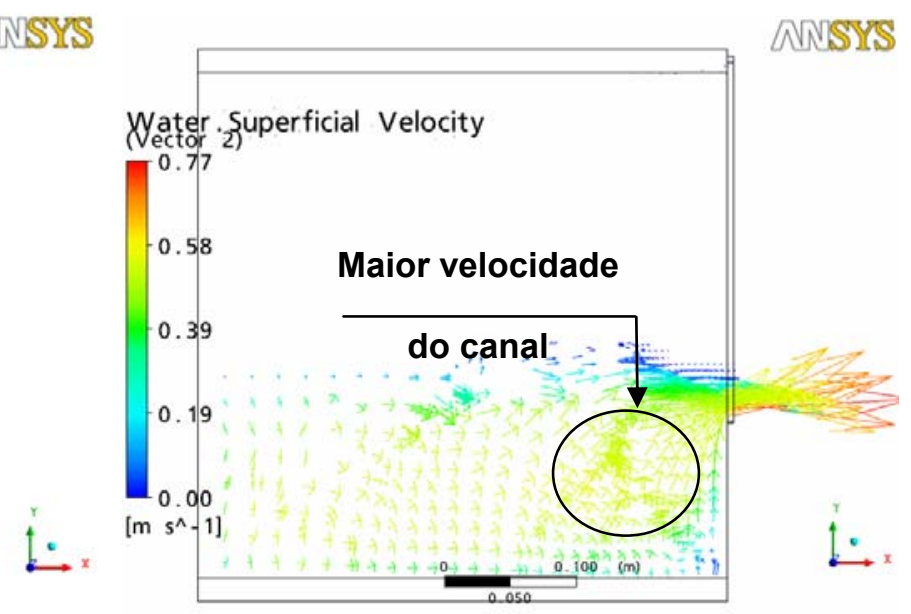

(d) Vetor $Z=1,50 \mathrm{~m}$.

Figura 6.34 - Distribuição transversal da velocidade ao longo do vertedor lateral para a condição Q1-C10.

As Figuras 6.35 a 6.37 apresentam a distribuição de velocidade na seção transversal do vertedor lateral. A condição Q1-C6, devido à pequena vazão escoada, não apresenta uma variação visível ao longo da soleira. 


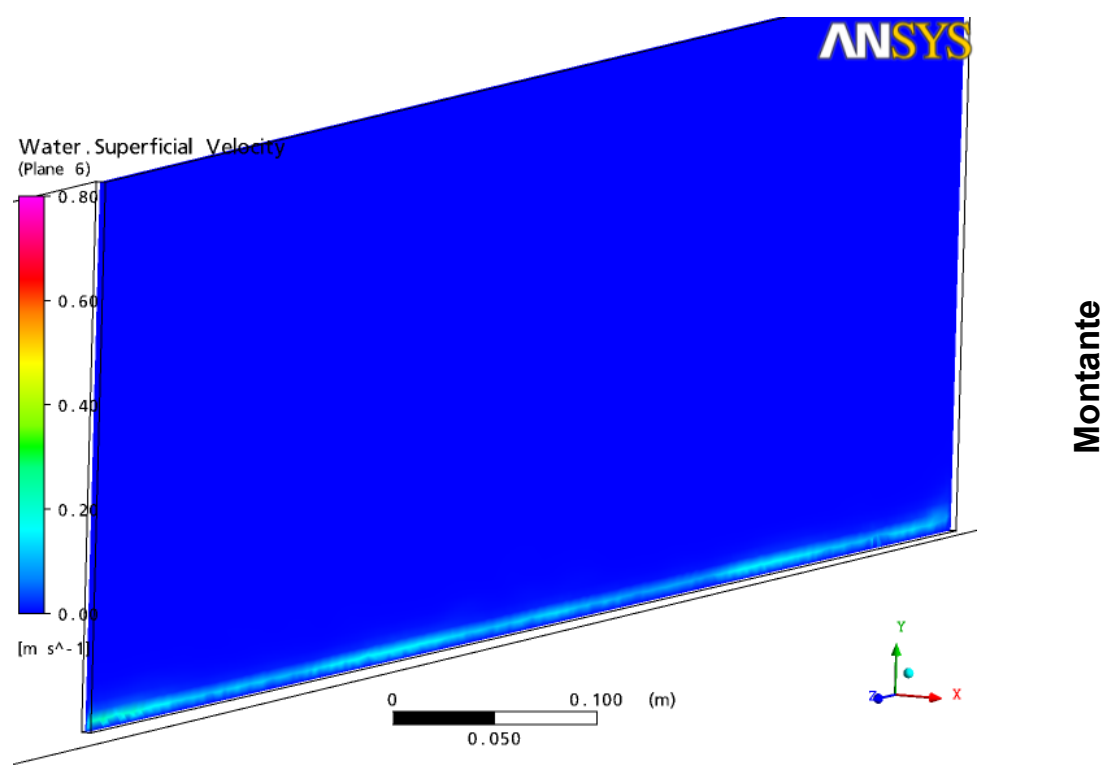

Figura 6.35 - Distribuição transversal da velocidade no vertedor lateral para a condição Q1-C6.

A distribuição de velocidade para as condições Q1-C8 e Q1-C10 (Figura 6.36 e 6.37) apresentam uma variação positiva ao longo da soleira de montante para jusante, e nota-se que nos $0,10 \mathrm{~cm}$ iniciais as velocidades são pequenas quando comparadas com toda a soleira. Também se observa as maiores velocidades fora da região das paredes laterais (extremidades).

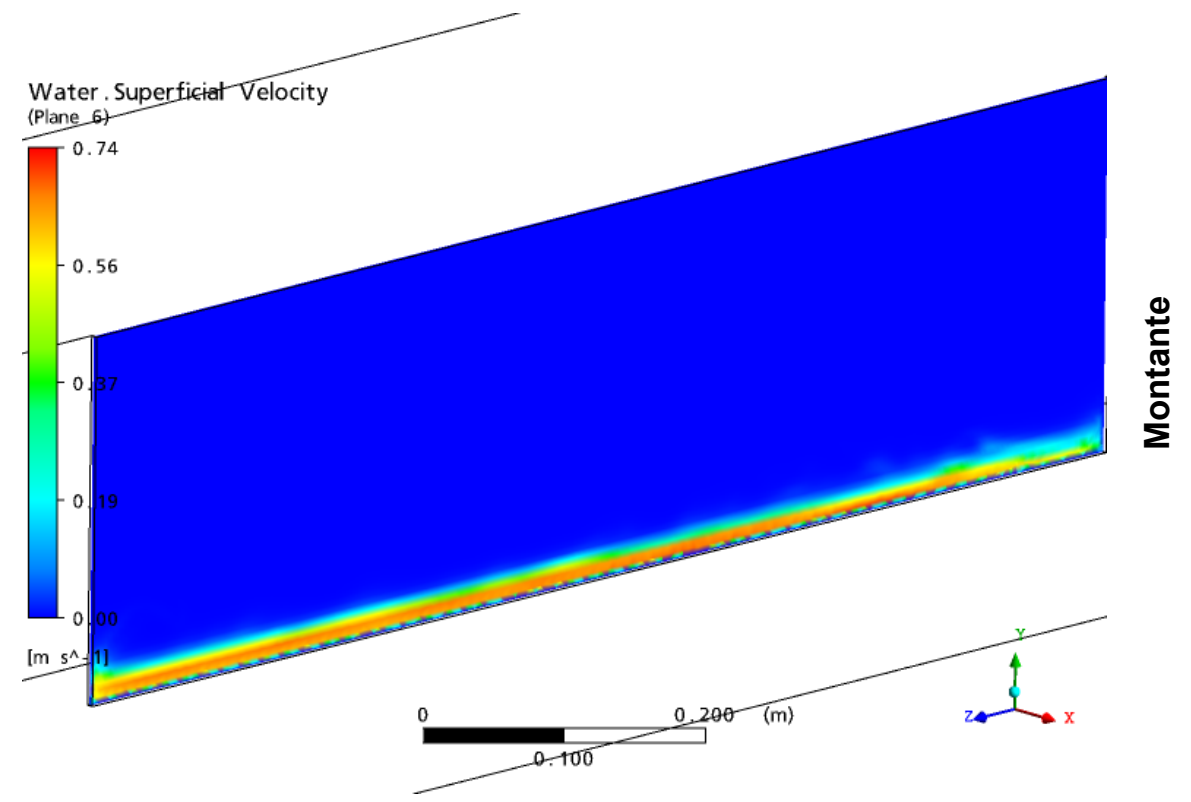

Figura 6.36 - Distribuição transversal da velocidade no vertedor lateral para a condição Q1-C8. 


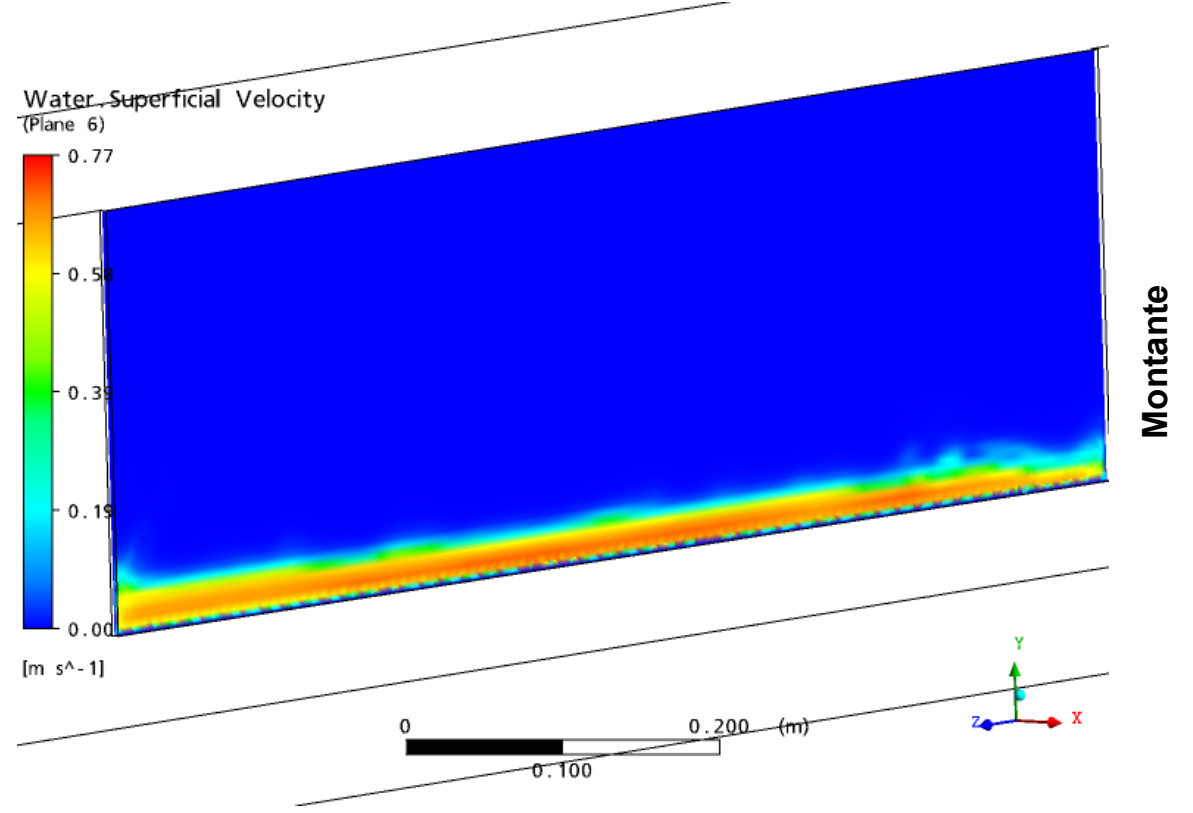

Figura 6.37 - Distribuição transversal da velocidade no vertedor lateral para a condição Q1C10.

As Figuras 6.38 a 6.40 representam a distribuição longitudinal do vetor velocidade ao longo do canal principal, onde se verifica a região de influência do vertedor lateral. Para a condição Q1-C6 (Figura 6.38), onde a relação entre a vazão escoada através do vertedor lateral e a vazão total do canal principal $\left(Q_{V L} / Q_{T}\right)$ é em torno de 0,02 , pode-se verificar a região de influência delimitada através dos pontos pretos.

Para as três condições, Q1-C6, Q1-C8 e Q1-C10, verifica-se que a montante as linhas de correntes não são afetadas, aproximadamente, a uma distância de 0,55 $\mathrm{m}$ do início do dispositivo. Já a jusante as mesmas não são afetadas a aproximadamente $0,70 \mathrm{~m}$ do fim do dispositivo. Na região do vertedor lateral nota-se a mudança de direção do vetor velocidade e as maiores velocidades em sua direção.

As condições Q1-C8 e Q1-C10, representadas pelas Figuras 6.39 e 6.40, apresentam a relação $Q_{\mathrm{V} /} / Q_{\mathrm{T}}$, respectivamente, de aproximadamente 0,21 e 0,37. 


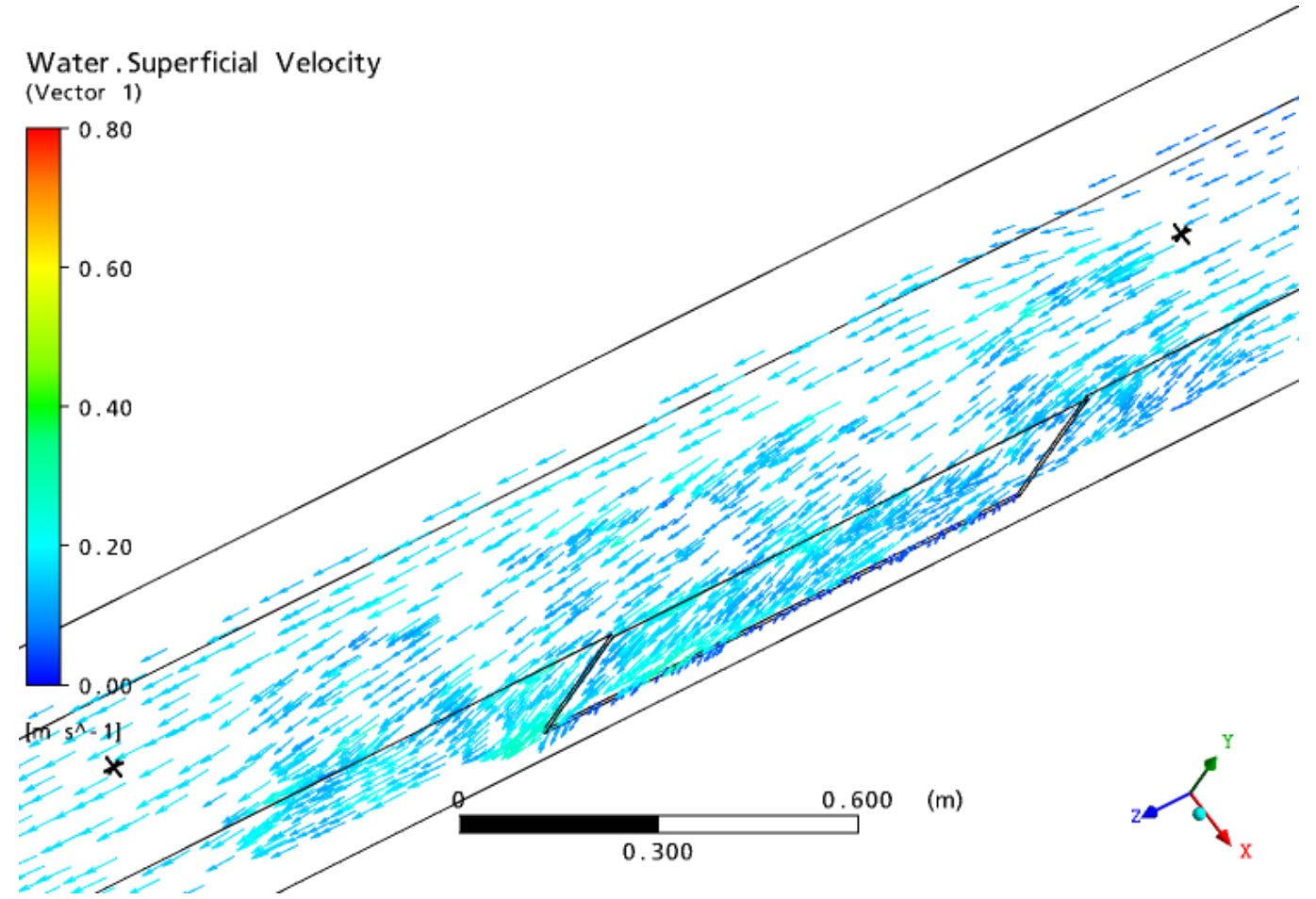

Figura 6.38 - Distribuição longitudinal do vetor velocidade para a condição Q1-C6.

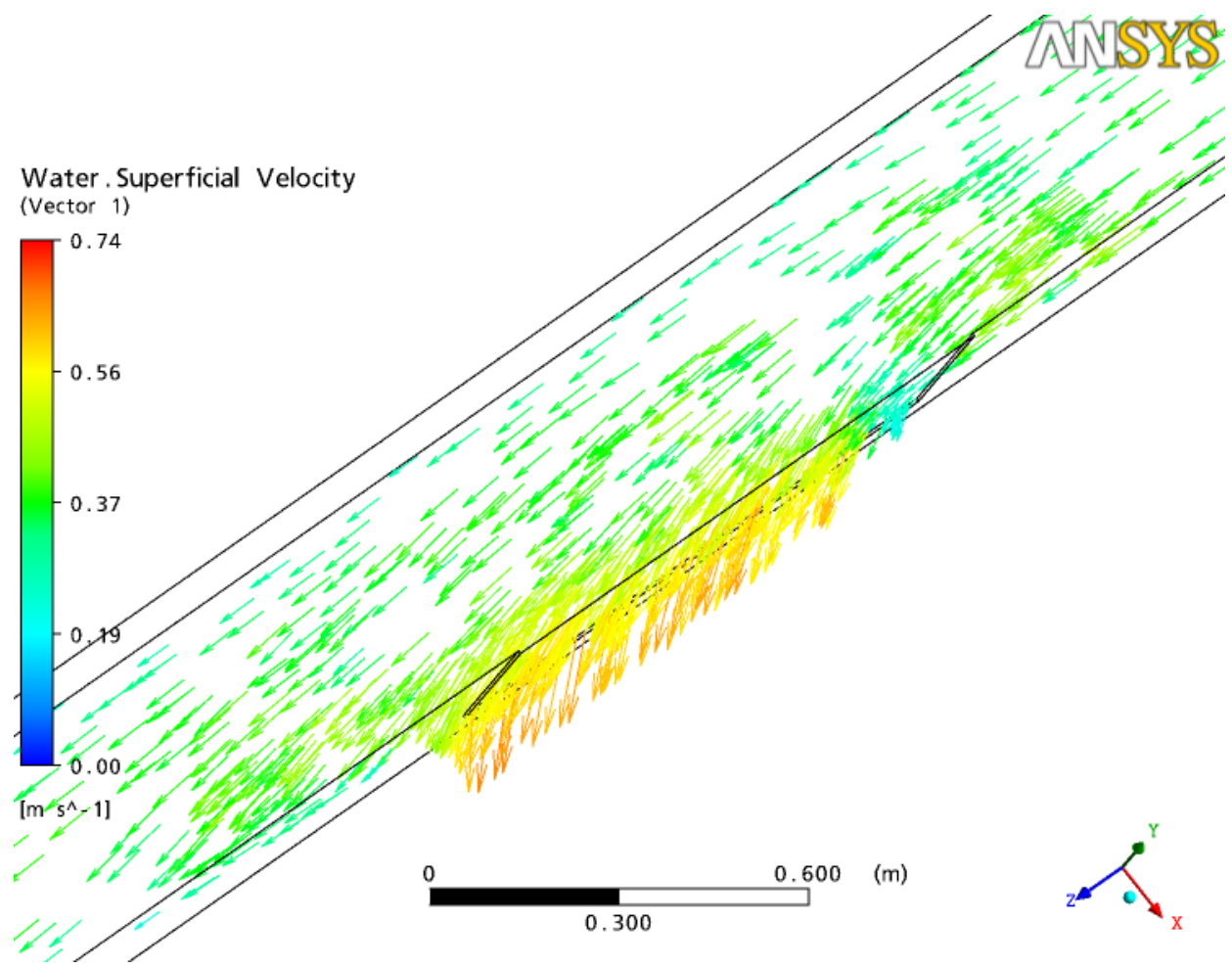

Figura 6.39 - Distribuição longitudinal do vetor velocidade para a condição Q1-C8. 


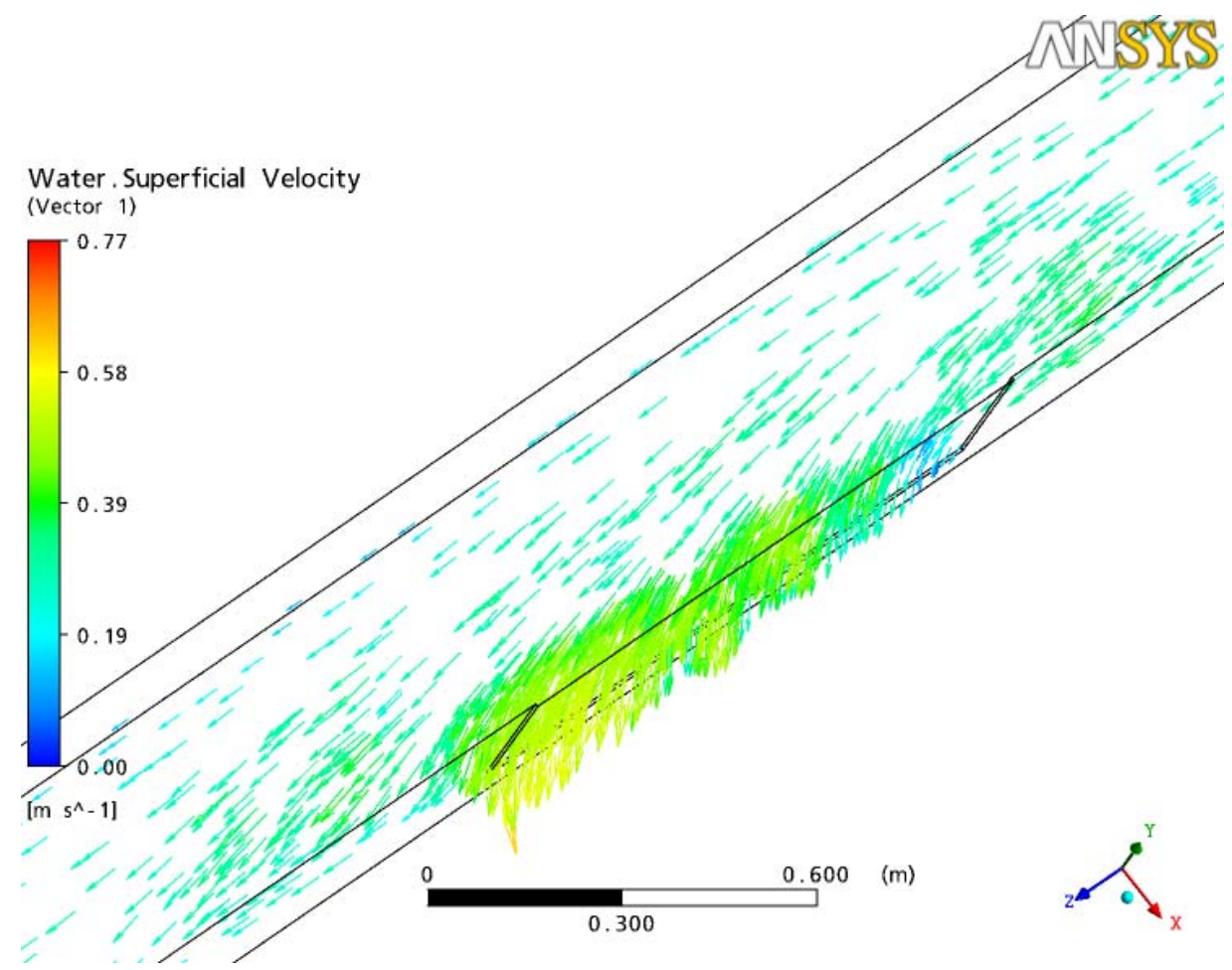

Figura 6.40 - Distribuição longitudinal do vetor velocidade para a condição Q1-C10.

\subsubsection{Condição Q2}

A condição Q2 representa a vazão escoada no canal principal $\left(\mathrm{Q}_{T}\right)$ de aproximadamente $38,5 \mathrm{~L} / \mathrm{s}$. Serão apresentados os resultados e análises das três condições de variação da comporta Q2-C6, Q2-C8 e Q2-C10.

A fração volumétrica do ar e da água pode ser visualizada nas Figuras 6.41 a 6.43 , onde a interface entre ambos define a superfície d'água, que está representada de azul claro. Observam-se perturbações mais intensas no canal principal, quando comparado com a condição Q1, devido ao aumento da vazão escoada, tanto no canal principal como no dispositivo lateral.

Para a condição Q2-C6 (Figura 6.41) a vazão escoada no vertedor lateral ( $\left.Q_{\mathrm{VL}}\right)$ é 3,88 L/s, já a condição Q2-C8 (Figura 6.42) escoa a vazão QVL de 12,12 L/s e a condição Q2-C10 (Figura 6.43) escoa a vazão QVL de 14,34 L/s. As perturbações no canal principal se modificam, principalmente, com a variação da vazão do dispositivo lateral. 


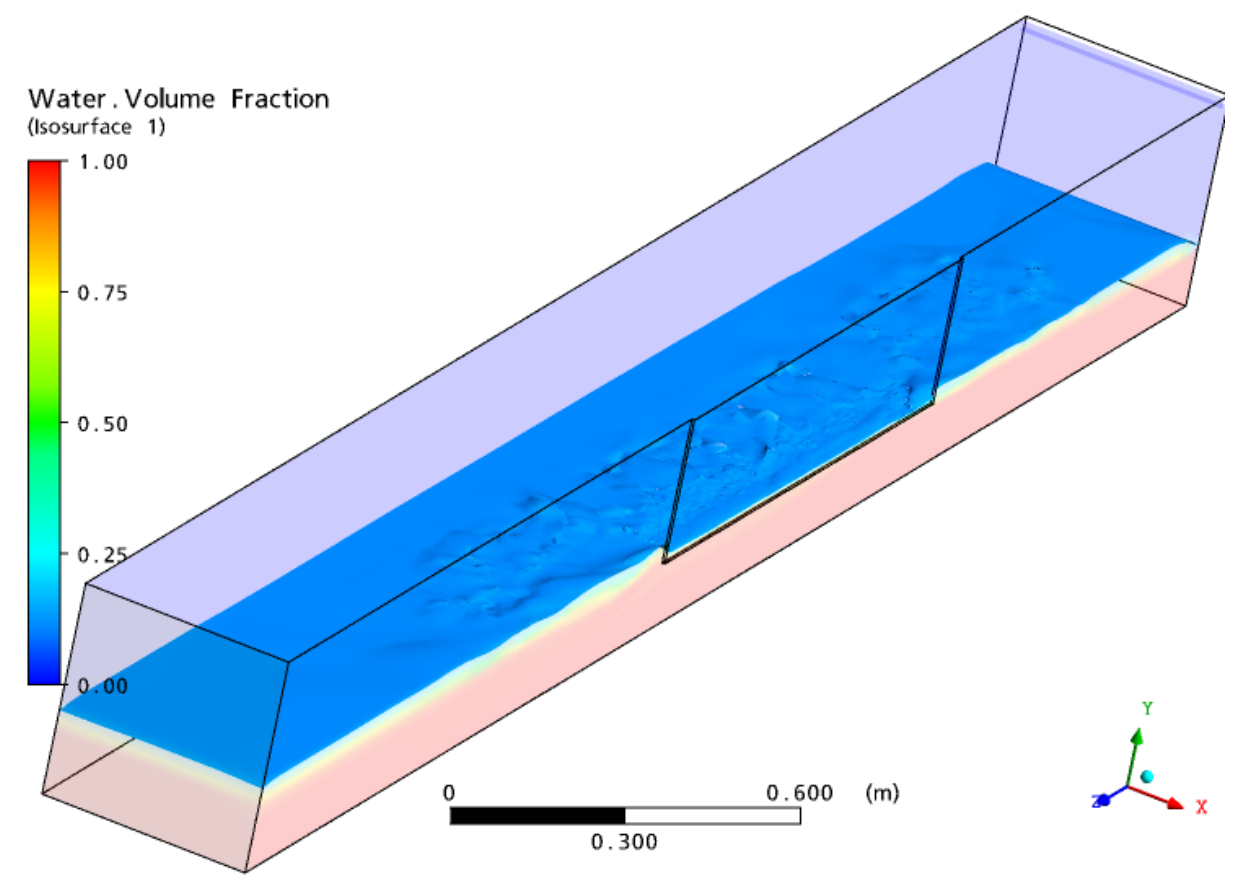

Figura 6.41 - Vista isométrica da superfície d'água para a condição Q2-C6.

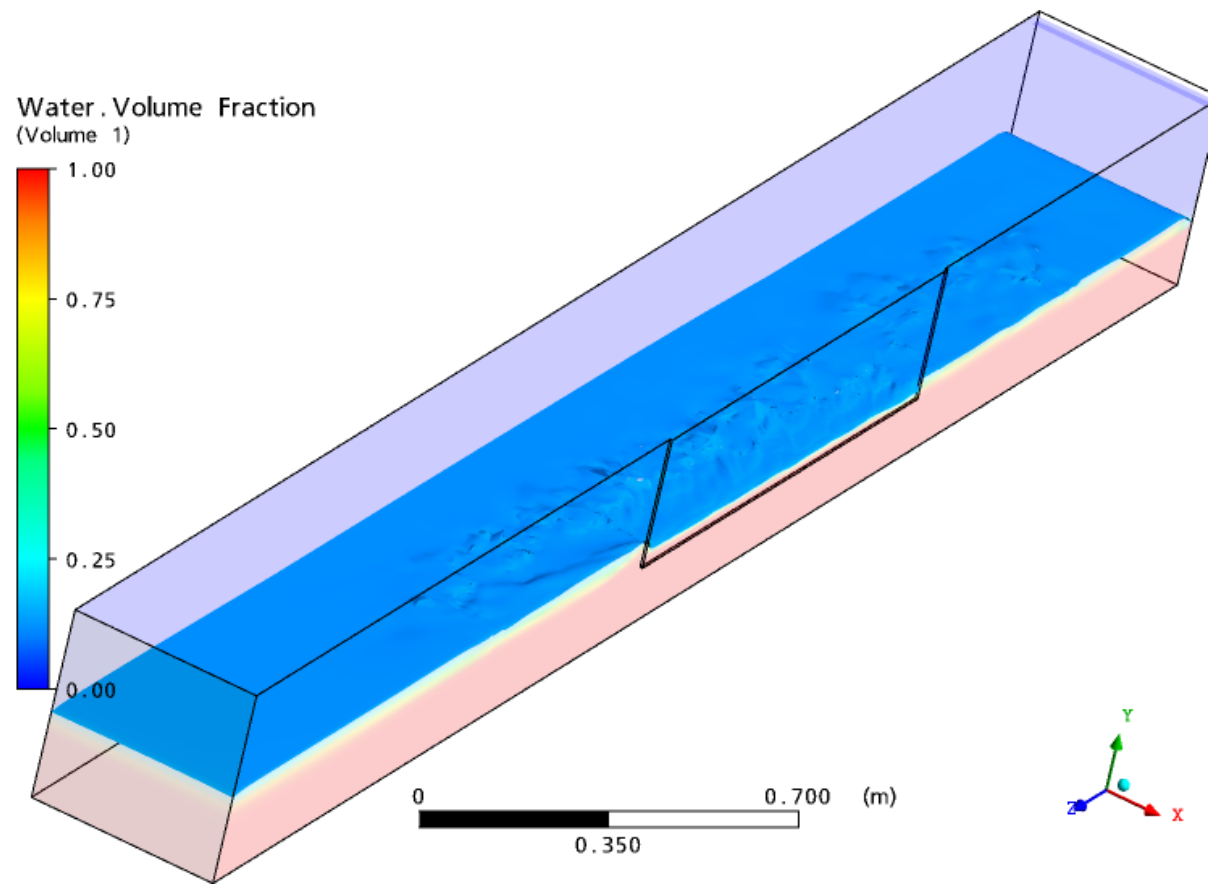

Figura 6.42 - Vista isométrica da superfície d'água para a condição Q2-C8. 


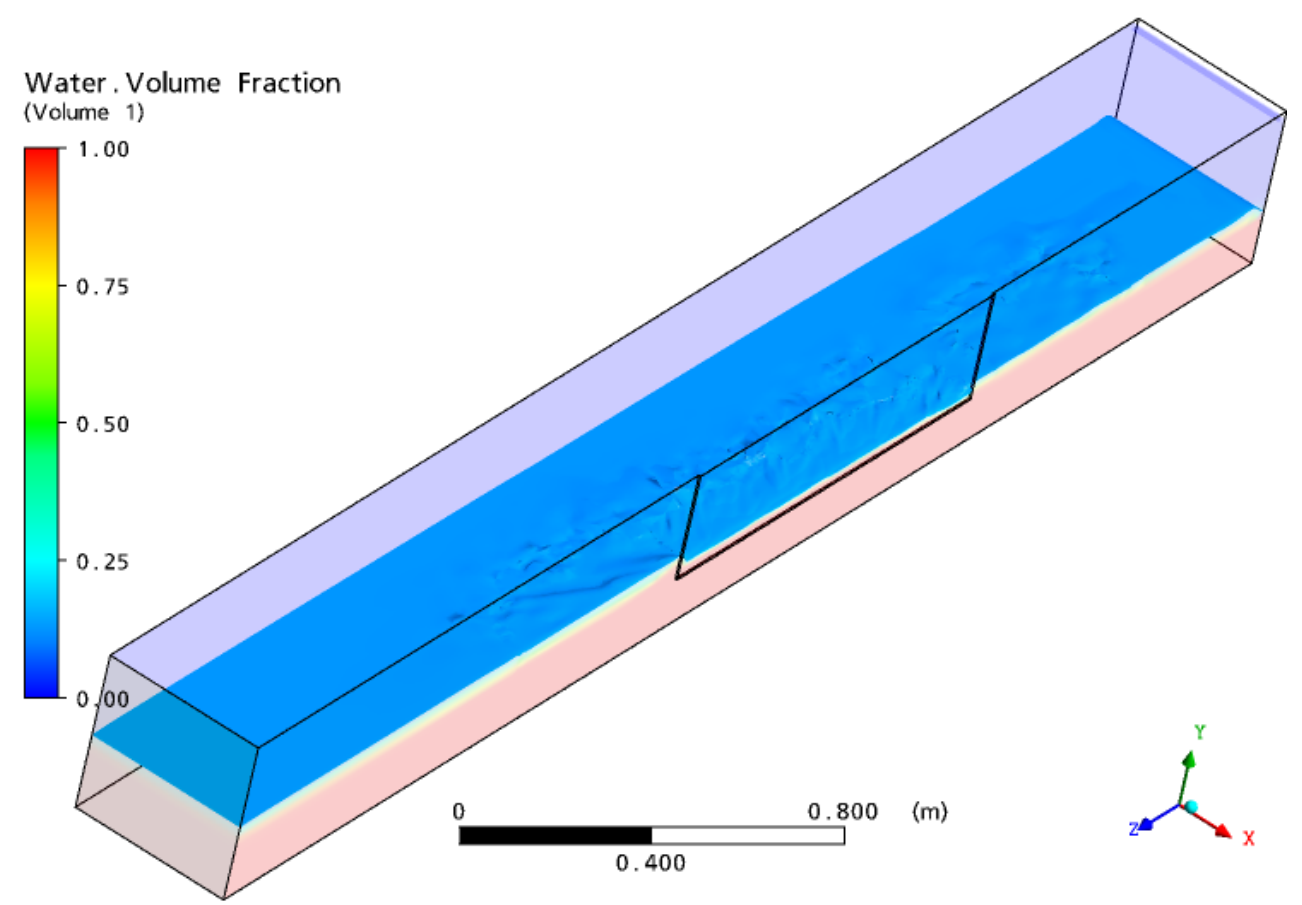

Figura 6.43 - Vista isométrica da superfície d'água para a condição Q2-C10.

Nas Figuras 6.44 a 6.46, tem-se a vista frontal do vertedor lateral (direita representa montante), podendo-se visualizar o nível d'água (NA) sobre a soleira e suas perturbações em detalhe. A variação mínima e máxima do NA sobre a soleira é representada na Tabela 6.5 .

Tabela 6.5 - Variação do NA sobre a soleira lateral.

\begin{tabular}{ccc}
\hline Ensaios & NA $_{\text {min. }}$ [cm] & NA $_{\text {máx. }}$ [cm] \\
\hline Q2-C6 & 0,70 & 1,75 \\
Q2-C8 & 2,10 & 4,15 \\
Q2-C10 & 2,20 & 4,60 \\
\hline
\end{tabular}




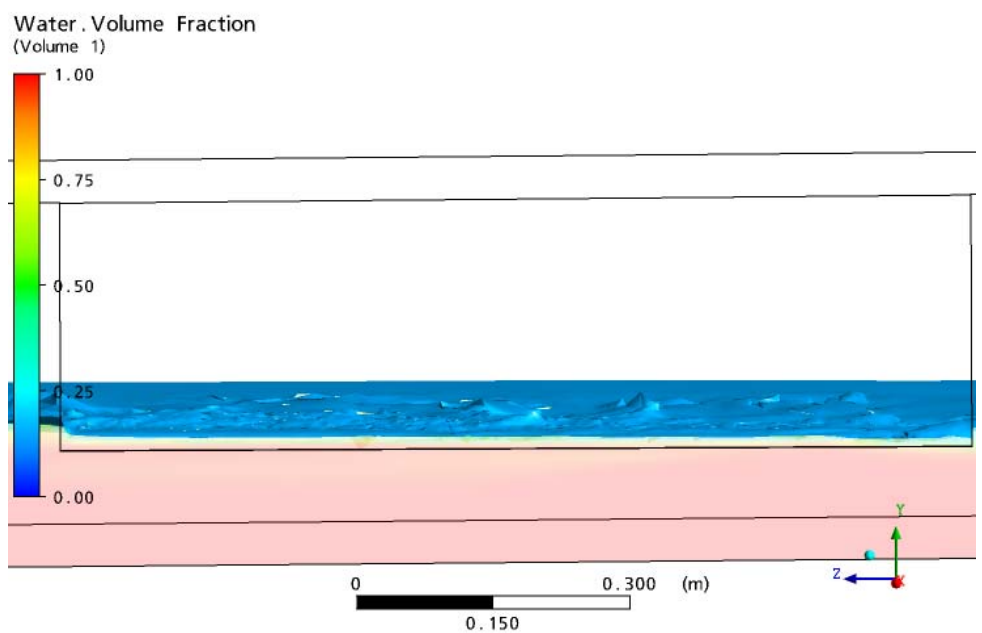

Figura 6.44 - Vista frontal da superfície d'água do vertedor lateral para a condição Q2-C6.

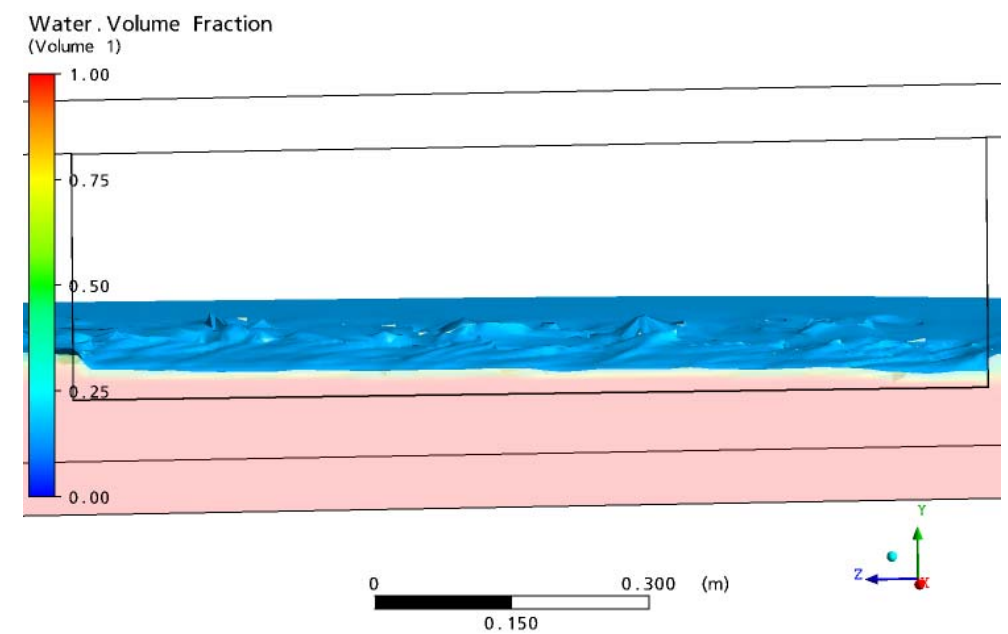

Figura 6.45 - Vista frontal da superfície d'água do vertedor lateral para a condição Q2-C8.

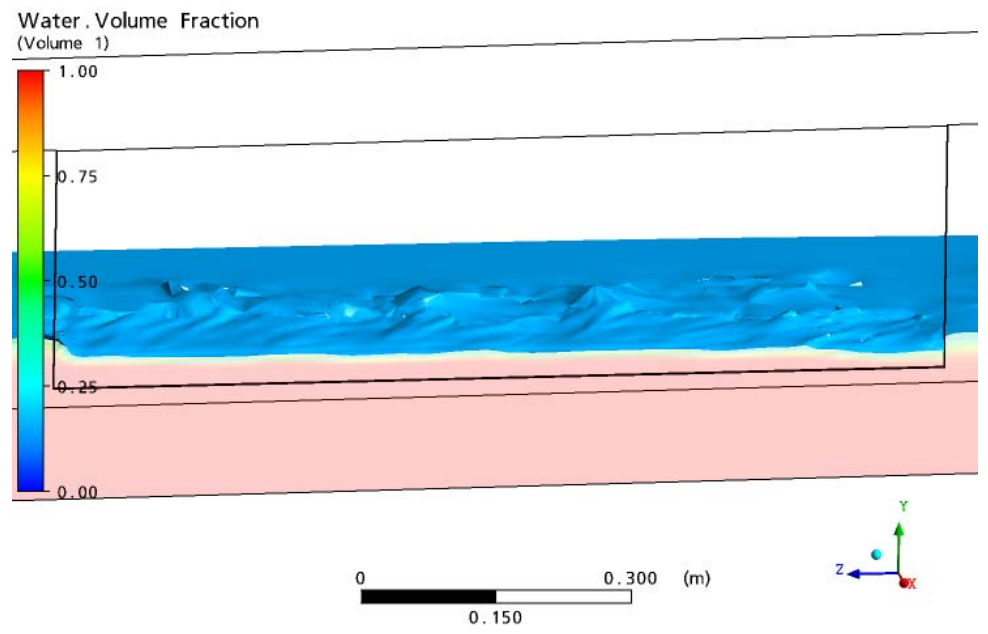

Figura 6.46 - Vista frontal da superfície d'água do vertedor lateral para a condição Q2-C10. 
Nos gráficos das Figuras 6.47 a 6.49 é representado no eixo das abscissas o comprimento da soleira, sendo a posição 0 montante, e a posição 100 jusante, e no eixo das ordenadas o nível d'água (NA) sobre a soleira. Para condição Q2-C6 o modelo matemático apresentou o erro médio, de 5,37\%, dentro do esperado para esse trabalho. Nota-se uma semelhança no comportamento do NA entre o resultado do modelo matemático com o ensaio experimental, principalmente na região central, da posição 25 a $60 \mathrm{~cm}$.

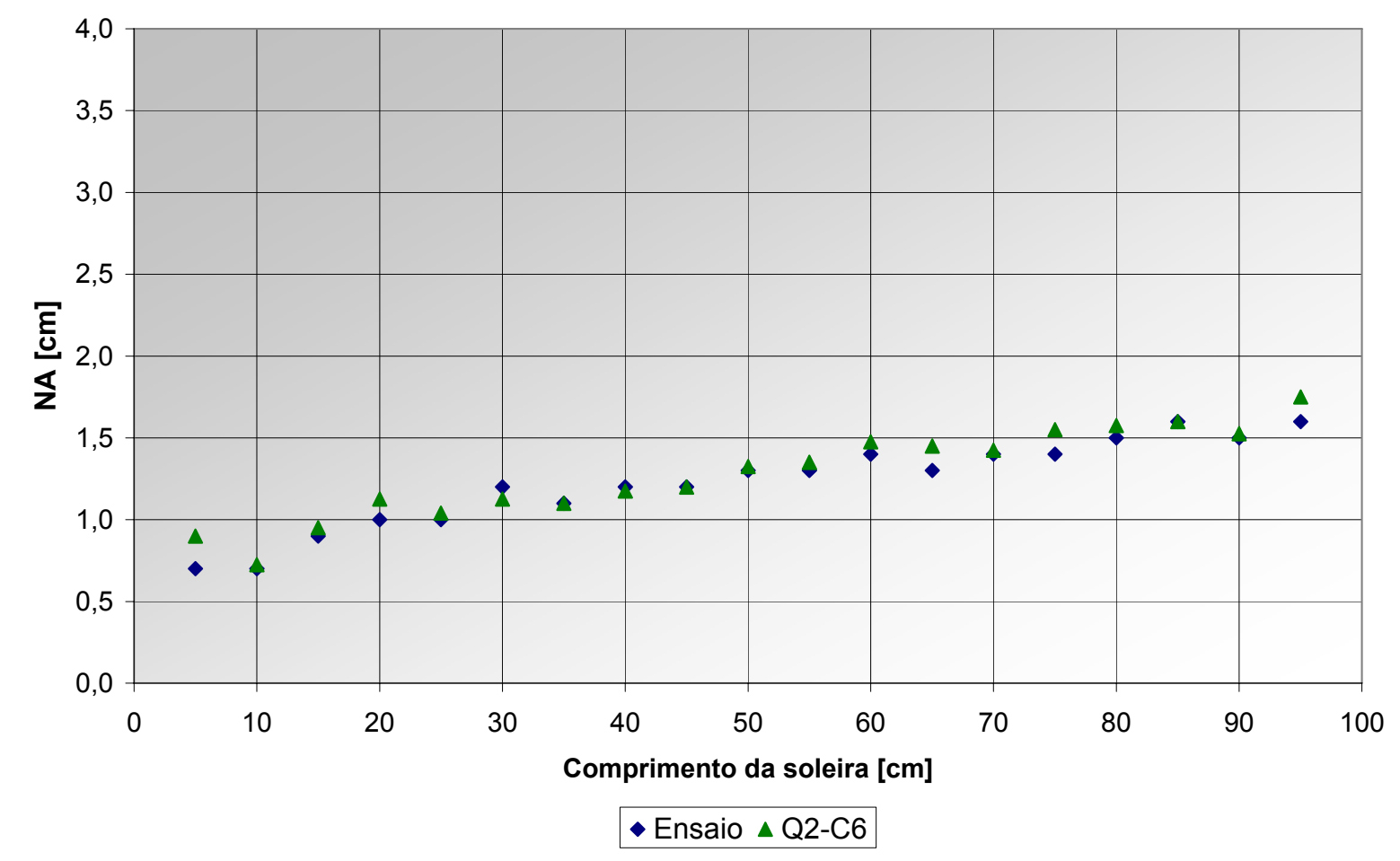

Figura 6.47 - Comparação do nível d'água sobre a soleira para a condição Q2-C6.

No gráfico da Figura 6.48, nota-se uma boa aderência dos pontos do resultado da simulação com os pontos do ensaio experimental, principalmente na região de 10 a $70 \mathrm{~cm}$. A região da extremidade de jusante, provavelmente foi afetada pelas imperfeições do modelo físico. $O$ erro médio da simulação para essa condição foi de $4,60 \%$.

Para a condição Q2-C10 (Figura 6.49), nota-se uma boa aderência dos pontos, principalmente na região de 50 a $95 \mathrm{~cm}$. Na extremidade de montante, de 5 a $15 \mathrm{~cm}$, também se verifica uma boa precisão dos resultados, sendo menores as influências das imperfeições do modelo físico para as maiores vazões escoadas pelo vertedor. O erro médio da simulação para essa condição foi de $4,47 \%$. 


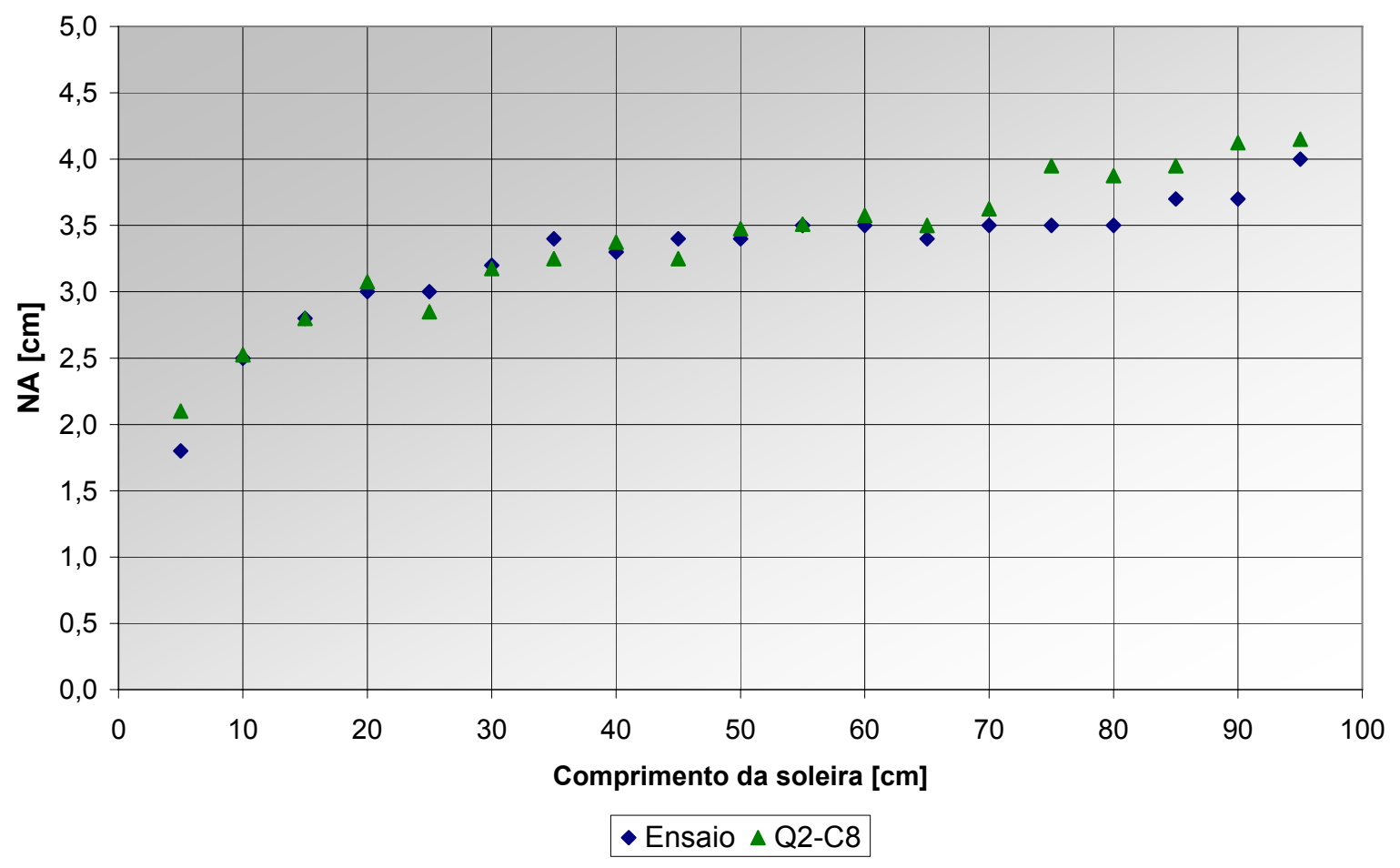

Figura 6.48 - Comparação do nível d’água sobre a soleira para a condição Q2-C8.

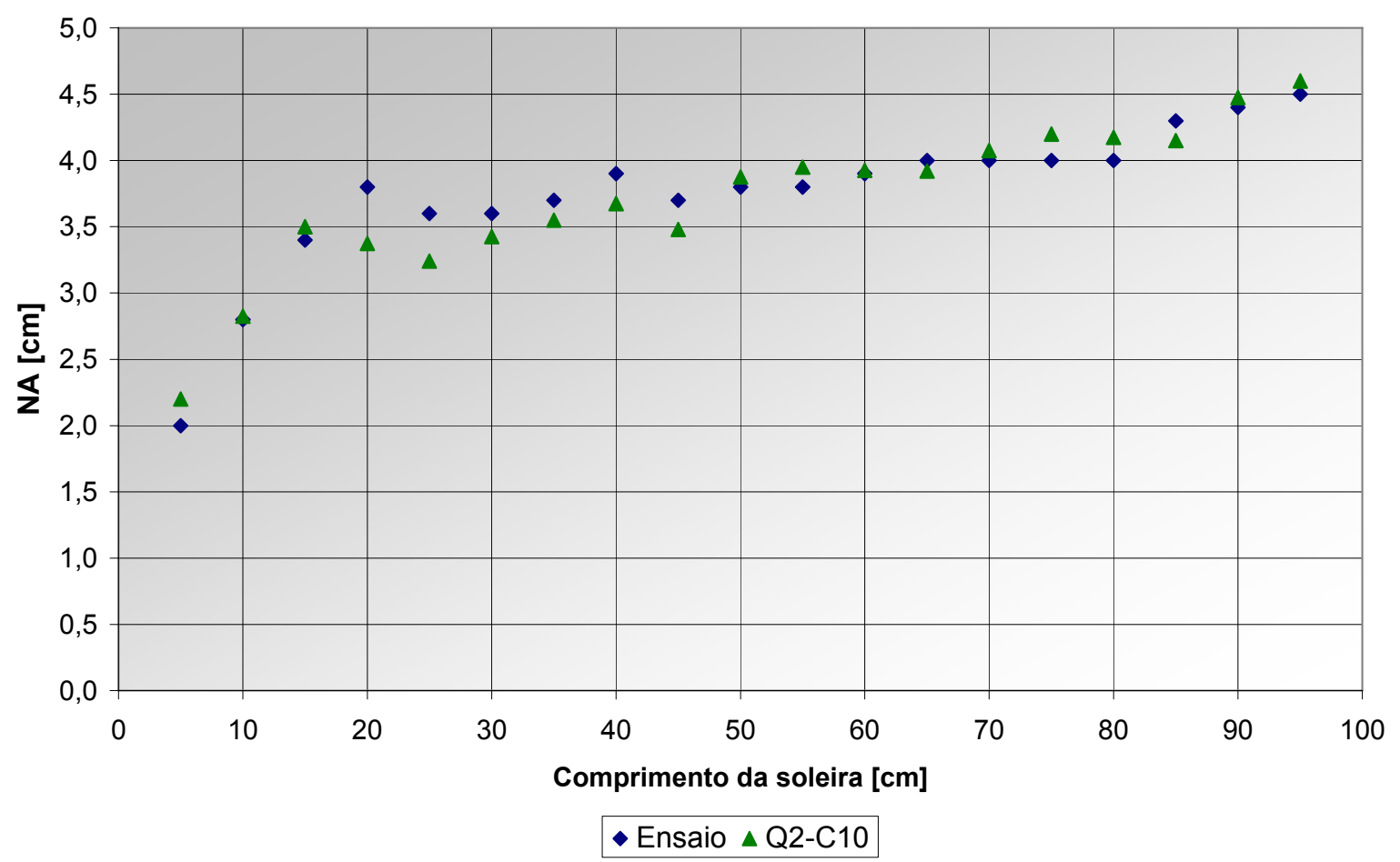

Figura 6.49 - Comparação do nível d'água sobre a soleira para a condição Q2-C10. 
A distribuição longitudinal de pressão estática relativa no canal principal para as condições Q2-C6, Q2-C8 e Q2-C10, não apresentou uma variação significativa ao longo do canal principal, sendo igual à distribuição hidrostática de pressões.

As distribuições longitudinais da velocidade no eixo do canal principal são representadas pelas Figuras 6.50 a 6.52. Essas distribuições são afetadas logo a montante do vertedor lateral, onde a linhas de fluxo do escoamento direcionam-se para o dispositivo lateral.

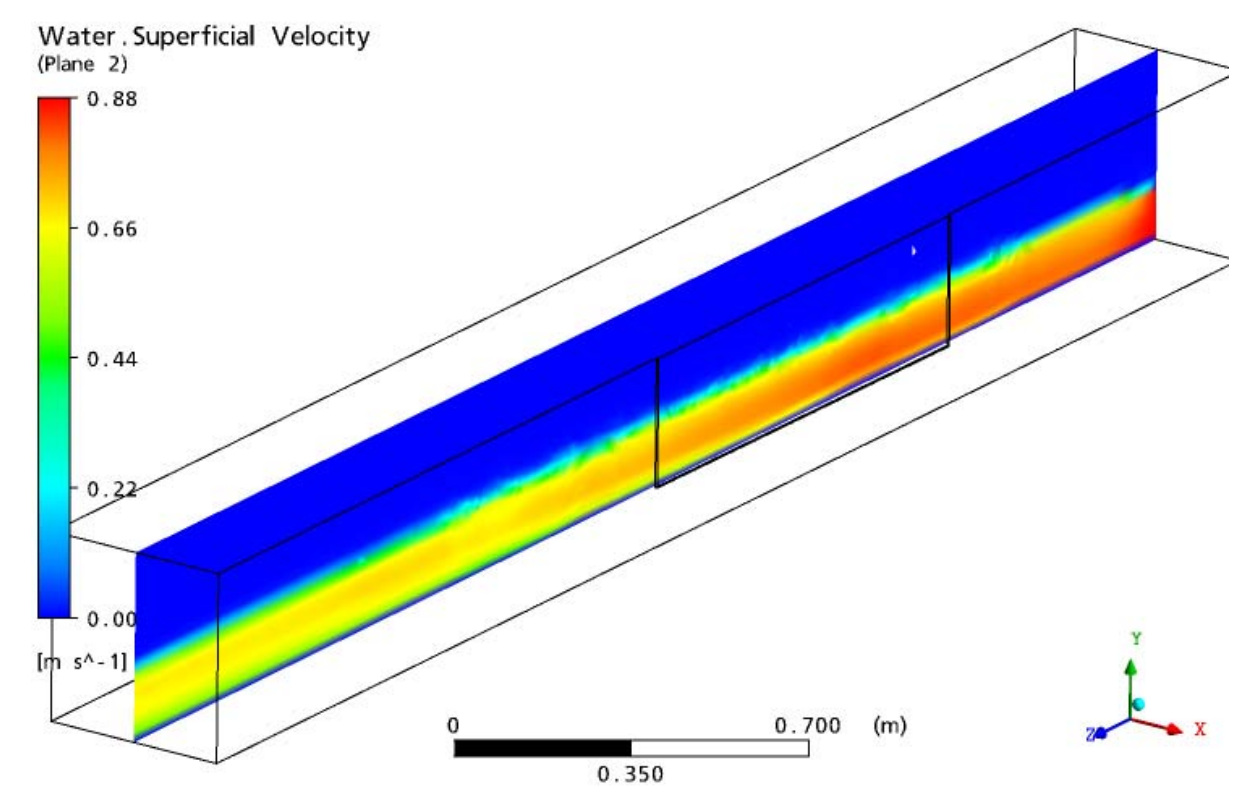

Figura 6.50 - Distribuição longitudinal da velocidade para a condição Q2-C6.

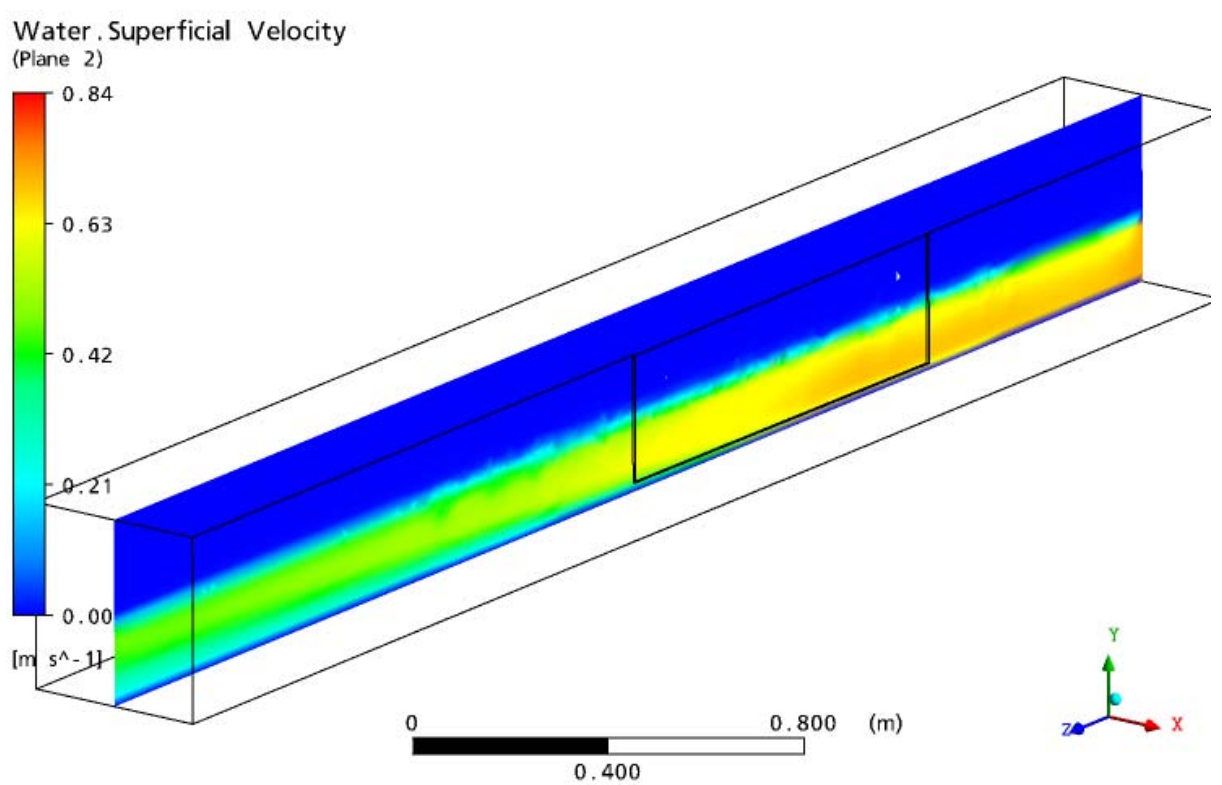

Figura 6.51 - Distribuição longitudinal da velocidade para a condição Q2-C8. 
As velocidades máximas observadas para as três condições são aproximadamente: $\mathrm{Q} 2-\mathrm{C} 6=0,88 \mathrm{~m} / \mathrm{s}, \mathrm{Q} 2-\mathrm{C} 8=0,80 \mathrm{~m} / \mathrm{s}$ e Q2-C10=0,75 m/s.

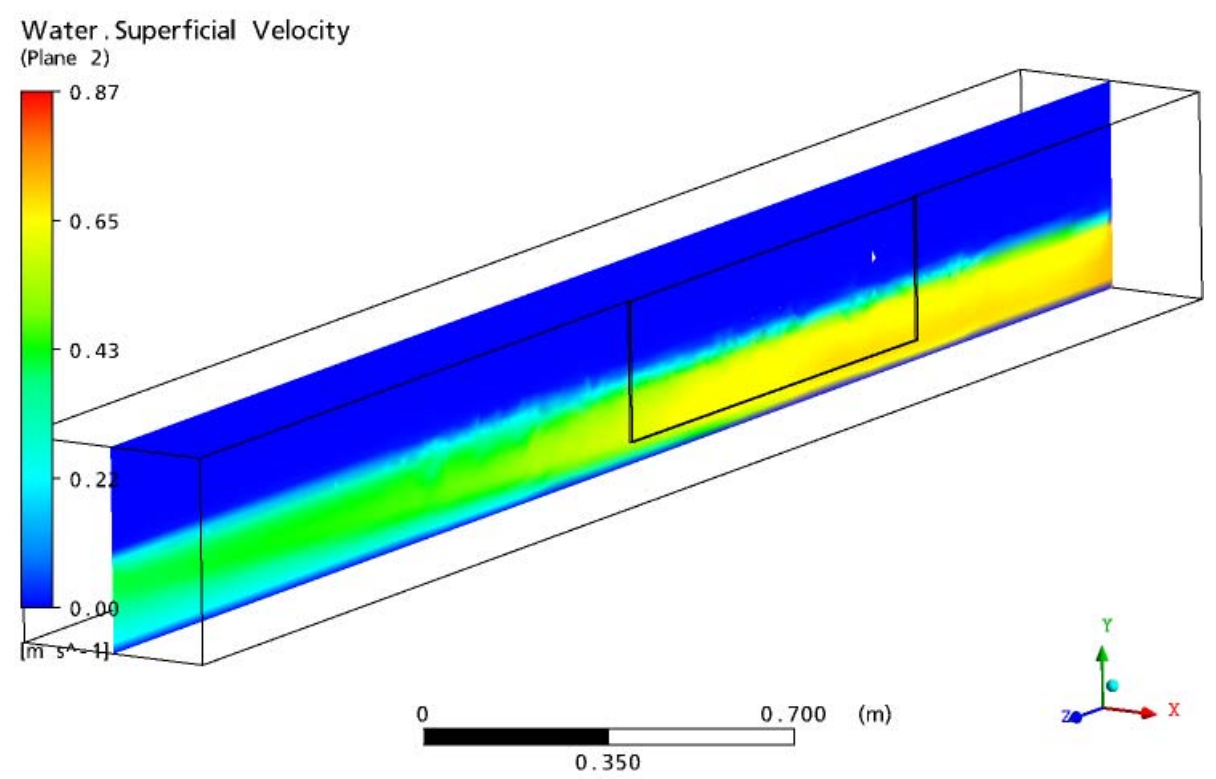

Figura 6.52 - Distribuição longitudinal da velocidade para a condição Q2-C10.

As Figuras 6.53 a 6.55 apresentam três seções transversais do canal principal na região do vertedor lateral para as três condições de Q2, a posição está referenciada ao eixo $Z$. No início do vertedor lateral $(Z=1,00 \mathrm{~m})$ nota-se a velocidade mais distribuída no canal principal, verificando também a influência da camada limite, com velocidades tendendo a zero próximo as paredes.

A condição $Z=1,50 \mathrm{~m}$ refere-se ao meio do vertedor lateral, onde a distribuição de velocidade altera-se devido ao escoamento do dispositivo lateral, e essa alteração é propagada para a condição $Z=2,0 \mathrm{~m}$, fim da soleira, onde se observa a diminuição da velocidade em sua distribuição nas três condições de Q2. Porém, para a condição Q2-C6 a velocidade média observada, de 0,85 m/s, no meio do vertedor foi aproximadamente $7 \%$ e $22 \%$ superior a velocidade, respectivamente, em seu início e fim.

Na Figura 6.53 no item (d), tem-se o vetor velocidade, que representa as linhas de fluxo do escoamento, na seção transversal $Z=1,50 \mathrm{~m}$, onde se pode observar o direcionamento dessas linhas para o vertedor lateral e a maior velocidade é observada em sua proximidade no canal principal. Pode-se delimitar uma região de 
0,10 m no canal principal, no lado oposto ao dispositivo lateral, que não apresenta uma perturbação visível.

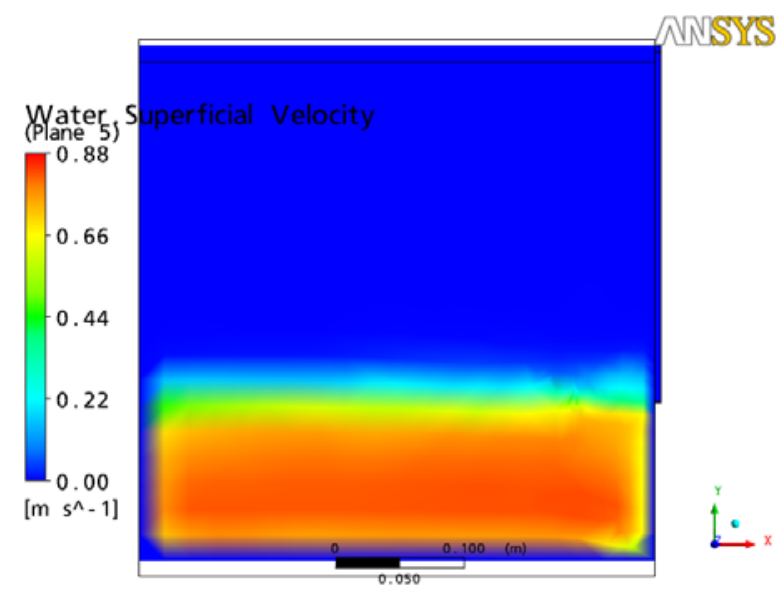

(a) $Z=1,00 \mathrm{~m}$.

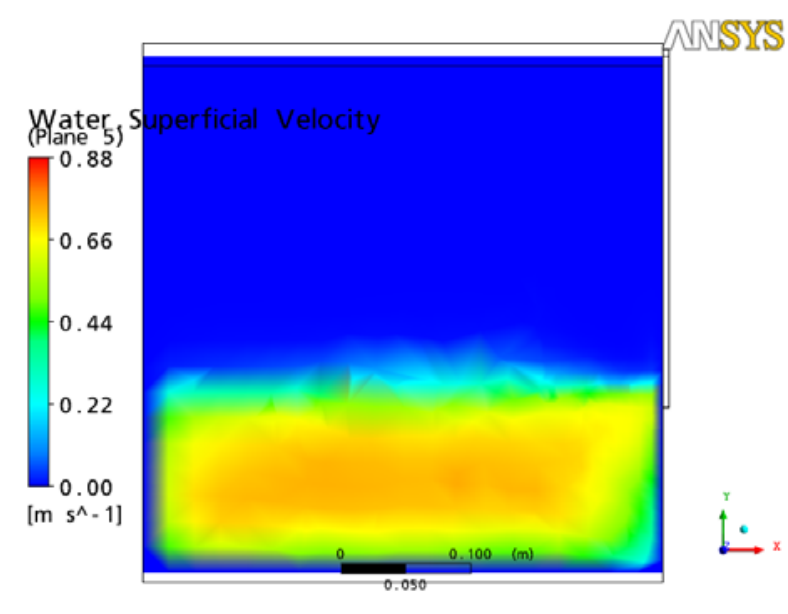

(c) $Z=2,00 \mathrm{~m}$.

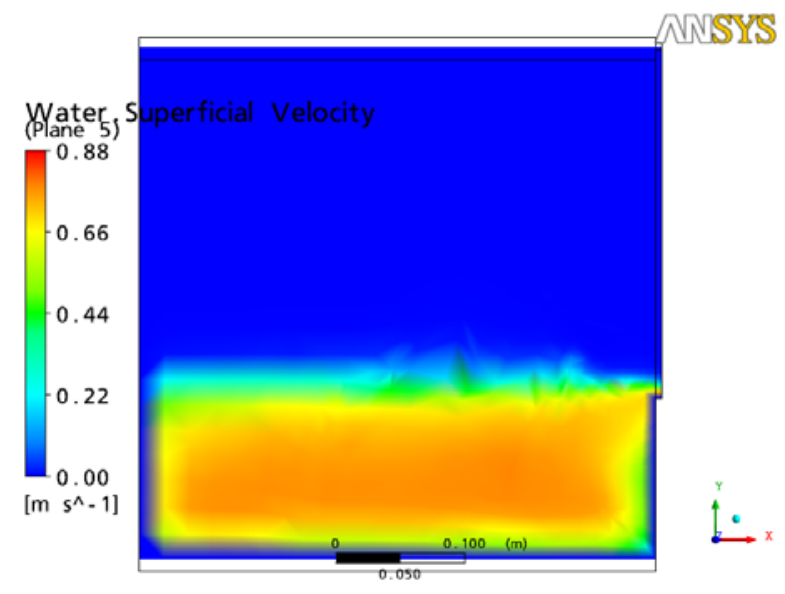

(b) $Z=1,50 \mathrm{~m}$.

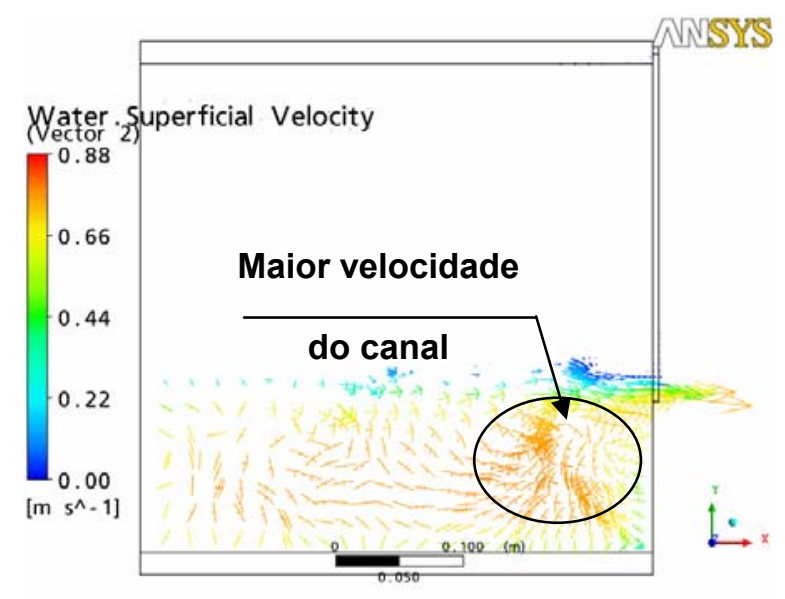

(d) Vetor $Z=1,50 \mathrm{~m}$.

Figura 6.53 - Distribuição transversal da velocidade ao longo do vertedor lateral para a condição Q2-C6.

A condição Q2-C8 (Figura 6.54) nos itens (b) e (c) se observou a diminuição da velocidade em sua distribuição e o desenvolvimento de uma região de mínima velocidade abaixo da soleira. Entretanto, a velocidade média observada no meio do vertedor foi de $0,69 \mathrm{~m} / \mathrm{s}$, aproximadamente $2 \%$ e $41 \%$ superior a velocidade, respectivamente, em seu início e fim. O canal principal de base $0,40 \mathrm{~m}$, não apresentou uma perturbação visível do escoamento nos $0,05 \mathrm{~m}$ da parede oposta ao eixo do canal. 


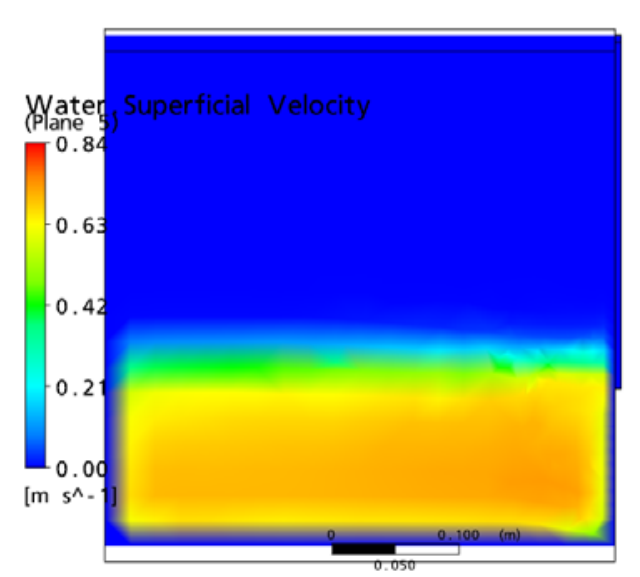

(a) $Z=1,00 \mathrm{~m}$.

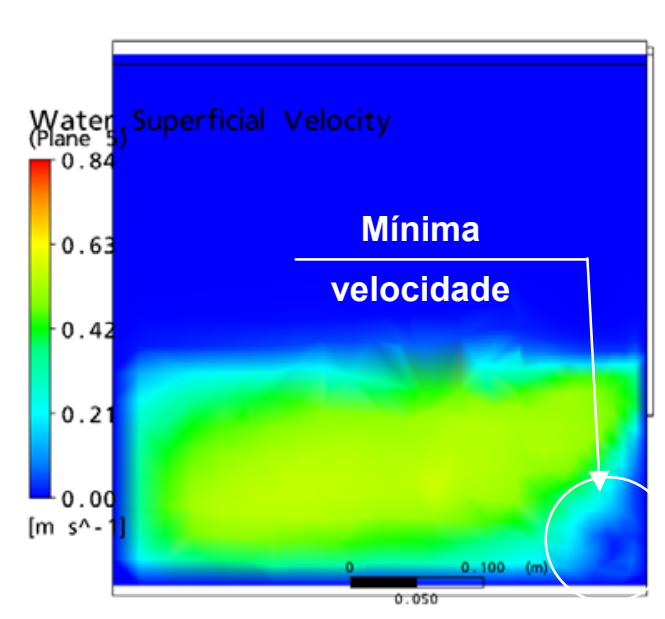

(c) $Z=2,00 \mathrm{~m}$.
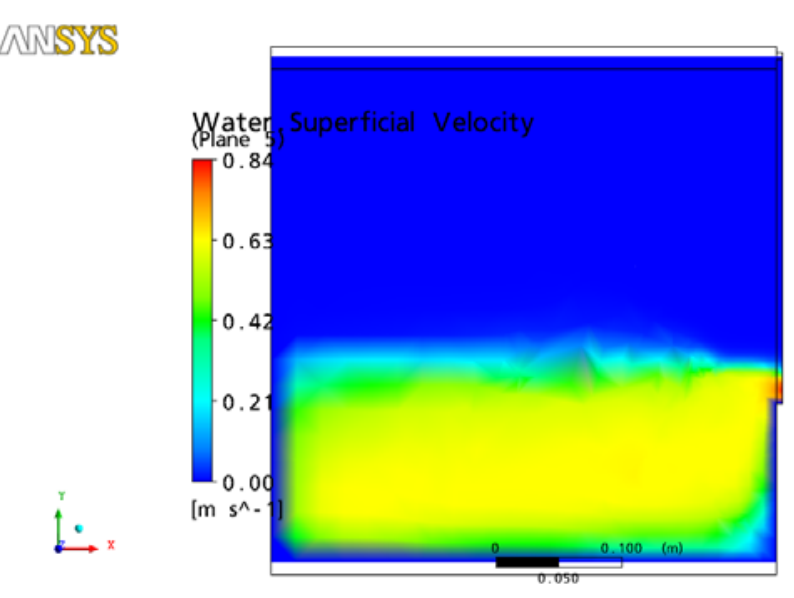

(b) $Z=1,50 \mathrm{~m}$.

aNsYis

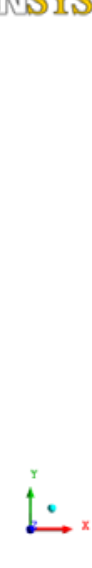

(d) Vetor $Z=1,50 \mathrm{~m}$.

Figura 6.54 - Distribuição transversal da velocidade ao longo do vertedor lateral para a condição Q2-C8.

Já a condição Q2-C10 (Figura 6.55) nos itens (b) e (c) também se observou a diminuição da velocidade em sua distribuição e o desenvolvimento de uma região de mínima velocidade abaixo da soleira. Porém, a velocidade média observada no meio do vertedor foi de $0,71 \mathrm{~m} / \mathrm{s}$, aproximadamente $2 \%$ e $47 \%$ da velocidade do seu início e fim. Verifica-se que quanto maior a vazão escoada pelo vertedor lateral, maior é a diminuição da velocidade a sua jusante no canal principal.

Com o aumento da vazão escoada pelo dispositivo lateral, maior é a sua influência no canal principal, para a condição Q2-C10 somente 0,05 m do lado oposto não sofre interferência, aparente, do dispositivo. 


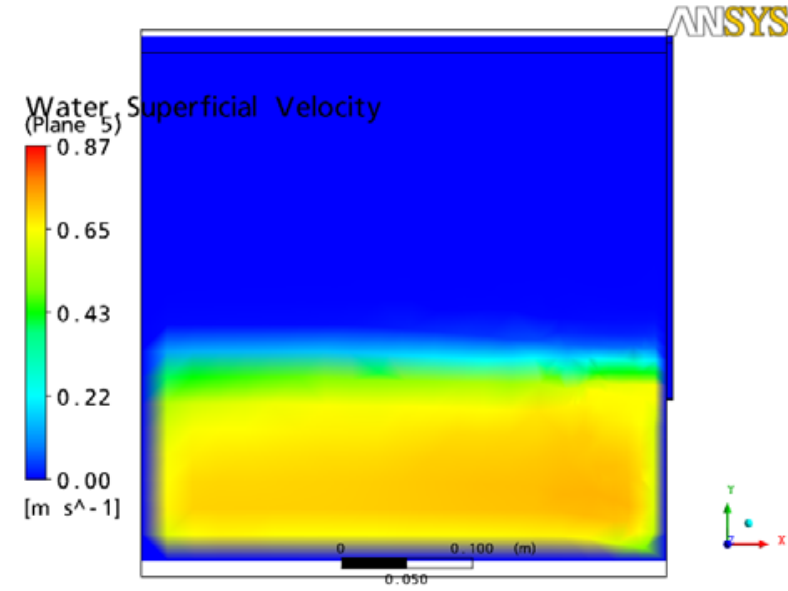

(a) $Z=1,00 \mathrm{~m}$.

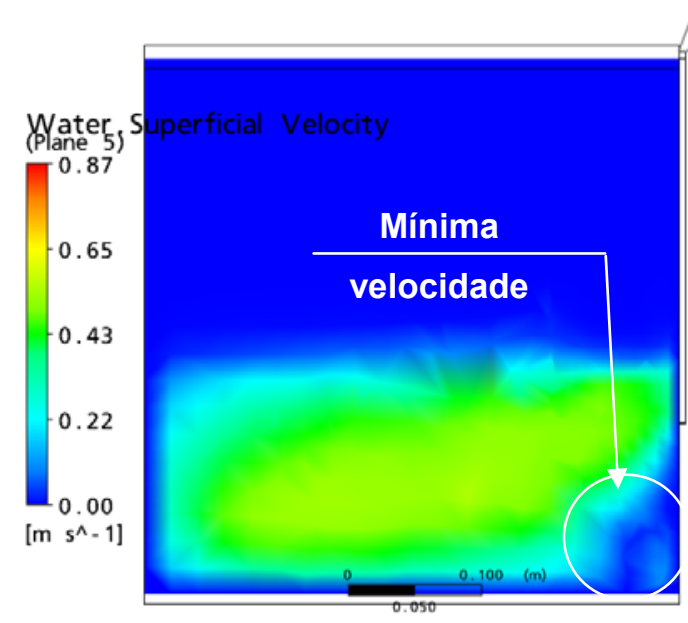

(c) $Z=2,00 \mathrm{~m}$.

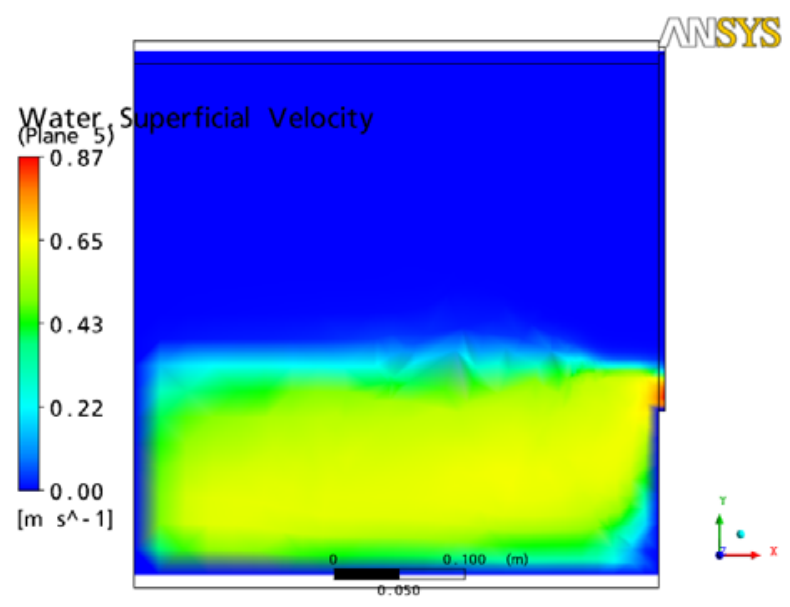

(b) $Z=1,50 \mathrm{~m}$.

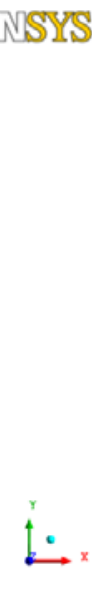

(d) Vetor $Z=1,50 \mathrm{~m}$.

Figura 6.55 - Distribuição transversal da velocidade ao longo do vertedor lateral para a condição Q2-C10.

As Figuras 6.56 a 6.58 apresentam a distribuição de velocidade na seção transversal do vertedor lateral. As três condições apresentam uma variação positiva ao longo da soleira de montante para jusante, e nota-se que nos $0,10 \mathrm{~cm}$ iniciais as velocidades são pequenas quando comparadas com toda a soleira. Também se observa as maiores velocidades fora da região das paredes laterais (extremidades). 


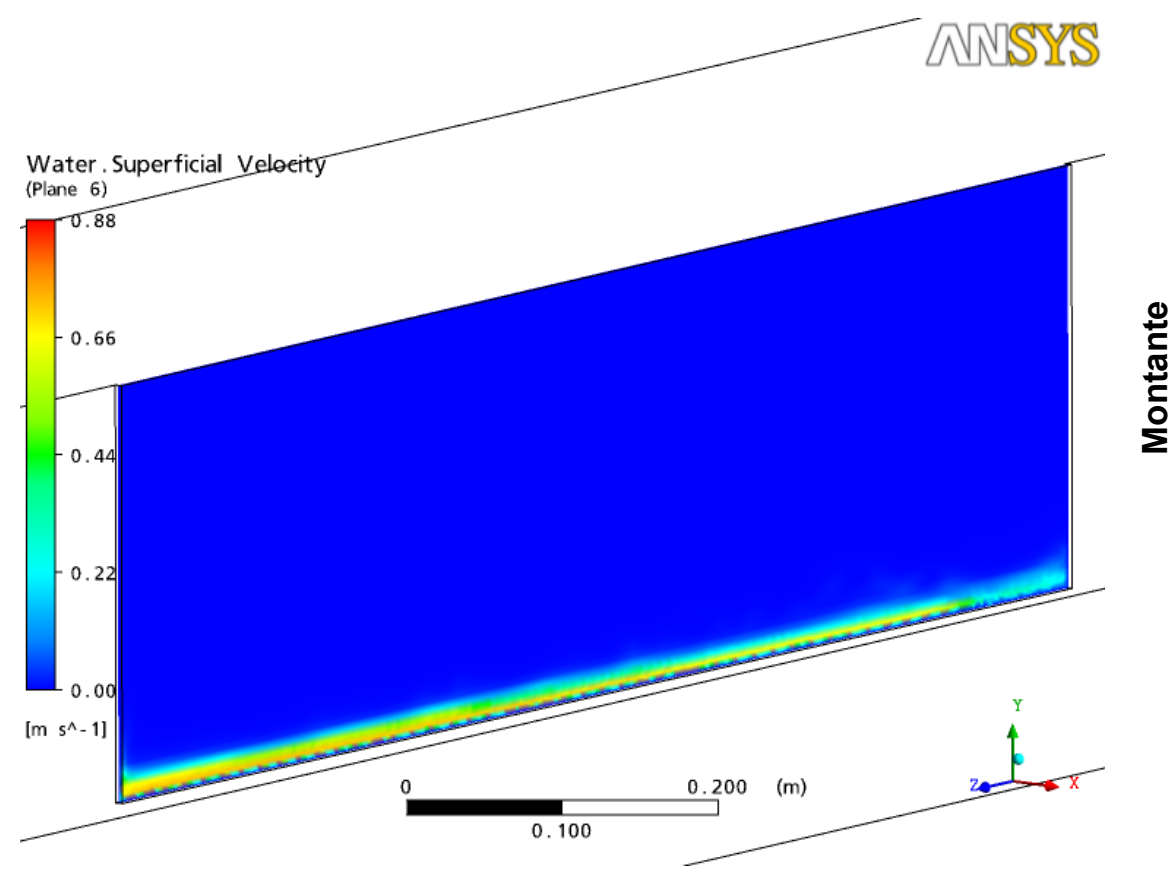

Figura 6.56 - Distribuição transversal da velocidade no vertedor lateral para a condição Q2-C6.

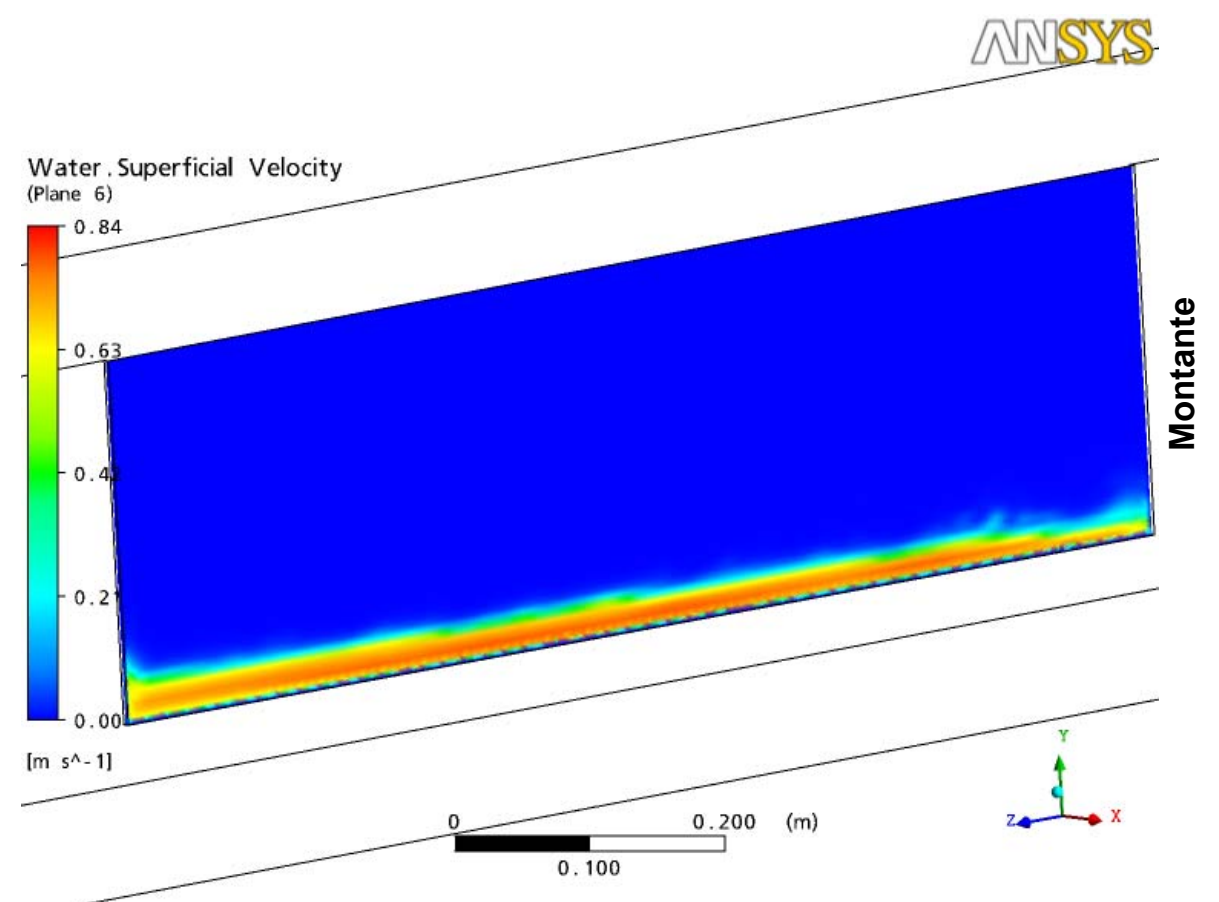

Figura 6.57 - Distribuição transversal da velocidade no vertedor lateral para a condição Q2-C8. 


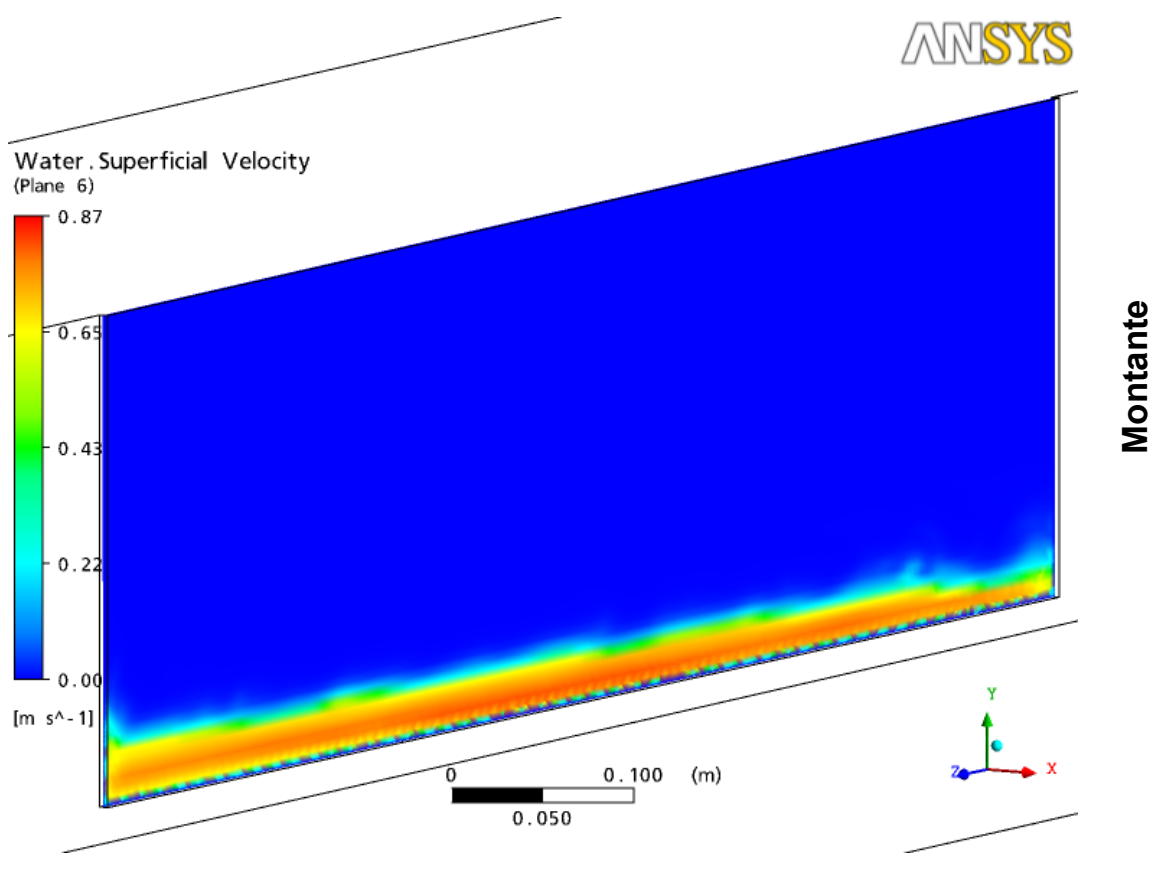

Figura 6.58 - Distribuição transversal da velocidade no vertedor lateral para a condição Q2C10.

As Figuras 6.59 a 6.61 representam a distribuição longitudinal do vetor velocidade ao longo do canal principal, onde se pode observar a mudança de direção do vetor velocidade, que muda com a variação da velocidade, e as maiores velocidades em sua direção.

A condição Q2-C6 (Figura 6.59) apresenta a relação entre a vazão escoada através do vertedor lateral e a vazão total do canal principal $\left(Q_{\mathrm{VL}} / Q_{\mathrm{T}}\right)$ em torno de 0,10, já as condições Q2-C8 e Q2-C10, representadas pelas Figuras 6.60 e 6.61, apresentam a relação $Q_{V /} / Q_{T}$, respectivamente, aproximadamente 0,31 e 0,37.

Para as três condições, verifica-se que a montante as linhas de correntes não são afetadas, aproximadamente, a uma distância de $0,55 \mathrm{~m}$ do início do dispositivo. Já a jusante as mesmas não são afetadas a aproximadamente $0,70 \mathrm{~m}$ do fim do dispositivo. 


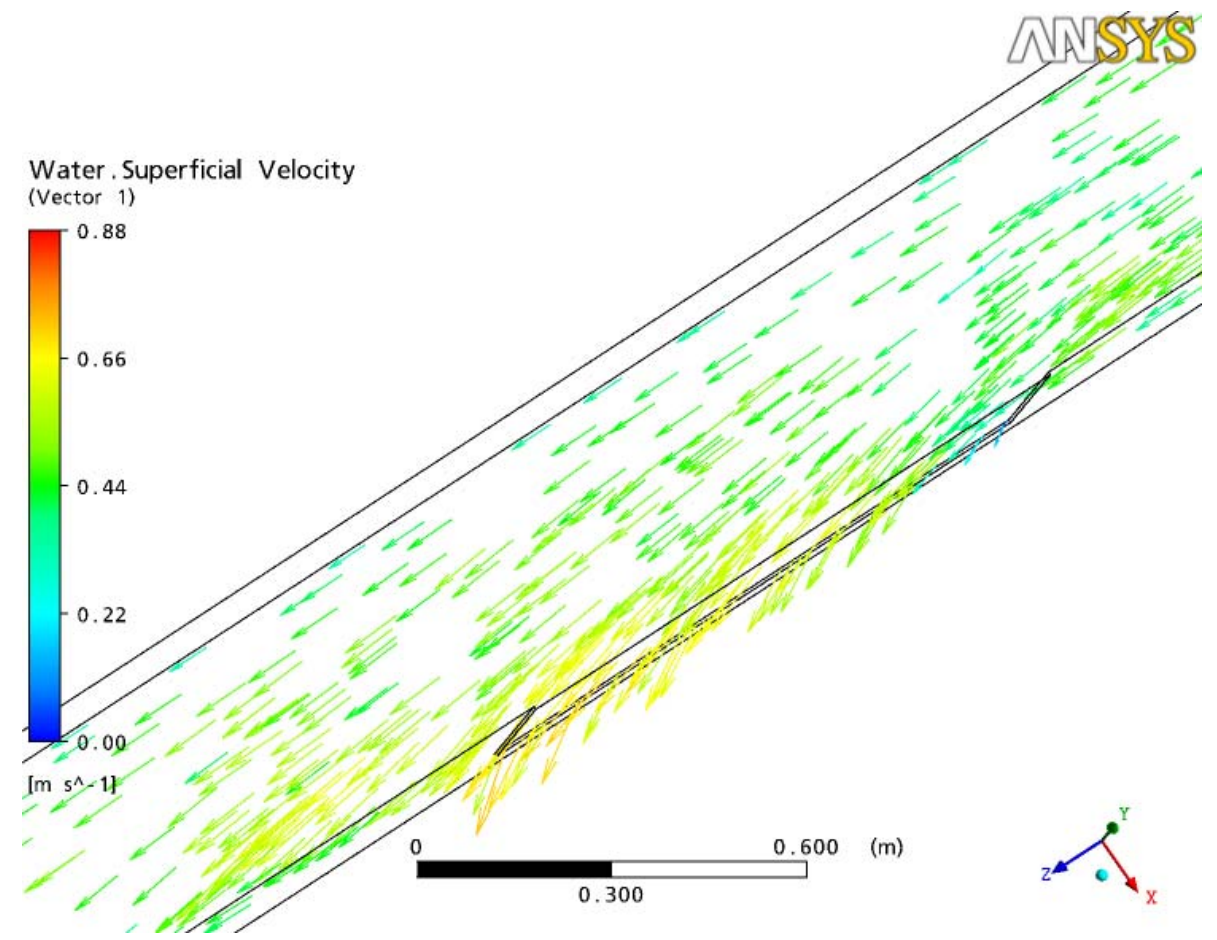

Figura 6.59 - Distribuição longitudinal do vetor velocidade para a condição Q2-C6.

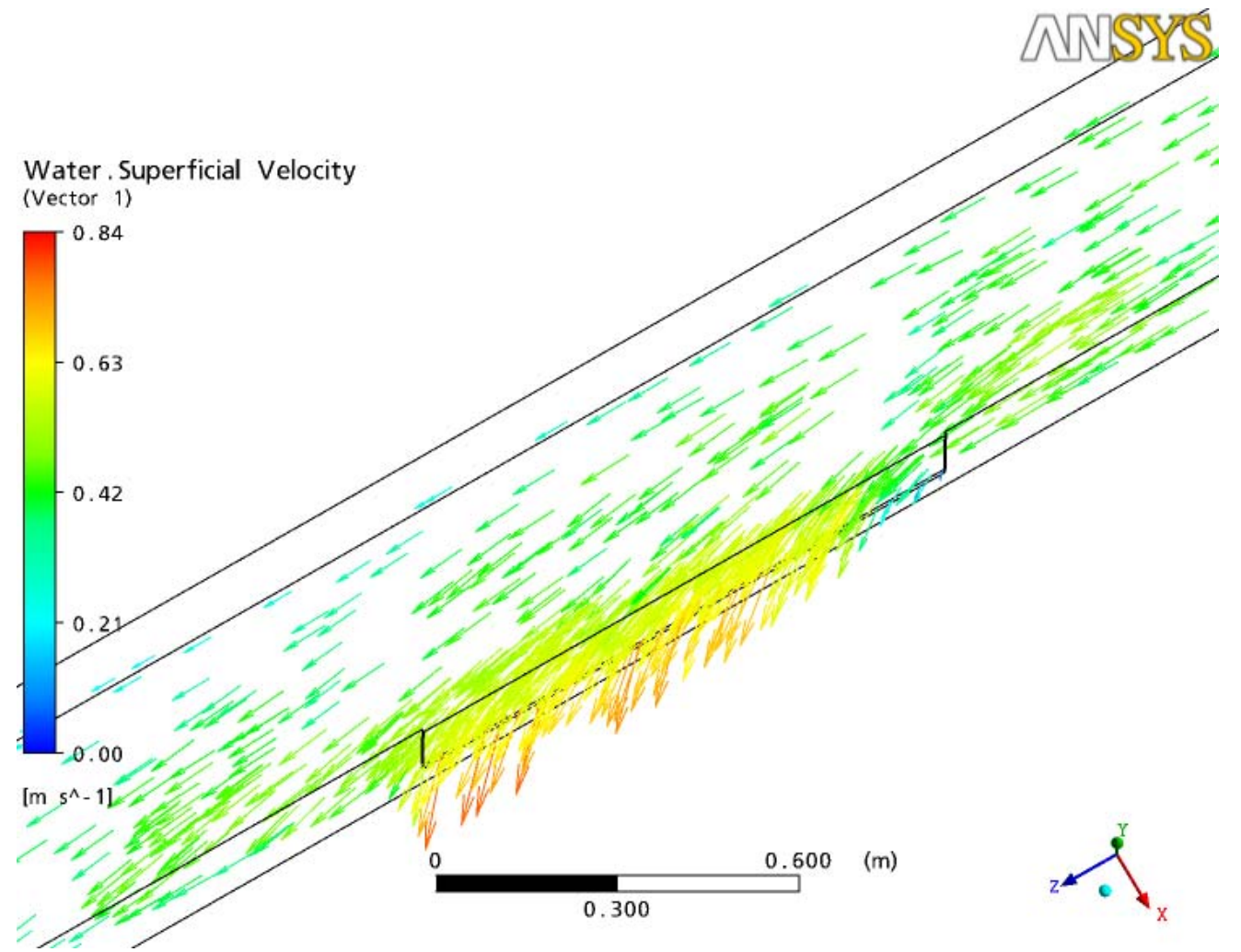

Figura 6.60 - Distribuição longitudinal do vetor velocidade para a condição Q2-C8. 


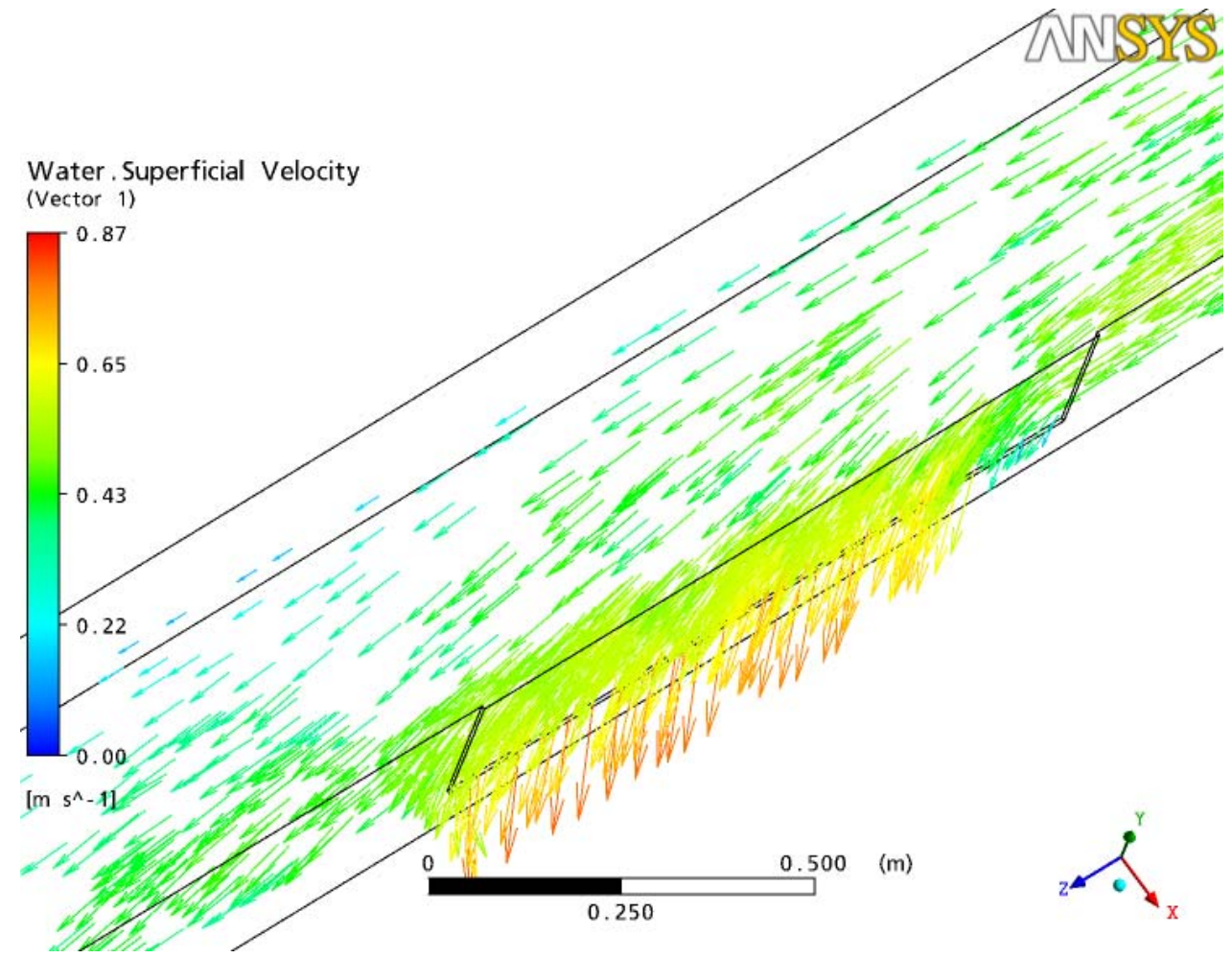

Figura 6.61 - Distribuição longitudinal do vetor velocidade para a condição Q2-C10.

\subsubsection{Condição Q3}

A condição Q3 representa a vazão escoada no canal principal $\left(\mathrm{Q}_{T}\right)$ de aproximadamente $48,5 \mathrm{~L} / \mathrm{s}$. Serão apresentados os resultados e análises das três condições de variação da comporta Q3-C6, Q3-C8 e Q3-C10.

A fração volumétrica do ar e da água pode ser visualizada nas Figuras 6.62 a 6.64, onde a interface entre ambos define a superfície d'água, que está representada de azul claro. Observam-se perturbações mais intensas no canal principal, quando comparado com as condições Q1 e Q2, que apresentam menores vazões.

Para a condição Q3-C6 a vazão escoada no vertedor lateral $\left(Q_{V L}\right)$ é 6,81 L/s, já a condição Q3-C8 escoa uma vazão $Q_{V L}$ de 15,39 L/s e a condição Q3-C10 escoa uma vazão $Q_{V L}$ de $20,11 \mathrm{~L} / \mathrm{s}$. As perturbações no canal principal aumentam com o aumento da vazão no dispositivo lateral. 


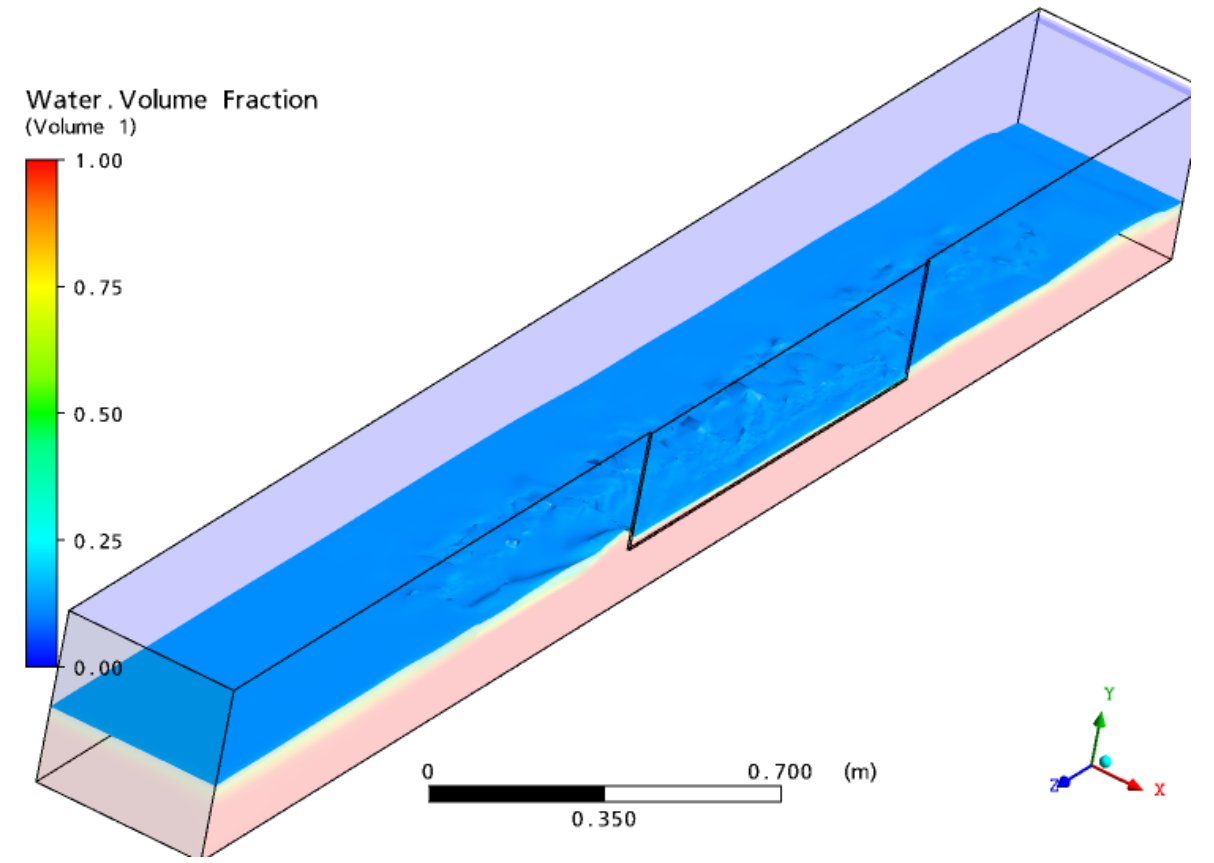

Figura 6.62 - Vista isométrica da superfície d'água para a condição Q3-C6.

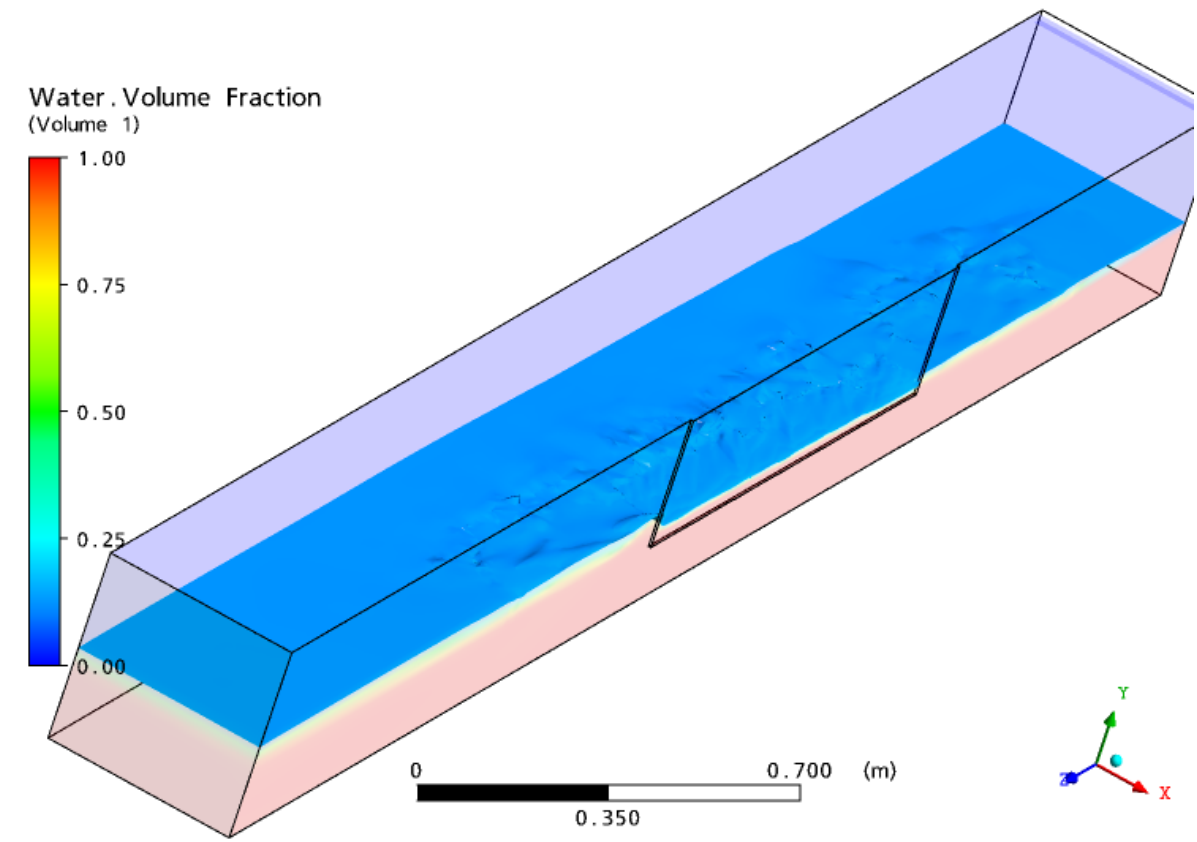

Figura 6.63 - Vista isométrica da superfície d'água para a condição Q3-C8. 


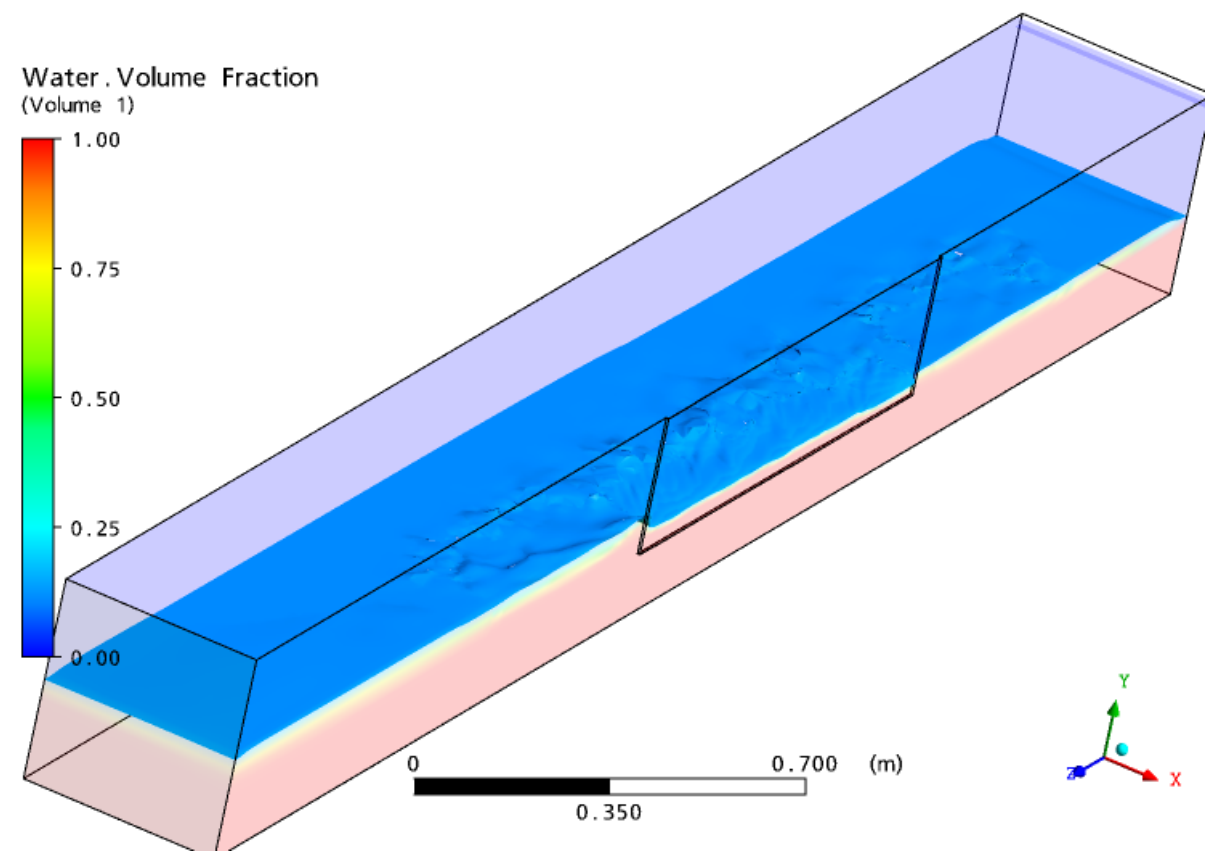

Figura 6.64 - Vista isométrica da superfície d'água para a condição Q3-C10.

Nas Figuras 6.65 a 6.67, tem-se a vista frontal do vertedor lateral (direita representa montante), podendo-se visualizar o nível d'água (NA) sobre a soleira e suas perturbações em detalhe. A variação mínima e máxima do NA sobre a soleira é representada na Tabela 6.6.

Tabela 6.6 - Variação do NA sobre a soleira lateral.

\begin{tabular}{ccc}
\hline Ensaios & NA $_{\text {min. }}$ [cm] & NA $_{\text {máx. }}$ [cm] \\
\hline Q3-C6 & 1,10 & 3,15 \\
Q3-C8 & 2,30 & 4,50 \\
Q3-C10 & 2,90 & 5,30 \\
\hline
\end{tabular}




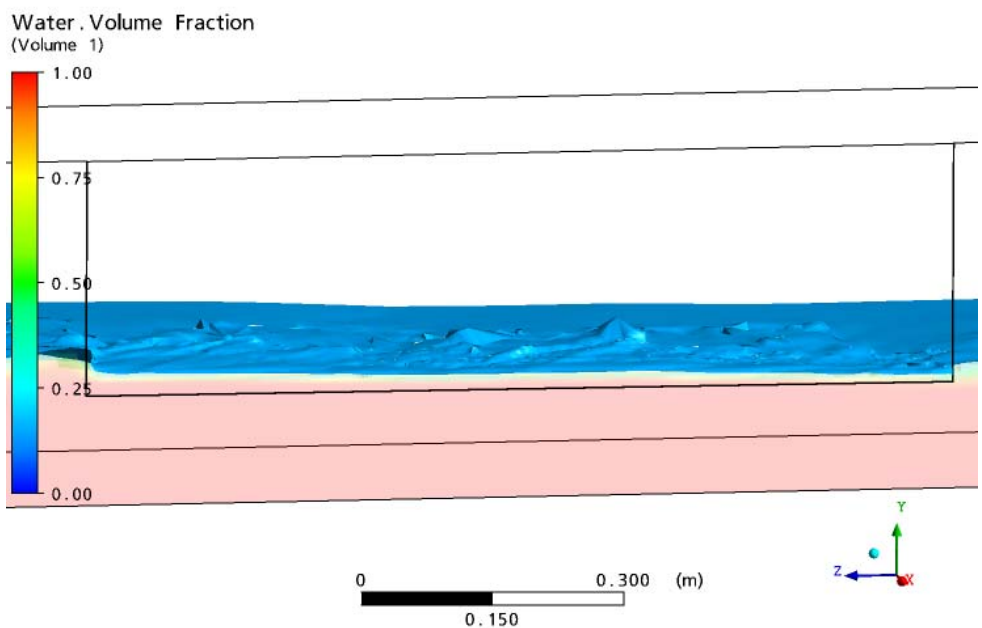

Figura 6.65 - Vista frontal da superfície d'água do vertedor lateral para a condição Q3-C6.

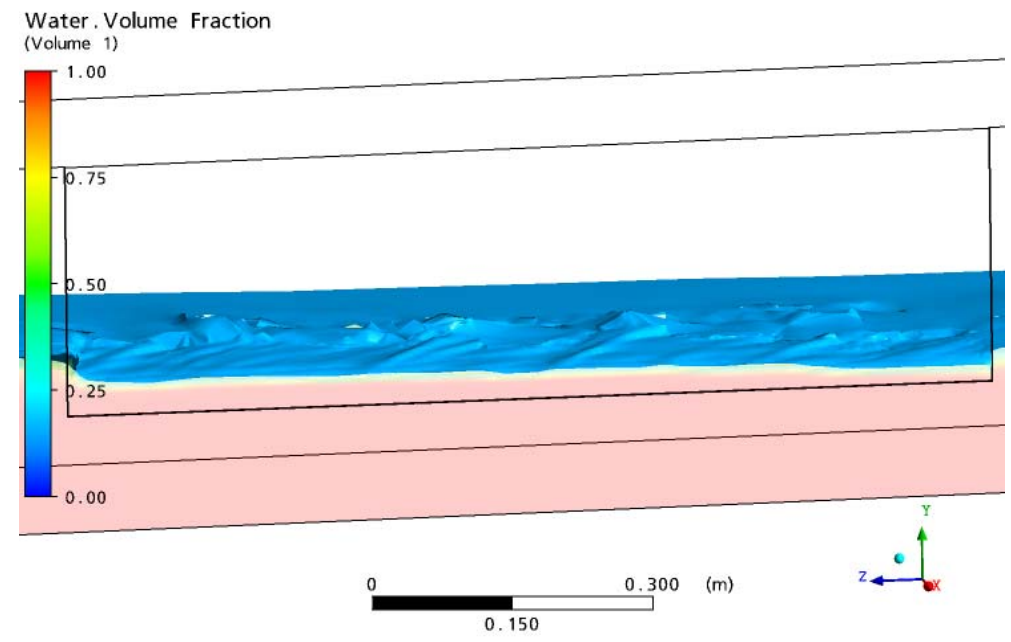

Figura 6.66 - Vista frontal da superfície d'água do vertedor lateral para a condição Q3-C8.

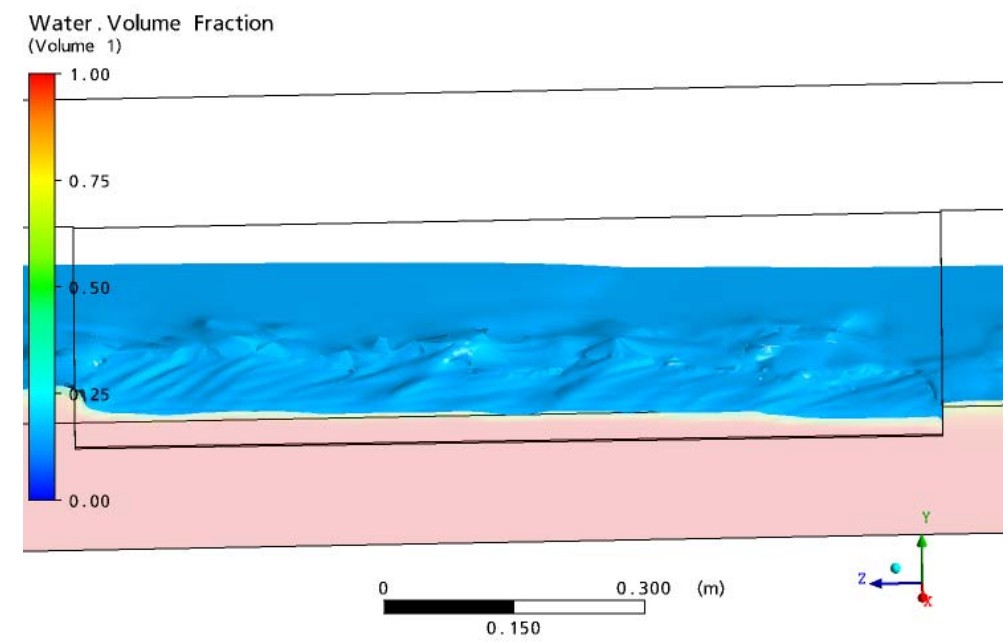

Figura 6.67 - Vista frontal da superfície d'água do vertedor lateral para a condição Q3-C10. 
Nos gráficos das Figuras 6.68 a 6.70 é representado no eixo das abscissas o comprimento da soleira, sendo a posição 0 montante, e a posição 100 jusante, e no eixo das ordenadas o nível d'água (NA) sobre a soleira. Para condição Q3-C6 o modelo matemático apresentou o erro médio, de 14,56\%, acima do esperado para esse trabalho. Essa divergência, provavelmente, está relacionada com imperfeições do modelo físico, juntamente com possíveis erros do ensaio para essa condição.

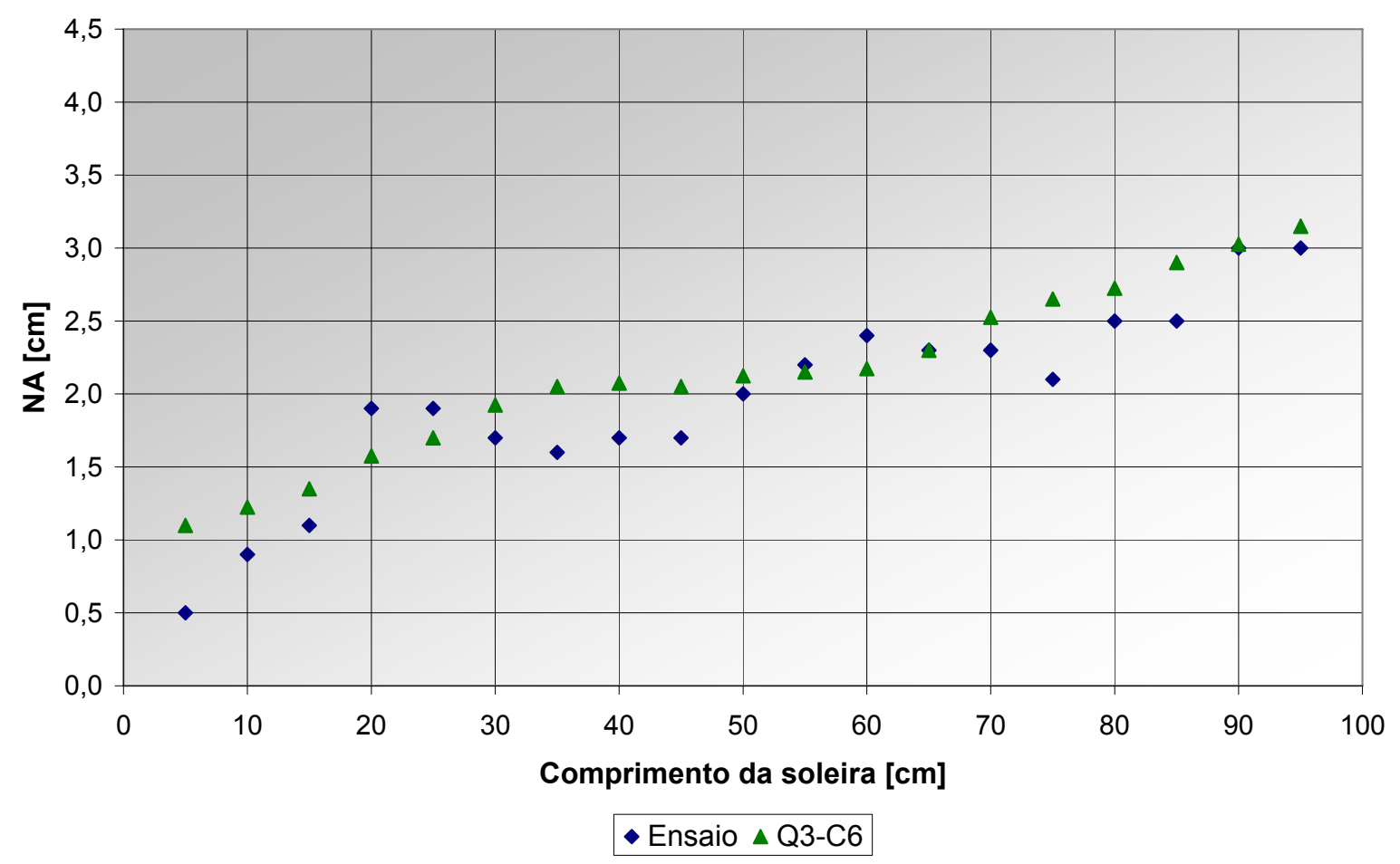

Figura 6.68 - Comparação do nível d'água sobre a soleira para a condição Q3-C6.

No gráfico da Figura 6.69, condição Q3-C8, nota-se uma boa aderência dos pontos do resultado da simulação com os pontos do ensaio experimental, principalmente na região de 10 a $45 \mathrm{~cm}$. As regiões de 55 a $65 \mathrm{~cm}$ e 80 a $85 \mathrm{~cm}$, apresentaram as menores precisões, porém mantiveram a semelhança do comportamento do escoamento observado em ensaio. O erro médio da simulação para essa condição foi de $5,35 \%$, dentro do esperado para esse trabalho.

A condição Q3-C10 (Figura 6.70), apresentou boa aderência dos pontos, principalmente na região de 20 a $60 \mathrm{~cm}$. Na extremidade de jusante, de 90 a $95 \mathrm{~cm}$, também se verifica uma boa precisão dos resultados, sendo menores as influências das imperfeições do modelo físico para as maiores vazões escoadas pelo vertedor. O erro médio da simulação para essa condição foi de $5,44 \%$, dentro do esperado. 


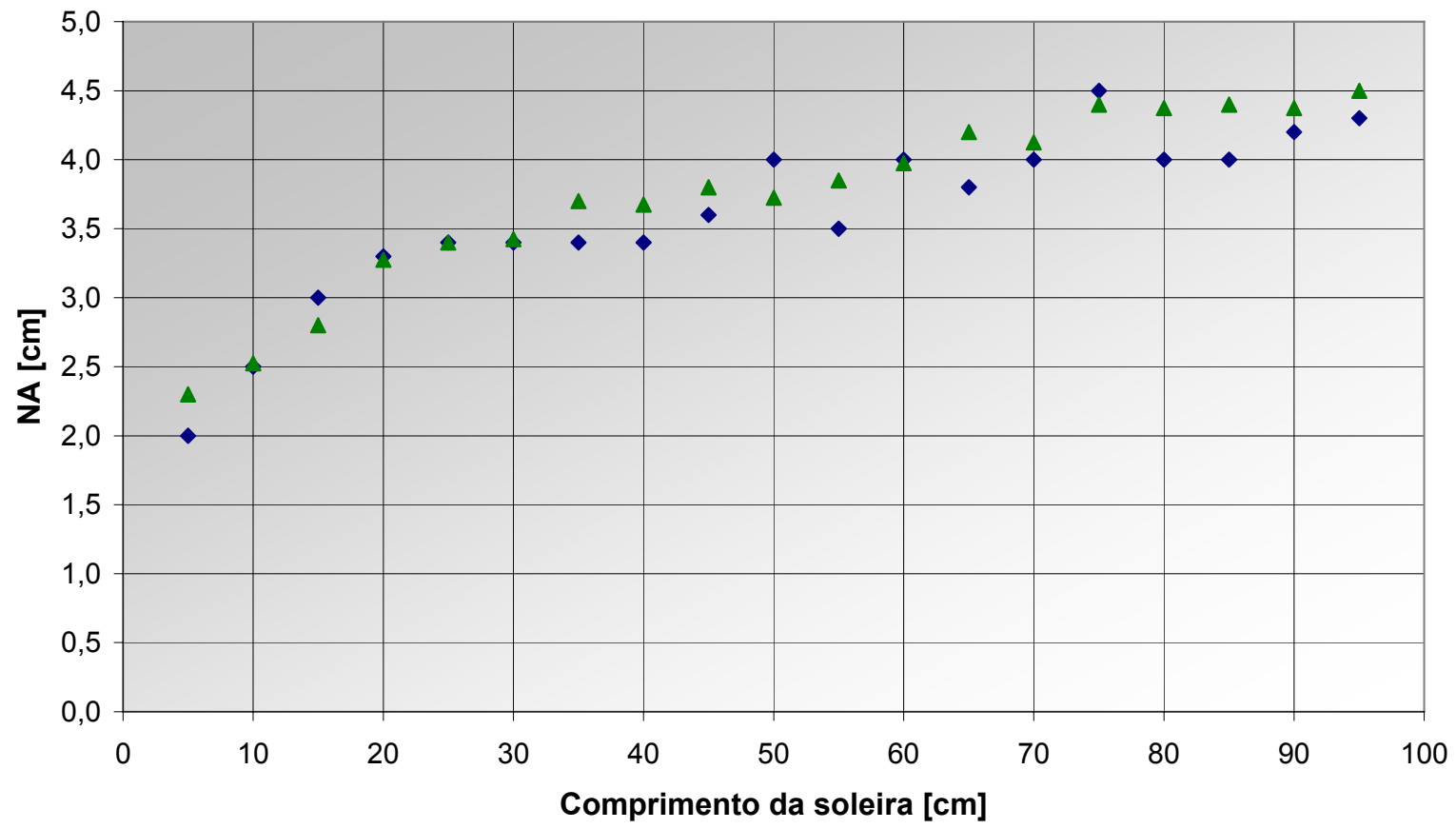

- Ensaio $\triangle$ Q3-C8

Figura 6.69 - Comparação do nível d'água sobre a soleira para a condição Q3-C8.

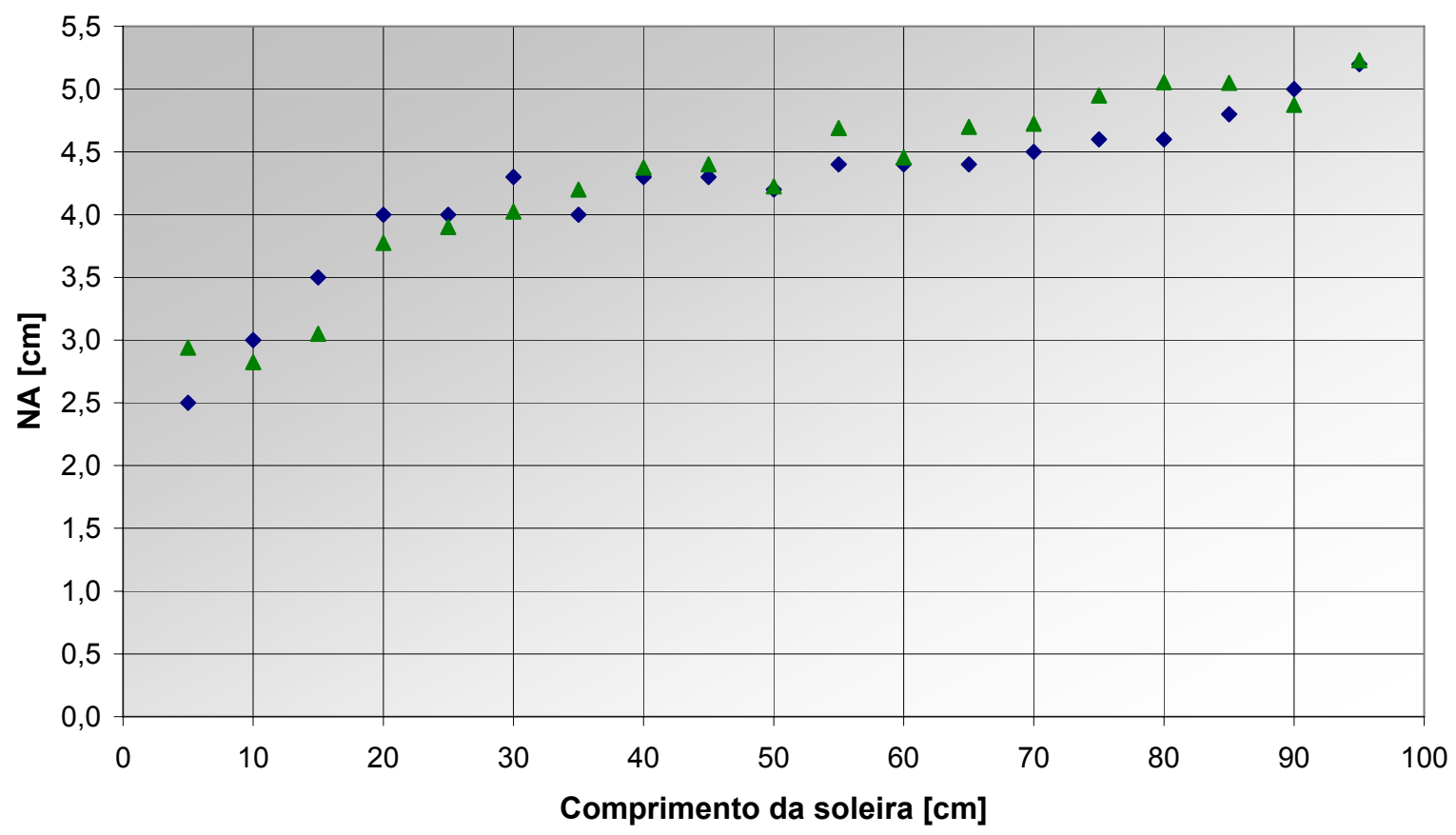

- Ensaio $\triangle$ Q3-C10

Figura 6.70 - Comparação do nível d'água sobre a soleira para a condição Q3-C10. 
A distribuição longitudinal de pressão estática relativa no canal principal para as condições Q3-C6, Q3-C8 e Q3-C10, não apresentou uma variação significativa ao longo do canal principal, sendo igual à distribuição hidrostática de pressões.

As distribuições longitudinais da velocidade no eixo do canal principal são representadas pelas Figuras 6.71 a 6.73 . Essas distribuições são afetadas logo a montante do vertedor lateral, onde a linhas de fluxo do escoamento direcionam-se para o dispositivo lateral.

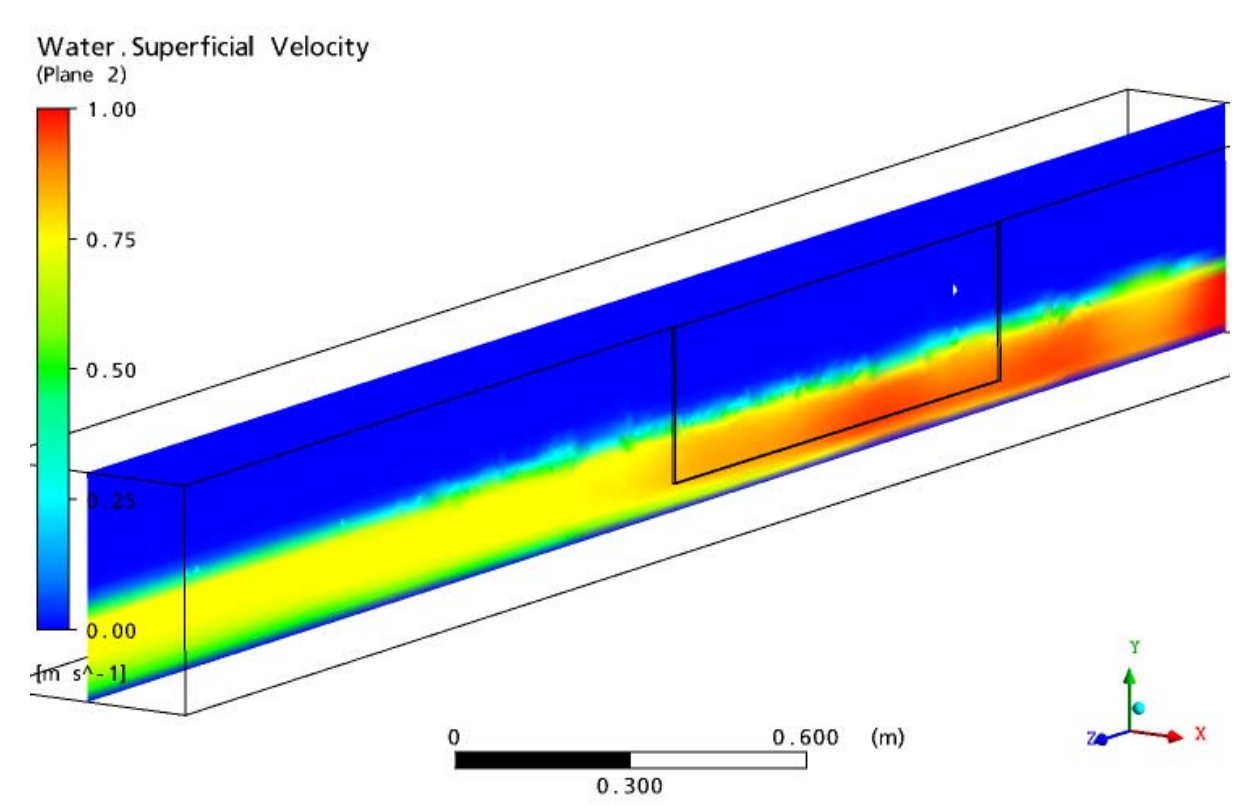

Figura 6.71 - Distribuição longitudinal da velocidade para a condição Q3-C6.

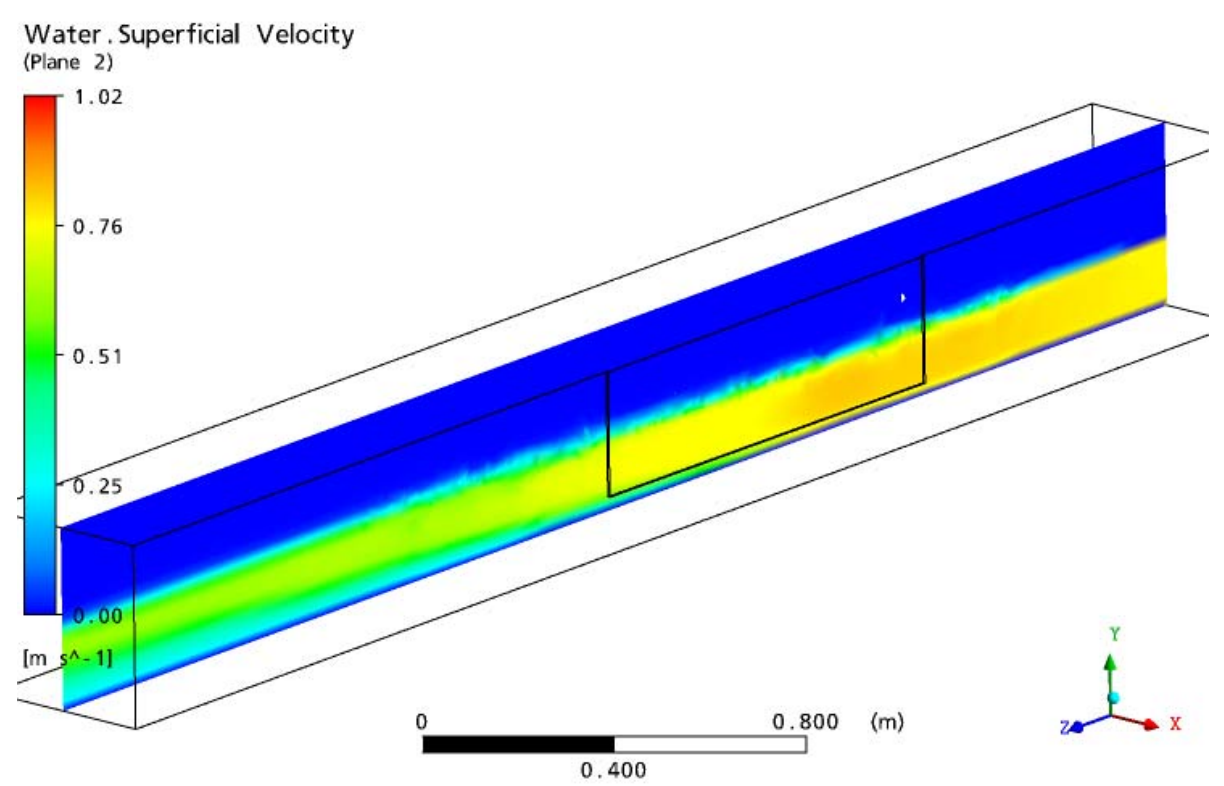

Figura 6.72 - Distribuição longitudinal da velocidade para a condição Q3-C8. 
As velocidades máximas observadas para as três condições são aproximadamente: Q3-C6=1,00 m/s, Q3-C8=0,90 m/s e Q3-C10=0,80 m/s.

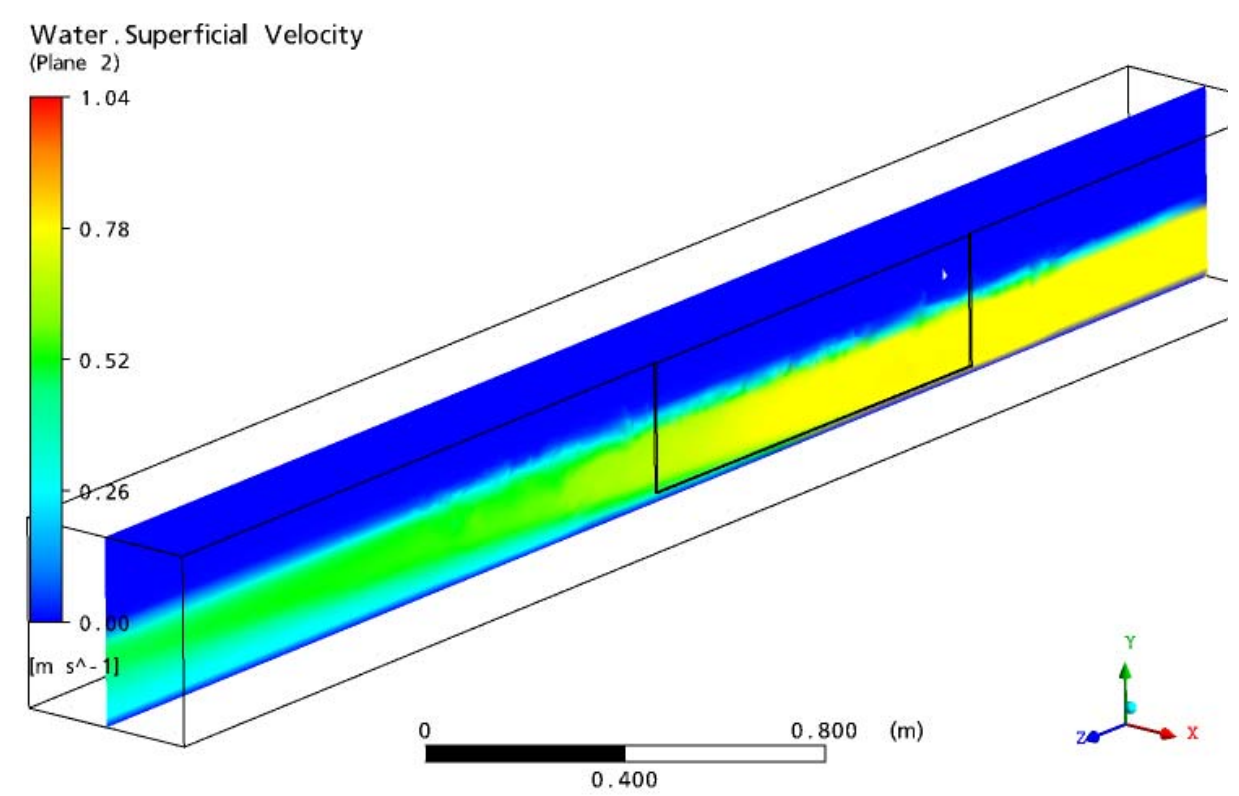

Figura 6.73 - Distribuição longitudinal da velocidade para a condição Q3-C10.

As Figuras 6.74 a 6.76 apresentam três seções transversais do canal principal na região do vertedor lateral para as três condições de Q3, a posição está referenciada ao eixo $Z$. No início do vertedor lateral $(Z=1,00 \mathrm{~m})$ nota-se a velocidade mais distribuída no canal principal, verificando também a influência da camada limite, com velocidades tendendo a zero próximo as paredes.

A condição $Z=1,50 \mathrm{~m}$ refere-se ao meio do vertedor lateral, onde a distribuição de velocidade altera-se devido ao escoamento do dispositivo lateral, e essa alteração é propagada para a condição $Z=2,0 \mathrm{~m}$, fim da soleira, onde se observa a diminuição da velocidade em sua distribuição nas três condições de Q3. Porém, para a condição Q3-C6 a velocidade média observada, de 0,96 m/s, no meio do vertedor foi aproximadamente $4 \%$ e $29 \%$ superior a velocidade, respectivamente, em seu início e fim.

Na Figura 6.74 no item (d), tem-se o vetor velocidade, que representa as linhas de fluxo do escoamento, na seção transversal $Z=1,50 \mathrm{~m}$, onde se pode observar o direcionamento dessas linhas para o vertedor lateral e a maior velocidade é observada em sua proximidade no canal principal. Pode-se delimitar uma região de 
0,10 m no canal principal, no lado oposto ao dispositivo lateral, que não apresenta uma perturbação visível.

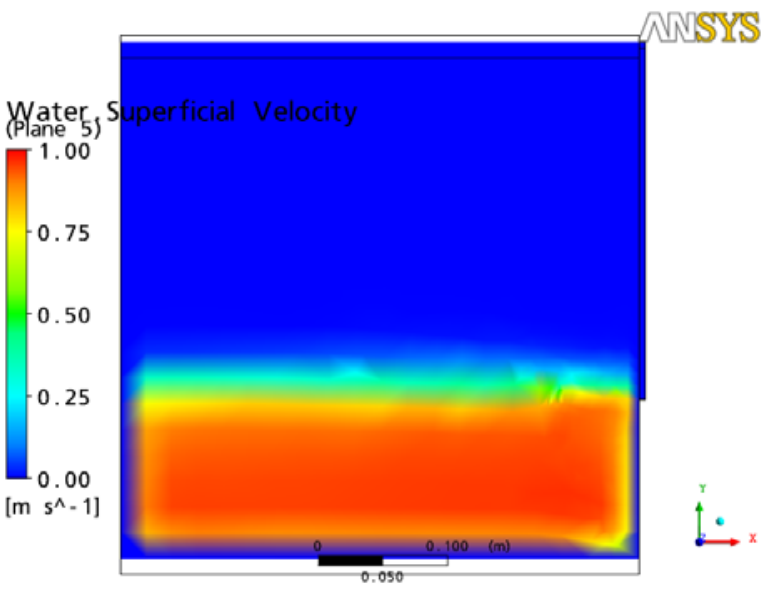

(a) $Z=1,00 \mathrm{~m}$.

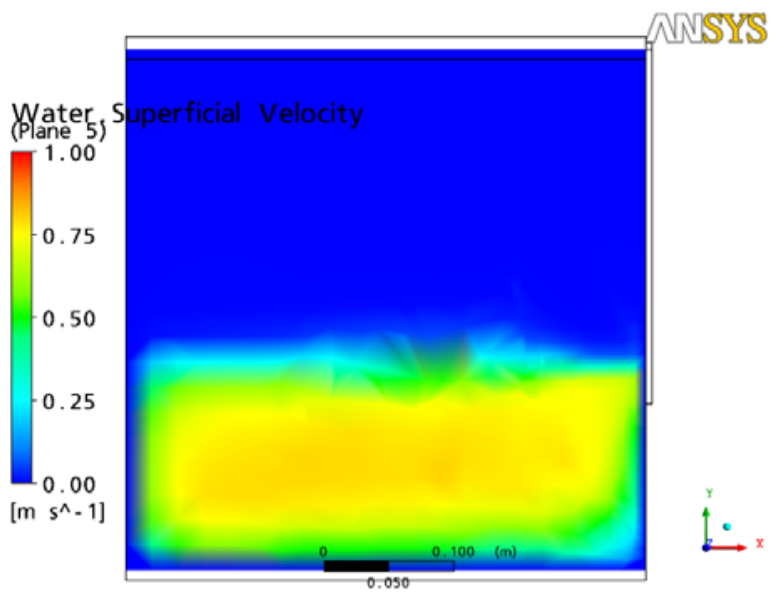

(c) $Z=2,00 \mathrm{~m}$.

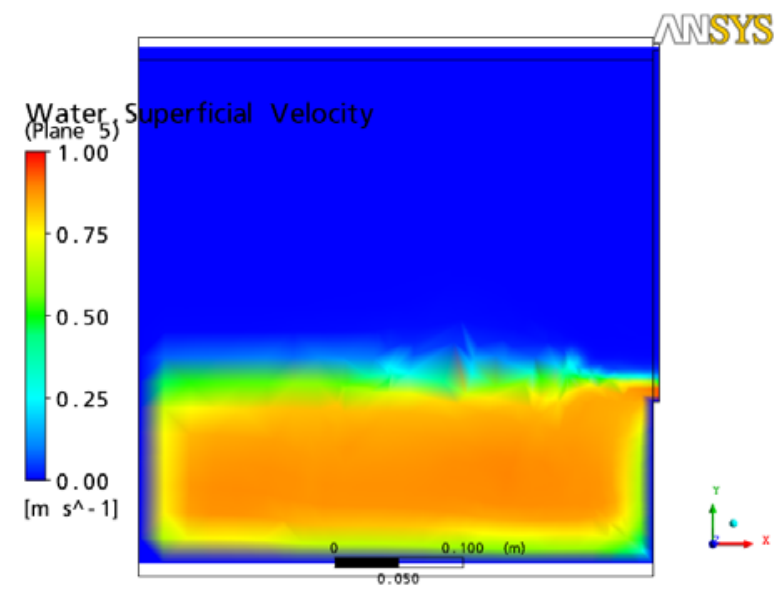

(b) $Z=1,50 \mathrm{~m}$.

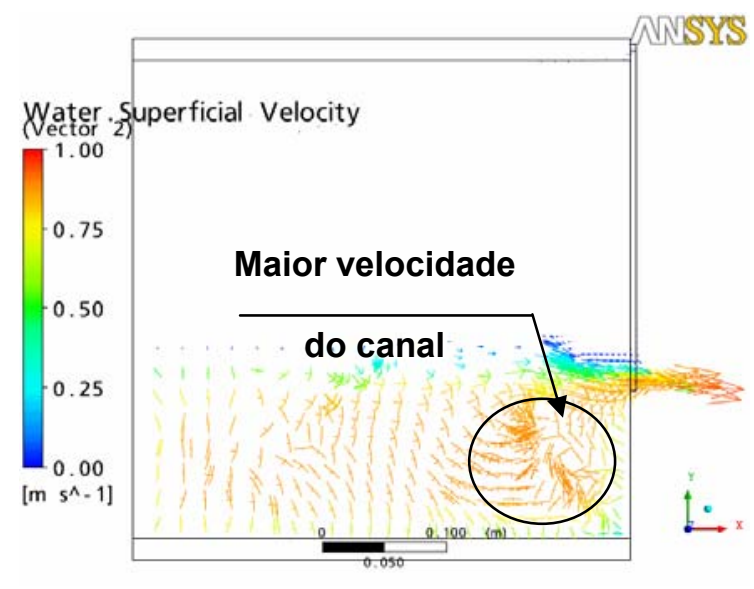

(d) Vetor $Z=1,50 \mathrm{~m}$.

Figura 6.74 - Distribuição transversal da velocidade ao longo do vertedor lateral para a condição Q3-C6.

A condição Q3-C8 (Figura 6.75) nos itens (b) e (c) se observou a diminuição da velocidade em sua distribuição e o desenvolvimento de uma região de mínima velocidade abaixo da soleira. Entretanto, a velocidade média observada no meio do vertedor foi de $0,75 \mathrm{~m} / \mathrm{s}$, aproximadamente $1 \%$ e $42 \%$ superior a velocidade, respectivamente, em seu início e fim. O canal principal de base 0,40 m, não apresentou uma perturbação visível do escoamento nos $0,05 \mathrm{~m}$ da parede oposta ao eixo do canal. 


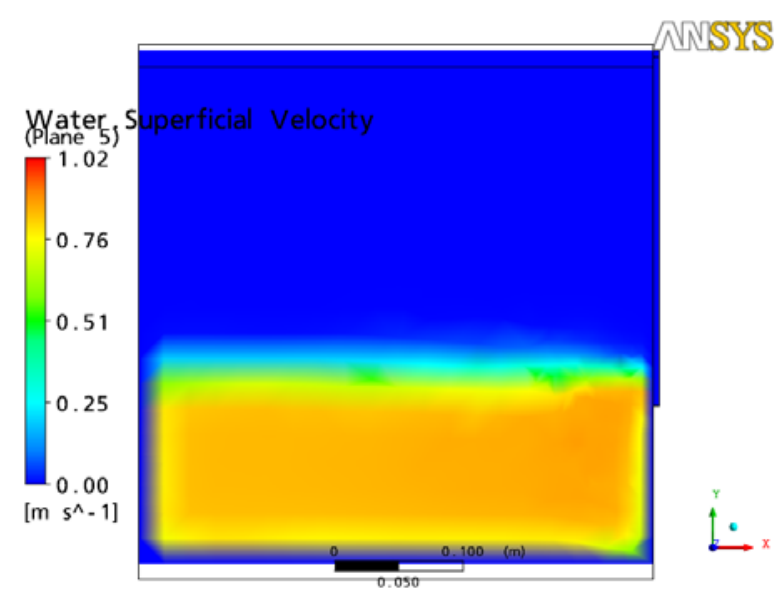

(a) $Z=1,00 \mathrm{~m}$.

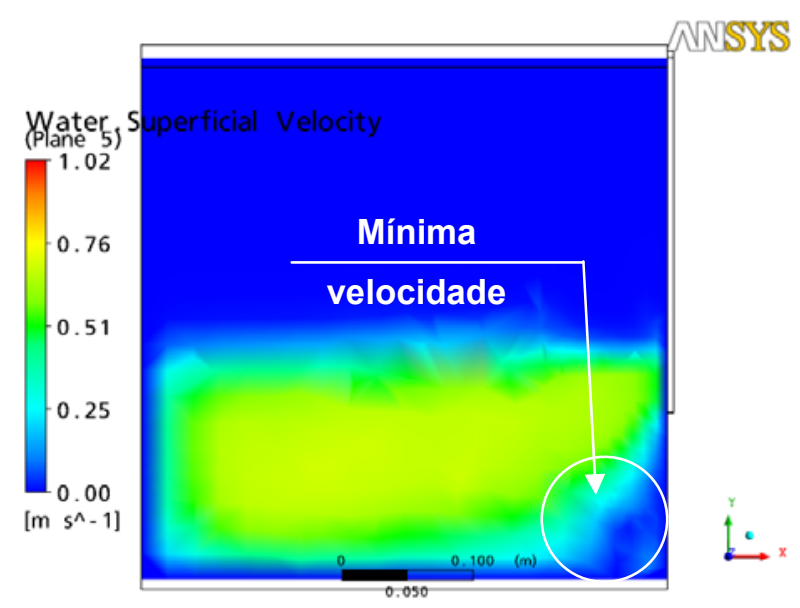

(c) $Z=2,00 \mathrm{~m}$.

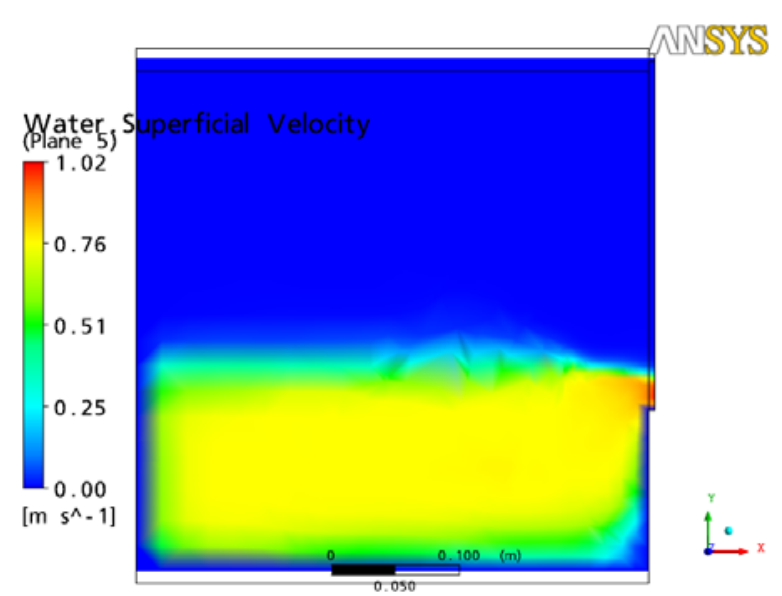

(b) $Z=1,50 \mathrm{~m}$.

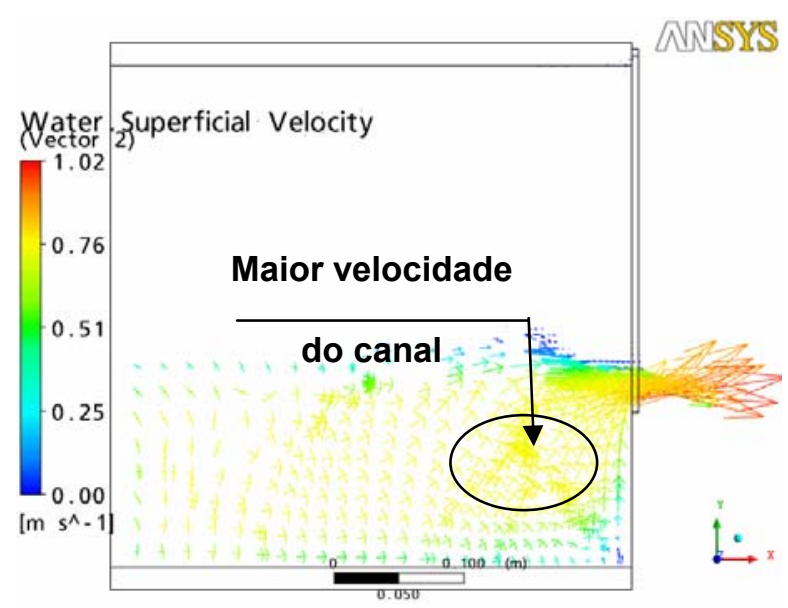

(d) Vetor $Z=1,50 \mathrm{~m}$

Figura 6.75 - Distribuição transversal da velocidade ao longo do vertedor lateral para a condição Q3-C8.

Já a condição Q3-C10 (Figura 6.76) nos itens (b) e (c) também se observou a diminuição da velocidade em sua distribuição e o desenvolvimento de uma região de mínima velocidade abaixo da soleira. Porém, a velocidade média observada no meio do vertedor foi de $0,73 \mathrm{~m} / \mathrm{s}$, aproximadamente $1 \%$ e $48 \%$ superior a velocidade do seu início e fim. Verifica-se que quanto maior a vazão escoada pelo vertedor lateral, maior é a diminuição da velocidade a sua jusante no canal principal.

Com o aumento da vazão escoada pelo dispositivo lateral, maior é a sua influência no canal principal, para a condição Q3-C10 somente 0,05 m do lado oposto não sofre interferência, aparente, do dispositivo. 


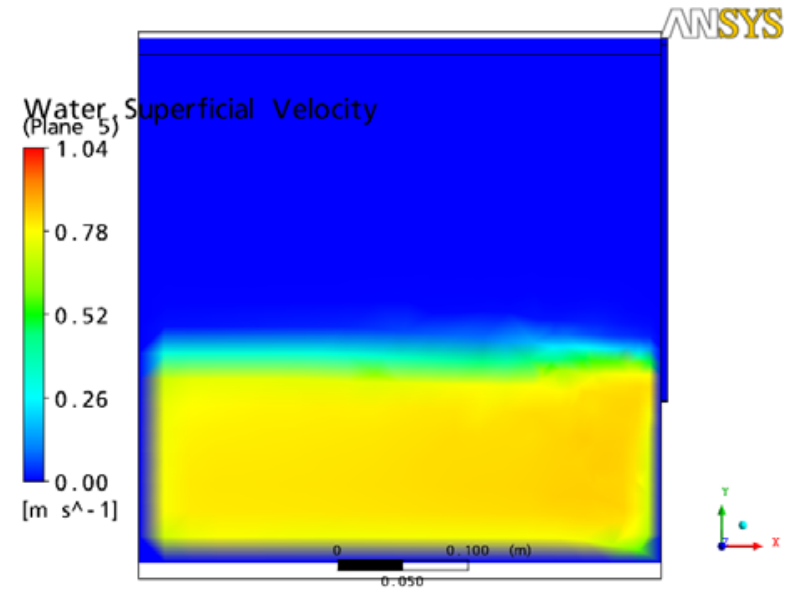

(a) $Z=1,00 \mathrm{~m}$.

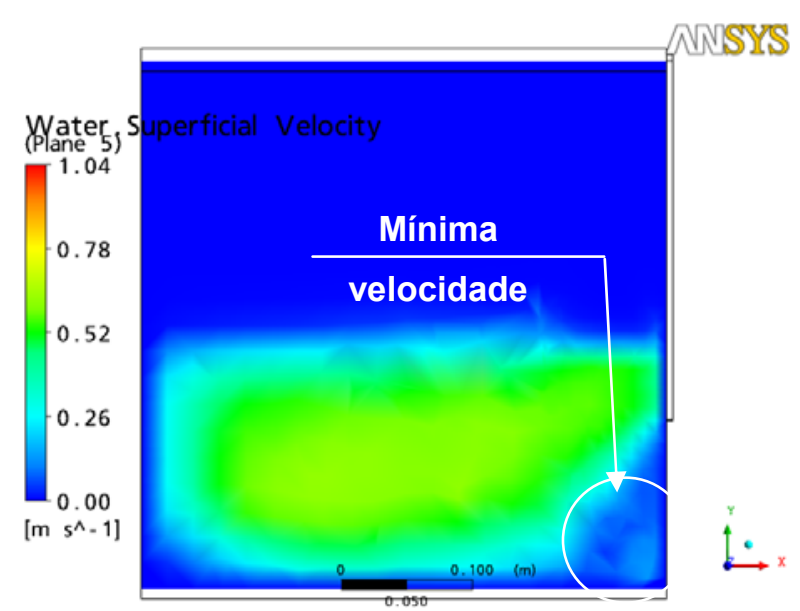

(c) $Z=2,00 \mathrm{~m}$.

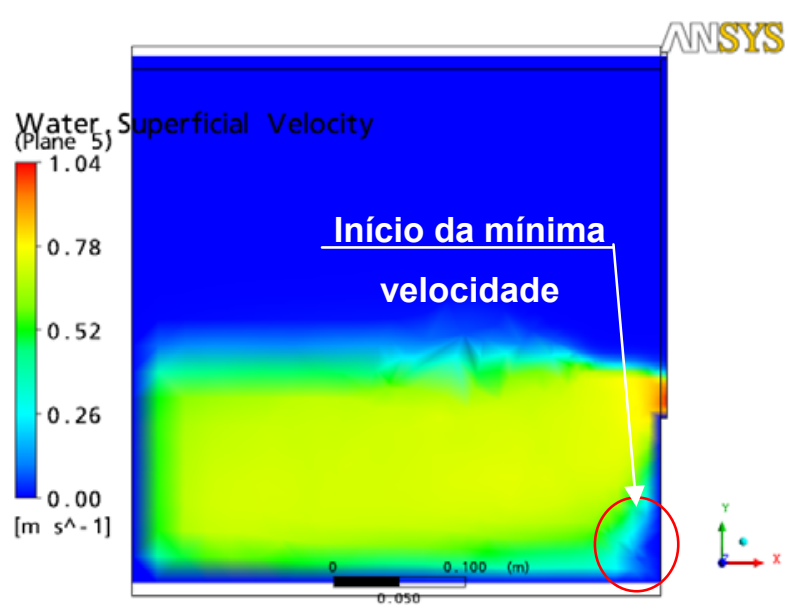

(b) $Z=1,50 \mathrm{~m}$.

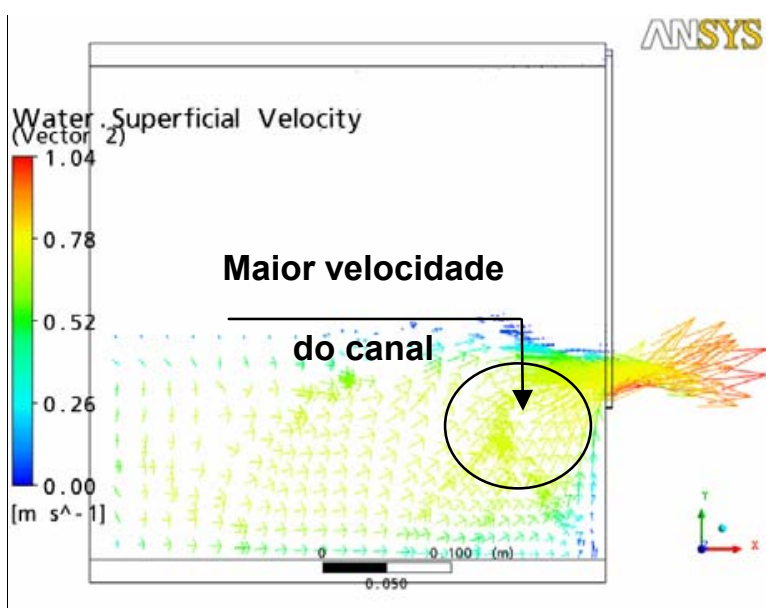

(d) Vetor $Z=1,50 \mathrm{~m}$.

Figura 6.76 - Distribuição transversal da velocidade ao longo do vertedor lateral para a condição Q3-C10.

As Figuras 6.77 a 6.79 apresentam a distribuição de velocidade na seção transversal do vertedor lateral. As três condições apresentam uma variação positiva ao longo da soleira de montante para jusante. Também se observa as maiores velocidades fora da região das paredes laterais (influência da camada limite). 


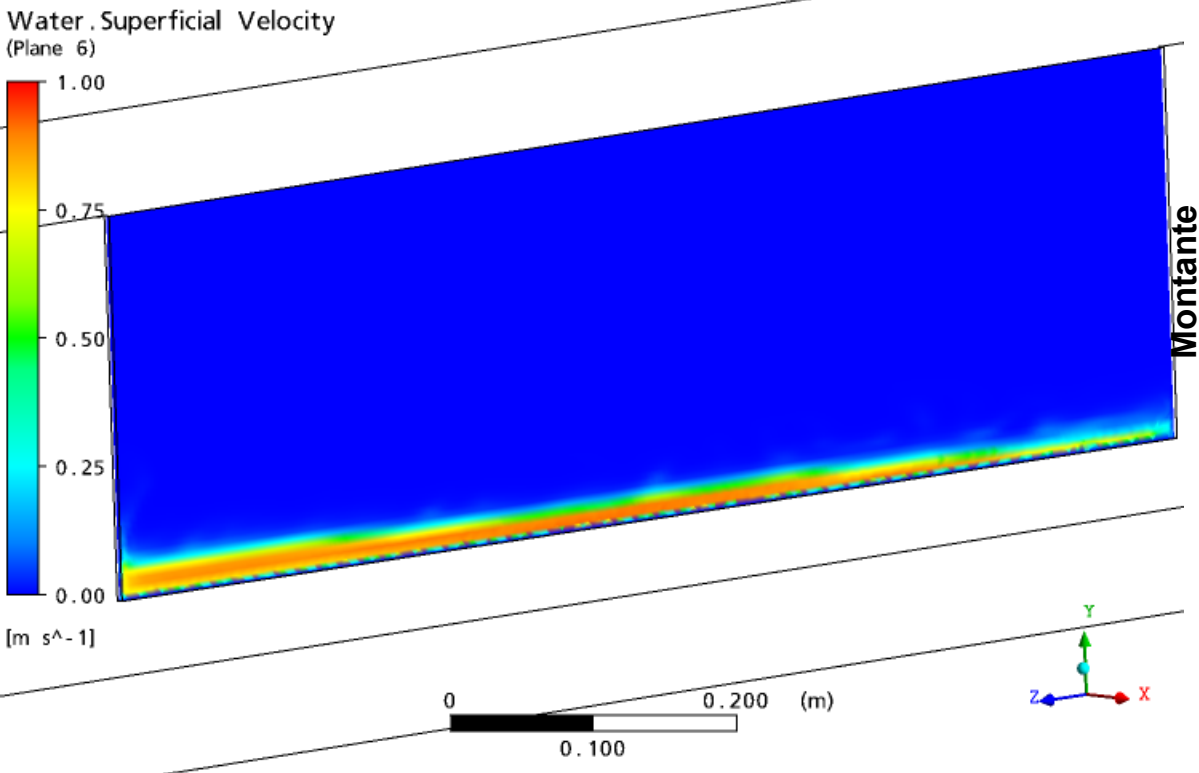

Figura 6.77 - Distribuição transversal da velocidade no vertedor lateral para a condição Q3-C6.

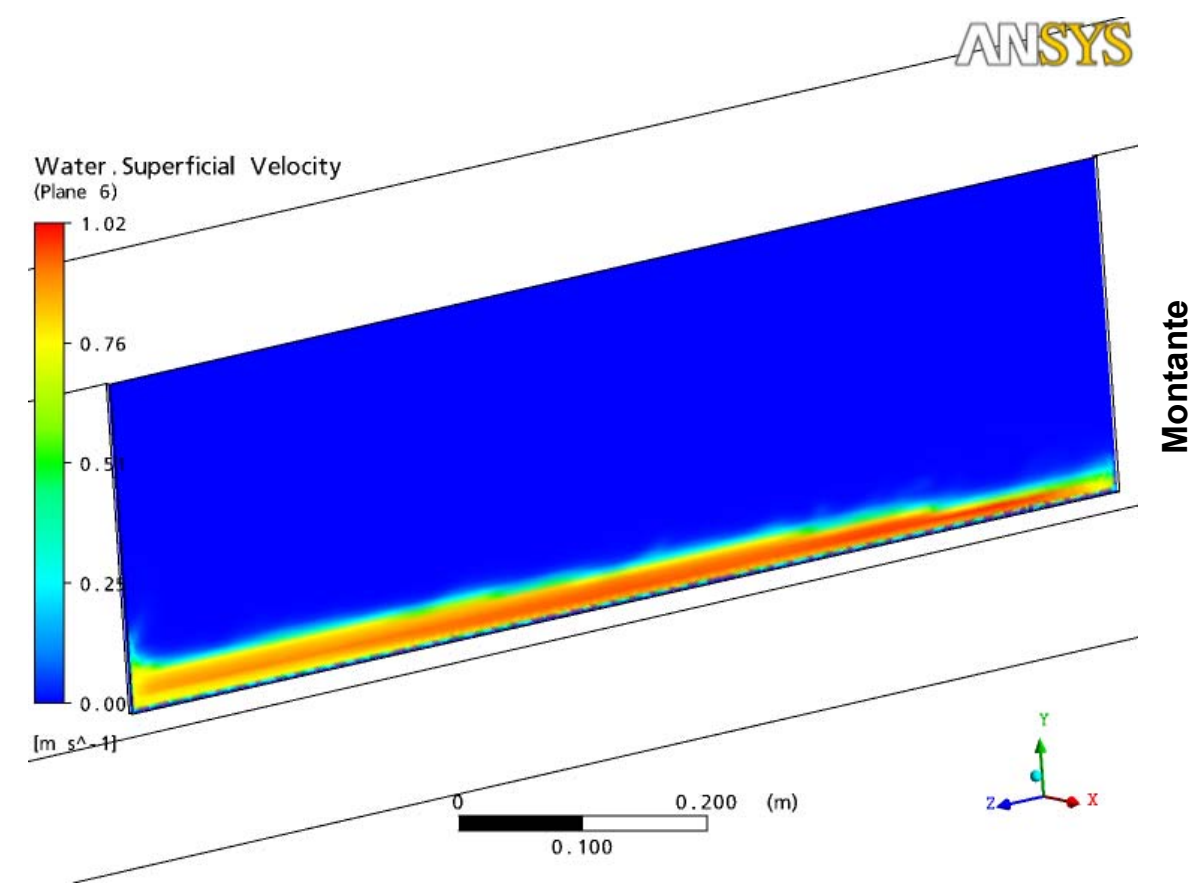

Figura 6.78 - Distribuição transversal da velocidade no vertedor lateral para a condição Q3-C8. 


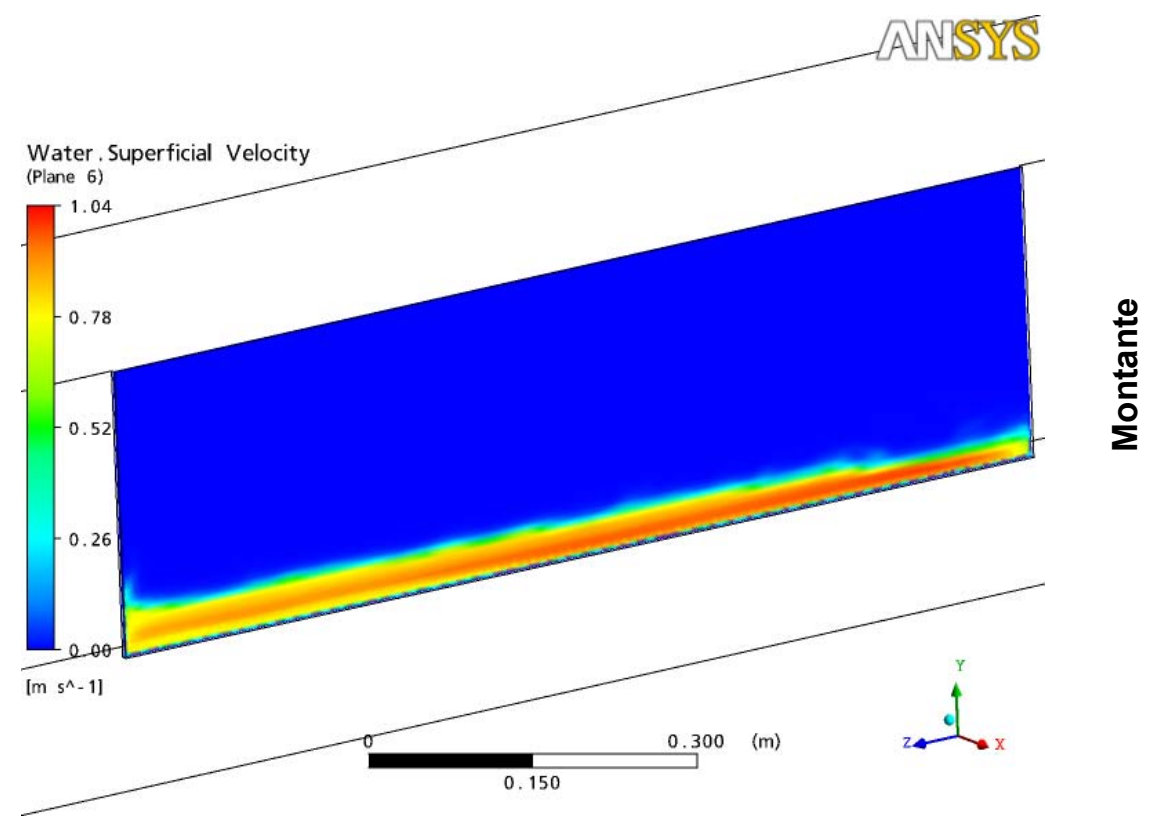

Figura 6.79 - Distribuição transversal da velocidade no vertedor lateral para a condição Q3C10.

As Figuras 6.80 a 6.82 representam a distribuição longitudinal do vetor velocidade ao longo do canal principal, onde se pode observar a mudança de direção do vetor velocidade, que muda com a variação da velocidade, e as maiores velocidades em sua direção.

A condição Q3-C6 (Figura 6.80) apresenta a relação entre a vazão escoada através do vertedor lateral e a vazão total do canal principal $\left(Q_{V L} / Q_{T}\right)$ em torno de 0,14, já as condições Q3-C8 e Q3-C10, representadas pelas Figuras 6.81 e 6.82, apresentam a relação $Q_{V L} / Q_{T}$, respectivamente, aproximadamente 0,32 e 0,41.

Para as três condições, verifica-se que a montante as linhas de correntes não são afetadas, aproximadamente, a uma distância de $0,55 \mathrm{~m}$ do início do dispositivo. Já a jusante as mesmas não são afetadas a aproximadamente $0,70 \mathrm{~m}$ do fim do dispositivo. Inclusive, essa situação foi observada em todas as condições estudadas. 


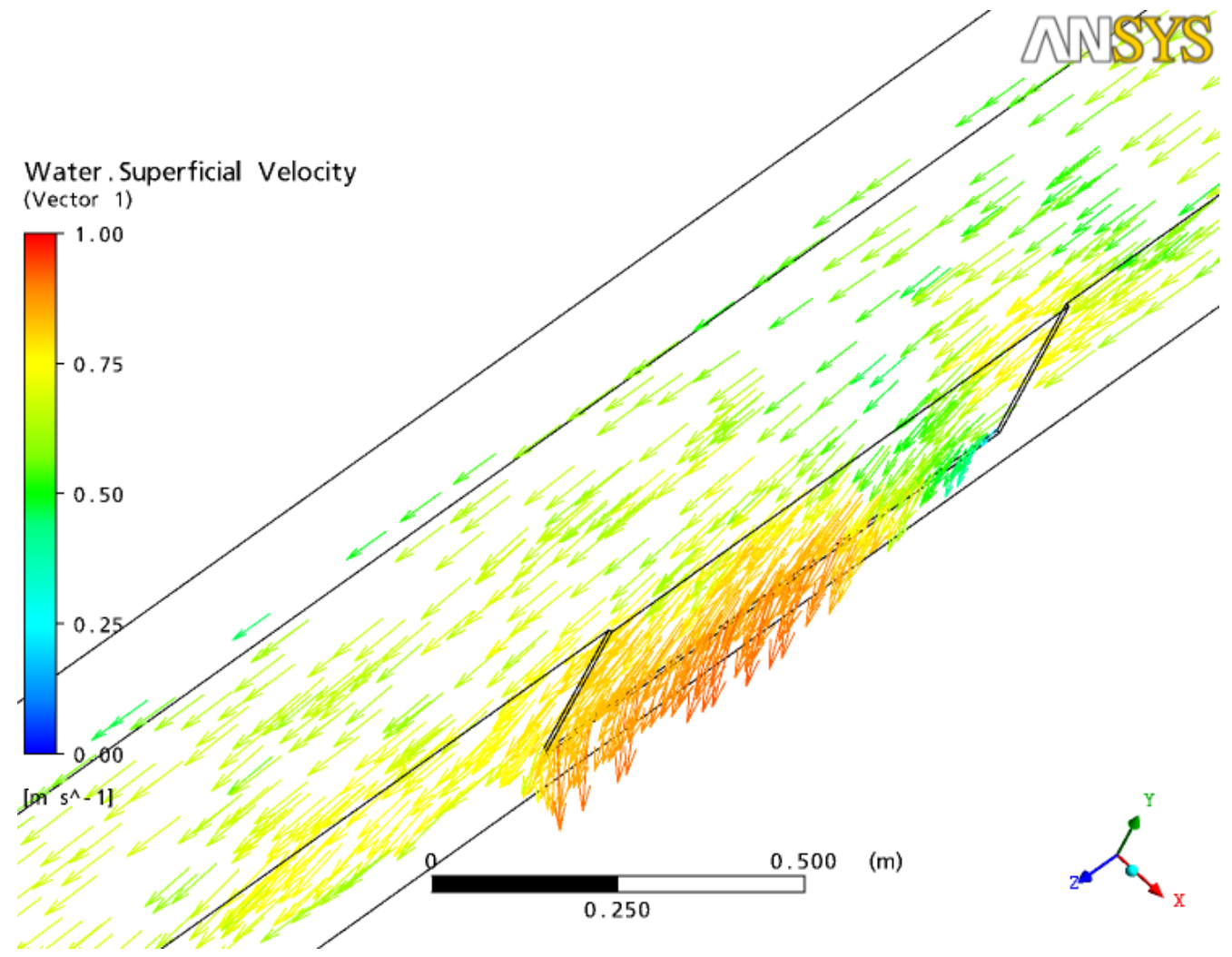

Figura 6.80 - Distribuição longitudinal do vetor velocidade para a condição Q3-C6.

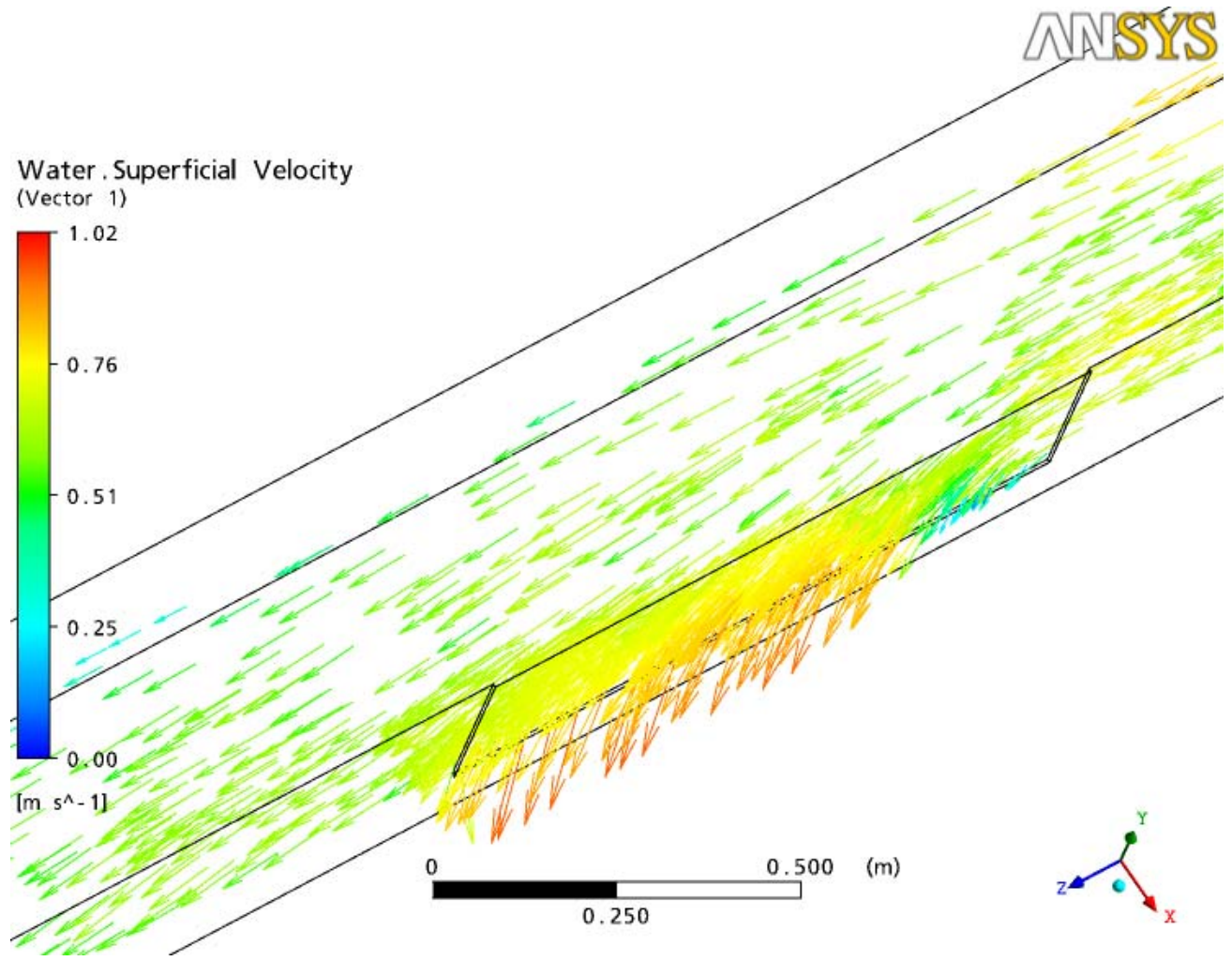

Figura 6.81 - Distribuição longitudinal do vetor velocidade para a condição Q3-C8. 


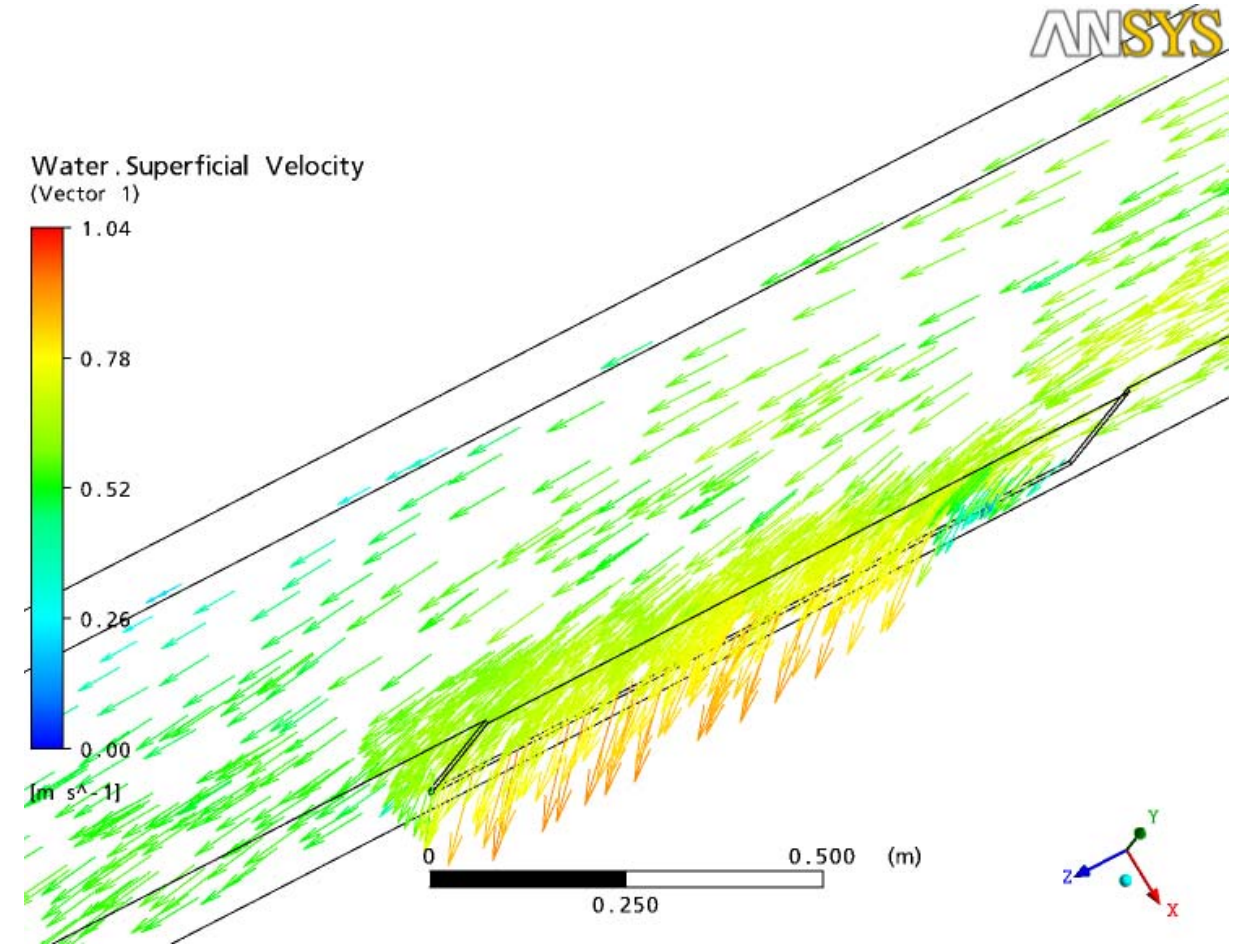

Figura 6.82 - Distribuição longitudinal do vetor velocidade para a condição Q3-C10. 


\subsection{COMPARAÇÃO DO COEFICIENTE DE DESCARGA}

O coeficiente de descarga $\left(C_{d}\right)$ do vertedor lateral modelado em CFX foi comparado com dois estudos experimentais. O estudo do Anchieta (2006) representado pela equação (3.32) e o estudo de Jalili \& Borghei (1996) representado pela equação (3.30). Devido a considerações de cada pesquisador, para comparar os valores de Anchieta e Jalili \& Borghei é necessário multiplicar o valor obtido na equação 3.32 por $2 / 3$ (dois terços).

$\mathrm{O} \mathrm{C}_{\mathrm{d}}$ do modelo matemático é representado pela equação geral para determinar a vazão do vertedor lateral (Equação (3.17)). Ajustando a equação para a vazão total escoada pelo vertedor e isolando $C_{d}$, tem-se:

$C_{d \bmod }=\frac{Q_{\mathrm{mod}}}{2 / 3 \cdot L \cdot \sqrt{2 \cdot g} \cdot\left(Y_{1}-P_{M}\right)^{3 / 2}}$

Sendo:

$\mathrm{C}_{\text {dmod }} \mathrm{O}$ coeficiente de descarga do modelo matemático;

$Q_{\text {mod }}$ a vazão volumétrica obtida através do CFX;

$\mathrm{L}$ o comprimento do vertedor lateral, igual a $1,00 \mathrm{~m}$;

g a aceleração da gravidade, considerado igual $9,81 \mathrm{~m} / \mathrm{s}^{2}$;

$\mathrm{Y}_{1}$ a profundidade a montante do vertedor lateral, obtida pelo CFX no eixo do canal principal;

$\mathrm{P}_{\mathrm{M}}$ a altura média da soleira, igual a $0,125 \mathrm{~m}$.

Os valores obtidos através do modelo do vertedor lateral e os cálculos resultantes desses valores, como o número de Froude $\left(\mathrm{Fr}_{\mathrm{M}}\right)$ e os coeficientes de descarga para as condições estudadas são apresentados na Tabela 6.7. 
Tabela 6.7 - Comparação dos coeficientes de descarga do vertedor lateral.

\begin{tabular}{ccccccc}
\hline Condição & $\begin{array}{c}\text { Vazão } \\
\text { Vertedor } \\
\text { Lateral } \\
\text { [L/s] }\end{array}$ & $\mathbf{Y}_{1}[\mathrm{~m}]$ & $\mathrm{Fr}_{\mathrm{M}}$ & $\begin{array}{c}\mathbf{C}_{\mathbf{d}} \\
\text { Anchieta }\end{array}$ & $\begin{array}{c}\mathbf{C}_{\mathbf{d}} \\
\text { Jalili \& } \\
\text { Borghei }\end{array}$ & $\begin{array}{c}\mathbf{C}_{\mathbf{d}} \\
\text { Modelo } \\
\mathbf{C F X}\end{array}$ \\
\hline Q1-C6 & 0,51 & 0,135 & 0,53 & 0,343 & 0,291 & 0,174 \\
Q1-C8 & 6,69 & 0,160 & 0,41 & 0,351 & 0,371 & 0,353 \\
Q1-C10 & 11,83 & 0,176 & 0,35 & 0,352 & 0,408 & 0,353 \\
Q2-C6 & 3,82 & 0,152 & 0,52 & 0,339 & 0,315 & 0,292 \\
Q2-C8 & 12,31 & 0,177 & 0,41 & 0,345 & 0,385 & 0,357 \\
Q2-C10 & 14,57 & 0,181 & 0,40 & 0,346 & 0,394 & 0,372 \\
Q3-C6 & 6,92 & 0,165 & 0,58 & 0,330 & 0,307 & 0,298 \\
Q3-C8 & 15,25 & 0,183 & 0,50 & 0,334 & 0,356 & 0,370 \\
Q3-C10 & 19,81 & 0,189 & 0,47 & 0,335 & 0,372 & 0,412 \\
\hline
\end{tabular}

Comparando os resultados dos $C_{d}$ obtidos através das equações dos pesquisadores com $\circ \mathrm{C}_{\mathrm{d}}$ do modelo matemático, verifica-se que a condição Q1-C6 apresentou resultados com uma discrepância muito grande, devido, provavelmente, a sensibilidade da baixa vazão escoada pelo vertedor e imperfeições inerentes ao modelo físico. Já os demais resultados de $\mathrm{C}_{\mathrm{d}}$, quando comparados, mostraram-se próximos.

O gráfico (Figura 6.83) apresenta no eixo das abscissas a vazão escoada pelo vertedor lateral $\left(Q_{V L}\right)$ e no eixo das ordenadas o erro percentual entre $\circ C_{d}$ do modelo e o $C_{d}$ dos pesquisadores. Para determinação do erro utilizou-se a equação 6.3.

$$
\text { Erro }=\frac{\left|C_{d \mathrm{mod}}-C_{d \text { pesq }}\right|}{C_{d \bmod }} \cdot 100
$$


Sendo:

Erro o erro percentual entre coeficiente de descarga do modelo e dos pesquisadores;

$C_{d \text { mod }}$ o coeficiente de descarga do modelo matemático;

$C_{d \text { pesq }}$ o coeficiente de descarga obtido através das equações dos pesquisadores.

Pode-se verificar na Figura 6.83 que a equação do $C_{d}$ de Jalili \& Borghei apresentou uma maior precisão quando comparada com o modelo matemático, com um erro médio, excluindo a condição Q1-C6, de 7,3\%. Já a equação de Anchieta apresentou um erro médio de $8,3 \%$.

Os valores de Jalili \& Borghei ficaram abaixo de $10 \%$, exceto para a condição Q1-C6 e Q1-C10, enquanto quatro valores de Anchieta ficaram acima de 10\%, a condição Q1-C6, Q2-C6, Q3-C6 e Q3-C10. Para as condições de menores vazões, C6, a equação de Anchieta mostrou-se mais sensível ao erro.

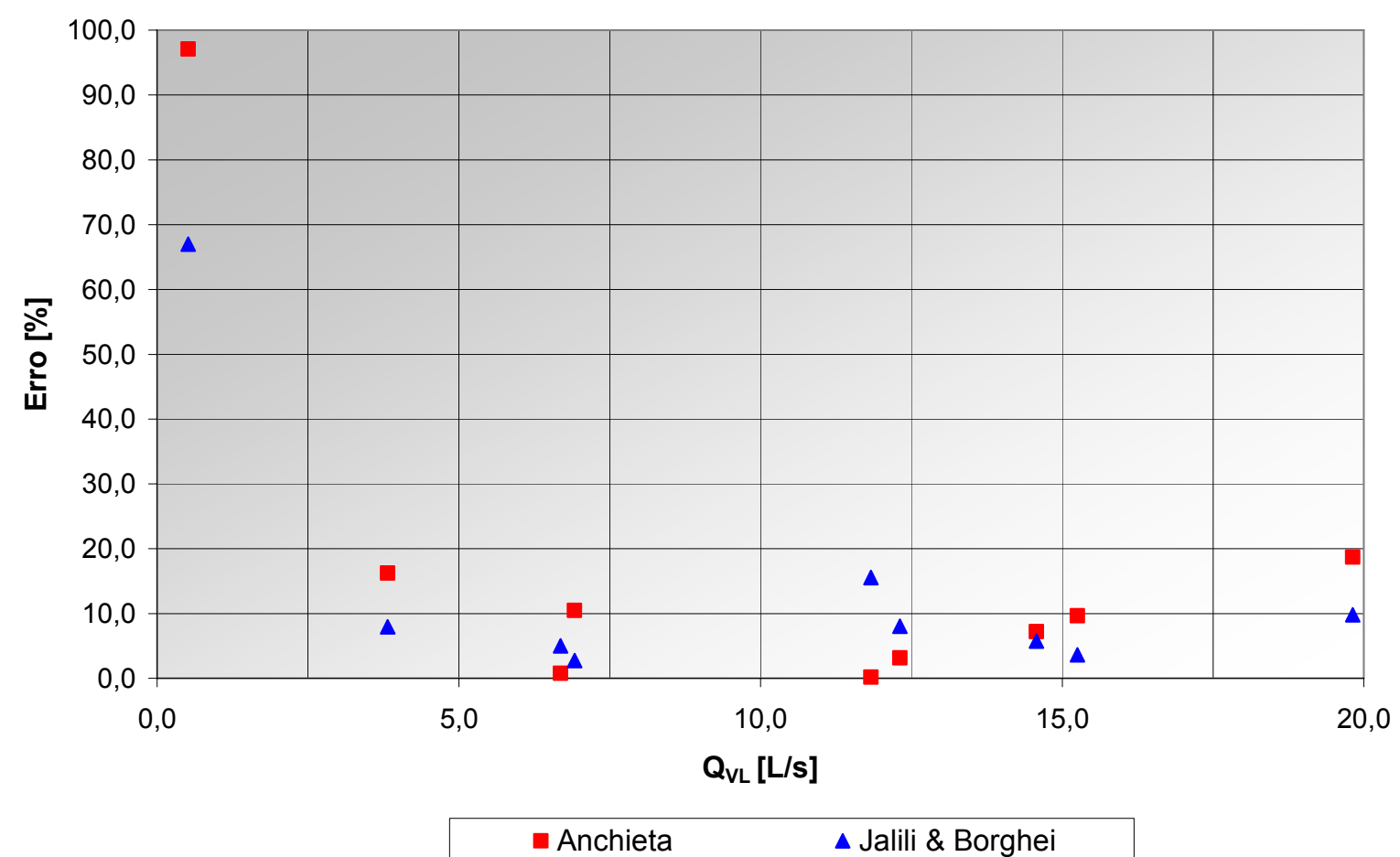

Figura 6.83 - Comparação dos erros entre coeficientes de descarga obtidos da literatura e do modelo matemático. 


\section{CONCLUSÕES E RECOMENDAÇÕES}

Nesse item são apresentadas as principais conclusões deste trabalho, bem como, as recomendações, observadas ao longo do estudo, para o desenvolvimento de futuros trabalhos.

\subsection{CONCLUSÕES}

A modelagem através da Dinâmica dos Fluidos Computacional (CFD) representou, com resultados significativos, o escoamento através do vertedor lateral. Essa representatividade que só era possível através de modelo físico, devido às particularidades do escoamento tipicamente tridimensional da soleira lateral, foi demonstrada com esse modelo matemático, sendo uma possível contribuição para o estudo de estruturas hidráulicas.

A escolha do tipo e refinamento da malha é muito importante para alcançar a precisão desejada. A malha 3 , que possui cerca de 342000 elementos, com predominância dos elementos hexaédricos, apresentou uma maior precisão dos resultados, devido ao seu maior refinamento na região de influência da soleira lateral. Entretanto, o refinamento da malha deve estar associado com o grau de precisão esperado dos resultados, evitando assim, onerar desnecessariamente o custo computacional da modelagem.

O modelo de turbulência $k-\varepsilon$ (RNG) apresentou os melhores resultados na simulação, quando comparado com os modelos k- $\varepsilon$ e SST k- $\omega$, tomando-se como referência os resultados do modelo físico. $O$ estudo, com os três modelos de turbulência, possibilitou evidenciar qual era o mais indicado para a aplicação neste tipo de problema.

As condições de contorno estabelecidas nesse trabalho, para representar o escoamento do vertedor lateral, isto é, definiram-se dois fluidos de trabalho, água e ar, ficando condicionada a pressão hidrostática na Entrada e na Saída do canal, já na Saída do Vertedor Lateral inseriu-se a pressão relativa igual a zero. Na Entrada inseriu-se a vazão mássica total e o nível d'água de montante e na Saída o nível d'água de jusante, no Fundo e Parede considerou-se como parede lisa e sem a 
ocorrência de escorregamento, e no Topo aberto, podendo ocorrer a entrada e saída de fluido do domínio. Também se definiu funções adimensionais para calcular a fração volumétrica de ambos os fluídos. Estas condições mostraram-se eficazes, sendo indicadas para elaboração de futuras pesquisas com essa estrutura hidráulica utilizando CFD. Entretanto, não foram feitas avaliações de outras formas de representação das condições de contorno do problema.

A verificação do modelo criado através da ferramenta ANSYS CFX, mostrou a compatibilidade dos seus resultados de vazão e níveis d'água sobre a soleira lateral, com os dados obtidos no ensaio experimental do modelo reduzido. O erro médio encontrado entre os modelos para vazão escoado através do vertedor lateral foi inferior a $1,50 \%$. Já o erro médio para os níveis d'água foi de aproximadamente $5,0 \%$, excluindo as condições Q1-C6 e Q3-C6, que apresentaram resultados com erros em torno de $13,0 \%$, acima do valor esperado como satisfatório para esse trabalho, devido provavelmente, aos defeitos e imperfeições do modelo físico que exercem maior influência sobre as menores vazões. A partir da validação, diversas análises e estudos podem ser realizados na estrutura simulada.

A análise da distribuição de velocidades ao longo do canal principal apresentou uma zona morta, região de mínima velocidade, que se intensifica com o aumento da vazão escoada através da soleira lateral. Observou-se em sua seção transversal que a área dessa zona é maior para as maiores vazões. Pode-se evidenciar que esse fenômeno na região abaixo da soleira lateral, seção transversal na posição $Z=2,00$ $\mathrm{m}$, por exemplo, nas Figuras 6.66, 6.73 e 6.80 representa um aumento progressivo das vazões escoadas pelo dispositivo lateral.

O modelo matemático, criado com a ferramenta CFD, possibilitou visualizar com clareza o comportamento da superfície d'água na região de influência da soleira lateral. Essa condição não pode ser representada por modelos matemáticos uni e bidimensionais, e destaca-se com uma importante facilidade dos modelos tridimensionais.

As imperfeições usualmente associadas aos modelos físicos foram encontradas no modelo utilizado para o desenvolvimento desse trabalho. Essas imperfeições podem ser identificadas na Figura 6.21, como o desgaste prematuro do material da parede e fundo, o acabamento e impermeabilização não uniforme da soleira lateral. Os resultados obtidos através do modelo matemático mostram uma maior influência dessas imperfeições sobre as menores vazões escoadas no canal 
principal e na soleira lateral, que provavelmente, está associada às irregularidades físicas locais que exercem uma maior perturbação sobre o escoamento. Por isso, um bom acabamento do modelo físico é importante para representar com mais fidelidade a estrutura hidráulica modelada e obter uma melhor precisão de seus resultados.

A modelagem em CFD também possibilitou visualizar e quantificar uma característica das soleiras laterais, que é a região de baixas velocidades e que resulta em um pior desempenho específico, isto é, menores vazões, situada na parte inicial (de montante para jusante) da soleira. Desta forma, com esta ferramenta é possível o prosseguimento do estudo para otimizar, através de melhorias geométricas, o seu desempenho, aumentando-se a capacidade de descarga.

A determinação do coeficiente de descarga através do modelo matemático CFD e a sua comparação com trabalhos de outros pesquisadores, sendo um artigo internacional de Jalili \& Borghei (1996) e um trabalho nacional mais atual de Anchieta (2006), mostrou a compatibilidade e representatividade dos resultados obtidos através do modelo CFD com estudos realizados em condições diferentes, onde foram ensaiados vertedores laterais distintos do qual se utilizou nesse trabalho.

Pode-se concluir ainda que a utilização de modelos matemáticos tridimensionais, fundamentado no método dos volumes finitos e com o uso de modelos de turbulência tipo k- $\varepsilon$ (RNG) são totalmente compatíveis para estudos de estruturas hidráulicas do tipo soleira lateral, contribuindo para uma melhor interpretação de seu funcionamento e otimização, constituindo-se numa ferramenta fundamental para o projetista e o pesquisador, aliada aos modelos físicos. 


\subsection{RECOMENDAÇÕES}

Analisando a modelagem em CFD do vertedor lateral e os seus resultados, pode-se sugerir os seguintes estudos futuros:

Simular em CFD um comprimento maior do modelo, acima de 1 metro a montante do início e 1,5 metros a jusante do final da soleira, possibilitando verificar se as condições de contorno não estão influenciando o desenvolvimento do escoamento e os resultados no vertedor lateral.

Explorar condições diferentes de modelagem, como a criação de um modelo que represente as condições físicas à jusante da soleira lateral, onde seja possível estudar a influência de sua espessura e formato sobre o escoamento.

Construir o modelo físico, principalmente na região da soleira lateral, o mais semelhante possível com a estrutura hidráulica padrão (sem imperfeições), para viabilizar a generalização do modelo matemático para outras condições de vertedores laterais.

Avaliar um maior refinamento da malha hexaédrica predominante em todo o modelo, criando uma transição suave entre as regiões de refinamento diferente da malha, evitando assim, zonas de transição que podem influenciar no escoamento do dispositivo estudado. Estudar também, o comportamento da camada limite para diferentes subcamadas;

Pesquisar outros tipos de condições de contorno para a simulação do modelo em CFD, como a inserção, na condição de contorno de montante, da distribuição de velocidades da seção transversal, ao invés, da velocidade média da seção. Acreditase que o modelo matemático apresente melhores resultados.

Estudar a possibilidade de eliminação da zona morta de velocidades, que provoca o acúmulo de sedimentos (Figura 7.1), problema existente nos vertedores laterais em funcionamento, criando vegetação e aumentando a freqüência de manutenção, prejudicando o coeficiente de descarga, conseqüentemente, a diminuição do desempenho do dispositivo. 


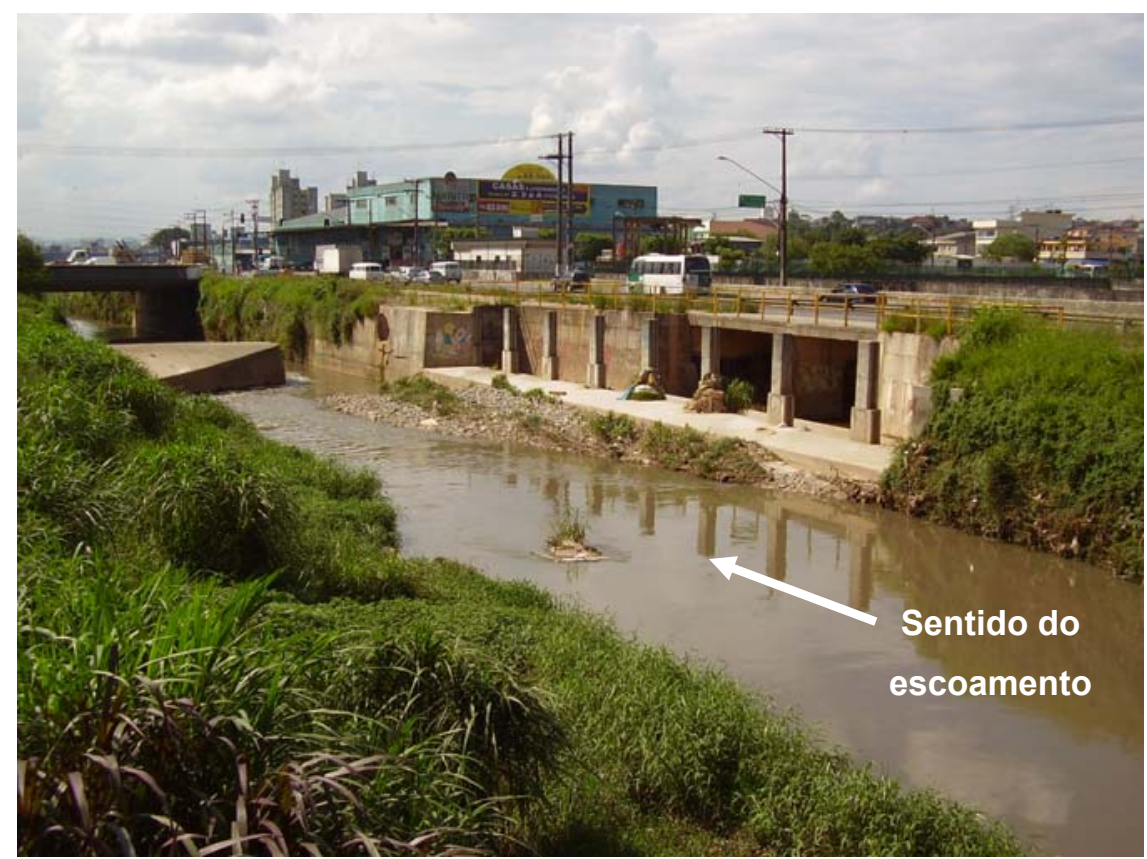

Figura 7.1 - Acúmulo de sedimentos no vertedor lateral do Córrego Aricanduva, RAR-05 (Fonte: RAIMUNDO, 2007). 


\section{REFERÊNCIAS BIBLIOGRÁFICAS}

ASSOCIAÇÃO BRASILEIRA DE NORMAS TÉCNICAS. NBR 13403: Medição de vazão em efluentes líquidos e corpos receptores - Escoamento livre. Rio de Janeiro, 1995. $7 p$.

ALENCAR, H. S. Estudo Numérico da Termo-Aerodinâmica de Câmaras de Combustão para Turbinas a Gás: Aplicação ao caso de Micro Turbinas. 2007. 151 f. Tese (Doutorado em Engenharia Mecânica na Área de Conversão de Energia) - Universidade Federal de Itajubá, Itajubá, 2007.

ANCHIETA, H. B. Coeficiente de Vazão em Vertedores Laterais. 2006. $82 \mathrm{f}$. Dissertação (Mestrado em Engenharia Hidráulica) - Escola Politécnica, Universidade de São Paulo, São Paulo, 2006.

ANSYS CFX. CFX-Solver Theory Guide. Ansys Canadá Ltda, Waterloo, Ontario, Canadá. 2006.

ARANTES, E. J. Caracterização do escoamento sobre vertedouros em degraus via CFD. 2007. 178 f. Tese (Doutorado em Engenharia Civil na Área de Hidráulica e Saneamento) - Escola de Engenharia de São Carlos, Universidade de São Paulo, São Carlos, 2007.

ARMELIN, L. F. Estudo do Comportamento dos Resíduos Sólidos Veiculados pelos Rios Urbanos junto aos Vertedores de Entrada de Reservatórios de Detenção, 2010. 77 f. Exame de Qualificação (Doutorado em Engenharia Hidráulica) - Escola Politécnica, Universidade de São Paulo, São Paulo, 2010.

BATISTA, V. H. F.; Geração de Malhas Não-Estruturadas Tetraédricas Utilizando um Método de Avanço de Fronteira, 2005. 85 f. Dissertação (Mestrado em Ciências em Engenharia Civil) - Universidade Federal do Rio de Janeiro, Rio de Janeiro, 2005. 
BORGHEI, S. M.; JALILI, M. R.; GHODSIAN, M. Discharge for sharped-crested side weir in sub-critical flow. J. Hydraulic Engineering, v. 125, No 10, p. 1051-1056, October 1999.

BURT, D.; CORTON, M.; HETHERINGTON, D.; BALMFORTH, D. Multiphase and the Prediction of Retention Efficiency in a Side Weir CSO. In: $9^{\text {th }}$ International Conference on Urban Drainage, ASCE, pp. 1-13, 2002.

CASTRO, C. J. R. O. Simulação da Interação Casco-Propulsor de uma Embarcação usando Mecânica dos Fluidos Computacional (CFD), 2006. 307 f. Dissertação (Mestrado em Engenharia Naval e Oceânica) - Escola Plitécnica, Universidade de São Paulo, São Paulo, 2006.

CEBECl, T. Analysis of Turbulent Flows. $2^{\text {a }}$ Edição, Indian Wells: Elsevier Publishing Company, 376 p, 2003.

CHOW, V. T. Hidraulica de Canales Abiertos. Santafé de Bogotá: McGraw-Hill, 667 p, 1994.

DIAS, A.; SILVA, F. G. B.; TIAGO FILHO, G. L.; ALENCAR, H. S. Estudo da Distribuição da Velocidade em Tubo Venturi. Revista Brasileira de Recursos Hídricos, v. 14, n 4, pp. 81-92, 2009.

ENGINEERING SIMULATION AND SCIENTIFIC SOFTWARE. Disponível em: $<$ http://www.esss.com.br>. Acesso em: 25 nov. 2009.

FORTUNA, A. O. Técnicas Computacionais para Dinâmica dos Fluidos. $1^{\text {a }}$ Edição, São Paulo: Editora da Universidade de São Paulo, 426 p, 2000.

FOX, R. W.; MCDONALD, A. T. Introdução à Mecânica dos Fluidos. $2^{\mathrm{a}}$ Edição, Rio de Janeiro: Editora Guanabara Dois, 562 p, 1981. 
GERT, L.; GUIDO, V.; JEAN, B. Surface load as predominant factor for CSO efficiency. In: $\mathbf{9}^{\text {th }}$ International Conference on Urban Drainage, ASCE, 2002.

HAGER, W. H. Lateral outflow of side weirs. J. Hydraulic Engineering, ASCE, v. 113, HY 4, pp. 491-504, 1987.

JALILI, M. R.; BORGHEI, S. M. Discussion of Discharge coefficient of rectangular side weir. J. Irrigation and Drainage Engineering, ASCE, 122(2), 132, 1996.

LAUNDER, B. E.; SPALDING, D. B. Lectures in Mathematical Models of Turbulence. Academic Press: London, 1972.

LESIEUR, M. Turbulence in Fluids. 4ª Edição, Dordrecht: Springer, 558 p, 2008.

LOMBARDI, J. C. Análise de distribuição de pressão em válvulas de diafragma poroso. 2005. 125 f. Tese (Doutorado em Computação Aplicada) - Instituto Nacional de Pesquisas Espaciais, São José dos Campos, 2005.

MALISKA, C. R. Transferência de Calor e Mecânica dos Fluidos Computacional. Rio de Janeiro: Livros Técnicos e Científicos Editora, 1995.

MAY, R. W. P.; BROMWICH, B. C.; GASOWSKI, Y. E RICKARD, C. E. Hydraulic design of side weirs. Thomas Telford Publishing: London, 133 p, 2003.

MORAES, A. G. Entropia máxima na modelação do fator de atrito $(f)$ de escoamento forçado. 2010. 151 f. Tese (Doutorado em Engenharia Civil na Área de Engenharia Hidráulica) - Escola Politécnica, Universidade de São Paulo, São Paulo, 2010.

MUSLU, Y. Lateral Weir Flow Model using a Curve Fitting Analysys. J. Hydraulic Engineering, ASCE, v. 128, № 7, pp. 712-715, 2002. 
MUSLU, Y.; TOZLUK, H.; YÜKSEL, E. Effect of Lateral Water Surface Profile on Side Weir Discharge. J. Irrigation and Drainage Engineering, ASCE, v. 129, № 5, pp. 371-375, 2003.

NETTO, J. M. A.; ALVAREZ, G. A. Manual de Hidráulica. $7^{\text {a }}$ Edição, Vol. 2. São Paulo: Edgard Blücher, 724 p, 1982.

OLIVETO, G.; BIGGIERO, V.; FIORENTINO, M. Hydraulic features of supercritical flow along prismatic side weirs. J. Hydraulic Research, v. 39, pp. 73-82, 2001.

PORTO, R. M. Hidráulica básica. 3a edição. São Carlos: EESC-USP, 519 p, 2004.

RAIMUNDO, A. P. Estruturas Hidráulicas Utilizadas em Reservatórios de Controle de Cheias, 2007. 178 f. Dissertação (Mestrado em Engenharia Hidráulica) - Escola Politécnica, Universidade de São Paulo, São Paulo, 2007.

RANGA RAJU, K. G.; PRASSAD, B. \& GUPTA, S. K. Side Weir in rectangular channel. J. Hydraulic Division, ASCE, v. 105, HY 5, pp. 547-554, 1979.

SINGH, R.; MANIVANNAN, D. \& SATUAMARAYANA, T. Discharge coefficient of rectangular side weirs. J. Irrigation and Drainage Engineering, ASCE, v. 120, $n^{\circ} 4$, pp. 814-819, 1994.

SOUZA, D. D. B. Redução do nível de água em canais de adução de PCH's. 2005. 134 f. Dissertação (Mestrado em Engenharia Hidráulica) - Universidade Federal do Paraná, Curitiba, 2005.

SOUZA, P. A.; MARTINS, J. R. S.; FADIGA, F. M. Métodos computacionais aplicados à engenharia hidráulica. $1^{\text {a }}$ Edição. São Paulo: Seção Técnica de Gráfica do DAEE, 170 p, 1991.

STREETER, V. L.; WYLIE, E. B. Mecânica dos fluidos. $7^{\text {a }}$ Edição. São Paulo: McGraw-Hill, 585 p, 1982. 
SUBRAMANYA, K. \& AWASTHY, S. C. Varied flow over side weirs. J. Hydraulic Division, ASCE, v. 98, HY 1, pp. 1-10, 1972.

SWAMME, P. K.; PATHAK, S. K.; MOLHAN, M.; AGRAWAL, S. K. \& ALI, M. S. Subcritical flow over rectangular side weir, J. Irrigation and Drainage Division, ASCE, v. 120, no 1, pp. 212-217, 1994.

TAN, H.; WANG, L.; GILBRETH, K. Design of Side Weirs in Subcritical Flow. Urban Drainage Modeling, ASCE, pp. 438-449, 2001.

TAN, H.; EINHELLIG, R. F.; PUGH, C. A. Physical Model Study of the Sevaine SideWeir Diversion. World Water Congress 2001, ASCE, 2001.

UYUMAZ, B. A. Side Weir in U-Shaped Channels. J. Hydraulic Engineering, ASCE, v. $123, N^{\circ} 7$, pp. 639-645, 1997.

VENUTELLI, M. Method of Solution of Nonuniform Flow with the Presence of Rectangular Side Weir. J. Irrigation and Drainage Engineering, ASCE, v. 134, N ${ }^{\circ}$ 6, pp. 840-846, 2008.

VERSTEEG, H. K.; MALALASEKERA, W. An Introduction to Computational Fluid Dynamics - The Finite Volume Method. New York: Longman Group, 255 p, 1995.

WENDT, T. Aplicação de Modelo Computacional Hidrodinâmico a Jusante de uma Estrutura Hidráulica, 2009. 107 f. Dissertação (Mestrado em Recursos Hídricos e Ambiental) - Universidade Federal do Paraná, Curitiba, 2009. 